\title{
DANIELE CATELAN
}

Absenteísmo no serviço ambulatorial do SUS:

estratégias e perspectivas das equipes de saúde na rede pública do Departamento

Regional de Saúde II - Araçatuba-SP 2011-2017

São Paulo

2018 


\section{DANIELE CATELAN}

\section{Absenteísmo no serviço ambulatorial do SUS: \\ estratégias e perspectivas das equipes de saúde na rede pública do Departamento \\ Regional de Saúde II - Araçatuba-SP 2011-2017}

\section{Versão Original}

Dissertação apresentada à Faculdade de Odontologia da Universidade de São Paulo, Programa Mestrado Profissional Interunidades em Formação Interdisciplinar, para obter o título de Mestre em Ciências da Saúde

Orientadora: Prof ${ }^{\mathrm{a}} \mathrm{Dr}^{\mathrm{a}}$ Eucenir Fredini Rocha 
Autorizo a reprodução e divulgação total ou parcial deste trabalho, por qualquer meio convencional ou eletrônico, para fins de estudo e pesquisa, desde que citada a fonte.

Catalogação-na-Publicação

Serviço de Documentação Odontológica

Faculdade de Odontologia da Universidade de São Paulo

Catelan, Daniele.

Absenteísmo no serviço ambulatorial do SUS: estratégias e perspectivas das equipes de saúde na rede pública do Departamento Regional de Saúde II Araçatuba-SP 2011-2017 / Daniele Catelan ; orientador Eucenir Fredini Rocha -São Paulo, 2018.

174 p. : fig., tab., graf.; $30 \mathrm{~cm}$.

Dissertação (Mestrado Profissional) -- Programa de Pós-Graduação Interunidades em Formação Interdisciplinar em Ciências da Saúde. -- Faculdade de Odontologia da Universidade de São Paulo.

Versão original

1. Absenteísmo. 2. Assistência ambulatorial. 3. Pacientes ambulatoriais. 4. Equipe de assistência ao Paciente. 5. Estratégias. 6. Acessos aos Serviços de Saúde. I. Rocha, Eucenir Fredini . II. Título. 
Catelan D. Absenteísmo no serviço ambulatorial do SUS: estratégias e perspectivas das equipes de saúde na rede pública do Departamento Regional de Saúde II - AraçatubaSP 2011-2017. Dissertação apresentada à Faculdade de Odontologia da Universidade de São Paulo, programa Interunidades para obter o título de Mestre em Ciências da Saúde.

Aprovado em:

\section{Banca Examinadora}

$\operatorname{Prof}(\mathrm{a}) . \operatorname{Dr}(\mathrm{a})$.

Instituição: Julgamento:

$\operatorname{Prof}(\mathrm{a}) . \operatorname{Dr}(\mathrm{a})$.

Instituição: Julgamento:

$\operatorname{Prof}(\mathrm{a}) . \operatorname{Dr}(\mathrm{a})$.

Instituição: Julgamento: 
Aos meus pais, Rubens e Marlene por todo o amor. Toda minha gratidão por toda a compreensão, presença e incansável apoio ao longo do período de elaboração deste trabalho.

E admiração pelo exemplo de seres humanos que são! 


\section{AGRADECIMENTOS}

Primeiramente, a Deus.

Ao meu irmão Anderson Catelan pelo exemplo profissional, por não poupar esforços para me ajudar e incentivar. À Pam e Mili por estarem sempre presentes e me amarem incondicionalmente.

Às famílias Hisamatsue Lu, em especialà tia Cleusa, por todo incentivo e ajuda. Sem vocês este trabalho não seria realidade.

À família Catelan, por compreenderem minhas faltas nos encontros familiares.

Aos meus amigos Douglas e Renato, por me acolherem em seu lar e sempre se disporem a me ajudar.

À minha afilhada Larissa que me inspira a estudar e a me dedicar mais ao futuro.

Às minhas amigas-irmãs Silmara e Viviane, que sempre se fizeram presentes e compreenderam as minhas ausências, e também sempre me incentivam.

Aos meus amigos da equipe do Núcleo de Regulação: Tânia, Márcia, Maria Canata, Poletto, Nivaldo, Cristiane, Silvia, Agda, Maria José e Letícia, por serem sempre amigos e compreensivos ao longo do período de elaboração deste trabalho.

Ao Departamento Regional de Saúde, principalmente ao Silvio, por toda a atenção e apoio para a realização desta pesquisa.

À gerente administrativa Renée e a toda equipe de trabalho, por se colocarem à disposição e sempre auxiliarem no que foi preciso.

À Eucenir Fredini Rocha, que, nos anos de convivência, muito me ensinou, contribuindo para meu crescimento científico e intelectual. 


\section{RESUMO}

Catelan D. Absenteísmo no serviço ambulatorial do SUS: estratégias e perspectivas das equipes de saúde na rede pública no Departamento Regional de Saúde II - Araçatuba-SP 2011-2017 [dissertação]. São Paulo: Universidade de São Paulo, Faculdade de Odontologia; 2018.

O absenteísmo, ou seja, a falha no atendimento (FA) ou não atendimento (NA) dos usuários nos serviços de saúde do Sistema Único de Saúde (SUS) é um assunto de crescente interesse devido ao grande número de pessoas aguardando atendimento e ao contexto econômico atual. A problemática acarreta prejuízos a todos envolvidos, pois prolonga a conclusão diagnóstica, prejudica o tratamento, diminui a produtividade do prestador, causa aumento de tempo na espera por atendimento dos demais usuários e desperdício de recursos públicos. Portanto, o objetivo deste estudo foi compreender os motivos do absenteísmo nos serviços de saúde e as estratégias praticadas para a redução de falhas no atendimento. Trata-se de pesquisa qualitativa, com desenho de estudo de caso descritivo-exploratório, baseado em entrevistas semi-estruturadas e grupo focal. A coleta de dados visou a identificar diferentes opiniões e explicações para o absenteísmo, as estratégias e perspectivas utilizadas pelas equipes de saúde da AME e das secretarias de saúde de quatro municípios. Foram selecionados quatro casos traçadores para evidenciar experiências típicas, ou seja, dois municípios que pudessem demonstrar uma dinâmica mais exitosa no controle do absenteísmo e outros dois representantes de experiências menos exitosas. A análise permitiu representar o perfil dos serviços locais "em situação", discutindo estratégias, processos de trabalho, facilidades e dificuldades. Foi possível evidenciar as diferentes características e fluxos nos quatro municípios estudados, bem como a pequena ou inexistente discussão sobre o absenteísmo. Durante as entrevistas, nenhum dos entrevistados sabia ao certo a taxa de falha de atendimento e demonstraram-se surpresos quando informados de que são em média 560 consultas especializadas perdidas por mês. Todos concordaram que devem ser adotadas estratégias de prevenção ao absenteísmo, e, principalmente, esses dados devem ser divulgados à população. Concordaram ainda que outros setores podem e devem ser copartícipes na efetivação de uma rede local de atenção à saúde, no registro do fluxo dos usuários, utilizando diferentes espaços para a promoção da frequência ao atendimento e educação em saúde. Foram compartilhadas várias estratégias e propostas de mudança para reorganização 
municipal e alteração nos fluxos de trabalho, bem como comunicação entre os serviços e os usuários. Este estudo proporcionou a oportunidade de discussão entre os envolvidos no processo de acesso aos serviços de saúde do AME Araçatuba. Permitiu a reflexão sobre responsabilidades e papéis dos atores no processo. O folder produzido a partir desta pesquisa e apoiado pela revisão bibliográfica será utilizado na capacitação de profissionais, com a finalidade de subsidiar o planejamento em saúde e melhorar a assistência proposta ao usuário do SUS.

Palavras-chave: Absenteísmo. Assistência Ambulatorial. Pacientes ambulatoriais. Equipe de assistência ao Paciente. Estratégias. Acesso aos Serviços de Saúde. 


\begin{abstract}
Catelan D. Absenteeism in the outpatient service of SUS: strategies and perspectives of health teams in the public network of the Regional Department of Health II - Araçatuba-SP 20112017 [dissertation]. São Paulo: University of São Paulo, School of Dentistry; 2018.
\end{abstract}

Absenteeism, that is, the non-attendance of users in health services of Unified Health System is a subject of growing interest due to large number of people waiting for care and current economic context. The problem entails damages to all involved, since it prolongs the diagnostic conclusion, impairs the treatment, decreases the provider's productivity, causes an increase in waiting time for other users' attention, and wastage of public resources. Therefore, the aim in this study was to understand the reasons for absenteeism in health services and the strategies used to reduce service failures. It is qualitative research, in the design of the case study, descriptive-exploratory based on interstructure interviews and focal group. The interview is a technique of collecting data through group interactions, mediated by a facilitator, to encourage the formation of opinions on the absenteeism, strategies and perspectives of the health teams. Four tracer cases were selected to show typical experiences, that is, two municipalities that could demonstrate the most successful dynamics in control of absenteeism and two other less successful representatives of the same. The analysis allowed to represent the profile of local services "in situation", discussing strategies, work processes, facilities, and difficulties. It was possible to show the different characteristics and flows between the four municipalities studied and how little or no discussion about absenteeism is available. During the interview, none of municipalities interviewed knew for certain that the rate of service failure was surprising when informed that they are on average 560 specialized consultations lost per month. All agreed that strategies should be taken, and especially, these data should be made public. They also agree that other sectors can and should be partners in the implementation of the local health care network, in execution of flow users, use of other spaces for awareness, and education in health. Several strategies and proposals for change have been shared for municipal reorganization and changes in workflows and communication between services and users. This study provided the opportunity for discussion among those involved in the process of access to the health services of Ambulatory Care of Araçatuba. It allowed for reflection on the responsibilities and roles of actors in the process. The folder 
produced from this research and supported by bibliographic review will be used to train professionals, with the purpose of subsidizing health planning and improving the proposed assistance to Unified Health System users.

Keywords: Absenteeism. Ambulatory Care. Outpatients Ambulatory. Patient Care Team. Strategies. Health Services Accessibility. 


\section{LISTA DE ILUSTRAÇÕES}

Mapa 1.1 - Região de abrangência do DRS II - Araçatuba: 40 municípios divididos em Lagos (amarelo) Central (verde) e Consórcio (azul).

Mapa 1.2 - Departamentos Regionais de Saúde do Estado de São Paulo dividido em

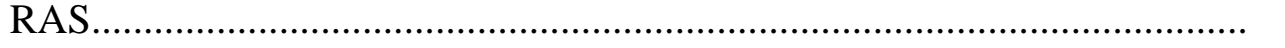




\section{LISTA DE TABELAS}

Tabela 4.1 Número de produção por ano de publicação, segundo indexação e países de origem da publicação, no período de 1966-

Set/2017

Tabela 4.2 Número de produções não indexadas por ano de publicação, países de origem da publicação e tipo de produção, no período de 1966-Set/2017.....

Tabela 4.3 O absenteísmo em consultas médicas e não médicas, interconsultas, retornos e exames/procedimentos do AME Araçatuba no período de 2010 a 2017.

Tabela 4.4 Especialidades distribuídas para primeira consulta do AME Araçatuba com maiores taxas de absenteísmo e número de dispensa, no período de 2011 a 2017.

Tabela 4.5 Número de primeiras consultas agendadas e alta global no AME Araçatuba por ano, no período de 2011 a 2017.

Tabela 4.6 Oferta e agendamentos/mês de consultas em especialistas do Município A, nos meses de novembro de cada ano no período de 2010 a 2017

Tabela 4.7 Oferta e agendamentos/mês de consultas em especialistas do Município B, nos meses de novembro de cada ano no período de 2010 a 2017

Tabela 4.8 Oferta e agendamentos/mês de consultas em especialistas do Município C, nos meses de novembro de cada ano no período de 2010 a 2017

Tabela 4.9 Oferta e agendamentos/mês de consultas em especialistas do Município D, nos meses de novembro de cada ano no período de 2010 a 2017. 


\section{LISTA DE GRÁFICOS}

Gráfico 4.1 - Demonstrativo do número de artigos encontrados no levantamento bibliográfico, segundo sua utilização para o estudo, no período de 1966Set/2017

Gráfico 4.2 - Número e proporção de produção por tipo de pesquisa com base nos procedimentos metodológicos utilizados e ano de publicação, no período de $1966-$ Set/2017.

Gráfico 4.3 - Número de produção por países de origem da publicação, no período de 1966-Set/2017.

Gráfico 4.4 - Número de produção por período de 1966 a Set/2017, segundo os países de origem da publicação.

Gráfico 4.5 - Número e porcentagem de publicações gerais por níveis de complexidades, no período de1966 a Set/2017

Gráfico 4.6 - Número e porcentagem de publicações na atenção primária de saúde (APS) por temáticas ou especialidades, no período de1966 a Set/2017.....

Gráfico 4.7 - Número e porcentagem de publicações na atenção secundária de saúde por temáticas ou especialidades, no período de1966 a Set/2017.

Gráfico 4.8 - Número e porcentagem de publicações na atenção terciária de saúde por temáticas ou especialidades, no período de1966 a Set/2017.

Gráfico 4.9 - Número de publicações por nível de complexidade à nível nacional e internacional, segundo os países de origem da publicação, no período de1966 a Set/2017.

Gráfico 4.10 Número de apontamentos sobre os motivos do absenteísmo coletados por meio de entrevistas com os usuários, depoimentos de profissionais de saúde, informações de banco de dados e experiências dos próprios autores, no período de1966 a Set/2017.

Gráfico 4.11 Número de apontamentos sobre os motivos do absenteísmo relatados tanto por usuários e profissionais de saúde, no período de1966 a Set/2017.

Gráfico 4.12 Número e porcentagem de apontamentos sobre os motivos do absenteísmo relatados por usuários, no período de1966 a Set/2017.

Gráfico 4.13 Número de apontamentos sobre os motivos do absenteísmo evidenciados pelos profissionais de saúde e pelos próprios autores, no período de1966 a Set/2017 
Gráfico 4.14 Número e porcentagem de apontamentos sobre os motivos do absenteísmo evidenciados em banco de dados, experiência dos autores e profissionais de saúde, no período de1966 a Set/2017

Gráfico 4.15 Número de publicações por estratégias sugeridas para prevenir ou diminuir os índices de absenteísmo, no período de1966 a Set/2017..........

Gráfico 4.16 Número e proporção de publicações por estratégias implantadas ou experimentadas pelos autores, no período de1966 a Set/2017.................. 


\section{LISTA DE ABREVIATURAS E SIGLAS}

ACS Agente comunitário de saúde

AIH Autorização de Internação Hospitalar

AME Ambulatório Médico de Especialidades

APS Atenção Primária à Saúde

AS Atenção Secundária

CDR Cadastro de demanda por recurso

CID Classificação Internacional das Doenças

CIR Comissão Intergestores Regionais

CRAS Centro de Referência da Assistência Social

CROSS Central de Regulação de Ofertas de Serviços de Saúde

DRS Departamento Regional de Saúde

EUA Estados Unidos da América

ESF Estratégia da Saúde da Família

FA Falha no Atendimento

NA Não Atendimento

NGA Núcleo de Gerenciamento Ambulatorial

OSS Organização Social de Saúde

PPI Programação Pactuada Integrada

PSF Programa da Saúde da Família

RAS Rede de Atenção à Saúde

RRAS Rede Regional de Atenção à Saúde

SAU Serviço de atendimento ao usuário

SES Secretaria do Estado de São Paulo

SMS Short Message Service (Serviço de Mensagem Curta)

SMS Secretaria Municipal de Saúde

SUS Sistema Único de Saúde

TCLE Termo de Consentimento Livre e Esclarecido

UBS Unidades Básicas de Saúde

USF Unidade de Saúde da Família 


\section{SUMÁRIO}

1 INTRODUÇÃ O........................................................................................

2 OBJETIVOS.................................................................................................. 28

3 PROCEDIMENTOS METODOLÓGICOS................................................... 29

4 RESULTADOS E DISCUSSÃO..................................................................., 33

5 REFLEX ÕES SOBRE OS DADOS............................................................... 115

6 CONSIDERAÇÕES FINAIS............................................................................. 143

7 PRODUTO: FOLDER PARA EDUCAÇÃO EM SAÚDE.............................. 145 REFERÊNCIAS............................................................................................... 147

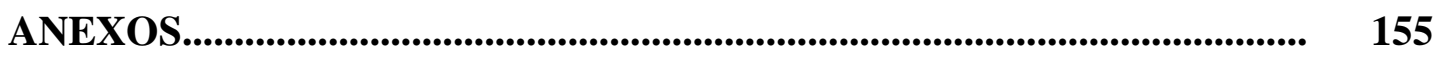




\section{APRESENTAÇÃO}

Graduei-me enfermeira em 2003 pela Faculdade de Medicina de Marília, SP. Desde então, obtive experiência assistencial e gerencial na área hospitalar, nos setores privado e público. Fui enfermeira assistencial na Santa Casa de Misericórdia de Araçatuba, Araçatuba, SP, de 2004 a 2006, nas unidades clínicas e cirúrgicas; unidades de terapia intensiva adulta e coronariana; oncologia, e hemodinâmica. Entre os anos de 2006 e 2010, trabalhei como enfermeira administrativa e na educação continuada do Hospital Unimed Araçatuba.

Em 2010, ingressei no serviço público, na área assistencial do Hospital Geral de Promissão, Promissão, SP. Fui transferida para o Departamento Regional da Saúde II Araçatuba, SP em 2014, e, desde então, trabalho no Núcleo de Regulação desse Departamento, na articulação da oferta de serviços de saúde ambulatoriais para seus quarenta municípios de referência. Dentre os vários serviços de referência regional, um é ofertado pelo Ambulatório Médico de Especialidade (AME) de Araçatuba, SP, o qual constituirá o cenário deste estudo. A gestão do acesso aos serviços de saúde despertou meu interesse quanto à necessidade de compreender a relação entre o grande número de usuários que aguardam por atendimento especializado frente à alta taxa de absenteísmo.

Vale a pena ressaltar que a gestão do AME Araçatuba é realizada por parceiros terceirizados pela Secretaria Estadual da Saúde do Estado de São Paulo, e é acompanhado e monitorado pelo Núcleo de Regulação do Departamento Regional de Saúde Araçatuba. Este equipamento de saúde é avaliado trimestralmente por meio de indicadores, produção e metas. A proposta deste estudo foi conhecer os processos organizacionais e as práticas de trabalho dos atores envolvidos, para otimizar recursos públicos e viabilizar o acesso dos usuários à rede de atenção à saúde.

Neste estudo, o termo absenteísmo foi aplicado aos serviços de saúde com algumas observações, pois a maioria da literatura pesquisada era relacionada ao absenteísmo no trabalho, ou seja, na área de recursos humanos.

Conforme Hamilton e Gourlay (2002), Bittar et al. (2016) e Reid et al. (2016) a palavra absenteísmo é utilizada por alguns autores como falha no atendimento (FA) ou não atendimento (NA). O termo absenteísmo teve origem no latim, absens, que significa "estar fora, afastado ou ausente". Para este trabalho, foi considerada a palavra absenteísmo para 
todos os casos de FA ou NA, ou seja, com enfoque no usuário e em todo processo envolvido para o atendimento do mesmo.

O absenteísmo tem ganhado cada vez mais espaço nas discussões e pesquisas na área de gestão e organização dos serviços em saúde (Gonçalves et al., 2015; Bittar et al., 2016). Embora seja um assunto de crescente interesse na saúde mundial, a primeira literatura brasileira sobre o tema foi publicada em 2006 e a produção se intensificou a partir de 2009 . Este tema será discutido e aprofundado ao longo deste estudo.

O propósito desta investigação foi compreender os motivos do absenteísmo nos serviços de saúde e as estratégias praticadas para reduzi-lo. Os resultados poderão subsidiar a capacitação de profissionais para o aperfeiçoamento no processo de formulação de políticas, planejamento e gestão do Sistema Único de Saúde. Nessa direção foi produzido um folder destinado aos gestores e serviços de saúde do DRS II Araçatuba, Município de Araçatuba, SP. 


\section{INTRODUÇÃO}

O absenteísmo em serviço de saúde é o não comparecimento ou a falha no processo de atendimento do usuário. São vários os motivos atribuídos à sua ocorrência pelos usuários: o esquecimento da data ou horário, a confusão sobre o local, a falta ou atraso do transporte, a percepção equivocada de saúde-doença e o imprevisto com familiares (Koshy et al., 2008; Perron et al., 2010; Travassos; Castro, 2012). O absenteísmo também é atribuído a situações que envolvem o serviço de saúde, definidas como falha técnica ou processual como: suspensão de procedimentos, cancelamentos ou transferências na agenda, avanço do horário programado, erros de comunicação, o que pode ser minimizado por medidas internas junto aos trabalhadores (Lira et al., 2001; Collins et al., 2003; Ezike et al., 2011; Cavalcanti et al., 2013; Sodré; Fahl, 2014).

A falha no atendimento (FA) ou o não atendimento (NA) acarreta prejuízos a todos os envolvidos, pois prolonga a conclusão diagnóstica, prejudica o tratamento, diminui a produtividade do prestador, causa aumento de tempo na espera por tratamento e desperdício de recursos públicos (Haynes; Sweeney, 2006; Downer et al., 2006; Koshy et al., 2008; Gonçalves et al., 2015; Nhavoto; Gronlund, 2014; Bittar et al., 2016).

Os erros processuais geram dificuldade no acesso e desconfiança por parte dos usuários quanto à qualidade da assistência, e se traduz muitas vezes na falta de adesão aos tratamentos, além do absenteísmo (Haynes; Sweeney, 2006; Downer et al., 2006; Koshy et al., 2008; Gonçalves et al., 2015; Nhavoto; Gronlund, 2014; Bittar et al., 2016). O vínculo e o envolvimento do usuário no processo de cuidado aumentam a corresponsabilidade e o grau de satisfação no tratamento (Hovlid et al., 2013). Além disso, a comunicação adequada e eficaz entre o serviço de saúde e o usuário possibilita o acesso e a utilização da vaga que seria desperdiçada nos casos de cancelamento. É necessário, portanto, organizara oferta e o acesso aos serviços de saúde para articular os diferentes níveis de atenção: primário, secundário e terciário.

O modelo de atenção à saúde no Brasil tem sido influenciado, e modificado, na tentativa de transformar o cuidado curativo e fragmentado em preventivo e integral (Paim, 1998; Gonçalves et al., 2015). O modelo atual de organização é composto por serviços de menor densidade tecnológica, como aqueles das Unidades Básicas de Saúde (UBS) e Estratégia da Saúde da Família (ESF), até as mais complexas, como hospitais, equipamentos para exames 
por imagem e patologias clínicas. A estrutura do serviço por pontos de atenção à saúde é denominada Rede de Atenção a Saúde (RAS). Esta rede mantém movimentos na vertical e na horizontal, entre os níveis de atenção e com as várias entradas e saídas no serviço de saúde (Mendes, 2010; Mendes, 2011; Paim, 2012; Travassos; Castro, 2012; Solla; Chioro, 2012).

Nessa concepção de RAS, o primeiro nível ocupa o centro da rede e se relaciona com os demais serviços de saúde. Os pontos de atenção primária de saúde (APS) devem ser numerosos e dispersos, ou seja, a APS tem o objetivo de ordenar e regular (fluxos e contra fluxos) o acesso aos serviços ambulatoriais especializados e hospitalares de maior complexidade tecnológica (Mendes, 2011). Segundo Erdmann et al. (2013), isso operacionaliza os recursos e densidades tecnológicas disponíveis em uma região, devendo ser considerado um estudo sobre a população, as regiões abrangidas e a estrutura operacional para adequado apoio técnico, logístico e gerencial (Lira et al., 2001).

Apesar de esta estratégia buscar diminuir a fragmentação e dificuldade de comunicação, somente a construção da rede não garante o pleno acesso aos serviços e não evita $o$ absenteísmo (Mendes, 2010; Mendes, 2011; Paim, 2012; Solla; Chioro, 2012). O sistema de referência e contrarreferência é o instrumento utilizado para estabelecer o acesso aos cuidados de saúde conforme o grau de complexidade, referência organizacional e geográfica (Travassos; Martins, 2004; Mendes, 2011; Travassos; Castro, 2012; Tristão et al., 2016).

Os municípios são os atores principais nesse processo, assumindo o papel de ampliar e fortalecer a regionalização, com apoio técnico do estado na articulação e ordenamento dos serviços de saúde regionais junto aos municípios de cada território. A regionalização significa mais que um processo de organização dos serviços de saúde. Ela constitui uma construção política para favorecer o diálogo entre os atores participantes e assegurar a integralidade e resolutividade da atenção em saúde (Mendes et al., 2015).

A atenção primária ou básica, em ambiente político favorável e a partir do vínculo entre os profissionais e usuários, possui a capacidade de resolver $80 \%$ dos motivos que levam o indivíduo a procurar o serviço de saúde. Apenas $15 \%$ seriam referenciados à atenção secundária (AS) e somente 5\% necessitariam de mais recursos na atenção terciária ou assistência hospitalar (Mendes, 2011; Solla; Chioro, 2012).

A estratificação de riscos, ou seja, a classificação de prioridade é fundamental para estabelecer a condição e necessidades de saúde dos usuários ou população atendida. As linhas-guia (normalização de ações e procedimentos) e protocolos clínicos (critérios para diagnóstico) devem nortear as ações da APS e dos centros de especialidades (Mendes, 2011). 
Estas premissas são importantes para garantir o acesso do usuário e prevenir o absenteísmo à diferentes modalidades de serviços: aos serviços de saúde e aos exames preventivos e diagnósticos.

A maior parte dos cancelamentos e faltas pode ser evitada por meio da reorganização dos processos internos, melhoria no planejamento e gestão, lembretes telefônicos e a realização de acolhimento na consulta dos usuários (Paschoal; Gatto, 2006; Ávila; Bocchi, 2013; Hovlid, et al., 2013). A corresponsabilidade do usuário no processo de decisão dos tratamentos propostos (Hovlid et al., 2013) aumenta o grau de satisfação, diminui o número de faltas e reduz os cancelamentos.

Portanto, a relação entre o acesso e o absenteísmo precisa ser analisada em toda a logística de agendamento e encaminhamento para que essa assistência à saúde seja de fato efetivada.

\subsection{O absenteísmo em serviços de saúde}

O não atendimento do usuário deve ser considerado em seu amplo feição e complexidade, envolvendo os usuários, os profissionais de saúde, as instituições, a organização, os fluxos e os processos, a acessibilidade, a organização e as fases envolvidas no processo de agendamento, cancelamentos e dispensas. A maior parte das faltas e cancelamentos pode ser evitada por meio da reorganização dos processos internos; melhoria no planejamento e gestão; lembretes telefônicos e a realização de acolhimento na consulta dos usuários (Paschoal; Gatto, 2006; Ávila; Bocchi, 2013; Hovlid et al., 2013), além da utilização dos sistemas de informação e a tecnologia móvel, que têm se desenvolvido rapidamente e conquistado espaço importante na área da saúde (Paschoal; Gatto, 2006).

A telefonia móvel se tornou um fácil, rápido e eficiente canal de comunicação ${ }^{1}$ (Nhavoto; Gronlund, 2014) e tem sido apontada como um apoio no enfrentamento do absenteísmo. O uso de "short message servisse" (SMS) e a ligação telefônica para as consultas no Hospital foram muito mais econômicos e possibilitaram o agendamento de outro usuário na vaga que seria desperdiçada (Hasvold; Wootton, 2011).

Informações em formato eletrônico e outras intervenções em ambiente web podem aumentar a confiança dos usuários e a participação nas decisões sobre sua saúde. Essa

\footnotetext{
1 segundo dados do IBGE (2013), era de cerca de 94,4\% o uso de telefonia móvel (nível técnico médio, serviço administrativo, profissionais gerais) na área urbana no Brasil, em 2011, e de $43 \%$ na área agrícola. Este crescimento de aparelhos móveis na zona rural é importante para viabilizar a comunicação com essa população.
} 
corresponsabilidade melhora os resultados sanitários, especialmente se são complementares às práticas educacionais ofertadas (Mendes, 2011). Os lembretes telefônicos e as mensagens de telefones móveis, também conhecidos como SMS foram eficientes, práticos, abrangem um grande número de usuários com rapidez e privacidade (Hasvold; Wootton, 2011; Haynes; Sweeney, 2006; Koshy et al., 2008; Gurol-Urganciet al., 2013; Tao et al., 2015).

Com a finalidade de compreender melhor esse fenômeno, foi realizado um levantamento bibliográfico nacional e internacional sobre o absenteísmo ou o não atendimento de usuários em ambulatórios e serviços de saúde, sem a limitação de tempo ou idioma. O corpus gerado pelo levantamento bibliográfico foi composto por artigos em periódicos indexados e não indexados, anais de congressos, resumos apresentados em simpósios e encontros, cartas, monografias de especializações, dissertações de mestrado e teses de doutorado, mas não foi encontrado nenhum livro ou capítulo a respeito.

\subsection{Universo de estudo}

O estudo foi realizado na região do Departamento Regional da Saúde (DRS) II Araçatuba, localizado no noroeste do estado de São Paulo. Em 2006, o governo de São Paulo dividiu o estado em 17 Departamentos Regionais de Saúde atendendo ao Decreto DOE $\mathrm{n}^{\circ}$ 51.433. O DRS II - Araçatuba é composto por 40 municípios $^{2}$, subdividido em 3 microrregiões: Central $^{3}$, Consórcios ${ }^{4}$ e $\operatorname{Lagos}^{5}$ (Mapa 1.1), com população estimada em 722.540 habitantes.

\footnotetext{
${ }^{2}$ A região possui um dos maiores complexos hidrelétricos do mundo, responsável pela produção de $47 \%$ da energia do estado, nas cidades de Ilha Solteira, Castilho e Pereira Barreto. A economia é predominantemente agropecuária. Possui grande número de famílias "sem terra" em acampamentos na região de Brejo Alegre e cerca de 200 famílias assentadas em fazendas próximas dos Municípios de Araçatuba, Andradina, Mirandópolis e Lavínia. A região possui sete unidades prisionais e três centros de ressocialização e progressão penal, os quais necessitam de atendimento nos serviços públicos do SUS.

${ }^{3}$ Araçatuba, Auriflama, Bento de Abreu, Bilac, Guararapes, Guzolândia, Nova Castilho, Nova Luzitania, Rubiácea, Santo Antônio do Aracanguá, Valparaiso.

${ }^{4}$ Alto Alegre, Avanhandava, Barbosa, Birigui, Brauna, Brejo Alegre, Buritama, Clementina, Coroados, Gabriel Monteiro, Glicerio, Lourdes, Luiziania, Penapolis, Piacatu, Santópolis do Aguapeí, Turiúba.

${ }^{5}$ Andradina, Castilho, Guaraçaí, Ilha Solteira, Itapura, Lavínia, Mirandópolis, Murutinga do Sul, Nova Independência, Pereira Barreto, Sud Mennucci, Suzanápolis.
} 
Mapa 1.1 - Região de abrangência do DRS II - Araçatuba: 40 municípios divididos em Lagos (amarelo) Central (verde) e Consórcio (azul)



Fonte: Secretaria da Saúde do Estado de São Paulo (2012)

Os DRS II-Araçatuba - e DRS XV-São José do Rio Preto - formam a Rede Regional de Atenção à Saúde (RRAS) 12, conforme o Mapa 1.2, criada em consonância com as diretrizes do Ministério da Saúde - Portaria n 4.279 , de 30 de dezembro de 2010. É composta por 142 municípios subdivididos em 10 microrregiões, a saber: Central; Lagos, Consórcios, Catanduva, Santa Fé do Sul, Jales, Fernandópolis, São José do Rio Preto, José Bonifácio e Votuporanga. Essa RRAS 12 abrange uma população total de 2.192.094 habitantes. 
Mapa 1.2 - Departamentos Regionais de Saúde do Estado de São Paulo divididos em RAS

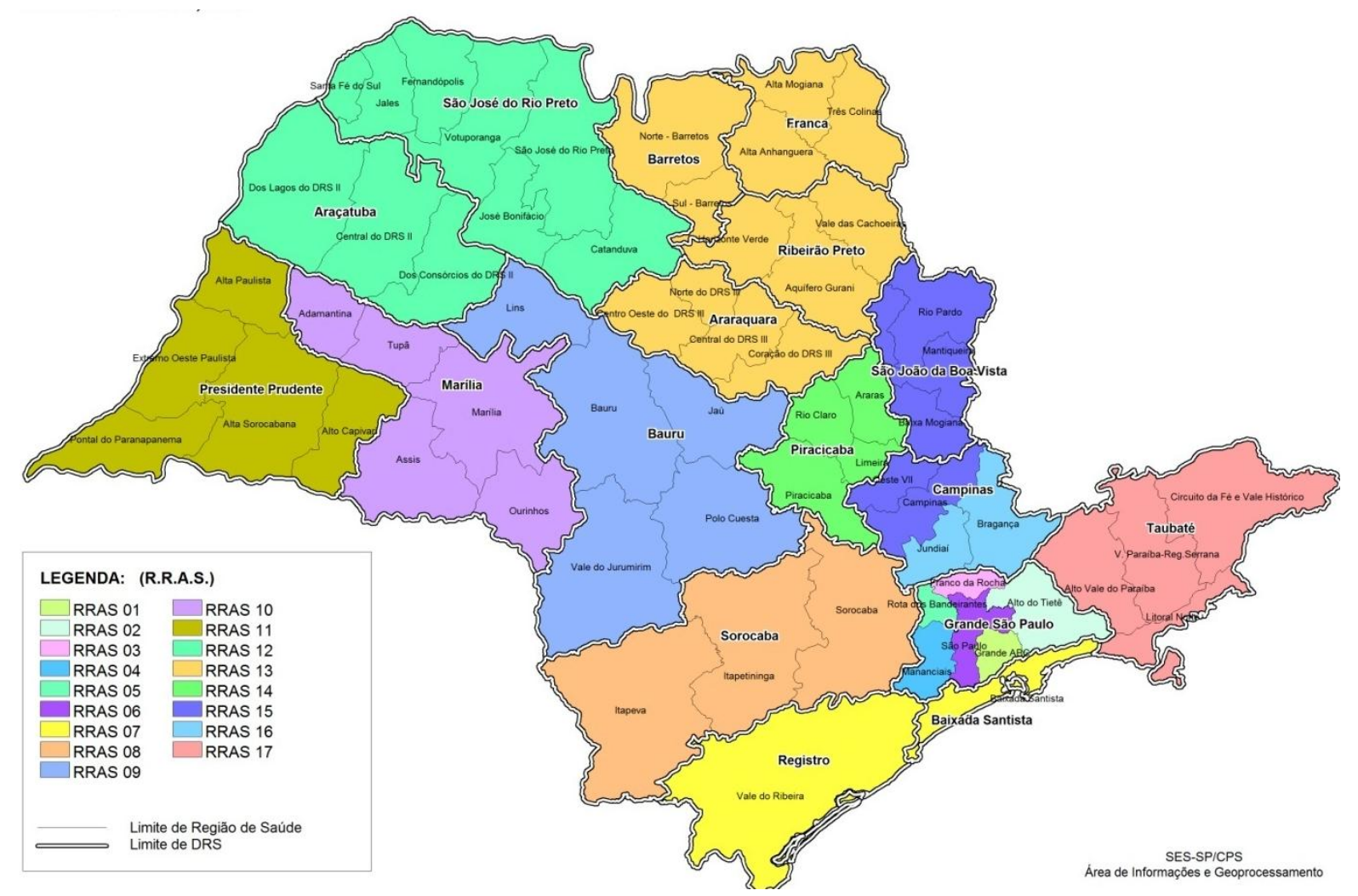

Fonte: Secretaria da Saúde do Estado de São Paulo (2012)

O Governo do Estado de São Paulo implantou em 2007o primeiro AME na cidade de São Paulo, nos moldes do ambulatório de alta complexidade espanhol (Barata et al., 2010). Em 10 anos foram criadas 55 unidades de $\mathrm{AME}^{6}$ por todo o estado de São Paulo, para referência e apoio diagnóstico de intervenção rápida e eficaz, orientação terapêutica com ênfase nas necessidades da rede básica.

A Secretaria de Estado da Saúde de São Paulo, entendendo a necessidade de integrar e gerenciar as ofertas do Sistema Único de Saúde (SUS) criou em 2010 um sistema informatizado denominado Portal CROSS (Central de Regulação de Oferta de Serviço de Saúde). Esse sistema reúne ações voltadas para a regulação do acesso na área hospitalar e ambulatorial, possibilita comunicação e gestão mais efetivas. O Portal CROSS é a unificação

${ }^{6}$ Governo do Estado de São Paulo. Secretaria da Saúde. [internet] São Paulo: Ambulatório Médico de Especialidades - AMEs; c2017 [acesso em 20 out 2017]. Disponível em: http://portal.saude.sp.gov.br/ses/perfil/cidadao/ambulatorio-medico-de-especialidades-ames/ambulatoriomedico-de-especialidades-ames 
dos sites de apoio à regulação em um mesmo local: Conexa, Leitos, Regnet Urgência, Hospnet e Resgate ${ }^{7}$, ou seja, esses sites integram parte do Portal CROSS. Essa ferramenta está sendo utilizada em todo o estado de São Paulo. É dividida por módulos: pré-hospitalar, internação AIH (Autorização de Internação Hospitalar), ambulatorial e urgência/emergência.

O Portal CROSS está disponível para todos os serviços de saúde que queiram utilizar a ferramenta de regulação de ofertas para o SUS. Dessa maneira, é possível interligar os diversos serviços com suas ofertas e disponibilidades conforme as necessidades das localidades, a fim de aperfeiçoar os recursos disponíveis (Simões; Silva, 2010). No DRS II Araçatuba foram implantados o Portal CROSS em 90\% dos serviços sob gestão estadual e prestadores contratados pela Secretaria de Saúde do Estado de São Paulo, dentre eles hospitais e ambulatório.

Além do sistema informatizado de regulação para apoio aos municípios e departamentos regionais de saúde, é disponibilizado o serviço automático de $S M S$ e de e-mail aos usuários com aviso da consulta, contendo data, horário e local do agendamento, com 7 dias de antecedência para todas as consultas, interconsultas e retornos.

Dentre os vários serviços ofertados na referência regional, o Ambulatório Médico de Especialidade (AME) de Araçatuba constituiu o cenário deste estudo. O AME Araçatuba é um ambulatório secundário, conhecido como de atenção especializada ou de média complexidade, tendo a função de oferecer suporte técnico e apoio diagnóstico à rede básica. Ele é referência em consultas especializadas, exames complementares e alguns procedimentos cirúrgico-ambulatoriais ${ }^{8}$ para as microrregiões Central e Consórcios (Mapa 1). A população atendida no AME Araçatuba é estimada em 522.000 habitantes, o qual também atende a região Lagos em algumas especialidades e linhas de cuidado ${ }^{9}$. Os demais tratamentos cirúrgicos e de acompanhamento de doenças crônicas são referenciados para outros serviços da rede de atenção à saúde (RAS).

Desde sua criação em 2009,o AME Araçatuba tem sido gerenciado por Organização Social de Saúde (OSS) e iniciou a prestação de serviços à população da região do DRS II

\footnotetext{
7 Todos esses sistemas auxiliam na regulação de ofertas SUS do estado de São Paulo. Conexa: ofertas ambulatórias; Regnet Leitos: todos os leitos de internação no sistema público por AIH (autorização de Internação Hospitalar); Regnet Urgência: vagas de urgência, Hospnet e Resgate: regulação médica de urgência e leitos de São Paulo.

${ }^{8}$ Cirurgias de catarata, pterígio, retirada de cisto ou crioterapia em pele, cirurgia de túnel do carpo, entre outros.

${ }^{9}$ Linhas de cuidado são estratégias de organização dos serviços com fluxos lógicos de assistência para otimizar os recursos e garantir a integralidade da atenção à saúde.
} 
Araçatuba em junho de 2010. A Secretaria de Saúde do Estado de São Paulo (SES) realiza anualmente o contrato de gestão ${ }^{10}$ e termos aditivos, se necessário, junto à OSS, gerenciada pela Irmandade Santa Casa de Andradina, por contrato com Secretaria de Saúde do Estado de São Paulo desde 2013 até a presente data.

Foram contratadas em 2015, por exemplo, 110.304 consultas de especialidades médicas e 19.800 exames/procedimentos, ou seja, um investimento anual de $\mathrm{R} \$ 12.426 .532,52$. O pagamento é proporcional à variação de serviços prestados, sendo mantido o valor inicial de contrato caso a produção for maior ou igual a $85 \%$ do pactuado. No entanto, a taxa média de não atendimentos foi de $19 \%$ no ano de 2015, o que resultou em 6.686 consultas desperdiçadas, no valor de $\mathrm{R} \$ 503.225,60$.

Apesar de a região possuir um hospital de alta complexidade e ser referência oncológica na cidade sede, ainda há muita deficiência de recursos humanos especializados para atender a região do DRS II - Araçatuba. Muitas especialidades e subespecialidades dependem da assistência à saúde na RRAS 12 (região de São José de Rio Preto) ou em hospitais-escola de São Paulo, como na especialidade de oftalmologia - estrabismo, glaucoma e uveíte. Assim, é percorrida uma distância de cerca de $550 \mathrm{~km}$ pelos usuários de transporte público, seja de ônibus ou micro-ônibus, ambulâncias ou utilitários até os grandes centros da Capital - São Paulo.

\footnotetext{
${ }^{10}$ Portal da transparência: Contratos de gestão e termos aditivos - Organizações sociais saúde [internet]. Governo de São Paulo. Secretaria da Saúde. [acesso em 02 de maio 2016]. Disponível em: Portal da transparência http://www.portaldatransparencia.saude.sp.gov.br define o que é a Organização Social de Saúde e disponibiliza todos os contratos de gestão e termos aditivos com a Secretaria de Saúde do Estado de São Paulo.
} 


\section{OBJETIVOS}

Analisar a natureza do absenteísmo em quatro municípios da área de abrangência do AME Araçatuba - "Dr. Oscar Gurjão Contrim” do Departamento Regional de Saúde (DRS) II - Araçatuba da Rede Regional de Saúde 12, do estado de São Paulo.

\subsection{Objetivos Específicos}

- Descrever e interpretar a organização do fluxo de agendamento das consultas e exames do AME Araçatuba - "Dr. Oscar Gurjão Contrim" - e serviços de saúde de quatro municípios da microrregião do DRS II - Araçatuba, dois com alta taxa de absenteísmo e dois com baixa taxa de absenteísmo;

- Identificar os conceitos, as tecnologias e as estratégias utilizados na efetivação dos atendimentos e sua relação com o absenteísmo no AME Araçatuba e nos serviços dos quatro municípios estudados;

- Elaborar um produto que possa ser utilizado como proposta de educação permanente para auxiliar na organização dos serviços junto aos gestores e trabalhadores de saúde das microrregiões do DRS II Araçatuba, com a finalidade de reduzir o absenteísmo na região de Araçatuba. 


\section{PROCEDIMENTOS METODOLÓGICOS}

Esta pesquisa é qualitativa, com desenho de estudo de caso descritivo-exploratório (Minayo, 2012). Busca-se detectar e compreender o absenteísmo no AME Araçatuba em 4 municípios - sendo 2 com desempenho exitoso no controle do absenteísmo e outros 2 com dificuldade no controle do mesmo, os quais representam dois grandes grupos dos municípios da região do DRS II Araçatuba -, bem como identificar estratégias utilizadas por seus atores no sentido de reduzir a sua ocorrência.

\subsection{Natureza do estudo}

A proposta da pesquisa consiste em identificar os processos organizacionais, as práticas de trabalho e o impacto de propostas de mudanças. A modalidade de estudo de caso é capaz de evidenciar mudanças políticas em estabelecimentos de saúde (Pope; Mays, 2009). Este desenho possibilita responder às questões de "como" e "por que" certos fenômenos acontecem, quando há pouca possibilidade de controle sobre os eventos estudados e quando o foco de interesse são os fenômenos atuais que poderão ser analisados em algum contexto de vida real (Pozzebon; Freitas, 1998).

A estratégia de investigação utilizada neste estudo foi a de casos traçadores, ou seja, casos representativos que possibilitaram o estudo "em situação" sobre estratégias, dificuldades, processos de trabalho, organização entre os serviços, anseios e autonomia dos profissionais da microrregião estudada (Feuerwerker; Merhy, 2008; Silva et al., 2010).

Os casos traçadores vêm sendo empregados amplamente na área de saúde, principalmente nas formas de ações coletivas, para a resolução de problemas em comum ou com o objetivo de transformar a prática profissional, com criticidade e reflexão sobre o cotidiano (Kessner et al., 1973). Desta maneira, os municípios considerados casos traçadores nesta pesquisa foram indicados pelos profissionais do AME Araçatuba que organizam a oferta de vagas em especialidades e exames, e auxiliam no monitoramento do absenteísmo nos municípios da região. Cabe ressaltar que a gestão dessas vagas para os municípios é feita pelo Departamento Regional de Saúde.

Foram realizadas 4 entrevistas semiestruturadas individuais com gestores municipais, com temas disparadores a respeito do assunto explorado, possibilitando pensamentos 
adicionais, conforme as respostas obtidas durante o processo (Anexo A). Essa técnica incentivou reflexões em profundidade acerca das experiências, das dificuldades, dos progressos e do planejamento quanto ao não atendimento no serviço especializado (Britten, 2005).

A coleta de dados realizada junto às equipes do AME Araçatuba (Anexo B) e dos 4 municípios (Anexo C) ocorreu por meio de 9 grupos focais, possibilitando a observação do processo organizacional das ações e serviços de saúde; do trabalho em equipe e entre as equipes; das dificuldades; de mecanismos e estratégias implantadas para a gestão das ofertas de consultas, exames e procedimentos (Mendes et al., 2015).

A dinâmica de grupo focal favoreceu a exploração das necessidades e atitudes do grupo em relação ao problema-chave trabalhado, por meio de interações grupais mediadas pelo facilitador. Ocorreu a provocação da discussão de ideias, incentivo à formação de opiniões, estratégias e perspectivas sobre o absenteísmo nas equipes de saúde (Morgan, 1997; Iervolino; Pelicioni, 2001; Gondim, 2003; Kitzinger, 2005).

A atividade de entrevistas semiestruturadas (Anexo E) e de grupos focais (Anexos B e C) foram iniciadas com breve apresentação da entrevistadora e dos participantes, seguida da leitura do Termo de Consentimento Livre e Esclarecido (TCLE - Anexo D), exposição dos objetivos e da justificativa da pesquisa. Após os esclarecimentos de dúvidas e autorização, foram gravados os áudios e iniciadas as solicitações de narrativas aos participantes sobre o processo de agendamento, as dificuldades envolvidas e as estratégias utilizadas para melhorar o atendimento dos usuários nos municípios e no AME Araçatuba.

As informações provindas das entrevistas e dos grupos focais foram gravadas e ouvidas, transcritas e transcriadas. Transcriação é a ação de recriar do oral para o escrito, no sentido de aproximar a escrita à preservação real intenção dos participantes (Meihy; Holanda, 2015). Os conteúdos foram devolvidos aos entrevistados para revisão, modificação, exclusão e inserção de informações conforme consenso dos participantes. Após a leitura exaustiva e a análise das entrevistas, os conteúdos das mesmas foram organizados em categorias mais evidentes e significativas. Os conteúdos foram analisados em profundidade após a finalização da categorização (Bardin, 1977).

Foi utilizada a literatura científica para análise das categorias e, desta maneira, foi possível evidenciar os principais núcleos de sentido que compuseram essas comunicações. Diante das dificuldades e estratégias evidenciadas, buscou-se estabelecer relações entre a singularidade do estudo de caso e outras experiências com base na revisão bibliográfica. 
Foram consultadas as bases de dados PubMed, CAPES, SIBi USP, MEDLINE e SciELO, e utilizado o Google Acadêmico para pesquisa da literatura cinza, usando-se os descritores: absenteeism e patient combinados com os descritores ambulatory e outpatient, e em português os descritores: absenteísmo e paciente combinados com o descritor ambulatorial. O levantamento da literatura abrangeu o período de 1966 a setembro de 2017, o que representou uma cobertura bastante compreensiva sobre o tema.

O levantamento bibliográfico foi organizado em planilha Excel. Os dados foram analisados sob diferentes recortes: 1. por período e tipo de publicação; 2. por tipo de pesquisa; 3. por países de origem da publicação; 4. por temática e nível de complexidade assistencial, e 5. por motivos, estratégias aplicadas e sugeridas para diminuição do absenteísmo.

Para compor a triangulação de dados (Pope; Mays, 2009; Minayo, 2005), foi considerada a coleta de documentos junto ao AME Araçatuba e os 4 municípios selecionados: documentos, relatórios, banco de dados do Portal CROSS, atas de reuniões, planos municipais de saúde, o controle de viagem dos municípios, check list de dispensa da portaria e organograma do AME Araçatuba. O cruzamento dos dados possibilitou uma análise descritiva e analítica da realidade empírica estudada.

\subsection{Comitê de Ética e Pesquisa}

Primeiramente, o estudo foi submetido ao Comitê de Ética e Pesquisa da Faculdade de Medicina da Universidade de São Paulo. Este estudo seguiu as diretrizes e normas regulamentadoras para pesquisa envolvendo seres humanos de acordo com a Resolução 466/12 do Conselho Nacional de Saúde e foi aprovado pelo Comitê de Ética em Pesquisa da FMUSP (Parecer da Plataforma Brasil n 2.079.796 24 de maio de 2017- Anexo E).

O termo de autorização para a realização da pesquisa (Anexo F) foi solicitado aos diretores e responsáveis técnicos do AME Araçatuba e DRS II Araçatuba. Seguem o TCLE que foi solicitado aos profissionais, gestores municipais e coordenadores/responsáveis técnicos pelo agendamento municipal (Anexo D).

\subsection{Riscos e benefícios da pesquisa}

Os riscos da pesquisa são mínimos e restringem-se à exposição de ideias na entrevista, risco de constrangimento e receio posterior de identificação. Porém, o sigilo e o anonimato 
foram garantidos mediante o TCLE. Não houve benefícios ou pagamento aos sujeitos participantes da pesquisa. Este estudo teve intenção de contribuir e melhorar a oferta de saúde na região do DRS II Araçatuba.

\subsection{Produto da pesquisa}

Os resultados alcançados foram organizados em tópicos reflexivos, estratégias e recomendações aos profissionais de saúde sobre o absenteísmo em um folder de Educação Permanente em Saúde. Esse material será destinado aos profissionais de saúde e gestores do DRS II Araçatuba, e de outras regiões administrativas interessadas no tema. 


\section{RESULTADOS E DISCUSSÃO}

O levantamento bibliográfico sobre o tema proposto resultou em um total de 66.919 registros, referentes ao período de 1966-Set/2017. Somente 180 deles estavam relacionados ao não atendimento do usuário em serviços de saúde, o que representou $0,11 \%$ do total da amostra inicial. É importante destacar que a maioria dos resultados obtidos nesse levantamento era sobre absenteísmo trabalhista, em geral relacionada a recursos humanos e gestão de pessoas na saúde.

\subsection{Revisão bibliográfica}

Foi utilizado o termo NOT work nas combinações com os descritores absenteeism, patient, ambulatory e outpatient com vistas a uma maior precisão no levantamento bibliográfico e na busca avançada da base de dados CAPES. À medida que novos descritores foram identificados, estes passaram a incorporar um repertório para refazer a pesquisa: non attendance, no-show, reason, missed appointments, service reminders e em português falta (faltoso), não comparecimento, não atendimento, motivo, compromissos perdidos, lembrete. Os descritores foram combinados nos idiomas português e inglês, totalizando 50 combinações de descritores. Vale ressaltar que os descritores non attendance e compromisso perdido não tiveram resultados nas buscas em bases de dados.

Essa segunda busca bibliográfica confirmou 180 registros de produções detectados anteriormente, os quais foram submetidos à leitura dos conteúdos em seus resumos. Após essa triagem, foram considerados 132 registros e desconsiderados 48 (Gráfico 4.1).

Dos 48 excluídos da amostra, 7 artigos, mesmo com a busca mais refinada, estavam relacionados ao absenteísmo trabalhista e outros 8 não tinham relação com o tema; referiamse à resistência farmacológica, torpedo educativo e lembrete de medicamentos. Também ficaram de fora do estudo outras 5 publicações em anais de congressos, 5 resumos apresentados em simpósios e encontros, 3 cartas e 2 monografias de especializações nacionais, cujos textos tinham conteúdos insuficientes, ou de natureza apenas descritiva, e alguns em forma de opinião. 
Não foram encontrados eletronicamente 6 artigos, apesar de serem indicados nas bases de dados pesquisadas. Uma vez que este estudo não contou com financiamento, outros 12 textos foram excluídos por ser exigido pagamento para acesso.

Gráfico 4.1 - Demonstrativo do número de artigos encontrados no levantamento bibliográfico, segundo sua utilização para o estudo, no período de 1966-Set/2017

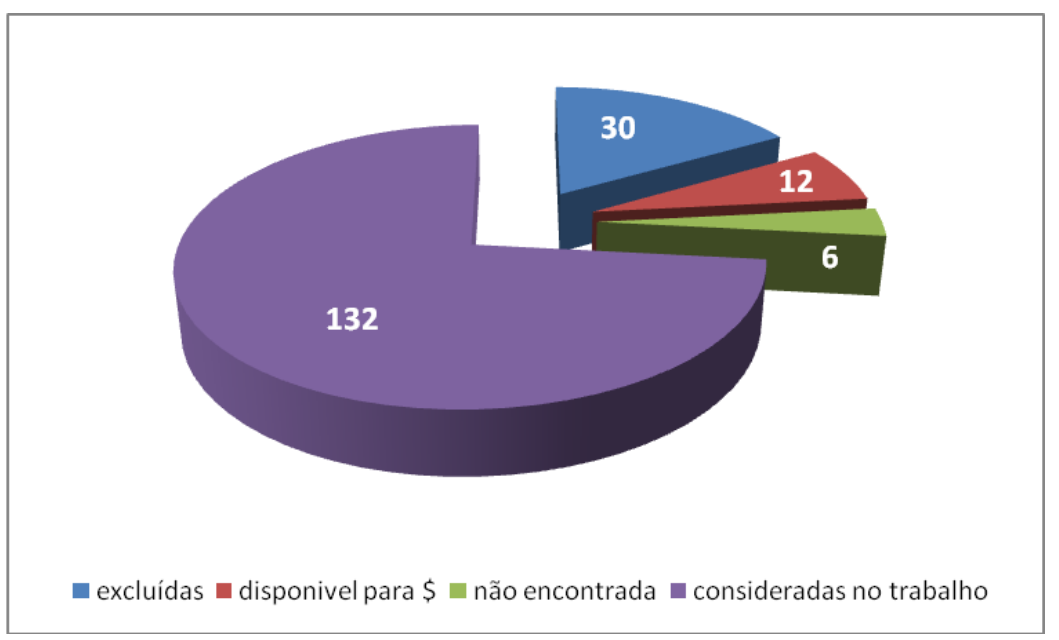

\begin{tabular}{|l|l|}
\hline $\begin{array}{l}\text { Produção dentre os 180 } \\
\text { registros tabulados }\end{array}$ & $\mathbf{N}^{\mathbf{o}}$ \\
\hline Não encontrados & 6 \\
\hline Disponíveis para compra & 12 \\
\hline Desconsiderados/excluídos & 30 \\
\hline Subtotal & $\mathbf{4 8}$ \\
\hline Considerados na pesquisa & 132 \\
\hline Total & $\mathbf{1 8 0}$ \\
\hline
\end{tabular}

Fonte: o autor

Essas produções foram organizadas para análise das seguintes formas: 1. por período e tipo de publicação; 2. por tipo de pesquisa; 3. por países de origem da publicação; 4. por temática e nível de complexidade assistencial e 5. por motivos, estratégias aplicadas e sugeridas para diminuir o absenteísmo.

\subsubsection{A produção por período e tipo de publicação}

Os 132 textos considerados neste estudo foram divulgados em endereços eletrônicos, revistas ou jornais de saúde, dos quais 89\% ( $\mathrm{n}=118$ artigos) foram encontrados em periódicos indexados e 11\% ( $\mathrm{n}=14)$ em periódicos não indexados (Tabela 4.1). Os quatorze artigos não indexados foram localizados pelo Google acadêmico nas seguintes revistas: Studies University of East London, Absentismo en consultas externas del Consorcio, Revista Pesquisa: Cuidado é Fundamental Online UNIRIO, Journal of Hospital Administration, Revista Brasileira Medicina de Família e Comunidade, NHS Health Scotland, Revista Brasileira Pesquisa Saúde e em alguns sites de dissertações e teses de diferentes universidades. 
Tabela 4.1 - Número de produção por ano de publicação, segundo indexação e países de origem da publicação, no período de 1966-Set/2017

\begin{tabular}{|c|c|c|c|c|c|}
\hline \multirow{2}{*}{$\begin{array}{c}\text { Tipo de produção } \\
\text { Período/ano }\end{array}$} & \multicolumn{2}{|c|}{$\begin{array}{c}\text { Produção (periódicos } \\
\text { indexados) }\end{array}$} & \multicolumn{2}{|c|}{$\begin{array}{l}\text { Produção (periódicos } \\
\text { não indexados) }\end{array}$} & \multirow[b]{2}{*}{ Total } \\
\hline & Nacional & Internacional & Nacional & Internacional & \\
\hline $1966-69$ & 0 & 1 & 0 & 0 & 1 \\
\hline $1970-79$ & 0 & 0 & 0 & 0 & $\mathbf{0}$ \\
\hline 1980-89 & 0 & 2 & 0 & 0 & 2 \\
\hline 1990-99 & 0 & 10 & 0 & 0 & 10 \\
\hline 2000-09 & 4 & 31 & 1 & 1 & 37 \\
\hline 2010 -set/17 & 14 & 56 & 8 & 4 & 82 \\
\hline Subtotal & 18 & 100 & 9 & 5 & 132 \\
\hline
\end{tabular}

No Brasil, a manifestação de interesse sobre o tema em estudo iniciou-se timidamente na década de 2000 e cresceu mais de $400 \%$ na década de 2010 (Tabela 4.1) em números absolutos: foram de 5 para 22 produções. O crescimento da publicação brasileira em 2010 coincidiu com o aumento das publicações internacionais. Porém, esse número de produções ainda é pequeno em relação ao tema, tanto no nível nacional quanto no internacional. A produção nacional corresponde a $20 \%(\mathrm{n}=27)$ de todas as publicações e a internacional a $80 \%(\mathrm{n}=105)$.

Todos os artigos referentes a revisões bibliográficas foram publicados em periódicos não indexados, com predominante concentração na década de 2010, assim como a produção de 3 dissertações de mestrado e 2 teses de doutorados (Tabela 4.2). Pode-se observar que a produção não indexada é maior no nível nacional do que no internacional. 
Tabela 4.2 - Número de produções não indexadas por ano de publicação, países de origem da publicação e tipo de produção, no período de 1966-Set/2017

\begin{tabular}{crrrrrrrr}
\hline $\begin{array}{c}\text { Tipo de } \\
\text { produção }\end{array}$ & $\begin{array}{c}\text { Artigos de revistas e } \\
\text { Revisão Bibliográfica }\end{array}$ & Dissertação Mestrado & Tese Doutorado & Total \\
\hline Período/ano & Nacional & Internacional & Nacional & Internacional & Nacional & Internacional & \\
\hline 1966 & 0 & 0 & 0 & 0 & 0 & 0 & $\mathbf{0}$ \\
$1970-77$ & 0 & 0 & 0 & 0 & 0 & 0 & $\mathbf{0}$ \\
$1987-89$ & 0 & 0 & 0 & 0 & 0 & 0 & $\mathbf{0}$ \\
$1990-99$ & 0 & 0 & 0 & 0 & 0 & 0 & $\mathbf{0}$ \\
$2000-09$ & 0 & 1 & 1 & 0 & 0 & 0 & $\mathbf{2}$ \\
$2010-$ Set/17 & 5 & 2 & 2 & 1 & 1 & 1 & $\mathbf{1 2}$ \\
\hline Subtotal & $\mathbf{5}$ & $\mathbf{3}$ & $\mathbf{3}$ & $\mathbf{1}$ & $\mathbf{1}$ & $\mathbf{1}$ & $\mathbf{1 4}$ \\
\hline
\end{tabular}

Fonte: o autor.

\subsubsection{A produção por tipo de pesquisa}

A produção também foi analisada quanto ao tipo de pesquisa que a originou, isto é, se foi resultado de revisão bibliográfica, relato de experiência ou estudo de caso, pesquisa expost-facto ou causal comparativa $^{11}$, pesquisa-ação $^{12}$, pesquisa experimental/quasiexperimental ${ }^{13}$ (Gráfico 4.2).

\footnotetext{
${ }^{11}$ Pesquisa ex-post-facto ou comparativa causal. Descreve diferenças nas variáveis que ocorrem naturalmente entre dois ou mais casos, sujeitos ou unidades de estudo (Gil, 2008).

${ }^{12}$ Pesquisa-ação é definida como uma das formas de investigação-ação. Caracteriza-se como toda tentativa continuada, sistemática e empírica na melhoria ou prática ou social, na qual a investigação deixa de ser observação para participar. Processo dinâmico, participativo, coletivo, com análise crítica da realidade(Tripp, 2005).

${ }^{13}$ Pesquisa quasi-experimental, denominada por alguns autores como "tipo antes e depois", é aplicada em situações complexas naturais, que, por razões éticas e/ou práticas,não é possível a manipulação e controle necessários em experiências de grupo verdadeiro e ideal, ou seja, não têm distribuição aleatória das pessoas ou grupos pelas condições experimentais. Estes grupos já existiam antes do experimento (Behi; Nolan, 1996).
} 
Gráfico 4.2 - Número e proporção de produção por tipo de pesquisa com base nos procedimentos metodológicos utilizados e ano de publicação, no período de 1966-Set/2017

\begin{tabular}{|l|r|r|r|r|}
\hline $\begin{array}{r}2011-2017 \\
2006-2010 \\
2001-2005 \\
1991-2000 \\
1966-1990\end{array}$ \\
\cline { 2 - 7 }
\end{tabular}

Fonte: o autor.

A pesquisa ex-post-facto ou causal comparativa e a pesquisa experimental/quasiexperimental foram os tipos mais utilizados na pesquisa sobre o assunto. Foram os primeiros e os únicos tipos de pesquisas utilizados entre 1966 a 1990, e, a partir de 1991 até 2000, ocorreram os primeiros estudos de casos e a primeira pesquisa-ação. Nota-se que, a partir de 2001, há diversificação dos procedimentos metodológicos, mas se mantém e a prevalência das pesquisas ex-post-facto ou causal comparativa e experimental/quasi-experimental.

Os estudos de revisão bibliográfica começaram a ser utilizados nos últimos 10 anos de forma crescente, tanto no nível nacional como no internacional (Gráfico 4.2).

\subsubsection{A produção por países de origem da publicação}

A primeira produção sobre absenteísmo foi publicada por Hayden e Small (1966), indexado na PubMed, sobre o não atendimento em clínica de saúde mental por faltas ou desistências do tratamento. Porém, a temática sobre o absenteísmo em serviços de saúde começou a despertar interesse e importância apenas no final da década de 1980, principalmente nos Estados Unidos da América (EUA) e no Reino Unido (RU). É importante destacar que os EUA foram os pioneiros, mas intensificaram as pesquisas sobre esse assunto 
somente no período de 2011 a 2017. O RU iniciou posteriormente, apenas em 1989, e manteve alta a produção até 2010 (Gráfico 4.3).

Gráfico 4.3 - Número de produção por países de origem da publicação, no período de 1966-Set/2017

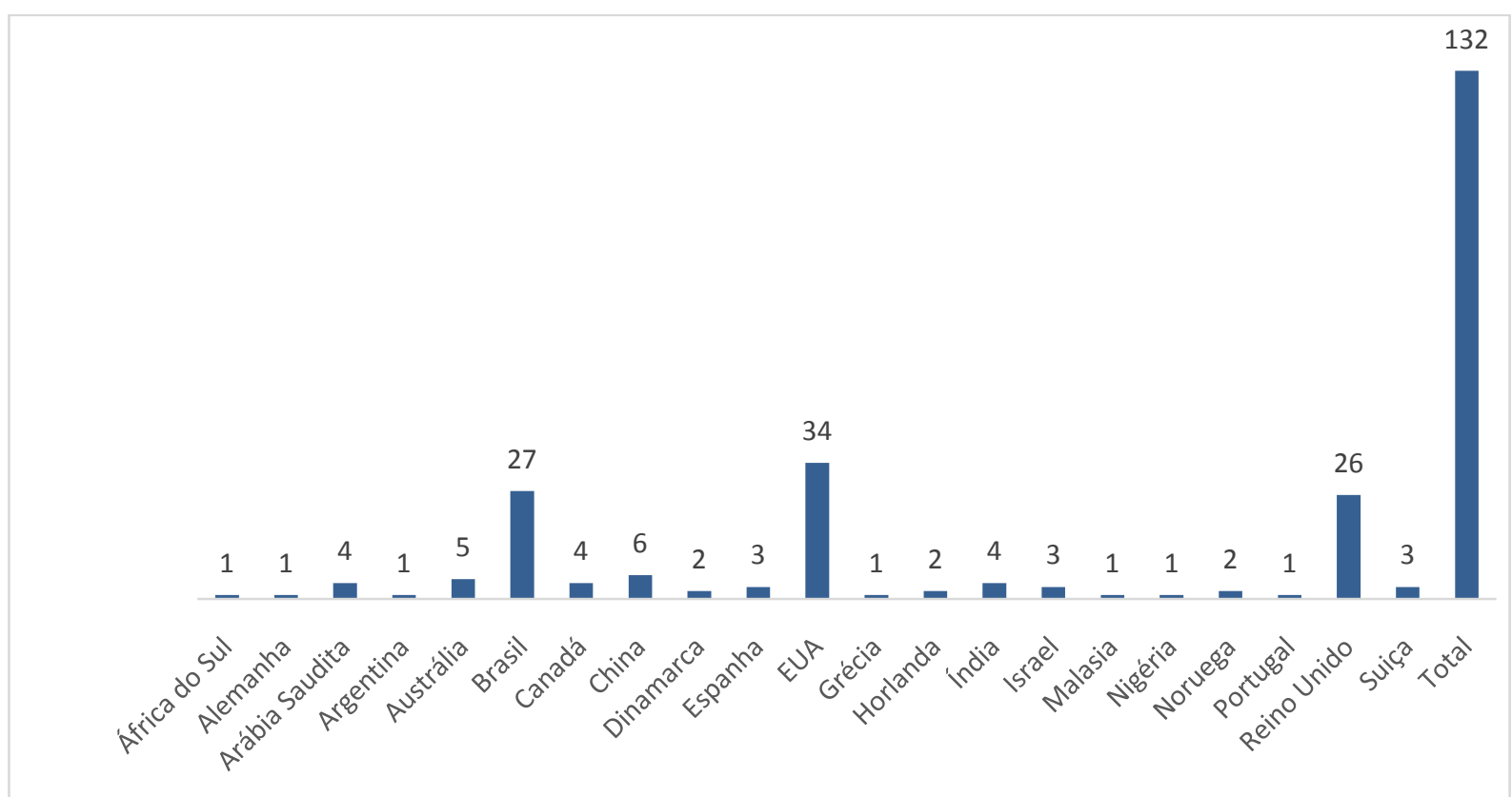

Fonte: o autor

O maior número de publicações por países de origem, no momento da publicação, é o dos EUA $(n=34)$, seguido pelo Brasil $(n=27)$ e, por último no Reino Unido $(n=26)$, conforme o Gráfico 4.3. A produção internacional corresponde a $80 \%(\mathrm{n}=105)$ do total de 132 estudos, e a maior concentração de produção sobre o tema estudado compreende o período de 2001 a Set/2017 ( $\mathrm{n}=58$ internacionais, e $\mathrm{n}=17$ nacionais) nesse mesmo período (Gráfico 4.4). 
Gráfico 4.4 - Número de produção por período de 1966 a Set/2017, segundo os países de origem da publicação

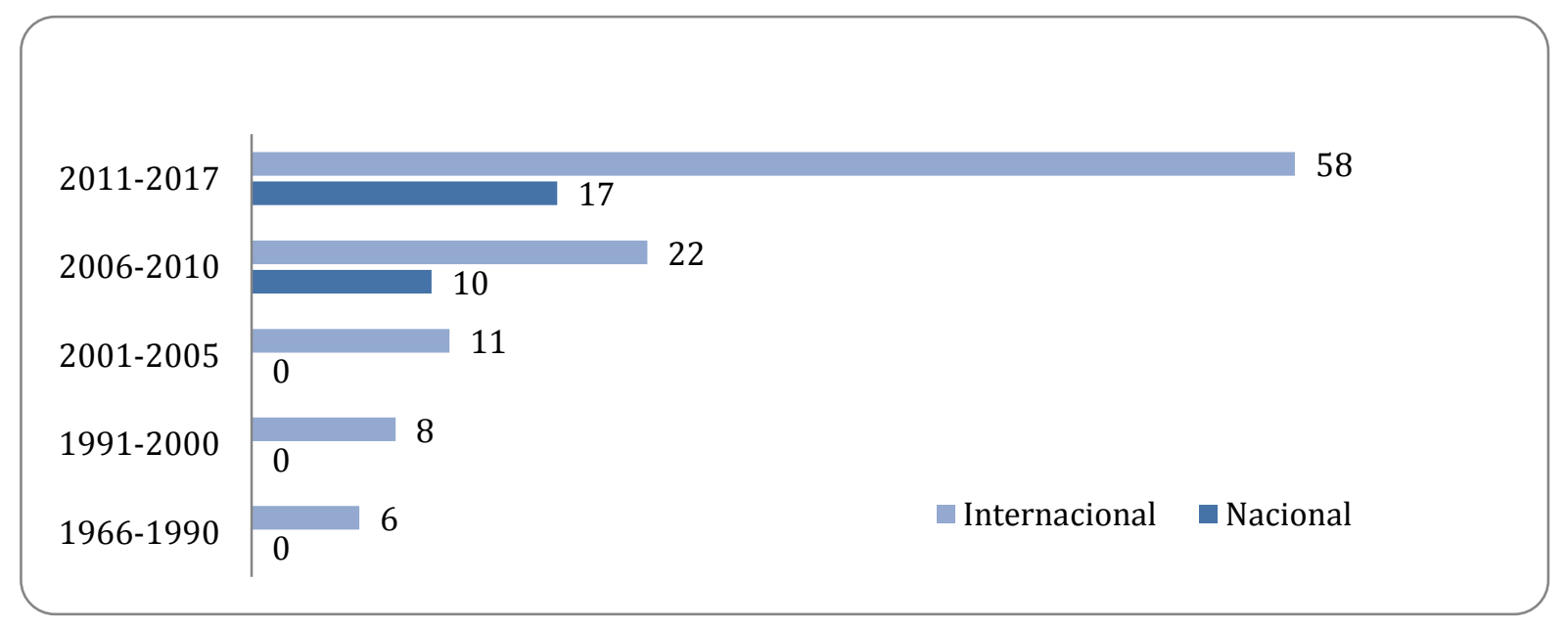

Fonte: o autor.

No Brasil, a primeira publicação foi realizada por Paschoal e Gatto (2006), que descreveram a taxa de suspensão de cirurgia hospitalar e os motivos envolvidos no absenteísmo de usuários nas cirurgias programadas.

No total das 27 produções brasileiras, a maior prevalência de produção nacional está em São Paulo ( $\mathrm{n}=13)$, Minas Gerais $(\mathrm{n}=4)$ e Rio de Janeiro $(\mathrm{n}=4)$, e, em menor frequência, em Santa Catarina $(\mathrm{n}=1)$, Paraná $(\mathrm{n}=1)$, Pernambuco $(\mathrm{n}=1)$, Ceará $(\mathrm{n}=1)$, Espírito Santo $(n=1)$ e Bahia $(n=1)$. Nos demais estados não foi encontrada qualquer produção referente ao tema.

Com esses dados é possível observar que a produção na área ainda é pequena em termos de abrangência, pois compreende apenas 22 países, sendo que, em muitos deles, foi encontrada apenas uma publicação, como na África do Sul, Alemanha, Argentina, Grécia, Malásia, Nigéria e Portugal.

\subsubsection{A produção por temáticas e nível de complexidade assistencial}

Em relação às temáticas ou especialidades estudadas nos 132 registros nacionais e internacionais considerados no levantamento bibliográfico, apenas 18 (14\%) tratam de serviços gerais da atenção primária. Na atenção secundária são 82 (62\%) e, na atenção terciária, 32 (24\%), conforme o Gráfico 4.5. 
Gráfico 4.5 - Número e porcentagem de publicações gerais por níveis de complexidades, no período de1966 a Set/2017

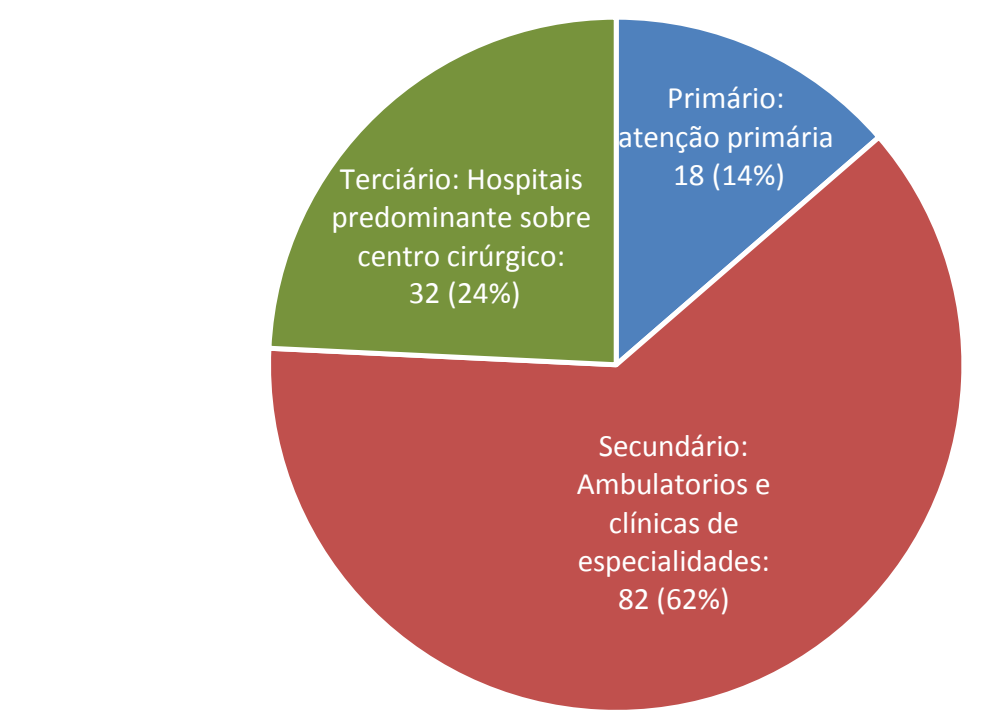

Fonte: o autor.

Na atenção primária, dos 18 trabalhos realizados, 15 (83\%) são sobre a APS, 2 (11\%) são na área de odontologia e $1(6 \%)$ é sobre o tratamento de ferida crônica (Gráfico 4.6). É possível evidenciar a escassez de pesquisas sobre o absenteísmo e dispensas em serviços de atenção primária. Este nível de atenção deveria estar orientado às necessidades de saúde da comunidade e distribuído de forma abrangente para resolver $80 \%$ das demandas de saúde (Mendes, 2011; Travassos; Castro, 2012; Solla; Chioro, 2012). Ele é muito importante e requererá mais pesquisas. 
Gráfico 4.6 - Número e porcentagem de publicações na atenção primária de saúde (APS) por temáticas ou especialidades, no período de1966 a Set/2017

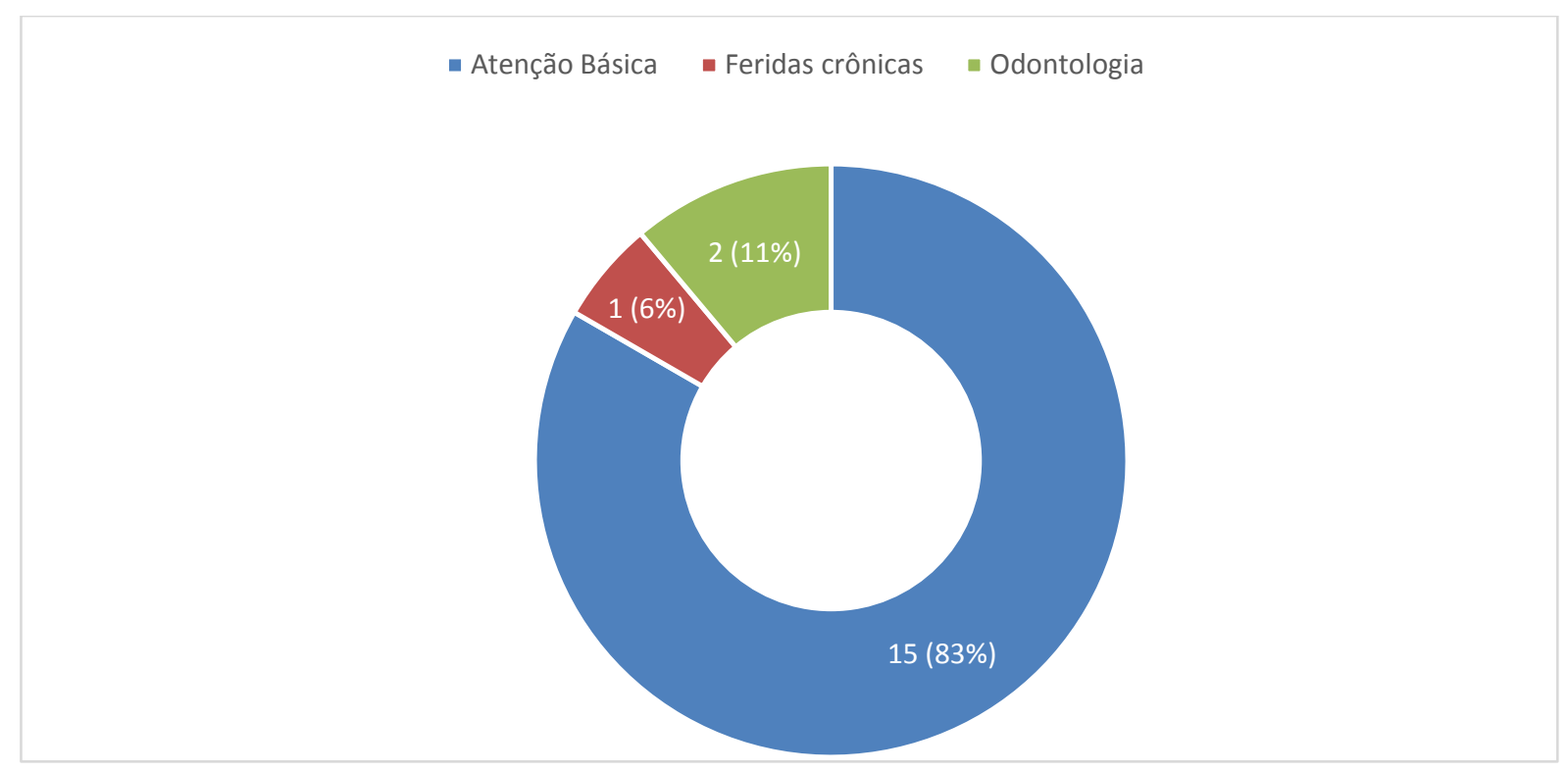

Fonte: o autor.

$\mathrm{Na}$ atenção secundária, a maior parte dos estudos está relacionada aos ambulatórios ou clínicas de especialidades gerais, perfazendo um total de 82 (62\%) produções, como demonstrado no Gráfico 4.5. Desses estudos realizados em serviços ambulatoriais, 27 (33\%) não possuíam especificação de especialidade, e 55 (67\%) eram relacionados aos ambulatórios de alergologia, cirurgia plástica, dermatologia, endocrinologia, fisioterapia, ginecologia/obstetrícia, laboratórios, neurologia, oncologia, otorrinolaringologia, pediatria, pneumologia, clínicas psiquiátricas/dependência química, radiologia, reumatologia, trauma/ortopedia e urologia (Gráfico 4.7). Essas pesquisas foram realizadas em clínicas de especialidades gerais ou ambulatórios em ambiente hospitalar, sendo que 72 delas eram internacionais e 10 nacionais. 
Gráfico 4.7 - Número de publicações na atenção secundária de saúde por temáticas ou especialidades, no período de1966 a Set/2017

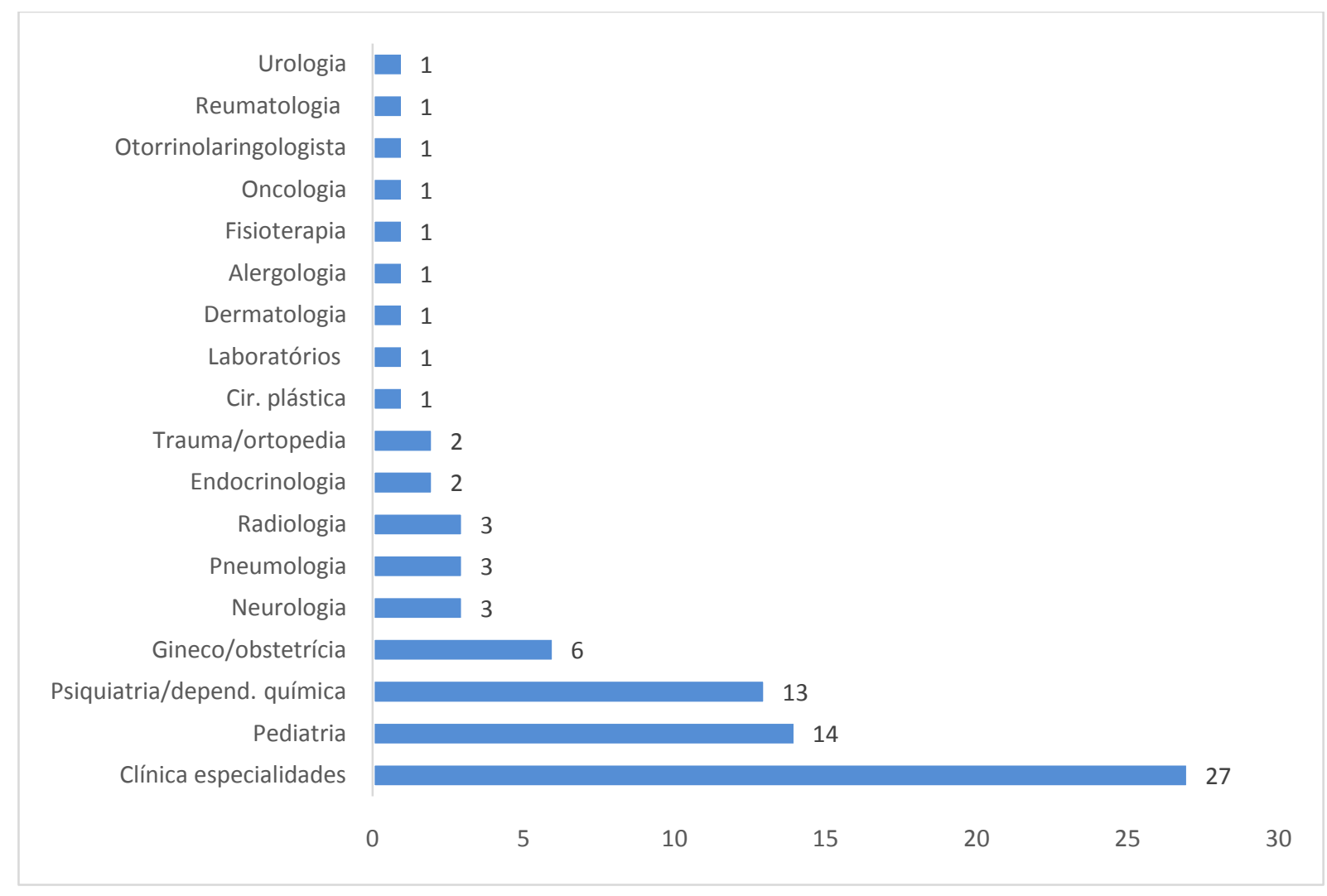

Fonte: o autor.

As pesquisas em serviços hospitalares correspondem a 32 produções, dentre elas 12 (37\%) em área hospitalar geral e $20(63 \%)$ relacionadas a tratamentos e procedimentos realizados em centro cirúrgico. Dentre os procedimentos cirúrgicos, 16 (50\%) referem-se aos exames endoscópicos do serviço de gastroenterologia e $4(13 \%)$ trataram da especialidade de oftalmologia (Gráfico 4.8). 
Gráfico 4.8 - Número e porcentagem de publicações na atenção terciária de saúde por temáticas ou especialidades, no período de1966 a Set/2017

$$
\text { - Gastroenterologia - Hospitalar Geral = Oftalmologia }
$$

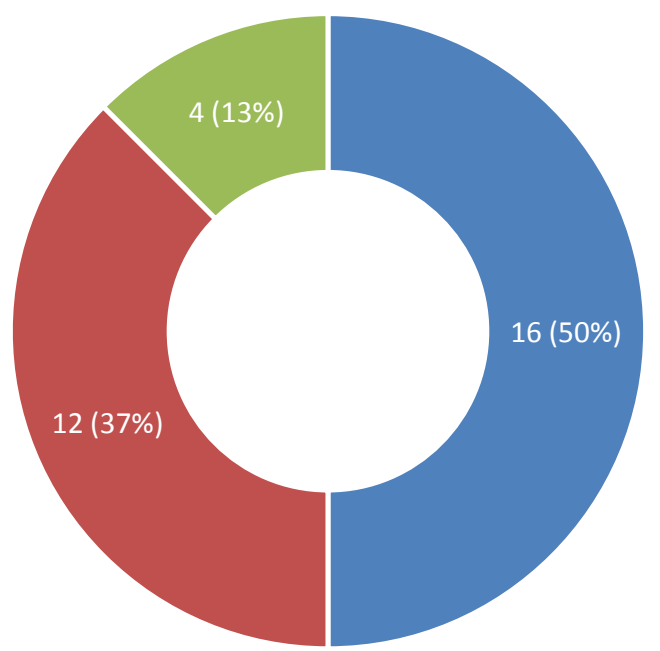

Fonte: o autor.

Pode ser considerado como expressivo no Brasil o número de pesquisas realizadas no nível terciário, pois correspondem a 13 (40\%) em relação ao total de 32 publicações. Em relação às pesquisas brasileiras dirigidas a investigar o tema no nível de atenção primária, elas correspondem a 33\% da produção mundial $(n=18)$, apesar da produção pequena, considerando as publicações nacionais $(n=6)$. No que se refere à produção dirigida ao absenteísmo no nível secundário, a produção nacional é de $12 \%(\mathrm{n}=10)$ do total de 82 , conforme Gráfico 4.9. 
Gráfico 4.9 - Número de publicações por nível de complexidade à nível nacional e internacional, segundo os países de origem da publicação, no período de1966 a Set/2017

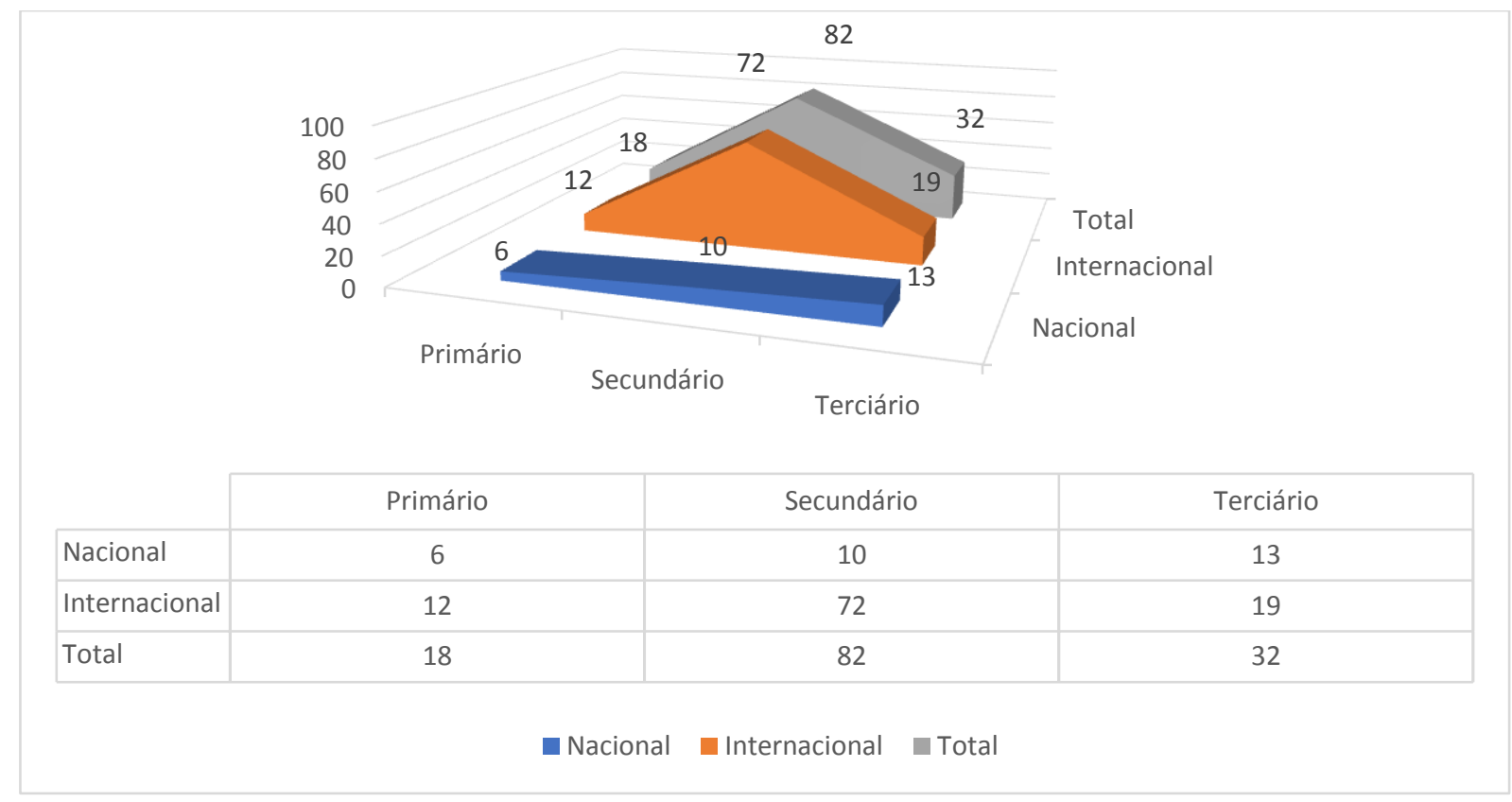

Fonte: o autor.

4.1.5 Motivos, estratégias aplicadas e sugeridas para diminuir o absenteísmo narrados na literatura

Das 132 publicações selecionadas, 59 (45\%) produções não citam os motivos de absenteísmo em serviços de saúde. Em 73 (55\%) eles são descritos, sendo que 20 dessas publicações são nacionais e 53 internacionais. São evidenciados relatos análogos entre os usuários e os profissionais de saúde; descritos somente por usuários; citados tanto pelos profissionais de saúde como pelos próprios autores e motivos identificados decorrentes de banco de dados dos serviços.

Em relação às estratégias, as produções mesclam propostas experimentadas em serviços de saúde. Outras produções sugerem estratégias para a diminuição do absenteísmo não testadas.

\subsubsection{1 motivos do absenteísmo nos serviços de saúde}

As informações sobre os motivos do absenteísmo foram coletadas de diferentes formas: em 42 (58\%) das produções, os motivos foram coletados a partir de depoimentos dos 
usuários; em 23 (31\%) foram utilizados bancos de dados dos serviços de saúde; em 5 (7\%) foram considerados os relatos de experiências dos próprios autores, e em 3 (4\%) foram realizadas entrevistas com profissionais de saúde.

Nesses 73 trabalhos são identificados 253 apontamentos sobre as causas pelas quais os vários não vieram a ser atendidos nas consultas e exames. Alguns apontamentos são comuns entre as diferentes fontes coletadas. Parte significativa da literatura pesquisada narra mais de um motivo.

Os motivos foram agrupadas em 23 categorias (Gráfico 4.10), a saber: 1. transtornos psiquiátricos ou dependência química; 2. falta de transporte; 3. tratamento em outro serviço; 4. consulta concomitante; 5 . dificuldade socioeconômica; 5 . cadastro desatualizado; 6 . falha na comunicação (não foi avisado); 7. barreira geográfica; 8. morosidade no atendimento médico ou exame; 9. desconhecimento do local da consulta ou exame; 10. medo; 11. tempo de espera muito grande (fila de espera); 12. melhora ou decisão de não levar (dependente) ou não ir; 13. desconhecimento da importância do procedimento; 14. falta de preparo para exames (endoscópicos); compromisso prévio na data agendada; intercorrência no dia; 15. adoecimento; 16. erro técnico/processual; 17. cuidado com dependentes; 18. esquecimento; 19. agendamento com mais de trinta dias de antecedência, e 20. devido ao trabalho (não teve liberação ou era recém-contratado). 
Gráfico 4.10 - Número de apontamentos sobre os motivos do absenteísmo coletados por meio de entrevistas com os usuários, depoimentos de profissionais de saúde, informações de banco de dados e experiências dos próprios autores, no período de1966 a Set/2017

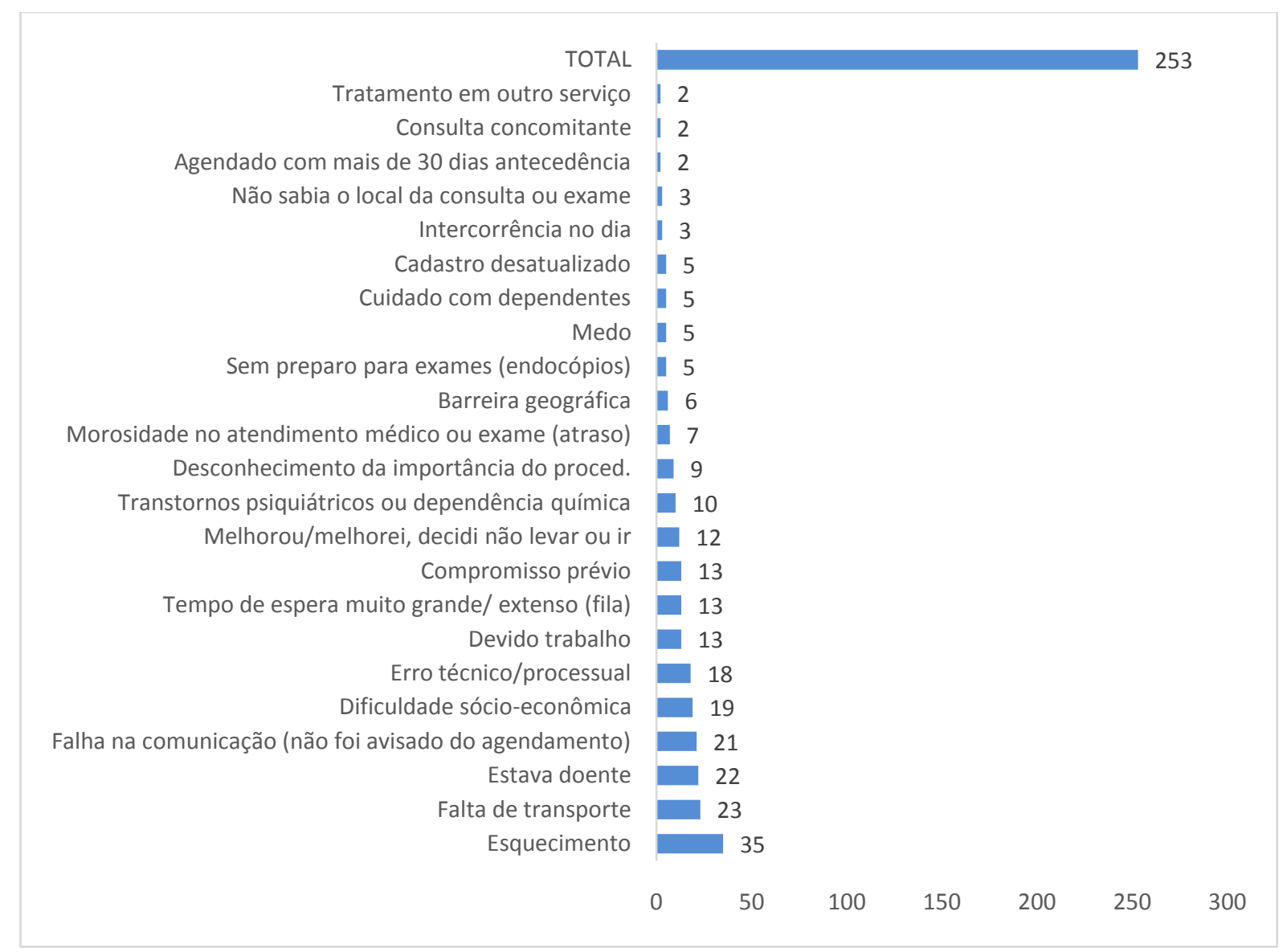

Fonte: o autor.

Foram detectados 79 apontamentos como motivos de absenteísmo comuns entre os relatos dos usuários e profissionais de saúde. Estes foram agrupados em 3 categorias gerais: 1. esquecimento apareceu em 35 (44\%) produções; 2. Falta de transporte em 23 (29\%), e 3. falha na comunicação, em 21 (27\%) (usuários não avisados; agendamentos cancelados pelo usuário, reagendados pelos serviços de saúde sem a devida comunicação ao usuário), conforme o Gráfico 4.11. 
Gráfico 4.11 - Número e porcentagem de apontamentos sobre os motivos do absenteísmo relatados tanto por usuários e profissionais de saúde, no período de1966 a Set/2017

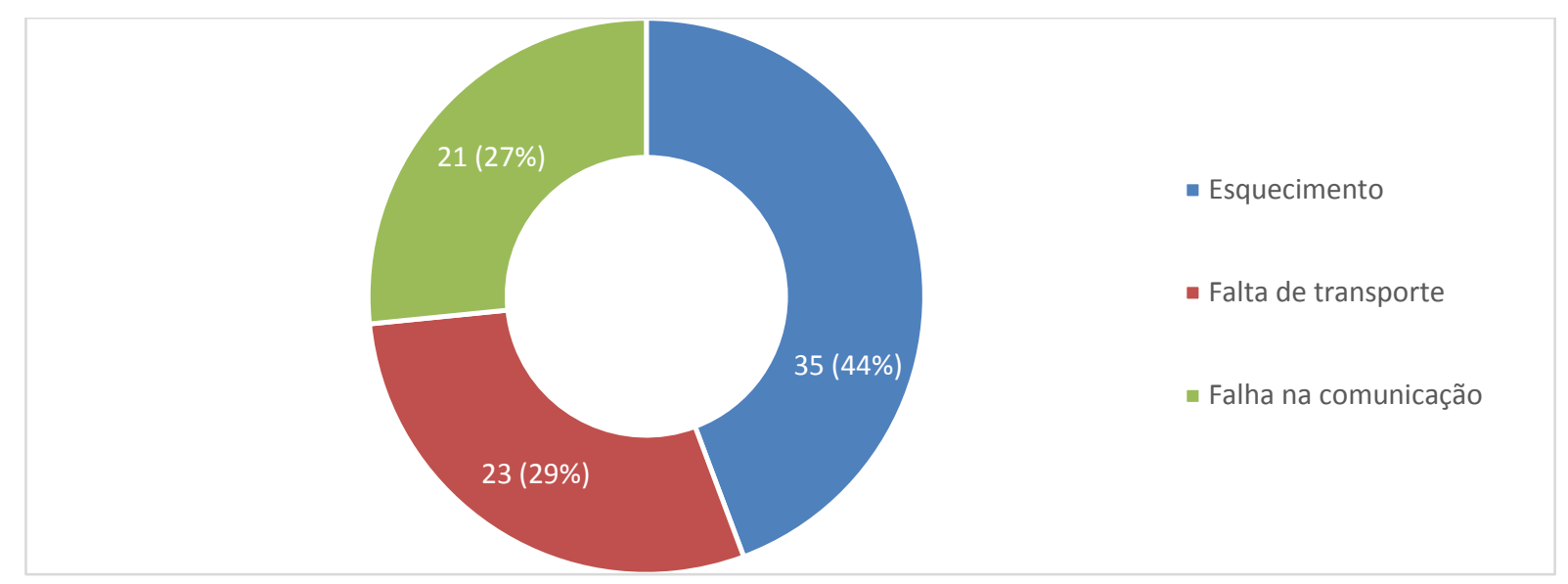

Fonte: o autor.

Na categoria de motivos referentes às faltas relatadas por usuários, ocorreram 105 apontamentos, agrupados em 13 categorias: 22 (21\%) justificaram a ausência por estarem doentes; 13 (12\%) faltaram devido a compromissos relacionados ao trabalho; 13 (12\%) afirmaram que já possuíam compromisso prévio ao agendamento; 13 (12\%) relataram o tempo demorado de espera para o agendamento; 12 (11\%) disseram que melhoraram ou o dependente (geralmente o filho) melhorou e não necessitavam mais do cuidado. Outros motivos menos expressivos, mas registrados nas respostas dos usuários, foram: 7 (7\%) relataram morosidade para o atendimento médico ou exames; $6(6 \%)$ mencionaram a barreira geográfica para o deslocamento; 5 (5\%) expuseram que tiveram medo; 5 (5\%) não compareceram porque tinham compromisso de cuidar de algum dependente; 3 (3\%) não sabiam o local da consulta ou exame; 2 (2\%) já estavam fazendo tratamento em outro serviço; $2(2 \%)$ tiveram atendimento concomitante de consultas, e $2(2 \%)$ justificaram que foram agendados com mais de 30 dias de antecedência, conforme Gráfico 4.12. 
Gráfico 4.12 - Número e porcentagem de apontamentos sobre os motivos do absenteísmo relatados por usuários, no período de1966 a Set/2017

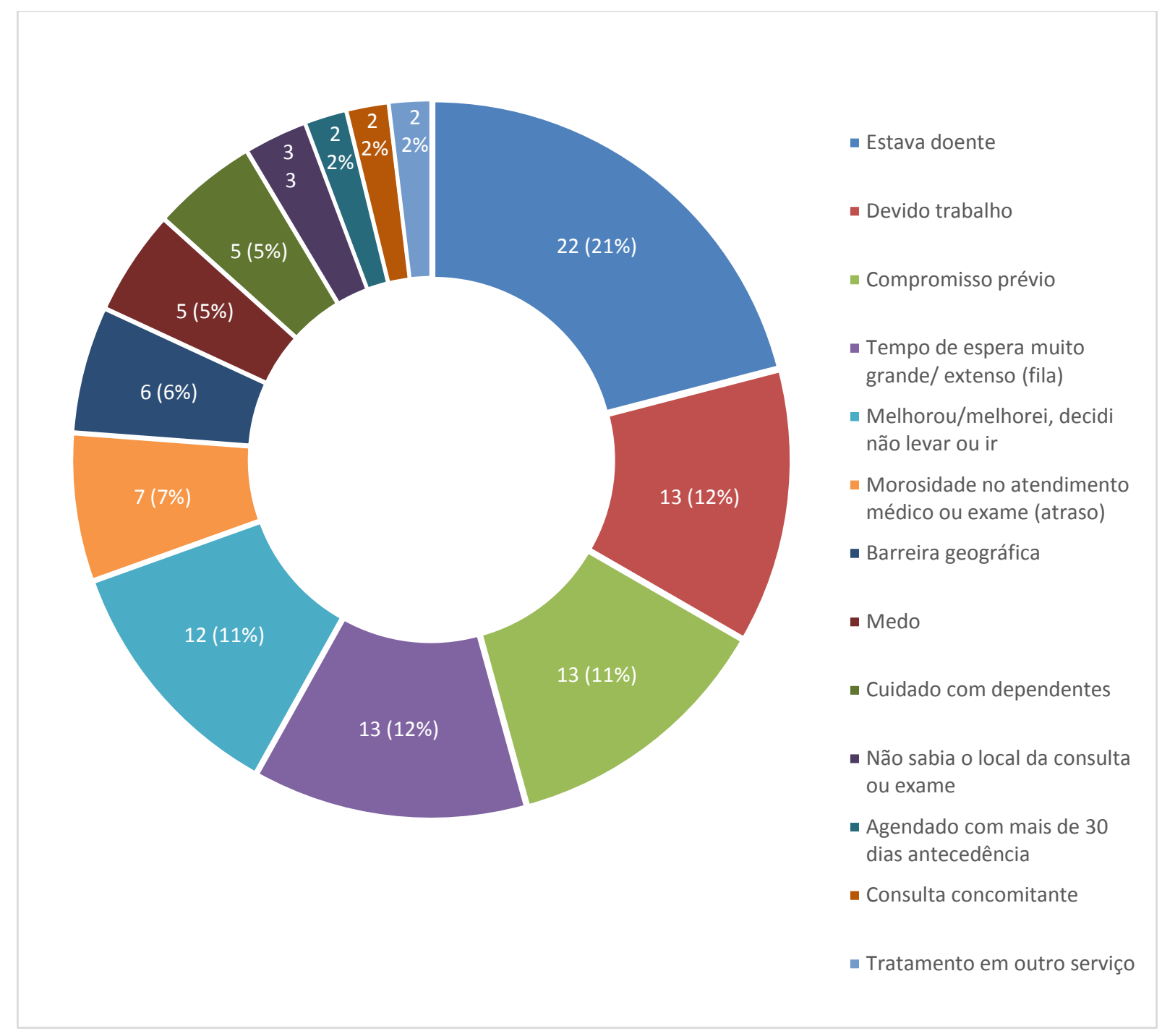

Fonte: o autor.

Os motivos indicados pelos profissionais de saúde ou pelos autores (38 apontamentos) foram agrupados em 3 categorias: 19 (50\%) foram relacionados à dificuldade socioeconômica da região estudada;10 (26\%)atribuíram as ausências a usuários com transtornos psiquiátricos, em sua maioria por depressão e dependência química, e 9 (24\%) associaram ao desconhecimento do usuário sobre a importância do procedimento ou tratamento (Gráfico 4.13). 
Gráfico 4.13 - Número e porcentagem de apontamentos sobre os motivos do absenteísmo evidenciados pelos profissionais de saúde e pelos próprios autores, no período de1966 a Set/2017

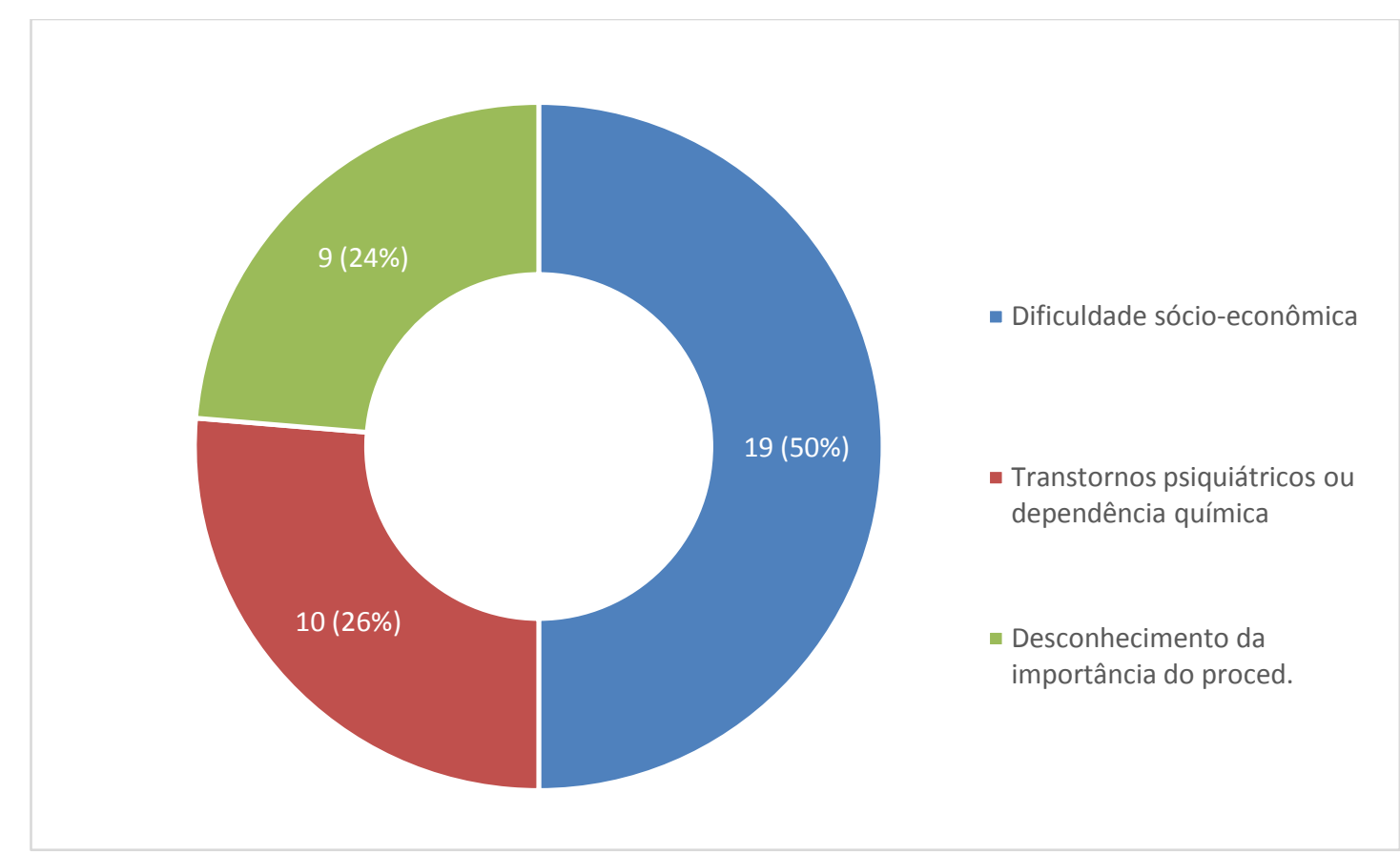

Fonte: $o$ autor.

Já em relação aos motivos evidenciados em bancos de dados dos serviços de saúde e experiências dos autores e profissionais de saúde, foram detectados 31 apontamentos, agrupados em 4 categorias (Gráfico 4.14): 18 (58\%)referiram haver erro técnico/processual por falta de fluxos internos; 5 (16\%) relataram dispensas dos usuários devido ao preparo inadequado para o procedimento; 5 (16\%) mencionaram que o usuário estava com o cadastro desatualizado, e 3 (10\%) foram decorrentes de intercorrências no dia do atendimento. 
Gráfico 4.14 - Número e porcentagem de apontamentos sobre os motivos do absenteísmo evidenciados em banco de dados, experiência dos autores e profissionais de saúde, no período de1966 a Set/2017

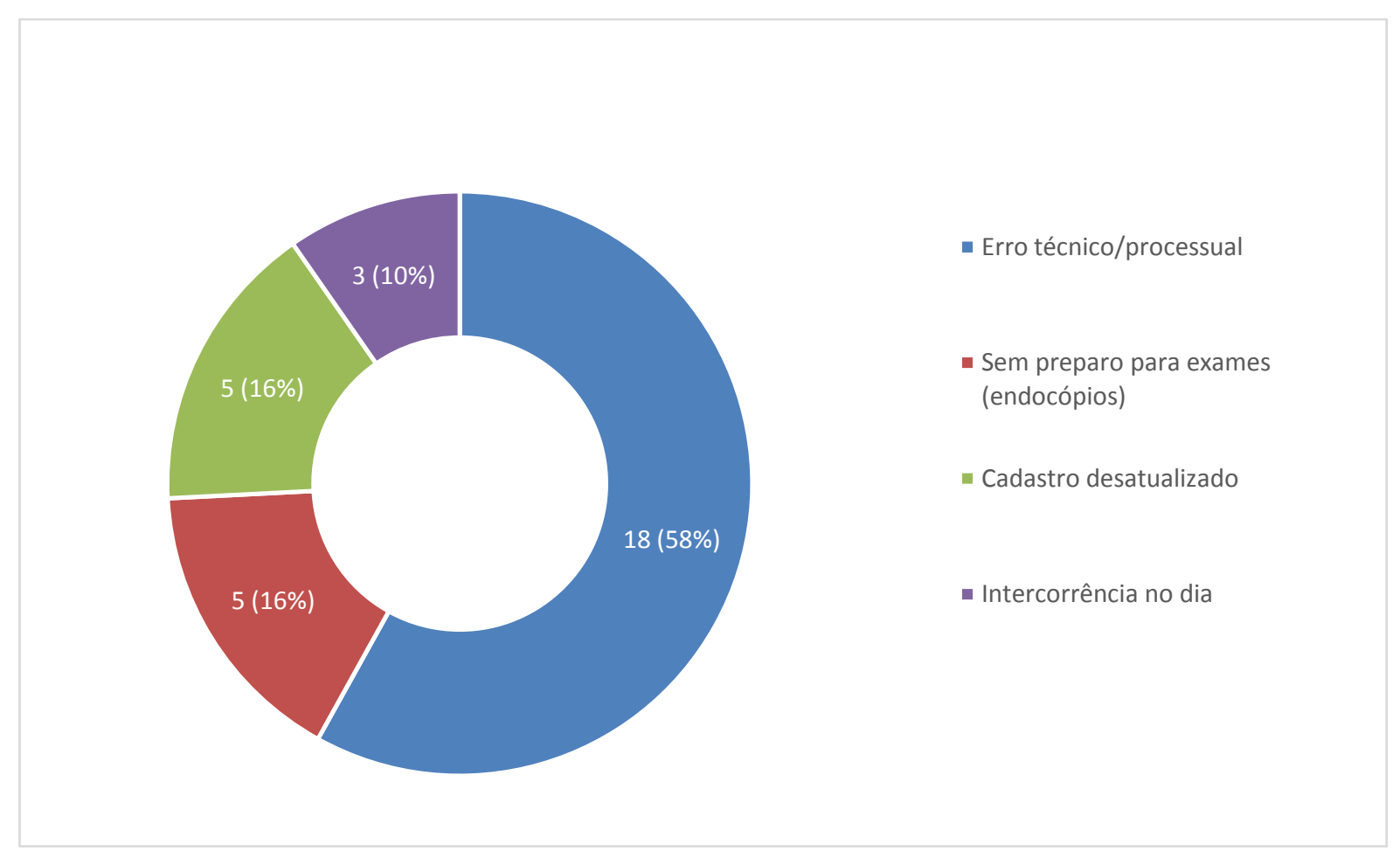

Fonte: o autor.

4.1.5.2 estratégias sugeridas para a diminuição do absenteísmo, porém não experimentadas

Dentre as 132 publicações utilizadas no estudo, em 67 delas há a sugestão de diversas estratégias para a diminuição do absenteísmo em serviços de saúde experimentadas ou implantadas pelos autores (Gráfico 4.15). Nessas 67 produções são identificadas 234 estratégias agrupadas em 29 categorias (Gráfico 4.15). Dentre essas categorias, os lembretes, representados por e-mails, cartas, mensagem de texto para celular, ligação telefônica, são citados $53(22,7 \%)$ vezes, seguidas por propostas de reavaliação dos fluxos e processos internos apontados 28 (12\%) vezes e, em 20 (8,5\%) produções, há a sugestão de investimentos em educação e informação em saúde por meio de vídeos, palestras e folhetos.

A proposta de gerenciamento de demanda reprimida corresponde a 15 (6\%) indicações; as melhorias em relação ao sistema de informação para agendamento eletrônico 
aparecem em $12(5,1 \%)$ pesquisas e o agendamento por meio da técnica de sobrecarga ${ }^{14}$ da agenda também aparecem em 12 (5,1\%) produções, estratégia denominada “overbooking". Onze (5\%) apontamentos indicam a necessidade de melhorias nos meios de comunicação como sistema de referência e contrarreferência, e outros 11 (5\%) sugerem o agendamento flexível, conforme a disponibilidade do usuário.

Com menor frequência, representados por índices abaixo de 5\%, são recomendados em 9 (4\%) estudos as melhorias no sistema de transporte e em outros 9 (4\%) há sugestão do mapeamento das características e necessidades regionais e locais para subsidiar a gestão das ofertas em serviços de saúde. Recomendações sobre a atualização dos cadastros, para facilitar a comunicação com os usuários, aparecem em $8(3,4 \%)$ produções, assim como propostas de reuniões periódicas em equipe citadas $8(3,4 \%)$ vezes. A criação de fluxo para reforçar os avisos de atendimentos de grupos com maior vulnerabilidade, como as crianças e os idosos, é sugerida em $5(2,1 \%)$ estudos. Já a capacitação profissional e a humanização, a necessidade de supervisão e acompanhamento da saúde dos ausentes e as propostas de reorganização da rede de atenção são citadas $4(1,7 \%)$ vezes cada uma delas, conforme pode ser observado no Gráfico 4.15.

As indicações pouco exploradas nas produções são: 3 (1\%) sobre a pontualidade no atendimento ao usuário, e $3(1 \%)$ recomendações de criação de central de regulação. São ainda citadas $2(0,8 \%)$ vezes, cada uma delas, as seguintes estratégias: melhorar a indicação para exames endoscópicos; manter a clínica aberta e realizar cirurgias no período noturno; descrever e recomendar a taxa de reserva reembolsável e utilizar o trabalho do agente comunitário de saúde (ACS) na comunicação com o usuário (Gráfico 4.15).

Com apenas $1(0,5 \%)$ citação no total de 132 publicações, são sugeridos: o fornecimento de telefone de amigos/parentes para facilitar a comunicação; o "contrato com usuário" sobre o tratamento proposto; a pós-consulta de enfermagem; a alteração do recado para prevenir atraso. Em específico nas literaturas internacionais, também com apenas 1 $(0,5 \%)$ citação, aparecem a indicação de sistema de recompensa ao usuário assíduo; o pagamento por serviços (provedor de seguro) e o sistema de reserva parcial (Gráfico 4.15).

\footnotetext{
${ }^{14}$ Conhecida como overbooking, amplamente utilizada em administração hotelaria e transporte, que significa um aumento na oferta, ou seja, de acordo com risco de absenteísmo. Essa técnica permite melhorar a ocupação dos recursos.
} 
Gráfico 4.15 - Número e porcentagem de publicações por estratégias sugeridas para prevenir ou diminuir os índices de absenteísmo, no período de1966 a Set/2017

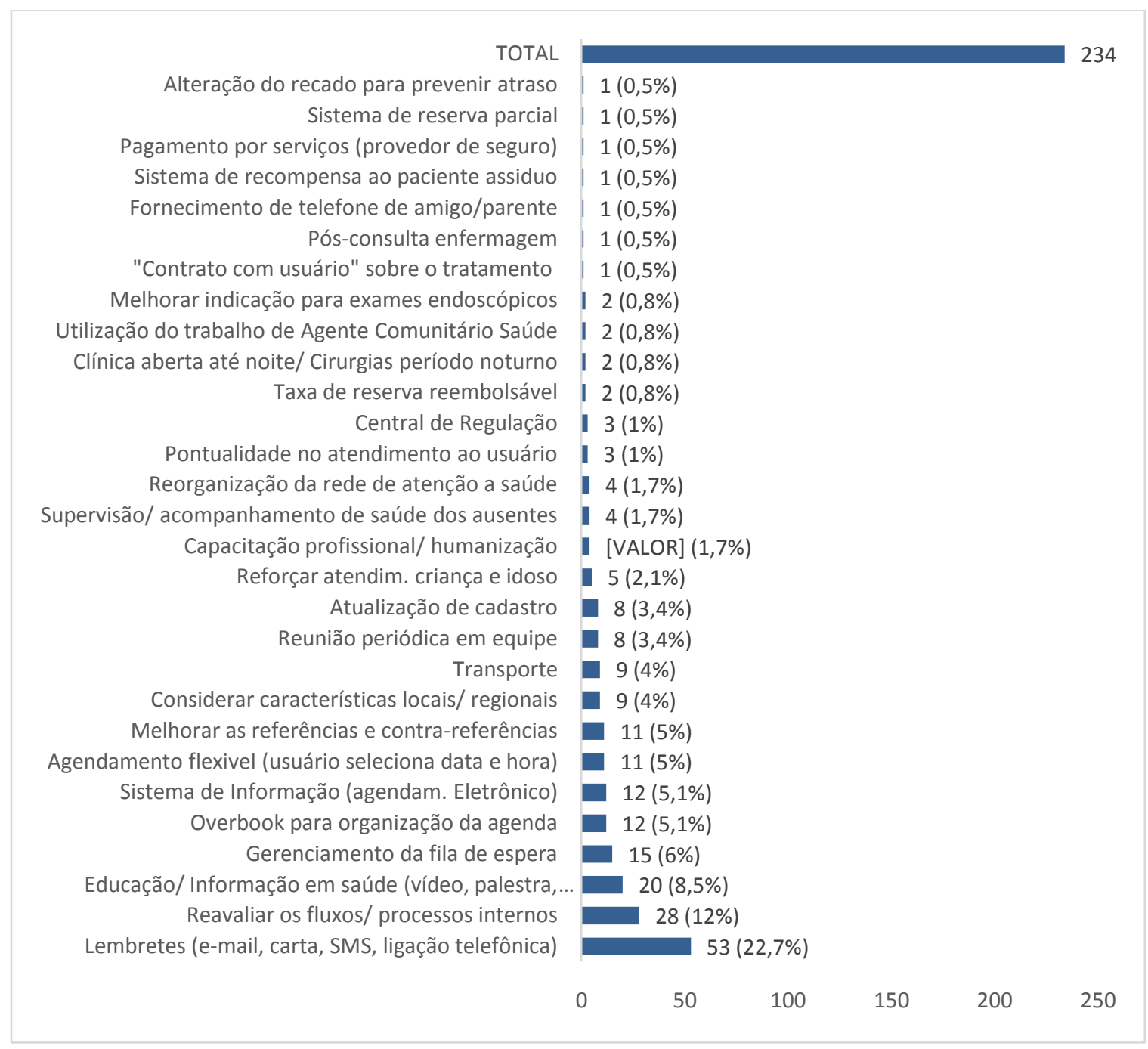

Fonte: o autor.

Os lembretes por meio de e-mail, cartas, SMS e ligações telefônicas são sugeridos como uma medida preventiva ao absenteísmo. Ainda no que se refere à comunicação com o usuário, há recomendações na literatura que mencionam a importância de informações no aviso aos usuários de forma a prevenir o atraso, e outras que indicam a necessidade de criação de mecanismos internos ao serviço para reforçar os avisos aos idosos e responsáveis por crianças.

É possível observar que a maioria das sugestões está relacionada à organização dos serviços de saúde como: 1. processo de trabalho e fluxos internos; 2. educação em saúde; 3. capacitação profissional e reuniões periódicas em equipe; 4. organização da fila de espera; 5. atualização de cadastros, e 6. overbooking de agenda. Além disso, também são sugeridas 
ações que visem a potencializar os recursos já empregados como: 1. melhorar a indicação de exames e encaminhamentos; 2 . fazer "contrato" com o usuário sobre o tratamento proposto; 3. realizar a pós consulta com o usuário; 4. respeitar a pontualidade do atendimento, e 5. utilizar o trabalho do ACS na conscientização e prevenção do absenteísmo.

Outras medidas operacionais propostas são a agenda flexível, a qual pode viabilizar a marcação de consultas, exames e procedimentos conforme a disponibilidade do usuário; a ampliação dos horários de funcionamento das clínicas e a realização das cirurgias em período noturno; a melhora dos meios de comunicação com o usuário, por meio de outros contatos (como de parentes e amigos), e implementação de sistema de informação para integrar os serviços de saúde.

Outras propostas referem a necessidade de modificações organizacionais locais ou macrorregionais que dependam de auxílio dos gestores de saúde, como: 1. melhorar o uso de referências e contrarreferências; 2. reorganizar a rede de atenção à saúde; 3. planejar a saúde segundo as características locais e regionais; 4. criar centrais de regulação, e 5. reorganizar o serviço de transporte. Especificamente na literatura internacional, há as sugestões de utilizar um sistema parcial de reserva que propõe agendamento mediante o pagamento de taxa mínima; o sistema de taxa reembolsável após comparecimento à consulta ou exame, e pagamento pelos serviços em saúde por meio de provedores de seguro.

\subsubsection{3 estratégias implantadas ou experimentadas em serviços de saúde}

Das estratégias implantadas e avaliadas pelos autores, citadas nas 132 publicações utilizadas neste estudo, 52 (39\%) experiências são narradas, sendo identificados 50 apontamentos de estratégias, organizados em 7 grupos (Gráfico 4.16). 
Gráfico 4.16 - Número e proporção de publicações por estratégias implantadas ou experimentadas pelos autores, no período de1966 a Set/2017

\section{Estratégias implantadas ou experimentais}

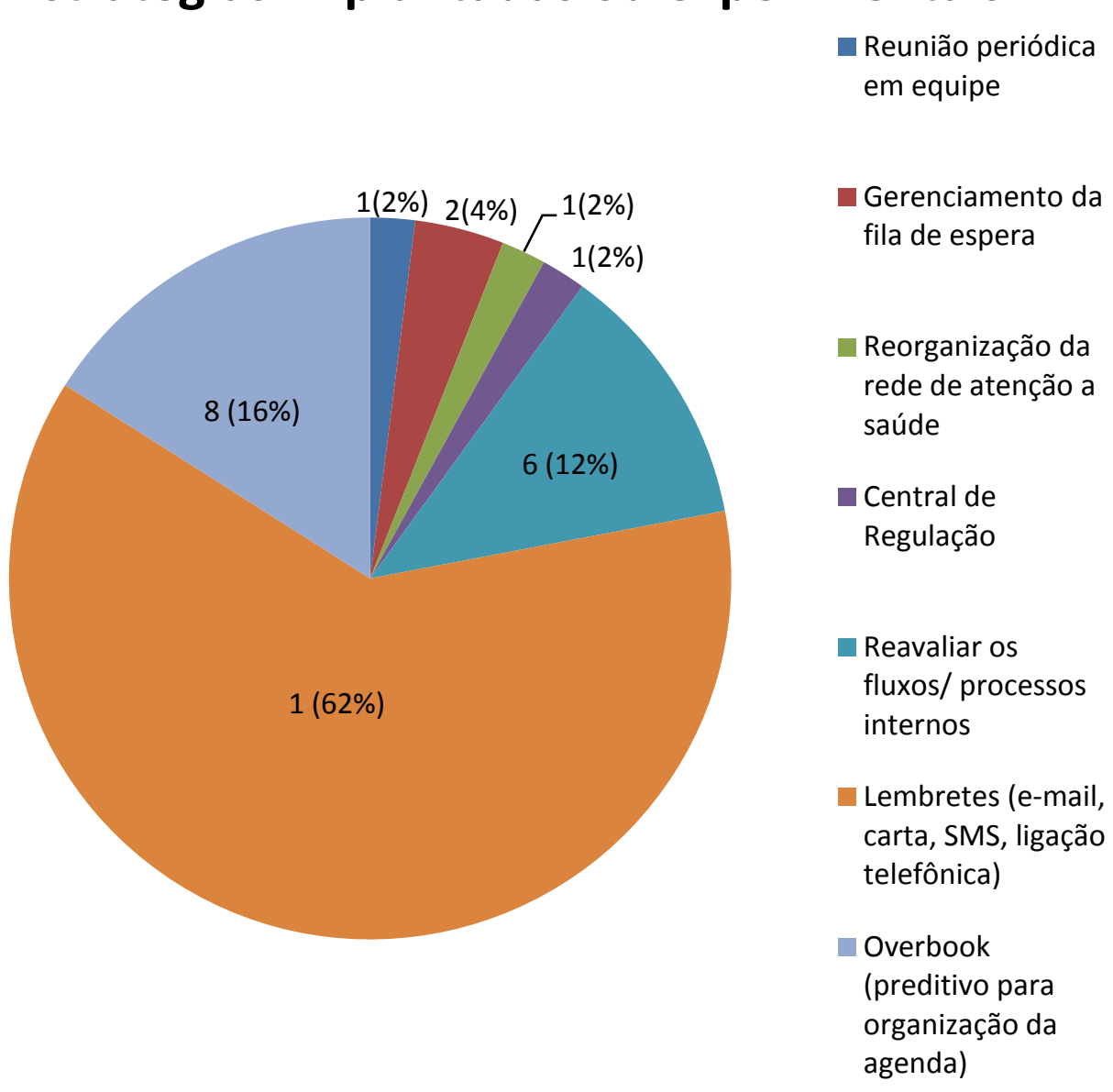

Fonte: o autor

A utilização de lembretes é a mais comum e muito defendida pelos autores (Gráfico 4.16) como: e-mails, cartas, mensagens de texto por celular, ligações telefônicas, perfazendo um total de 32 (62\%) experiências. São descritos 8 (16\%) experimentos de overbooking, ou seja, disponibilização de número de vagas maior que a capacidade da agenda diária. Essa abordagem, encontrada predominantemente na literatura internacional e muito utilizada na prestação de serviço comerciais (hotelaria entre outros), é empregada na área da saúde principalmente para exames endoscópicos, como relatam Reid et al. (2015, 2016).

A estratégia de reavaliar os fluxos e processos internos é apontada em $6(12 \%)$ estudos nacionais (Paschoal; Gatto, 2006; Bender et al., 2010; Gonçalves, 2013; Gonçalves et al., 
2015), como forma de melhorar o sistema de agendamento, gestão em saúde, educação e comunicação interna.

Em 2 (4\%) experimentos é demonstrado melhor aproveitamento das vagas disponíveis por meio do gerenciamento de filas de espera, pois o tempo dispensado nas mesmas seria um preditor ao absenteísmo (Machado et al., 2015; Barcelos, 2016). Este gerenciamento consiste na avaliação das reais necessidades dos usuários, que podem ocorrer por meio da implantação de protocolo clínico, reconvocação ou ligação para confirmação de presença no compromisso agendado. Essas medidas podem detectar casos de melhora do usuário e consequente dispensa do atendimento (Gráfico 4.16).

Estratégias experimentadas pelos pesquisadores e sugeridas em apenas 1 (2\%) estudo, cada uma delas, são: reunião periódica de equipe; reorganização da rede de atenção à saúde e criação de central de regulação (Gráfico 4.16).

Dentre as estratégias testadas e narradas por autores internacionais, a mais frequente e bem-sucedida, é o envio de mensagens de texto por celular, pois tem melhor aceitação pelos usuários e envolve menor investimento financeiro (Roberts et al., 2011; Youssef, 2014). As mensagens de texto por celular são apontadas como a estratégia mais acessível financeiramente e preferida, em especial entre os usuários jovens, enquanto a ligação telefônica é apontada como a mais efetiva e melhor aceita entre os idosos e usuários da psiquiatria (O'Brien; Lazebnik, 1998; Hashim et al., 2001; Wang et al., 2007; Mendel; Chow; 2017).

Em estudo de Ramos e Gress (2016) que trata de atendimentos telefônicos realizados por enfermeiros, há a defesa de que são operacionais e financeiramente eficazes se direcionados aos grupos de maior risco de faltas ou de preparo inadequado para exames ou procedimentos. Há artigos que relatam experiência de ligações telefônicas realizadas por enfermeiros, com a finalidade de oferecer suporte ao preparo de exames e orientações em saúde. Segundo esses estudos, são efetivos os contatos com os usuários, sendo positiva a relação custo-benefício, pois diminui as faltas, reduz as dispensas por motivo de preparo inadequado e acolhe os anseios e medos em relação a procedimentos e exames (Wang et al., 2007; Mendel; Chow; 2017).

A revisão da literatura sobre o não atendimento do usuário nos serviços de saúde proporcionou maior clareza sobre a dimensão e complexidade desse assunto. Frente aos desafios da efetiva implantação do SUS, a necessidade da garantia do acesso pleno de todos os usuários aos serviços de saúde, esse campo de estudo se tornou um instigante cenário de 
pesquisa para otimizar recursos e garantir assistência plena, capaz de contribuir para a efetivação da integralidade na atenção à saúde da população.

Visando a contribuir nesse sentido, este estudo analisou a natureza do absenteísmo em quatro municípios da área de abrangência do AME Araçatuba - "Dr. Oscar Gurjão Contrim" do Departamento Regional de Saúde (DRS) II - Araçatuba, da Rede Regional de Saúde 12, estado de São Paulo.

\subsection{O absenteísmo no Departamento Regional de Saúde (DRS) II - Araçatuba da Rede Regional de Saúde 12, do estado de São Paulo}

Os cadastros de demanda por recurso, por especialidades, procedimentos cirúrgicos e exames têm sido crescentes. As taxas de absenteísmo global em consultas, retornos, interconsultas e exames vêm aumentando desde implantação do AME Araçatuba, em junho de 2010.

Em dezembro de 2017, o cadastro de demanda por recurso (CDR ${ }^{15}$ do Portal CROSS continha 13.501 usuários aguardando consulta ou avaliação cirúrgica nas especialidades; 6.016 exames da Comissão Intergestores Regionais (CIR $)^{16}$ da região Central; 10.518 usuários aguardando consultas, e 4.742 exames da CIR Consórcio.

A taxa de absenteísmo ideal é a mais baixa possível. A SES considerou o percentual tolerável de até $15 \%$ para o estabelecimento de indicadores e direcionamentos gerenciais junto as OSS e DRS. Apesar dos fluxos existentes, das ligações, dos lembretes e e-mails, do sistema informatizado e integrado, as taxas de absenteísmo do AME Araçatuba e dos agendamentos feitos pelos municípios das microrregiões Central e Consórcio eram muito diferentes entre si, e, na maioria, acima de $15 \%$.

Como mencionado na Metodologia, os atores deste estudo serão descritos como Unidade AME Araçatuba e Municípios A, B, C e D.

O AME Araçatuba foi considerado por ser um importante prestador de serviço público em ambulatório de especialidades e exames para a região do DRS II Araçatuba. Os Municípios C e D foram indicados pela equipe do AME Araçatuba como exitosos no controle do absenteísmo, e os Municípios A e B os com dificuldade no controle do mesmo. Nos

\footnotetext{
${ }^{15}$ Cadastro de fila de espera por recursos em serviços de saúde no Portal CROSS.

${ }^{16}$ Comissão Intergestores Regionais é a instância deliberativa regional, na qual ocorre a cogestão em um canal permanente e contínuo de negociação e decisão entre os gestores municipais e do estado para constituição de uma rede regionalizada de serviços de saúde integrados.
} 
municípios, foram indicadas duas unidades com maior controle e duas com menor controle pelo gestor de saúde municipal. Apenas o Município A tinha mais de 4 unidades para participar, sendo indicadas as Unidades I e M como as com maior controle; U e T com mais dificuldade.

Abaixo são apresentados a organização e fluxo de agendamento, a fila de espera, comunicação ao usuário, serviço de transporte e cancelamento ou desistência, assim como os motivos e reflexões sobre o absenteísmo, as tecnologias e estratégias do AME Araçatuba e dos quatro municípios estudados para sua prevenção.

\subsubsection{Unidade AME Araçatuba}

Os dados da unidade AME Araçatuba foram coletados no banco de dados do Portal CROSS, em impressos internos, atas de reuniões e do grupo focal realizado com a equipe e gerência do AME Araçatuba. A seguir são descritos os dados desta coleta.

\subsubsection{1 descrição do grupo focal com a gerência e equipe do AME Araçatuba}

Foi agendado um grupo focal, conforme a disponibilidade da equipe do AME Araçatuba. Toda a organização e indicação dos representantes foram realizadas pelo gerente administrativo do AME Araçatuba. Os profissionais poderiam aceitar ou não o convite.

O grupo focal aconteceu na sala de reuniões do próprio serviço, no final do período da manhã, com duração de 60 minutos, reunindo ao menos um representante de cada setor que participa do processo de agendamento de retornos, interconsultas, serviço social, enfermagem, central de ligações, recepção, portaria e administrativo, totalizando 9 participantes. A receptividade e expectativa do grupo sobre o objetivo do estudo foi positiva. Eles se sentaram em posição de roda espontaneamente e houve a apresentação inicial dos participantes. Em seguida, a pesquisadora apresentou o primeiro tema disparador (Anexo B). A equipe passou a explicar como se dava o processo de agendamento, de monitoramento, de aviso aos usuários sobre as consultas, exames e preparos. Na sequência, os outros disparadores foram expostos para a equipe, que aderiu com facilidade ao debate, relatando as dificuldades vivenciadas, dúvidas e estratégias organizadas por eles no enfrentamento dessa problemática.

Durante a dinâmica do grupo focal, os participantes interagiram em grupo, complementando as falas uns dos outros. A dinâmica de contar sobre a função de cada 
integrante, incentivando os comentários sobre suas experiências e pontos de vista, facilitou a participação e interação de todos.

No final da entrevista, foi solicitado ao grupo de representantes do AME Araçatuba que elegesse os dois municípios com maior dificuldade de controlar o absenteísmo e os dois com melhor controle do mesmo. Os participantes entraram em consenso sobre os quatro municípios.

Posteriormente, a pesquisadora entrou em contato por telefone e e-mail com os gestores municipais dos quatro municípios indicados. Porém, um dos municípios indicados com maior dificuldade de controle de absenteísmo não respondeu às tentativas de contato. Foi solicitado ao grupo do AME Araçatuba que indicasse outro município. Assim que esse foi indicado, foram agendadas entrevistas com os gestores municipais e com as respectivas equipes de saúde.

\subsubsection{2 caracterização da Unidade AME Araçatuba}

O AME é formado por 10 gerências, no total de 177 trabalhadores, distribuídos da seguinte maneira: 10 na área administrativa; 51 na área de gerencia atendimento; 5 na área de tecnologia da informação; 61 na área da enfermagem; 26 na área de serviços ambulatoriais; 4 na área de recursos humanos; 2 na área da gerência médica; 3 na área de serviços de saúde (manutenção); 3 na área de suprimentos e compras, e 7 na área financeira.

A categoria profissional não médica é formada por psicólogo, enfermeiro, fisioterapeuta, fonoaudiólogo, nutricionista, terapeuta ocupacional, farmacêutico, assistente social, além dos técnicos em tecnologia da informação, radiologia, farmácia, laboratório, segurança. A categoria médica é contratada por prestação de serviços nas especialidades de neurologia, ortopedia, oftalmologia, dermatologia, cardiologia, nefrologia, gastroenterologia, cirurgia vascular, pneumologia, otorrinolaringologia, proctologia, urologia, hematologia, cirurgia geral e pequenas cirurgias, alergologia, endocrinologia, ginecologia, reumatologia, obstetrícia, mastologia e infectologia.

O AME Araçatuba utiliza exclusivamente o sistema CROSS para organização, disponibilização e agendamentos, seja para consultas em especialidades médicas, não médicas, exames e procedimentos. As consultas possuem características diferentes: 1 . primeira consulta refere-se àquelas ofertadas para a atenção primária ou equipes de regulação das secretarias municipais, ou seja, para agendamento de "novos" usuários 
encaminhados pela APS que necessitam definir o diagnóstico; 2. retorno, e 3. interconsultas, relacionadas ao uso do próprio AME Araçatuba, a fim dar continuidade aos cuidados subsequentes. De acordo com o contrato anual de consultas e exames, cerca de $50 \%$ de toda a oferta é disponibilizada para a rede e os outros $50 \%$ para interconsultas e retornos.

Os agendamentos no Portal CROSS são realizados pelos profissionais responsáveis, que recebem login e senha mediante treinamento específico e renovação de acesso anual. O AME Araçatuba realiza treinamentos e reciclagens dos agendadores municipais.

Em relação aos exames de diagnóstico e imagem, o AME Araçatuba realiza a audioimpedanciometria, colposcopia, densitometria, eletroneuromiografia, eletroencefalograma, eletrocardiograma, ecocardiograma, ultrassonografia, colonoscopia, endoscopia, espirometria, teste de holter e mapa, mamografia, nasofibrolaringoscopia, radiologia, urodinâmica, cistoscopia com biópsia e ressonância magnética. Também são contempladas as linhas de cuidados pré-estabelecidas pela SES como: microcefalia, mulheres de peito, saúde do homem e reflexo vermelho, assim como alguns procedimentos cirúrgicos ambulatoriais de catarata, pterígio, retirada de cisto ou crioterapia em pele, cirurgia de túnel do carpo, entre outros.

Os exames e procedimentos possuem agendas distintas: uma agenda para atendimento da demanda gerada pelo próprio AME e outra que atende às demandas advindas dos municípios de sua referência. As vagas ofertadas são distribuídas para os municípios, e aquelas que não foram utilizadas, ou seja, as remanescentes, são readequadas pelo núcleo de regulação do DRS II Araçatuba entre os municípios que necessitam das mesmas. A distribuição é realizada por critério populacional para os 27 municípios de sua referência, e a readequação das vagas mediante o CDR disponibilizado no Portal CROSS.

De acordo com o contrato anual da SES com a OSS de consultas e exames, entre $45 \%$ e $50 \%$ de toda oferta é disponibilizada para a rede, ou seja, para a $\mathbf{1}^{\circ}$ consulta, e as demais são utilizadas para agendamento de interconsultas e retornos do próprio AME.

\subsubsection{1 organização e fluxo de agendamentos de consultas e exames internos do AME Araçatuba}

O usuário comparece ao AME Araçatuba na data e horário indicado na filipeta ${ }^{17}$, portando documento de identificação com foto, encaminhamento ou pedido de exame

\footnotetext{
${ }^{17}$ Denominação utilizada pelos AMEs para o comprovante de marcação do agendamento. Este impresso é emitido pelo sistema informatizado do Portal CROSS com informações referentes ao atendimento como: identificação do usuário, data, horário, local do atendimento e orientações sobre preparo e documentação necessária.
} 
devidamente preenchido e assinado. Ao adentrar no AME, ele passa na recepção para a confirmação e atualização dos dados e é acompanhado até a sala de espera. Após passar pela consulta médica ou não-médica, ele recebe instruções sobre o retorno ou alta médica na recepção de pós-consulta. Os agendamentos internos ocorrem conforme a disponibilidade de vagas. O usuário é agendado para o retorno, interconsulta ou exame, mas, se houver demanda por estes recursos, são inseridos no CDR por data de solicitação médica.

[...] todos os cadastros são conferidos. Na primeira consulta, é quando o cadastro está mais pobre... que vem da atenção básica, eles colocam só o básico mesmo para gerar (cadastro no Portal CROSS) e chega aqui as meninas completam... Eu acho que a questão do cadastro, o paciente tem que saber que o telefone dele... é primordial para o nosso trabalho. Deve ser constante a fala sobre a importância de manter cadastro atualizado e que a gente necessita trabalhar em cima disso! Todo o sistema AME, ele é feito todo foi montado em cima do contato da gente com o paciente, então necessitamos do contato dele sempre, sempre, sempre atualizado [...] dois tipos de agendamento: os retornos e as interconsultas de um especialista para outro especialista e os agendamentos de exames solicitados aqui (gerente de atendimento do AME Araçatuba).

Quando há indicação médica de prioridade ou urgência, esses casos são tratados de forma diferenciada. São comunicados e solicitados à administração ou encaminhados para o serviço de nível terciário, dependendo da gravidade. Nos casos de prioridade para retorno, interconsulta ou exames internos, é entregue a filipeta e são feitas as orientações ao usuário na própria recepção, assim que o agendamento for realizado.

[...] passa pelo médico e depois pela recepção, se não houver prioridade, o paciente irá seguir o fluxo normal, mas se tem alguma observação que necessite de agendamento imediato é tratado de forma diferente.

[...] se o médico pedir urgência, o paciente já é marcado como encaixe, às vezes ele pede um laboratório em tanto tempo... um exame em tanto tempo... Então elas já fazem o agendamento ou o encaixe. (gerente de atendimento do AME Araçatuba)

A equipe demonstrou possuir um fluxo específico para os casos indicados como prioritários e atentaram sobre a responsabilidade de todos os trabalhadores na área da saúde sobre manter os cadastros atualizados para viabilizar a comunicação com o usuário.

\subsubsection{2 organização da fila, comunicação aos usuários e cancelamento dos retornos, interconsultas e exames internos no AME Araçatuba}

Todos os agendamentos seguem o fluxo padrão no sistema CROSS, que utiliza a ferramenta de fila por demanda, o que possibilita a exclusão automática do CDR. A comunicação interna entre os setores é feita por e-mails ou documentos com prévia autorização administrativa sobre as transferências e os encaixes. O fluxo administrativo é composto pelos seguintes setores: o setor de liberação, que autoriza as vagas, e o setor de 
monitoramento, que apoia a organização dos agendamentos de interconsultas e retornos, conforme a realização dos exames solicitados em consulta médica. Assim que agendado qualquer um desses serviços (consultas, exames ou procedimentos), é necessário entrar em contato com o usuário, tarefa realizada pelo setor denominado CALL center $^{18}$.

\begin{abstract}
Alguns exames e consultas que nós não temos filas, o próprio monitoramento do AME, já passa um e-mail avisando que exames e consultas podem ser agendados, porque não tem fila!

[...] assim que agendado vai automático no sistema, e tudo que for encaixe e transferências vai por e-mail ou algum bilhete direto para elas no CALL center.(gerente de atendimento do AME Araçatuba)

[...] eu só ligo pra avisar sobre as consultas de encaixe e a outra menina só os exames extras e transferência. (profissional do CALL center)
\end{abstract}

No entanto, com o passar dos anos, o setor responsável pela comunicação com os usuários observou a insuficiência desse único contato e, em 2015, foi criado o Recall $^{19}$, com a finalidade de reforçar as orientações pré-procedimentos. Essa estratégia foi iniciada para o preparo de colonoscopia e teve resultado positivo. Aos poucos foi ampliada para vários outros exames e algumas consultas com especialistas como: endoscopia, ultrassonografias, consultas de oftalmologia e linha de cuidados saúde do homem. Em caso de procedimentos como tomografias, ressonâncias, biópsias de próstata, entre outros, o serviço social entra com ações presenciais na orientação dos usuários.

Nesse processo de reorganização da comunicação com o usuário, também foram observadas falhas no atendimento em exames por falta de acompanhantes e de receitas médicas para o fornecimento de medicamentos apropriados ao preparo, ou seja, o usuário, após a consulta médica, passa pela recepção de pós-consulta onde todos os pedidos e encaminhamentos são conferidos, agendados ou orientados conforme a necessidade.

[...] preparos de colono e endoscopias somos nós do CALL center e o Recall que avisamos. Orientações sobre a necessidade de acompanhantes, alguns remédios que devem ser parados e paciente vir em jejum. Alguns exames como colono que precisam de três dias de preparo ou a alergologia que precisa ficar 7 dias sem tomar algum determinado antialérgico, e o otorrino que tem que aplicar um produto no ouvido por 7 dias para retirar a cera [...] (profissional do CALL center)

[...] dispensa por falta do antibiótico que o médico do município não fazia as receitas. Então nós criamos um fluxo que o médico (AME) já solicita a medicação para o paciente tomar antes da biópsia de próstata e o fleet enema também, que sãos necessários para esses exames! Tinha muito paciente que chegava desorientado, o

\footnotetext{
${ }^{18}$ O CALL Center foi criado desde a inauguração do AME, em 2010, para comunicar os usuários sobre os retornos, interconsultas e exames internos por ligação telefônica.

${ }^{19} \mathrm{O}$ Recall foi criado em 2015, devido à elevada taxa de absenteísmo em exames médico-dependentes, ou seja, exames realizados pelos profissionais médicos, como colonoscopia e endoscopia. Muitos usuários faltavam por medo ou eram dispensados por preparo inadequado.
} 
pessoal da unidade básica não conseguia orientar, mesmo tendo o preparo impresso na filipeta. A gente repara que eles não leem. (enfermagem do AME Araçatuba)

[...] o preparo de biópsia de próstata que necessita de anticoagulante e a catarata que precisa parar o anticoagulante! ... exames de tomografias, o paciente vem buscar os documentos e a gente explica sobre o exame e o preparo. (serviço social do AME Araçatuba)

[...] no início eram os enfermeiros que ligavam e orientavam por telefone. Mas melhorou mesmo quando a gente passou a orientar "cara a cara ...o absenteísmo diminuiu pela metade! Por telefone eles ainda possuíam muita dificuldade de assimilar. Então foi passado para o serviço social porque agenda delas é mais específica de atendimento, e melhorou muito, muito, muito! (enfermagem do AME Araçatuba)

Durante as ligações para comunicação de retornos, interconsultas e exames agendados pelo AME Araçatuba, é verificado com o usuário se ele poderá comparecer na data agendada. Caso não possa, o agendamento é cancelado e o próximo usuário do $\mathrm{CDR}$ é agendado. $\mathrm{O}$ serviço de Recall, ou seja, a reconvocação do usuário em geralmente 7 dias antes de consulta ou exame, auxilia na diminuição dos índices de faltas e da morosidade na definição de diagnósticos e tratamentos.

[...] o paciente pode ter algum imprevisto e ele não consegue ligar para nós, assim a gente consegue fazer uma troca e evitar uma falta!

A troca é realizada. E isso ajudou a dar dinamismo na fila... então se o paciente avisa que teve algum imprevisto o Recall já avisa para o setor de agendamento. (gerente administrativo do AME Araçatuba)

\subsection{Absenteísmo interno da Unidade AME Araçatuba}

As orientações sobre a marcação de consulta ou exame estão descritas na filipeta, como: horário de chegada, preparo medicamentoso, jejum, necessidade de acompanhante, documentos necessários para o atendimento no serviço.

A falha no atendimento - por faltas em consultas, exames, procedimentos e cirurgias, e por dispensa devido à falta de documentação, preparo inadequado para exames, atrasos ou falta de acompanhante para algumas consultas e exames - era um problema habitual e crônico no AME Araçatuba desde sua criação, em 2010. 
Tabela 4.3 - O absenteísmo em consultas médicas e não médicas, interconsultas, retornos e exames/procedimentos do AME Araçatuba no período de 2010 a 2017

\begin{tabular}{l|c|c|c|c}
\hline Período & $\mathbf{1}^{\circ}$ Consulta & Interconsultas & Retornos & Exames/ Procedimentos \\
\hline Jun-Dez de 2010 & $18 \%$ & $10 \%$ & $13 \%$ & $13 \%$ \\
\hline Jan-Dez de 2011 & $19 \%$ & $14 \%$ & $18 \%$ & $14 \%$ \\
\hline Jan-Dez de 2012 & $20 \%$ & $16 \%$ & $15 \%$ & $14 \%$ \\
\hline Jan-Dez de 2013 & $20 \%$ & $15 \%$ & $15 \%$ & $13 \%$ \\
\hline Jan-Dez de 2014 & $20 \%$ & $17 \%$ & $15 \%$ & $13 \%$ \\
\hline Jan-Dez de 2015 & $19 \%$ & $17 \%$ & $13 \%$ & $20 \%$ \\
\hline Jan-Dez de 2016 & $20 \%$ & $14 \%$ & $11 \%$ & $15 \%$ \\
\hline Jan-Dez de 2017 & $17 \%$ & $12 \%$ & $11 \%$ & $14 \%$ \\
\hline Fonte: São Paulo (2010) & & & &
\end{tabular}

Os índices de absenteísmo entre 2010 e 2017, de maneira geral, tiveram diminuição em 2017. As consultas, que permaneceram em $20 \%$ por quatro anos, foram reduzidas para $17 \%$; as interconsultas, que chegaram a $17 \%$ por dois anos, depois diminuíram para $12 \%$; os exames e procedimentos (internos e externos) caíram de $20 \%$ para $14 \%$, e os retornos, que eram $18 \%$ em 2011, foram reduzidos para $11 \%$ (Tabela 4.3 ).

Foram selecionadas na Tabela 4.4 as especialidades com maiores índices de absenteísmo, de 2013 a 2015. Analisados os números inteiros, é possível observar, por exemplo, a especialidade de neurologia, que teve a menor oferta de todos os anos em 2015, ou seja, 648 consultas, houve 346 faltas, um absenteísmo de 53,40\%. No mesmo ano, houve a diminuição expressiva na oferta da neurologia por falta de profissional no quadro de recursos humanos do AME Araçatuba. Em números absolutos, esses valores foram impactantes quando associados ao número de usuários nas filas de demanda interna do AME Araçatuba, aguardando diagnóstico, e as dos municípios, conforme Tabela 4.4. 
Tabela 4.4 - Especialidades distribuídas para primeira consulta do AME Araçatuba com maiores taxas de absenteísmo e número de dispensa, no período de 2011 a 2017

\begin{tabular}{|c|c|c|c|c|c|c|c|c|c|c|c|c|}
\hline \multirow{3}{*}{$\begin{array}{l}\text { ANO } \\
2013\end{array}$} & \multicolumn{4}{|c|}{ Acupuntura } & \multicolumn{4}{|c|}{ Cirurgia Geral } & \multicolumn{4}{|c|}{ Neurologia } \\
\hline & \multirow{2}{*}{$\frac{\text { AGEND }^{1}(n)}{4248}$} & \multirow{2}{*}{\begin{tabular}{|c|}
$\operatorname{DISP}^{2}(\mathrm{n})$ \\
0 \\
\end{tabular}} & \multicolumn{2}{|c|}{$\mathrm{ABS}^{3}$ (n e \%) } & \multirow{2}{*}{\begin{tabular}{|c|} 
AGEND(n) \\
1642 \\
\end{tabular}} & \multirow{2}{*}{$\begin{array}{c}\operatorname{DISP}(\mathrm{n}) \\
0 \\
\end{array}$} & \multicolumn{2}{|c|}{ ABS (n e \%) } & \multirow{2}{*}{\begin{tabular}{|c|} 
AGEND(n) \\
2764 \\
\end{tabular}} & \multirow{2}{*}{$\begin{array}{c}\operatorname{DISP}(n) \\
0 \\
\end{array}$} & \multicolumn{2}{|c|}{$A B S$ ( $n$ e \%) } \\
\hline & & & 950 & 22.36 & & & 313 & 19.06 & & & 532 & 19.25 \\
\hline 2014 & 4546 & 56 & 1214 & 25.34 & 1553 & 0 & 381 & 20.14 & 1099 & 1 & 212 & 18.21 \\
\hline 2015 & 2374 & 0 & 855 & 36.02 & 1897 & 0 & 586 & 30.89 & 648 & 0 & 346 & 53.40 \\
\hline 2016 & 2393 & 21 & 561 & 23.44 & 2339 & 55 & 483 & 20.65 & 2096 & 168 & 402 & 19.18 \\
\hline 2017 & 2282 & 28 & 471 & 20.64 & 2276 & 35 & 412 & 18.10 & 3720 & 36 & 682 & 18.33 \\
\hline
\end{tabular}

*2011 e 2012 os dados não estavam disponíveis no sistema CROSS.

1. Agendamento

2. Dispensados

3. Absenteísmo

Frente às altas taxas de absenteísmo (Tabelas 4.3 e 4.4) e às demandas reprimidas para essas e outras especialidades, a equipe de trabalho do AME Araçatuba criou, em 2015, uma comissão interna para discutir o absenteísmo. Esse trabalho teve impacto positivo, pois várias estratégias, as quais serão apresentadas adiante, foram elaboradas e aplicadas pelos envolvidos no processo de atendimento. É possível observar o aumento acentuado de absenteísmo no ano de 2015, nas três especialidades, e depois uma melhora nos anos seguintes.

\subsection{Criação da comissão interna de acompanhamento do absenteísmo no AME Araçatuba}

Foi criado em 2015 o grupo interno do AME Araçatuba para discutir o absenteísmo. A princípio era formado por representantes das gerências: administrativa, atendimento, tecnologia da informação, enfermagem, ambulatório, além dos setores do CALL Center, serviço de atendimento ao usuário (SAU), recepção, portaria e serviço social. O grupo estudou inicialmente o absenteísmo nas consultas, quantificou por municípios e discutiu estratégias para buscar a natureza das faltas.

[...] as reuniões ocorrem desde o ano retrasado (2015) ...quando foi criada a comissão do absenteísmo! (CALL Center do AME Araçatuba)

[...] foi feito um estudo, pois não sabíamos os motivos das faltas. Com os relatórios que nós tínhamos no sistema a gente até sabia quem eram os faltosos, mas não o motivo do absenteísmo! (gerente de atendimento do AME Araçatuba)

A vantagem desse grupo foi juntar todos os atores envolvidos desde na portaria até administração porque cada um trabalha e vê a realidade em um momento! (enfermagem do AME Araçatuba) 
Para a qualificação dos motivos das faltas, foi criado, ainda em 2015, o Recall, que identificou em seu trabalho os motivos que levaram os usuários a faltar. Dentre os motivos apresentados estavam: o esquecimento; dificuldade com transporte; situação pessoal inesperada; sentir-se doente; trabalho; medo (em caso de colonoscopia e biópsia); desconhecimento, e ainda dispensas pelo AME Araçatuba. Foi realizada pelo grupo a discriminação da amostragem relativa aos motivos - aqueles que dependiam do usuário e os motivos que envolviam os serviços de saúde.

O Recall foi criado por causa do grande número de dispensa, principalmente dos exames de colono e endoscopia. (enfermagem do AME Araçatuba)

Um dos aspectos evidenciados foi a dispensa de usuários realizada na portaria ${ }^{20}$ ou durante o atendimento no AME Araçatuba. Este motivo é diferente dos usuários faltosos, uma vez que eles compareceram ao compromisso, mas a instituição o dispensou. A análise das falhas relativas a essas dispensas do atendimento é um aspecto importante a considerar nas causas de absenteísmo, pois decorrem das falhas no processo organizacional da instituição. Até então, o sistema CROSS permitia a quantificação dessas dispensas no histórico dos usuários, mas não estava sendo bem utilizada.

Os motivos atribuídos às dispensas identificadas pelo Recall levaram o grupo a novas discussões e estratégias: a criação de instrumento para a portaria registrar os motivos das dispensas (atraso, falta de encaminhamento, encaminhamento incorreto ou incompleto e campo aberto para outros registros), e a implantação do termo de responsabilidade, segundo o qual o usuário permite a realização do procedimento mesmo sem o acompanhante e aguarda no serviço a recuperação da anestesia até a liberação médica.

[...] criado um termo de responsabilidade, para a pessoa quando vem sem acompanhante... E para que ele não perca o exame, ele assina o termo de responsabilidade no qual ele se responsabiliza para o resguardo da instituição.

Portanto, o usuário realiza o procedimento e aguarda no serviço a recuperação da anestesia até a liberação médica. (enfermagem do AME Araçatuba)

Sobre a dificuldade de contato com os usuários, trazida pelas trabalhadoras do Call Center, foram realizadas campanhas internas de conscientização sobre a importância do cadastro atualizado por meio de teatros, paródias, vídeos que aconteceram no hall de espera. Além do problema com os dados cadastrais no Portal CROSS, foi evidenciada a presença de dois ou mais cadastros para o mesmo usuário. Portanto, foram intensificados os treinamentos

\footnotetext{
${ }^{20}$ A portaria e a recepção central realizam o controle de entrada entre a sala de entrada e o saguão central conforme o horário agendado na filipeta e a conferência do encaminhamento e dos documentos pessoais. Se o usuário comparece em desconformidade com as orientações da filipeta como: atraso, documentos incompletos ou errados, falta de acompanhante em algumas consultas ou exames, entre outras, o usuário é dispensado.
} 
dos profissionais responsáveis por alimentar o sistema CROSS como estratégia, tema que passou a fazer parte das pautas nas reuniões mensais do AME Araçatuba com o DRS II Araçatuba e municípios.

Dá para perceber também o CROSS (cadastro) está virando igual o cartão SUS, no início se tinha um cuidado de ser unificado, mas hoje você pega o paciente com 2, 3, 4 cartões SUS e o CROSS está ficando assim. Tem pacientes com 2, 3, 4 números de CROSS diferentes e vem aqui para a gente unificar! (enfermagem do AME Araçatuba)

Aqui dentro do AME... nós fizemos uma campanha de atualização de cadastro e foi levado aos municípios através de reuniões, na verdade até hoje a gente fala por telefone quando entramos em contato com os municípios! (gerente de atendimento do AME Araçatuba)

[...] a própria Secretaria do Estado deveria fazer propagandas, mais intensificadas a respeito desse problema! O paciente usa o serviço do AME, ele tem que manter os dados dele atualizado! (gerente administrativo do AME Araçatuba)

Outra ação realizada a partir dos relatos dos trabalhadores do Call Center foram as melhorias no sistema de telefonia, pois eram comuns as queixas de usuários sobre ruídos e dificuldade de compreender as telefonistas quanto aos dados do agendamento.

[...] a localização é desfavorável, a maior parte dos contatos são por celulares em sítios e lugares afastados... Fizemos investimentos e melhorou bastante! (gerente administrativo do AME Araçatuba)

O trabalho desse grupo demonstrou avanços na diminuição do absenteísmo durante o ano de 2015. As taxas de absenteísmo de 2014 para 2015, em relação aos retornos, diminuíram de $15 \%$ para 13\%; mantiveram-se, sem alteração, em 17\%, as interconsultas. Porém, os exames (internos e externos) tiveram um crescimento de $13 \%$ para $20 \%$. Após a análise dos avanços alcançados, o grupo interno de absenteísmo passou a direcionar as ações focadas na prevenção de absenteísmos e dispensas em exames.

A gestão do AME Araçatuba estava com dificuldade em relação aos exames médicodependentes $^{21}$, pois, desde o início de 2016, o pagamento passou a ser por produção, e o Recall teve importante papel na caracterização das faltas e preparo incorreto de exames. A partir de vários relatórios e discussões do grupo, foi implantado novo fluxo de informação aos usuários: os avisos sobre os exames de colonoscopia e endoscopia passaram a ser realizados por profissionais capacitados, visando a desmistificar alguns medos e receios, além de orientar sobre o preparo adequado. As biópsias e tomografias passaram a ser realizadas por meio de orientações face-a-face, que consiste em explicar o preparo para o usuário.

\footnotetext{
${ }^{21}$ Exames de ultrassonografia, cistoscopia, nasofibrolaringoscopia, endoscopia, colonoscopia, ecocardiografia, histeroscopia diagnóstica, biópsias, entre outros procedimentos.
} 
E por causa das faltas e preparo inadequado, os médicos começaram a reclamar que não tinha paciente. Por que os médicos recebem aqui por produção.

Havia muitos pacientes que vinham com o preparo inadequado e perdia o exame. $\mathrm{Na}$ verdade, eles compareciam, eram atendidos, mas acabavam sendo dispensados. No início, as orientações eram feitas pela enfermagem, mas devido às dificuldades internas em manter o serviço, fizeram treinamento com o administrativo responsável pelas ligações aos usuários.

Eles ficaram uma semana junto da enfermagem no centro cirúrgico, acompanhando como era o exame e quais são as orientações que devem ser dadas aos pacientes. (enfermagem do AME Araçatuba)

Após o levantamento de informação sobre absenteísmo e motivos registrados por municípios de origem, o grupo propôs ampliar as estratégias para as primeiras consultas e exames agendados pela rede. Foi sugerido pelo grupo reuniões com os secretários municipais de saúde para a apresentação dos dados levantados e discussão da problemática. No segundo semestre de 2016, foi convidado um representante técnico do DRS II Araçatuba e os resultados dos estudos foram pautados nas reuniões com os gestores.

Concomitantemente, os gestores municipais dos municípios com maiores índices de absenteísmo foram convidados para uma explanação de forma individualizada. Foram agendadas 4 reuniões separadas por município, comparecendo os gestores municipais em 3 delas e em 1 apenas os agendadores do município.

As reuniões ocorreram por todo segundo semestre de 2016, com pautas sobre o absenteísmo: porcentagem de faltas e dispensas por trimestre, motivos coletados pelo Recall. Nesses encontros também foram sugeridas novas estratégias para auxiliar os municípios, como a qualificação das demandas reprimidas, ligação de confirmação de interesse antes do agendamento, entre outras. Para melhor acompanhamento do absenteísmo, foi pactuado em reunião o envio por e-mail de relatórios sobre os motivos de dispensas por municípios de origem, para ciência e providências.

Outro assunto discutido e votado em reunião de CIR foi a alta administrativa, que consistiu na conclusão de atendimentos no AME Araçatuba para os usuários que tivessem 3 faltas consecutivas e sem justificativa em uma especialidade ou exame. Essa ação gerou a diminuição expressiva de usuários sem diagnóstico concluído na demanda interna do serviço. Essa medida possibilitou indiretamente novas vagas de primeira consulta e repercutiu de forma conscientizadora junto à população, pois os usuários faltosos eram obrigados a retornar à APS para iniciar nova investigação.

Ainda no final de 2016, em reunião entre os gestores de contrato da Secretaria de Saúde do Estado de São Paulo, representantes do DRS II Araçatuba e gerentes do AME Araçatuba foram discutidas as ofertas de vagas, conforme a série histórica de cada município, 
ou seja, os assíduos passaram a receber maiores ofertas em relação aos municípios com altos índices de falha no atendimento (conforme a taxa de 15\%). Esta estratégia e as ações iniciadas em 2015 permaneceram até o final de 2017, com impacto positivo no absenteísmo global da rede.

\subsubsection{5 reflexões sobre o absenteísmo dos agendamentos internos do AME Araçatuba}

As taxas de absenteísmo nas primeiras consultas agendadas pela rede passaram, de 2016 para 2017 , de $20 \%$ para $17 \%$; os retornos mantiveram diminuição de $13 \%$ para $11 \%$. As interconsultas e exames (internos e externos), que, no ano de 2015, eram de $17 \%$ e $20 \%$, consecutivamente, passaram em 2016 e 2017 de 14\% para 12\% nas interconsultas, e de 15\% para $14 \%$ nos exames (internos e externos).

As ações realizadas pela comissão interna do AME Araçatuba e as estratégias que se estenderam aos municípios tiveram resultados exitosos frente ao absenteísmo e ao aumento das altas globais. Os usuários que dependiam de exames e vagas de retorno para definição de diagnóstico ou realização de cirurgias no AME Araçatuba foram atendidos (Tabela 4.5), devido ao aproveitamento das vagas com o aumento da alta global. Em 2017, houve redução da alta global de 108,08\% para 83,29\%, o que correspondeu à taxa de alta global esperada, ou seja, a permanência dos usuários no aguardo de exames, ou o tempo para uso de determinadas medicações, ou ainda o período necessário entre os procedimentos realizados no AME Araçatuba.

Tabela 4.5 - Número de primeiras consultas agendadas e alta global no AME Araçatuba por ano, no período de 2011 a 2017

\begin{tabular}{l|r|r|r|r|r|r|r|}
\hline Ano & 2011 & 2012 & 2013 & 2014 & 2015 & 2016 & 2017 \\
\hline 1ㅇ consulta & 50.645 & 43.972 & 39.991 & 36.550 & 30.130 & 30.288 & 33.108 \\
\hline Alta global (\%) & 59,72 & 70,48 & 66,29 & 76,18 & 102,54 & 108,08 & 83,29 \\
\hline \multicolumn{2}{l|}{ Fonte: São Paulo ([2010)]. }
\end{tabular}

Durante o grupo focal, todos os atores envolvidos demonstraram elevado nível de compromisso em reorganizar e conscientizar os demais profissionais do AME Araçatuba e dos municípios sobre a responsabilidade e importância de cada um no acesso à saúde dos usuários. Houve contribuições importantes de todos os participantes, evidenciadas durante a dinâmica sobre fluxo de trabalho e relação colaborativa natural entre eles. 
[...] eu acho que quem fez o cadastro tem que fazer correto, eu acho que a informação acaba sendo responsabilidade de todas as pessoas que trabalham com a saúde. (gerente administrativo do AME Araçatuba)

Principalmente nos atendimentos não médicos, como a fisioterapia, psicologia, nutricionista... porque agora eles possuem uma preocupação, se eles faltarem duas seguidas eles sabem que interromperam o tratamento. Melhorou essa conscientização! (Call Center do AME Araçatuba)

Alguns médicos continuam fazendo transferência de agenda, por que são dadas com 60 dias de antecedência, nesse período muita coisa acontece... congresso, viagem, e acaba tendo transferência! (gerente administrativo do AME Araçatuba)

A proposta da comissão interna de acompanhamento do absenteísmo relatada foi a de manter as atividades como um processo contínuo no AME Araçatuba em parceria com o DRS II Araçatuba para apoio técnico aos municípios. Estava em andamento o projeto de matriciamento a ser desenvolvido com os médicos da rede.

[...] nós estamos discutindo em fórum do colegiado dos AMEs, que aí junta o DRS II Araçatuba e o DRS XV Rio Preto, ...vários aspectos e assuntos em comum e um deles foi o matriciamento. Estamos discutindo várias estratégias que irão ajudar a gente também no absenteísmo, porque agora a gente já está fazendo um envolvimento para melhoria da qualidade do encaminhamento. Com isso, a gente vai se aproximar ainda mais dos municípios e isso abre um canal mais próximo e um elo mais fortalecido entre o AME e os municípios. E a gente vai poder trocar mas as experiências de dificuldades de ambas as partes para melhoria do absenteísmo! (gerente administrativo do AME Araçatuba)

\subsubsection{Município A}

O Município A tem população estimada de 194.874 habitantes (IBGE 2017), sendo o maior município dos quatro pesquisados. Apresenta índice de desenvolvimento humano municipal, em 2010, de 0,788. Possui 44 estabelecimentos de saúde do SUS, dentre os quais18 unidades de atenção primária, dois serviços hospitalares de gestão municipal, ambulatórios, prontos-socorros e outros serviços. Destes, apenas1 hospital e 1 ambulatório estão sob gestão estadual. Sua economia é caracterizada pelo crescimento das lavouras de cana-de-açúcar. Esse quadro incluiu também a pecuária, atividade que a tornou conhecida no país como a capital do Boi Gordo. Atualmente, possui uma economia diversificada. O setor de serviços é predominante na cidade.

Os dados do Município A foram coletados do banco de dados do Portal CROSS; impressos internos; plano municipal de saúde; entrevista com o gestor e o responsável pela central de agendamento, e grupos focais com as equipes de saúde da APS. Participaram dos grupos focais os profissionais de saúde das Unidades $\mathrm{M}, \mathrm{I}, \mathrm{U}$ e $\mathrm{T}$, conforme descrito na 
metodologia sobre a seleção das unidades representativas do Município A. A seguir são descritos os dados desta coleta.

\subsubsection{1 entrevista com o gestor e o responsável pelo agendamento do Município A}

A entrevista semiestruturada foi realizada com o gestor SMS A e o representante do setor de agendamento SMS A, na Secretaria Municipal de Saúde (SMS), com duração de 60 minutos. Essa foi a única entrevista - dentre as quatro realizadas com os gestores - que contou com a participação de outro profissional, além do mesmo. Essa decisão partiu do gestor.

O gestor municipal e o agendador da SMS A demonstraram interesse em relação ao assunto. Relataram mudanças no processo de agendamento e narraram a natureza das reuniões desenvolvidas junto às equipes da APS. Na ocasião, a pesquisadora solicitou os documentos utilizados pelo serviço na organização interna e o plano de saúde municipal, os quais foram prontamente disponibilizados.

Ao final da entrevista, foi solicitada aos participantes a indicação de 2 unidades de saúde da APS com maior dificuldade em controlar o absenteísmo e outras 2 unidades com melhor controle do mesmo, para participarem de grupo focal que iria discutir o tema. $\mathrm{O}$ gestor indicou as Unidades de Saúde U e T como unidades de maior dificuldade e as Unidades M e I como aquelas de melhor controle do absenteísmo.

Todos os grupos focais com as Unidades de Saúde M, I, U e T foram agendados junto à Organização Social de Saúde (OSS) contratada pela SMS A para gestão da APS. Os grupos focais ocorreram nas respectivas unidades de saúde, conforme a disponibilidade de datas e horários definidos pelas equipes. O grupo participante de cada unidade de saúde contou com a participação de diferentes profissionais, em número e categorias, como será descrito abaixo.

\subsubsection{2 descrição do grupo focal com a equipe da Unidade de Saúde U da SMS A}

O enfermeiro da unidade foi receptiva e explicou que possui sete equipes de Estratégia de Saúde da Família (ESF) e apresentou os agentes comunitários de saúde (ACS) que estavam na sala de reunião. O grupo focal ocorreu no período da tarde. $\mathrm{O}$ enfermeiro não pôde participar, pois ela e os demais enfermeiros, médicos e auxiliares de enfermagem estavam em atendimento. Permaneceram apenas os ACS. 
Os ACS não haviam sido informado do grupo focal e, no início, não se mostraram receptivos. Logo em seguida, mudaram de atitude em relação à proposta.

A atividade foi iniciada com a apresentação dos objetivos e da justificativa do estudo. Não foi necessária a leitura das questões disparadoras (Anexo F), pois os atores iniciaram espontaneamente falas de preocupação sobre o absenteísmo e o quanto são numerosas as filas de espera. Foi possível identificar insatisfação com o processo de agendamento realizado no Município A por meio dos exemplos da falha de comunicação, tempo de espera, perda de encaminhamento, entre outros.

Participaram no início do grupo os ACS representantes de 3 ESF e 1 profissional da recepção. No decorrer da dinâmica, chegaram outros ACS que estavam em visitas domiciliares e os profissionais presentes no grupo focal solicitaram à pesquisadora a inclusão dos demais colegas na atividade. Eles argumentaram que seria muito importante a participação de todos os ACS das 7 equipes, o que foi corroborado por aqueles que tinham acabado de chegar. Deste modo, tornou-se premente a inclusão dos novos participantes, totalizando 20 ACS e 1 recepcionista. Esta atitude do grupo preveniu a negativa da proposta.

Foi possível verificar em alguns relatos o sentimento de alienação dos ACS no processo de agendamento de seus usuários, a sobrecarga de trabalho e a insatisfação com as atividades desenvolvidas por eles no período que coincide com a realização da pesquisa.

No decorrer do grupo focal, demonstraram disposição em ajudar com muitas ideias de estratégias para diminuir o absenteísmo; os pontos positivos e negativos, e as ações que poderiam contribuir junto às famílias que acompanhavam. Os ACS expuseram a necessidade de treinamento, pois eles eram novos no serviço e nunca haviam sido capacitados.

Esse grupo focal foi o mais longo, contando com 100 minutos de discussão intensa.

\subsubsection{3 descrição do grupo focal com a equipe da Unidade de Saúde T da SMS A}

Os enfermeiros da unidade foram receptivas, mas explicaram que também não poderiam participar, pois os demais enfermeiros, médicos e auxiliares de enfermagem estavam em atendimento na unidade ou em visita domiciliar programada, permanecendo apenas os ACS. O grupo focal ocorreu no período da tarde com os ACS que estavam disponíveis na unidade e uma representante da recepção, totalizando 9 participantes e duração de 85 minutos. A equipe de ACS e a recepcionista também não haviam sido informados a respeito da pesquisa, mas, após a apresentação dos objetivos e da justificativa, participaram de forma receptiva. 
Realizada a leitura dos temas disparadores (Anexo C), a participação de todos envolvidos foi intensa. Eles explicaram as especificidades da microrregião, como a área rural, e a presença predominante da população idosa. Demonstraram empatia sobre várias situações que dificultam o acesso. Foi possível também identificar nas falas boa interação entre os membros da ESF, o compromisso em discutir estratégias para diminuir o absenteísmo e sugestões de ações que poderiam ser desenvolvidas junto às famílias.

\subsubsection{4 descrição do grupo focal com a equipe da Unidade de Saúde I da SMS A}

A responsável técnica pela unidade de saúde estava aguardando com representantes das 2ESF. Participaram da atividade o enfermeiro, os ACS e a representante da recepção, organizados na forma de roda.

Todos os participantes se mostraram receptivos. O fluxo foi explicado em detalhes pelas ACS e os participantes demonstraram compreender o processo. O grupo focal teve duração de 80 minutos com a participação de 11 profissionais da unidade, representantes das 2 equipes de ESF, ou seja, o enfermeiro, o auxiliar de enfermagem, e os agentes comunitários, com exceção do médico. Foi possível evidenciar ações e fluxos estabelecidos por iniciativa deles para tentar melhorar a comunicação com os usuários por microárea.

\subsubsection{5 descrição do grupo focal com a equipe da Unidade de Saúde M da SMS A}

O grupo focal foi agendado para o período da manhã na Unidade de Saúde $\mathrm{M}$ e teve a duração de 70 minutos. Foi aproveitado o período de reunião das 3 ESF. A recepção na unidade foi realizada por 2 enfermeiros das Unidades de Saúde da Família (USF ${ }^{22}$ ) que já estavam aguardando junto aos ACS, médico e a representante da recepção, totalizando 11 profissionais. O grupo focal ocorreu na sala de reuniões da ESF e todos estavam organizados em forma de roda.

Todos os participantes se mostraram envolvidos e explicaram as especificidades da microrregião. Falaram em especial sobre a ausência de transporte coletivo na área rural, a dificuldade de acesso em relação à logística para a própria Unidade de Saúde e para o AME Araçatuba. Fizeram vários relatos e exemplos sobre os possíveis motivos do absenteísmo.

\footnotetext{
${ }^{22}$ Unidade de Saúde da Família (USF) integra a atenção primária de saúde, na qual trabalhar uma ou mais equipes de Estratégia da Saúde da Família (ESF).
} 
Relataram o trabalho realizado, por iniciativa das equipes, para identificar usuários não encontrados pela central de agendamento. Os participantes explicaram as dificuldades enfrentadas em relação à localização de endereço e de famílias que não pertencem à área de cobertura da ESF.

Durante a dinâmica, foi possível também identificar a boa interação entre os membros da ESF e entre as equipes, além do interesse em discutir o tema proposto.

\subsubsection{6 caracterização dos serviços de saúde: Município A}

O Município A utiliza o Portal CROSS para agendamento no AME Araçatuba, mas possui um sistema informatizado próprio, no qual a APS insere toda a demanda por recursos, sinalizando as prioridades para a gestão de saúde. A APS está distribuída por todo o Município A, sendo dezesseis unidades em área urbana e quatro em área rural, com cobertura da Estratégia da Família em 80\% do território.

\footnotetext{
Aqui nós temos um sistema informatizado que se chama gestão de saúde. (agendador SMS A)

[...] o restante (20\% da população não coberta por ESF) é atendida na unidade de saúde como fora de área, ...eles ficam sem a cobertura do agente comunitário de área! (gestor da SMS A)
}

A Secretaria de Saúde do Município A centraliza a gestão das ofertas em saúde e a maior parte da marcação de consultas e exames ocorre em uma central de agendamento. Essa central funciona no prédio da Secretaria e mantém a comunicação com as unidades de saúde de atenção básica por meio de e-mails e telefone.

[...] a gente continua agendando para o AME de forma centralizada ou distribuindo algumas cotas (especialidades ou exames que não há fila de espera)! (gestor da SMS A)

A central de agendamento é um grupo de profissionais aqui dentro da secretaria, cada agendador fica responsável por duas a três especialidades. (agendador SMS A)

De 2011 a 2015, o Município A manteve as taxas de absenteísmo acima de 15\% (Tabela 4.6) e teve uma demanda reprimida sob controle e gestão do próprio município. Por meio desses dados foi possível analisar que o município agenda mais do que é ofertado a ele, ou seja, aproveita as vagas disponibilizadas e as do sistema de bolsão ${ }^{23}$ do Portal CROSS. Para amostragem da oferta e agendamentos de consultas com especialistas do Município A foi

\footnotetext{
${ }^{23}$ Mecanismo para tornar disponíveis todas vagas de consultas e exames no período de sete dias que antecedem a data. Desse modo, o sistema CROSS possibilita de forma automática o agendamento das ofertas remanescentes.
} 
escolhido o mês de novembro de forma aleatória (Tabela 4.6), sendo evitados os meses de dezembro, janeiro, junho e julho por serem períodos de férias e festas e terem diminuição das ofertas de agendas médicas.

Tabela 4.6 - Oferta e agendamentos/mês de consultas em especialistas do Município A, nos meses de novembro de cada ano no período de 2010 a 2017

\begin{tabular}{|c|c|c|c|c|c|c|c|c|c|c|}
\hline \multirow{2}{*}{$\begin{array}{l}\text { Consultas } \\
\text { Especialista }\end{array}$} & \multirow[b]{2}{*}{ Período } & \multirow[b]{2}{*}{ Oferta $^{1}$} & \multicolumn{3}{|c|}{ Agendamentos } & \multicolumn{5}{|c|}{ Recepção } \\
\hline & & & Total $^{2}$ & $\operatorname{Cota}^{3}$ & Bolsão $^{4}$ & Pre $^{5}$ & Aus $^{6}$ & $\mathrm{Dis}^{7}$ & Alta $^{8}$ & Abs $\%^{9}$ \\
\hline \multirow{8}{*}{ Município A } & nov/10 & 93 & 117 & 97 & 20 & 105 & 12 & - & - & 10,26 \\
\hline & nov/11 & 871 & 988 & 867 & 121 & 717 & 271 & - & 19 & 27,43 \\
\hline & nov/12 & 927 & 1.060 & 922 & 138 & 799 & 261 & - & 123 & 24,62 \\
\hline & nov/13 & 1134 & 1222 & 1135 & 87 & 934 & 288 & - & 97 & 23,57 \\
\hline & nov/14 & 798 & 1.008 & 796 & 212 & 771 & 233 & 4 & 114 & 23,12 \\
\hline & nov/15 & 788 & 800 & 731 & 69 & 593 & 203 & 4 & 106 & 25,38 \\
\hline & nov/16 & 896 & 964 & 893 & 71 & 780 & 143 & 41 & 126 & 14,83 \\
\hline & nov/17 & 944 & 981 & 942 & 39 & 825 & 137 & 17 & 124 & 13,97 \\
\hline
\end{tabular}

1. Oferta

2. Total de agendamentos

3. Cotas agendadas

4. Bolsão vagas agendadas

5. Presente na consulta
6. Ausente na consulta

7. Dispensado da consulta

8. Alta

9. Absenteísmo em \%

Dentre as 4 unidades indicadas pelo gestor do município $\mathrm{A}$, as unidades representativas de saúde $\mathrm{M}$ e I eram as com mais facilidade de controle do absenteísmo e as unidades $\mathrm{U}$ e $\mathrm{T}$ as com menor controle do mesmo.

A Unidade de Saúde M possui 3 equipes de ESF que atendem cerca de $6 \%$ da população municipal, o que corresponde a 11.196 munícipes cadastrados. Elas realizam reuniões periódicas em equipe, demonstram boa interação profissional e consenso nas respostas dadas à pesquisadora pelos membros da equipe.

A Unidade de Saúde I possui 2 equipes de ESF e atende cerca de 3\% da população municipal, o que corresponde a 6.657 munícipes cadastrados. Essa unidade apresenta áreas que não possuem cobertura de ESF e a presença na microrregião de vários condomínios residenciais. Parte da área de cobertura da USF possui barreiras geográficas, como a área rural e, em alguns bairros, as ruas são de terras. A equipe realiza reuniões periódicas, apresenta ótima integração profissional e concordância nas respostas dadas à pesquisadora pelos membros da equipe. 
A Unidade de Saúde U possui 7 equipes de ESF, as quais atendem cerca de $14 \%$ da população municipal. Isso corresponde a 26.339 munícipes cadastrados. Possui também extensa área fora de cobertura, o que demanda muito da unidade de saúde. É uma unidade grande, que possui alta taxa de atendimento e procedimentos diários. Houve relatos de descontentamento em relação o trabalho desenvolvido pelo ACS.

A Unidade de Saúde T possui 5 equipes de ESF que atendem cerca de $9 \%$ da população municipal, o que corresponde a 17.521 munícipes cadastrados. A área de abrangência conta com áreas rurais e vários condomínios residenciais.

\subsubsection{1 organização e fluxos de agendamentos de consultas e exames no Município A}

No Município A, todas as unidades de APS seguem este fluxo de atendimento: 1. avaliação e conduta pelo médico da família ou clínico geral; 2. no pós-consulta, o usuário é encaminhado para a especialidade ou pedido de exame; 3. na recepção, são agendadas de imediato consultas de especialidade ou exames de demanda livre: 4. se houver demanda reprimida, a solicitação é inserida no sistema informatizado do Município A; 5. é atualizado o endereço e telefones do usuário no sistema municipal, e 6. é devolvido ao usuário o encaminhamento ou pedido, sendo ele orientado a aguardar contato da central de agendamento.

Geralmente o paciente passa pelo clínico, o clínico é a porta de entrada para especialidade, aí o clínico encaminhou paciente conforme o que ele está precisando. (ACS M1 do Município A)

O clínico geral avalia a necessidade de passar por algum especialista ou exames. Paciente sai do consultório médico e passa pela pós-consulta, onde a enfermagem realiza o preenchimento das guias com nome e endereço do paciente. Na recepção, se é uma especialidade que não temos cotas para nós mesmos realizarmos o agendamento, a recepção insere na lista de espera, que é do assessor público (sistema informatizado próprio da SMS A) e já atualiza o endereço e telefones do paciente. O paciente é orientado a aguardar na casa dele com a guia de encaminhamento ou exame, que assim que a central agendar, ela entrará em contato com ele. (enfermeiro da unidade I do município A)

O nosso agendamento é de no máximo 40 dias e não chega menos que 15 dias. A não ser se for trocas. E em casos de bolsão que são menos de sete dias, mas geralmente são agendamentos de prioridades! (agendamento SMS A)

A solicitação para o especialista ou exame fica registrada no sistema, seguindo uma fila única para o Município A. Desta forma, o setor de agendamento realiza a maior parte dos agendamentos, em torno de $90 \%$, pois são distribuídas para as unidades de saúde as vagas de demanda espontânea, ou seja, apenas as vagas que não possuem demanda reprimida. Os casos 
indicados de prioridade médica são agendados à medida que as vagas são disponibilizadas pelo DRS.

[...] a fila fica disponível no sistema para a Secretaria Municipal, e quando paciente for agendado, eles (central de agendamento) ligam aqui para nossa recepção. (ACS T1 do Município A)

$\mathrm{O}$ raio $\mathrm{x}$, por exemplo, é demanda livre. Eu agendo o raio $\mathrm{x}$ do paciente, já vejo se na data e horário que estou agendando ele poderá ir. Se eu percebo que esse horário não ficou bom, pergunto se ele prefere para o final da tarde ou logo no começo do dia. (recepcionista T do Município A)

As unidades (APS) inserem... e a gente gera uma fila única, ou seja, não temos uma fila por UBS. E a gente vai trabalhando por ordem cronológica, salvo os casos que o profissional médico solicitou prioridade. Aí assim, nós vamos organizando as cotas conforme disponibilizadas pelo DRS... dentro da nossa central de agendamento. (agendador SMS A)

\subsubsection{2 organização da fila, comunicação aos usuários, transporte e cancelamento de consultas e exames no Município A}

Antes do ano de 2017, a primeira comunicação sobre os agendamentos - com orientações sobre local, horário, documentos necessários e a filipeta - era geralmente realizada pela central de agendamentos, por telefone. Porém, os avisos eram oferecidos, até então, a qualquer pessoa adulta que atendesse a ligação telefônica. A partir do segundo trimestre de 2017, os agendamentos passaram a ser realizados após confirmação prévia com o próprio usuário e checagem dos documentos necessários.

A gente avisava qualquer pessoa que pudesse receber o recado sobre o agendamento. Só que aí, muitas vezes não era passado o recado... Então, de uns 6 meses (maio de 2017) para cá, nós começamos a trabalhar de forma diferente, a gente só avisa ou agenda diretamente com paciente.

Não imprimimos as filipetas, a gente só liga para o paciente e faz o agendamento, confirmando a data e o horário que ele pode ir e orientamos para que ele se dirija ao posto de saúde do bairro com seu encaminhamento (paciente fica com o encaminhamento ou pedido de exame original) e retire a filipeta lá, para que ele possa ser orientado pessoalmente. Então ele vai até a unidade Básica de Saúde com o encaminhamento, e eles lá irão orientar sobre não chegar atrasado, levar os documentos pessoais, e anexar a filipeta no encaminhamento. Verificando se o encaminhamento está correto! (agendador SMS A).

A comunicação entre a central de agendamento da SMS A e as unidades de saúde ocorre semanalmente, por meio de planilha enviada por e-mail com todos os agendamentos realizados por unidade de saúde; a identificação dos usuários sem contato telefônico, e as informações pertinentes. As equipes de ESF auxiliam na busca dos usuários não encontra dose relatam as dificuldades encontradas para manter os endereços e telefones atualizados e o trabalho com os usuários das áreas fora de cobertura da saúde da família. 
[...] se não conseguir contato com o paciente, a secretaria de saúde entra em contato com a gente. Assim a gente identificar de quem é e nós vamos atrás, porque as vezes mudou de casa ou o telefone e não mudou no cadastro, mas pelo nome dele a gente já sabe se é nosso!

Eles mudam de casa, e geralmente mudam de área. Só que eles não vêm aqui atualizar o cadastro, eles não atualizam endereço. Então eles mudam muito de endereço, trocam o telefone... eles não vêm avisar! (ACS M2 do Município A)

A gente emite uma lista de todos os agendamentos realizados por unidade semanalmente e mandamos para as unidades básicas de saúde. Esta semana todo mundo agendado já foi encaminhado para sua unidade. E aí nós orientamos também que devem ficar atentos para ver se seu paciente procurou unidade ou pedir para o agente comunitário que verifique. A gente faz esse trabalho também! Assim, os dois (o paciente e a unidade) são avisados do agendamento. Isso é semanal, esta listagem de Excel que a gente manda com nome do paciente, a especialidade, data do agendamento, para todas as unidades básicas de saúde. (agendador SMS A)

Ao ter atendimento agendado e comunicado, o usuário tem a possibilidade de adquirir a filipeta em qualquer unidade de saúde municipal. Para tanto, é necessária a apresentação do encaminhamento ou pedido de exame para que a recepcionista da APS grampeie os papéis e reforce as orientações necessárias.

A gente imprime a filipeta, grampeia e faz as orientações pertinentes. Mas é comum o paciente não saber onde está o pedido. A central de agendamento orienta a vir aqui na unidade e informar que não possuem o encaminhamento, porque perdeu... e assim que o paciente tiver um encaminhamento na mão a gente liga na central e eles agendam no momento. Às vezes, se o paciente demorar para conseguir um encaminhamento, a gente liga lá e eles avisam que ficará para próxima cota que houver! (recepcionista U do Município A)

A minha equipe trabalha já com grampeador na bolsa, para entregar para o paciente e orientar sobre o agendamento. Por que as ACS perceberam que o paciente estava voltando muito por dispensa, devido a faltando de algum documento na hora da consulta. (enfermeiro da unidade I do Município A)

[...] eu já sei tudo de cabeça (orientações e preparos), o ultrassom e colonoscopia, por exemplo (risos). No caso de acompanhante para cirurgias de catarata, eu oriento e reforço que o acompanhante deve permanecer durante todo processo cirúrgico, se não a cirurgia é suspensa! (recepcionista T do Município A)

As equipes de saúde da APS relataram que era frequente os usuários não encontrarem os encaminhamentos ou pedidos de exame, mas cada equipe trabalhava de maneira diferente sobre essa problemática. Em algumas unidades de saúde, esses usuários eram agendados com prioridade assim que era comunicada a falta dos documentos. Em outras, o agendamento seguia a ordem da agenda, muitas vezes demorando até três meses. Apenas nesse momento era possível reavaliar a necessidade do encaminhamento ou pedido de exame, pois a maior parte dos usuários já apresentava melhora ou haviam sido atendidos em serviços particulares, por exemplo. 
[...] tem gente que perde com um mês! Não sabe onde colocou! (ACS T5 do Município A)

Eles têm que ter responsabilidade sobre os papéis deles! (ACS T2 do Município A)

Perder... sempre acontece! Acontece porque... porque demora muito a marcação da consulta ou exame, que quando é agendado já fazem um ou dois anos e aí eu tenho que fazer o pedido de novo. (médico da família M do Município A)

[...] agendar outra consulta... o nosso clínico já está com agenda para janeiro (três meses). Essa vaga acaba se perdendo, querendo ou não! Aí atrapalha todo mundo!(ACS U1 do Município A)

A equipe de saúde da Unidade $U$ evidenciou algumas falhas na comunicação aos usuários pela central de agendamentos. Por exemplo, houve reclamação de muitos usuários em relação a ter recebido apenas duas ligações e ter seu agendamento desmarcado.

Em relação a central de agendamento, onde os pedidos estão parados, é o que ela está falando: eles falam que ligam e depois de três tentativas são cancelados! Mas na hora que nós ligamos, o paciente atende rápido e aí a gente pergunta: você recebeu alguma ligação da secretaria? E o paciente disse que não... (ACS U3 do Município A)

Ontem aconteceu exatamente isso com a minha paciente, colocaram no sistema que não estavam encontrando uma gestante de alto risco, que tinham tentado três vezes. Eu sai daqui e fui até lá e disse para ela, e ela disse que não entraram em contato com ela. (ACS U8 do Município A)

Eu era o contato para avisar de uma pessoa, e aconteceu comigo, o meu celular tocou apenas um toque e parou. E aí registram no sistema da secretaria municipal que tentaram contato. (recepção da unidade U do Município A)

Eu estava gestante, e as meninas me avisaram que o meu exame de ultrassom estava sendo cancelado, porque tinham tentado me ligar e não estavam conseguindo, mas eu não tinha nenhuma ligação perdida! (ACS U9 do Município A).

A central de agendamento da SMS A acessa por sistema informatizado próprio toda a demanda municipal e a organiza por grupo de especialidades, formando uma fila única de necessidades para o município. Ela é gerenciada pelo próprio Município A. Cada agendador fica responsável por algumas especialidades e realiza os agendamentos à medida que confere as solicitações e as confirma com o usuário.

Eles organizam a lista de demanda por recurso diariamente, verificam os
encaminhamentos quanto ao CID (código internacional de doenças), se a solicitação
condiz com o solicitado. Fazem contato com o paciente que será agendado,
confirmando a necessidade e já orientando sobre levar o encaminhamento ou
solicitação de exame que está com ele até a unidade de saúde mais próxima para
receber o comprovante de marcação: filipeta. (agendador SMS A) A inserção da demanda por recursos e a atualização dos cadastros no Portal CROSS são realizadas pelas unidades da APS do Município A.O CDR é geralmente inserido pela recepção ou enfermagem das unidades, mas a atualização do cadastro é realizada apenas pelo 
sistema próprio do município, pois os ACS não possuem acesso ao CROSS. A falha na manutenção de CDR e de cadastros atualizados dificultam a comunicação e o gerenciamento pela central de vagas da SMS A, do AME Araçatuba e pelo DRS.

Neste sistema (próprio do Município A) todas as unidades básicas de saúde conseguem inserir as solicitações por especialidade, por data, elas conseguem colocar o nível de prioridade que o médico solicitou, ou seja, prioridade baixa, média, alta e elas conseguem também identificar para qual unidade esse paciente precisa ser encaminhado. Dependendo do tipo de diagnóstico que o médico pretende fechar, agendamos para o AME ou para o $\mathrm{NGA}^{24}$ que é o serviço de especialidades próprio também! (agendador SMS A)

O usuário é retirado da fila de demanda assim que agendado, e somente retorna para a demanda se a unidade de saúde o reinserir como prioridade. Neste caso, o responsável pela unidade de saúde deve justificar a reinserção à central de agendamentos.

A partir do momento que ele (usuário) foi agendado, ele é retirado da fila de espera, ele não consta mais, a menos que a enfermeira da unidade básica ligue e justifique. Os únicos que inserem paciente na fila são os funcionários da atenção básica. E esta justificativa tem que ser algo sério para que ela volte para fila. Ele é reinserido, porém com uma nova data. Ele passa por uma nova consulta... bom é pelo menos isso que a gente orienta!

Faltou por que? Ahhh estava passando mal, no pronto-socorro, apresentou atestado, tudo bem... Mas se faltou por outra razão, a gente baixa a prioridade! Porque o sistema grava o dia que foi inserido! E aí que entra nossa discussão da prioridade... (agendador da SMS A)

O agendamento da oferta de livre demanda em algumas unidades da APS não segue os mesmos critérios da central de agendamento e manejo da fila de espera. Havendo vagas disponíveis, algumas recepções da APS reagendam os usuários que faltaram, sem qualquer questionamento ou anotação sobre o motivo da falta. Outras unidades de saúde possuem critérios para agendar e os anotam em prontuário. Além disso, recolhem a assinatura do usuário como atestado de ciência. Essas condutas divergentes foram manifestadas em opiniões dos atores do serviço de saúde.

Se o paciente faltou e eu poder agendar, faço a marcação na hora! E se eu não tenho a cota ele volta para fila. Hoje, nós não temos nenhum relatório em prontuário que o paciente faltou! Hoje não fazemos isso aqui!

Quando é oftalmologia, por exemplo, já aconteceu de o paciente dizer que já foi no particular, mas não quer sair da fila, porque no ano que vem ele usa para renovar os óculos... Aí eu falo que eu não posso, daí ele disse que se conseguir no particular ele vem cancelar, mas nunca aconteceu! (recepção da unidade Tdo Município A)

Vamos falar com nossa enfermeira (anotação em prontuário sobre as faltas)! Ela já tornou obrigatório que seja anotado no prontuário qual receita foi refeita! (ACS T2 do Município A)

\footnotetext{
${ }^{24}$ O Núcleo de Gestão Assistencial (NGA) está sob gestão municipal e possui atendimento ambulatorial especializado no nível de atenção secundário.
} 
E tem aqueles que faltam e ainda dizem: ahhh, deixa eu volto pra fila e agendam de novo. Por isso que eu acho errado remarcar quem faltou! Porque quem precisa não falta! A não ser que tem um motivo ou justificativa! (ACS U1 do Município A)

Eles faltam mesmo, não avisam! Depois eles procuram para dizer que não foram e pede para reagendar! (ACS T5 do Município A)

Se ele disser que não vai ou faltar, a gente pega assinatura dele na filipeta com a data e horário tal, e que ele não quer mais (ACS M4 do município A).

O deslocamento dos usuários do Município A ocorre por meio do transporte urbano coletivo ou pelo próprio usuário. Existem problemas graves nesse aspecto, pois, além de não existir transporte gratuito para os serviços de saúde, há regiões que não possuem linhas, outras apresentam logística prejudicada, e a circulação de veículos inicia suas atividades apenas às 6h, o que coincide com o primeiro horário de atendimento do AME Araçatuba.

[...] não tem coletivo que vem direto para a unidade de saúde desse bairro! O paciente tem que ir até o centro e depois pra cá!

Os meus pacientes de chácara... não tem condições também, porque lá não tem ônibus! (ACS M1 do Município A)

O ônibus só começar a correr a partir das 6 h00 da manhã! Porque se ele não tiver carro ou alguém para levar ...ele não consegue chegar a tempo no AME. (ACS M2 do Município A)

O gestor de saúde municipal, e a agendadora da SMS A reconheceram as dificuldades relacionadas ao transporte coletivo, à parcela da população com dificuldade financeira e às situações de risco. Os grupos focais com as unidades de saúde da APS elencaram vários riscos e limitações do transporte municipal:

[...] estamos fazendo um levantando pontual... têm bairros que não tem o coletivo. Estas dificuldades de coletivo estão sendo trabalhadas agora e tem lugar que realmente não passa o coletivo. E aí é difícil essas pessoas saírem! A questão é que tem coletivo na cidade inteira, único problema são alguns lugares pontuais, que são condomínios novos, bairros novos, ... Agora tem algumas pessoas que ainda não temos o levantamento certo, mas acreditamos que são pessoas que não tem dinheiro para pegar o transporte coletivo. A prefeitura, tem um sistema de concessão de transporte coletivo, que fornece o passe para estas situações. até então, apenas os pacientes da saúde mental e pacientes idosos. E para pacientes com deficiência física e alguns casos de saúde mental! (gestor da SMS A)

[...] ônibus é muito alto, imagina o impacto para quem já tem problema nos joelhos, na coluna. (ACS T2 do Município A)

O transporte dos usuários demonstrou ser um fator preditivo importante no absenteísmo do Município A, pois, além das dificuldades de acesso - como não haver transporte gratuito disponível para locomoção local, risco de quedas, vários bairros sem linhas de coletivo -, a logística é prejudicada para a maioria dos bairros, chegando a demorar 1 hora e meia o transporte até o AME ou até a unidade de saúde de referência. 
Os cancelamentos de consultas e exames no Portal CROSS podem ser realizados apenas com 48 horas de antecedência, mas é muito difícil acontecer. Geralmente, o usuário busca o serviço de saúde já solicitando outro agendamento, por falta no agendamento anterior.

A gente pede e orienta, tanto para os pacientes quanto para atenção primária sobre as 48 horas sagradas para efetuar o cancelamento. Então qualquer dificuldade, avisem antes, mas os problemas que acontecem na véspera ou esquecimento, infelizmente isso ainda acontece. Quando o cancelamento informado em tempo hábil, a gente faz a troca $\operatorname{sim} .$. (agendador da SMS A)

É muito difícil cancelar, é raro, acontece muito deles quererem permanecer na fila porque vai que mais para a frente eles precisem! (recepção da Unidade Udo Município A)

Outra dificuldade apontada foi a falta de cobertura da ESF, pois os usuários "fora de área" saíam do controle da unidade. Eles constam da lista de usuários agendados e avisados, mas não comparecem à unidade para buscar a filipeta. Não é possível saber se eles foram em outras unidades de saúde ou se realmente faltaram.

Os usuários “fora da área” são aqueles que não têm o agente comunitário! E não tem
como ter controle... não sabemos se o paciente vai ou não, se teve interesse, se ainda
precisa, a gente também não pode trocar porquê e se esse ele já não foi até qualquer
outra unidade de saúde e imprimiu a filipeta. Por que, por exemplo, eu ligo para
alguém... Aviso que tem uma consulta tal data, tal hora, e se tem o encaminhamento
com ela... Eu explico: então vem e traz o encaminhamento aqui no postinho pra
gente colocar a filipeta! Mas ele não passou aqui, ele pode também ter ido em outro
posto... não dá pra saber se ele não quer mais a consulta ou se já está pronto com o
comprovante de marcação com paciente. Assim eu não posso passar essa consulta
para outro paciente, porque eu não posso ter certeza que ele não quer essa consulta.
Diferente dos pacientes de cobertura do PSF (programa da saúde da família) ...
(enfermeiro da Unidade Ido Município A)

Não, muito difícil alguém avisar! (ACS M1 do Município A)

Não ficamos sabendo, a não ser que a filipeta venha parar na nossa mão, aí a gente vai perguntar se ele interessa. Como demorou muito agendamento a consulta... ele assina, data e a gente coloca no prontuário dele! Mas é muito difícil a filipeta chegar para nós! (ACS M4do Município A)

Em 4 meses que trabalho aqui, hoje foi a primeira vez que me procuraram para cancelar! (recepção da Unidade Tdo Município A)

\subsubsection{3 reflexões sobre o absenteísmo no Município A}

Os quatro grupos focais com as Unidades de saúde I, M, U e T do Município A, e as entrevistas com a responsável pela central de agendamentos e o gestor da SMS A possibilitaram demonstrar os complexos processos de trabalho, a relação entre os profissionais da mesma equipe e entre as equipes envolvidas no processo de regulação do acesso a serviços de saúde. 
Em concordância com a indicação feita pelo gestor da SMS A sobre as unidades de saúde com experiência exitosa no controle do absenteísmo, as Unidades de Saúde I e M demonstraram elevado grau de comprometimento, autonomia profissional, boa articulação entre os membros da equipe e com os demais atores envolvidos. Apenas nesses grupos focais participaram os profissionais enfermeiros e médico, além dos ACS e recepcionistas.

A central de agendamento orienta, se estiver sem o encaminhamento, procure a enfermeira e avisa que você está sem a guia. $\mathrm{O}$ médico aproveita e reavalia se realmente precisa da consulta! Tem casos de agendamentos que são cancelados... Assim q a gente consegue a guia, a gente liga na central de agendamento e já é agendado na hora a consulta ou exame! (enfermeiro da Unidade I do Município A)

Eu fui entregar o agendamento de oftalmologia, hoje, do AME... A paciente procurou o encaminhamento, procurou, procurou e disse que não encontrava. Eu peguei a filipeta e voltei aqui no posto pra médica ver no prontuário, mas aí... Ela achou e eu já grampeei a filipeta no encaminhamento. E é assim que funciona! (ACS I5 do Município A)

Da forma que está organizado hoje, não sabemos nem dos retornos e nem dos agendamentos!!!! (médico da família da Unidade M do Município A)

As Unidades de Saúde U e T foram indicadas como representantes dos casos com dificuldade no controle de absenteísmo. Foi possível comparar as características dessas duas unidades de saúde com as unidades exitosas, quanto à maior extensão da área de abrangência, superior número de famílias e de equipes por unidades. Nessas duas unidades, os enfermeiros responsáveis estavam cientes e presentes na unidade, mas não puderam participar dos grupos focais, os quais contaram apenas com os ACS e os representantes das recepções.

Nossa área é muito extensa! Estamos trabalhando sobrecarregados, são 19 bairros! Onde deveriam ser 24.000 são 47.870 na última contagem! Hoje eu sirvo apenas para entrar no quintal do meu paciente para revirar lixo! Eu falo para as meninas que são novas e eu fui ensinando o que eu sabia! (ACS U1 do Município A)

Na dinâmica do grupo focal da Unidade U, surgiram falas que traduziram conflitos e dificuldades no relacionamento entre os membros da equipe de saúde, sentimentos de desmotivação e angústia pelo grupo de ACS. Essa situação afeta diretamente os índices de absenteísmo, pois foram identificados vários problemas: a alienação sobre o cuidado; a concepção equivocada sobre o vínculo e o trabalho do ACS; além do desestímulo profissional.

Você sabe que a gente é essencial no trabalho com as famílias, mas a gente não se sente assim! Muitas vezes a gente sente um "lixo". A gente serve apenas para ver os quintais, verificar o lixo das famílias, somos comparados com gari! Desculpa, mas você está vendo aqui um desabafo, um pedido de ajuda! (ACS U1 do Município A)

A cobrança aqui é em relação ao quintal! (ACS U4 do Município A) 
[...] nós estamos desmotivadas! Já ouvimos que não podemos ter vínculo com paciente! Se perdermos um paciente, não podemos nem ir ao velório! Somos proibidos! (ACS U8 do Município A)

[...] vou ver quintal... enquanto ele está com câncer, ou não anda..., por que o papel dele está lá para ser agendado num lugar que diz que liga... mas não liga! (ACS U1 do Município A)

Foram evidenciadas diferentes configurações de interação entre os trabalhadores nas quatro unidades de saúde e entre os serviços. A relação de trabalho e comunicação das Unidades I, M e T com a central de agendamento demonstrou ser satisfatória, mas foram identificadas algumas dificuldades com a Unidade $U$, principalmente na comunicação da central com os usuários agendados. Apesar disso, foi comum nos quatro grupos a percepção de não corresponsabilidade e participação no processo organizacional da saúde do Município A.

Olha que interessante, o setor de agendamento da secretaria não consegue falar com a gente, mas o AME consegue! Vem mensagens, eles ligam para nós pedindo ajuda para avisar os pacientes! (ACS U6 do Município A)

A secretaria municipal tem uma central de vagas, e a gente somente insere os pacientes nesse sistema de especialidades, então quem organiza a fila é essa central... (enfermeiro da Unidade M do Município A)

[..] eu comentei com a recepção, agora o número de filipeta se diminuiu, são poucos os avisos de agendamento que a gente tem que entregar. Mas a gente está perdendo controle nessa parte, a gente nem fica sabendo dos agendamentos realizados dos nossos pacientes (ACS I3 do Município A)

[...] agora gente não sabe mais, quem passou pelo doutor e o que ele pediu. Às vezes o médico pergunta a respeito de fulano, se o paciente não fala pra nós... a gente não sabe! (ACS M7 do Município A)

Foram observados, também, diferentes tipos de atuação e arranjos organizacionais entre as equipes em relação a alguns problemas semelhantes. Na Unidade $\mathrm{M}$, o médico sobrecarregava a agenda para reavaliar o usuário e realizar um novo encaminhamento ou pedido de exame quando necessário. Já no relato da ACS da Unidade U, o usuário aguardava consulta por dois a três meses. A Unidade I foi a única que realizou ações para evitar o absenteísmo, como a impressão de filipeta das famílias que ainda não procuraram a unidade, a organização da entrega por microárea por meio do ACS e a realização de arquivo em prontuário dos documentos entregues ao usuário.

[...] tem que ter um pouco de flexibilidade nesses casos (perda de encaminhamento), quando acontece eu atendo antes. Nós sobrecarregamos agenda de atendimento para poder atender esse paciente. (médico da família M do Município A)

E necessito agendar outra consulta para conseguir um encaminhamento... Quem está doente, está doente hoje, não daqui dois meses ou três meses! (ACS U1 do Município A) 
[...] já imprimi a filipeta para o mês que vem, e não costumo entregar muito antes, porque se eu entregar meses antes eles podem esquecer ou perder o encaminhamento... (ACS I5 do Município A)

Todos os encaminhamentos que entregamos a gente registra e o paciente assina! Para não dizer que não recebeu! (ACS I4 do Município A).

Foi comum às 4 equipes de saúde relatos de angústia sobre a dificuldade de acesso, as longas filas de espera e concepções subjetivas a respeito de desfavorecimento do Município A em relação aos municípios menores da região quanto à oferta de serviços do AME Araçatuba. Todos os atores envolvidos no estudo eram cientes a respeito das altas taxas de absenteísmo no Município A, mas desconheciam os valores numéricos por especialidade.

Às vezes dá impressão que o AME é só das cidadezinhas daqui de perto... Ahhhh... vamos supor, você chegar lá na porta do AME, tem Van de num sei onde, outra de outra cidade... aí eu fico me perguntando, pois como demora muito tempo para agendar a população que é daqui de Araçatuba, parece que o AME atende mais as cidades menores! (ACS U3 do Município A)

Eu tenho paciente que deu endereço de outra cidade daqui do lado e fez a cirurgia mais rápido! (ACS I5 do Município A)

A gente vê que as cidades pequenas, parece que tem preferência no AME! Eles têm mais cotas! Não tem quase paciente daqui no AME, isso é um erro grave! Nós estamos necessitando de médicos... necessitando de atendimento...

(ACS U2 do Município A)

O gestor da SMS A tem realizado, desde o início de sua gestão, reuniões com a APS, e identificou algumas dificuldades. Ele e o agendador da SMS A expuseram a necessidade de rever os fluxos de agendamento e descreveram algumas estratégias.

[...] eu estou tendo reuniões com os ACS, com cada unidade de saúde, para ouvir um pouco e eles relatam que esta medida foi muito boa. [...] estou programando duas reuniões por semana para ouvir os agentes comunitários de saúde as equipes, as angústias e necessidades! (gestor da SMS A)

[...] talvez comecemos com um piloto, não sei... Disseram que os pacientes perdem os encaminhamentos, então uma de nossas propostas será de rever dos encaminhamentos ficarem nas unidades básicas. (gestor da SMS A)

[...] se o encaminhamento ficar nas unidades básicas de saúde, dá para fazer um trabalho muito melhor, modificar toda a logística. A gente agenda e eles separam os encaminhamentos por agente comunitário e o ACS vai entregar! Muda muito! (agendador da SMS A)

\subsubsection{Município B}

A SMS B possui população estimada de 2.812 habitantes (IBGE 2017), com índice de desenvolvimento humano municipal de 0,710 em 2010. A SMS B possui dois 
estabelecimentos de saúde do SUS: Centro de Especialidades e Unidade de Saúde da Família. A economia local baseia-se principalmente na agricultura, com os cultivos de cana-de-açúcar, soja, milho, pimentão e tomate, e pecuárias de leite e de corte. A cidade possui 5 aglomerados de famílias rurais assentadas: Assentamento Salvador, Área de Reserva do Assentamento Salvador, Assentamento São José, Olaria São Sebastião e Acampamento.

Os dados do Município B foram coletados do banco de dados do Portal CROSS; impressos internos; Plano Municipal de Saúde; entrevista com o gestor, e grupos focais com a equipe de saúde da APS e responsáveis do agendamento e transporte. A seguir são descritos os dados desta coleta.

\subsubsection{1 entrevista com o gestor do Município B}

A entrevista com o gestor (SMS B) ocorreu na Secretaria Municipal de Saúde (SMS), no período da manhã, com duração de 45 minutos. O gestor relatou que o profissional responsável pelo agendamento poderia informar com mais detalhes sobre essa tarefa. No entanto, reconheceu as dificuldades que o Município B tem em aproveitar as ofertas colocadas à disposição pelo AME Araçatuba. No decorrer da entrevista, foram descritas as ações realizadas pelo setor de agendamento junto às USF: modificações na forma de comunicação ao usuário sobre o agendamento e o arquivo de documentos no prontuário em caso de faltas e desistências.

Sobre a organização da atenção primária, o gestor descreveu a cobertura pela ESF, caracterizou as 3 microrregiões atendidas, explicou as especificidades dos assentamentos e como funciona o transporte dos usuários até o AME Araçatuba. Ele fez algumas reflexões sobre os possíveis motivos do absenteísmo no Município $\mathrm{B}$, e acrescentou que grande quantidade de consultas, exames e algumas cirurgias eram compradas pela Prefeitura Municipal, principalmente nos consórcios.

$\mathrm{Na}$ ocasião, foram solicitados os documentos utilizados pelo serviço na organização interna e o Plano de Saúde Municipal, os quais foram prontamente disponibilizados. Ao final da entrevista, foi solicitada ao gestor a participação dos demais profissionais de saúde no grupo focal. O gestor explicou que não seria possível fazer com todos juntos. A equipe ESF estava na sala de reuniões já aguardando, mas o agendador e a responsável pelo transporte 
estavam em outro local ${ }^{25}$ e não poderiam participar. Portanto, foram realizados dois grupos focais no Município B.

4.2.3.2 descrição do grupo focal com as ACS e a enfermeiro da Atenção Primária do Município B

O gestor apresentou as 3 ACS e o enfermeiro da unidade. O gestor e o enfermeiro saíram da sala e foi iniciada a apresentação dos objetivos e a justificativa do estudo. Foi introduzida a discussão por meio dos temas disparadores. $\mathrm{O}$ grupo focal teve duração de 45 minutos (Anexo C).

As ACS explicaram que os agendamentos de consultas e exames eram realizados no Centro de Especialidades, pelo agendador, e o transporte já vinha organizado também. Elas falaram sobre as especificidades de cada microrregião, em especial sobre os assentamentos e a região central da cidade, os quais possuem necessidades de saúde diferentes.

Decorridos 10 minutos do grupo focal, o enfermeiro retornou à sala, mas não se sentou à mesa. Permaneceu em uma cadeira perto da porta. Ele interrompeu o trabalho do grupo focal, questionando os objetivos do trabalho, perguntando sobre os termos de consentimento, se o estudo havia sido aprovado pelo Comitê de Ética, provocando tumulto no trabalho do grupo.

Apesar dessas interrupções, o grupo se recompôs e voltou a discutir intensamente sobre o tema proposto. As ACS continuaram a contar sobre as reuniões realizadas junto ao agendador. Relatam algumas ações adotadas em relação ao registro das faltas ou desistências documentadas no prontuário familiar e providências tomadas.

Houve reflexões acerca dos motivos que levam os usuários a faltar ou cancelar atendimento, relacionados ao longo tempo de espera, à procura por outros serviços pela própria prefeitura - ou no setor privado por parte do usuário -, além da intolerância dos usuários em aguardar os períodos de transporte oferecidos pela Prefeitura.

Relataram que todos os avisos e orientações necessárias aos usuários eram realizados por elas e, quando identificada uma desistência ou cancelamento, as mesmas procuravam o setor de agendamento para a troca pelo próximo usuário na fila de espera. Descreveram que

\footnotetext{
${ }^{25} \mathrm{O}$ setor de agendamento está instalado no Centro de Especialidades, ou seja, em outro espaço físico separado da secretaria de saúde e USF.
} 
os agendamentos chegavam no tempo hábil, possibilitando seu trabalho na comunicação aos usuários.

Durante a dinâmica do grupo focal, foi possível identificar interesse em discutir as estratégias para reduzir o absenteísmo e promover boa interação entre as ACS com o setor de agendamento e de transporte.

O profissional enfermeiro não aceitou os convites de se juntar ao grupo e, no final do grupo focal, relatou que não havia necessidade de assinar do TCLE, pois não havia contribuído para a discussão.

\subsubsection{3 descrição do grupo focal com o setor de agendamento e transporte do Município B}

O grupo focal aconteceu na sala de agendamento do Centro de Especialidades, com participação do agendador e da responsável pelo transporte do Município B, e teve duração de 55 minutos. A pesquisadora apresentou os objetivos e a justificativa do estudo, e foi introduzida a discussão por meio dos temas disparadores (Anexo F).

Os participantes explicaram todo o fluxo em detalhes, demonstraram as mudanças antes citadas pelo gestor e pelas ACS sobre o registro das faltas e desistência no prontuário do usuário, além da comunicação de agendamento e transporte. Foi possível verificar ações e fluxos estabelecidos por meio das pastas de demanda reprimida de consultas e exames, planilhas e agenda de transportes.

Foi possível notar a influência política do prefeito nas condutas referentes à saúde. Durante o grupo focal, uma usuária interrompeu as atividades para solicitar aos entrevistados informações sobre o agendamento em oftalmologia, o qual, segundo ela, foi agendado pelo prefeito. Esta informação não constava nos registros oficiais da Secretaria.

O grupo refletiu sobre uma possível falta de compromisso dos usuários em relação aos agendamentos realizados, principalmente no AME Araçatuba, pois eles não demonstravam disposição em aguardar os horários de transporte disponibilizados pela prefeitura.

\subsubsection{4 caracterização dos serviços de saúde: Município B}

O Município B utiliza exclusivamente o sistema CROSS, na gestão das ofertas do AME Araçatuba e de sua demanda por recurso. Possui uma equipe de ESF e um Centro de Especialidades, com cardiologista, ginecologista, cirurgião geral e pediatra. O setor de 
agendamento funciona em período integral, com um funcionário responsável pelos agendamentos e outro pelo serviço de transporte municipal. Os agendamentos para o AME Araçatuba são realizados pelo Portal CROSS conforme as vagas disponíveis no DRS II Araçatuba. Muitos outros serviços são comprados pela Prefeitura no consórcio intermunicipal.

Esse Município apresenta uma demanda reprimida com características diferentes dos demais municípios, ou seja, ele possui muitos exames de média e alta complexidade, como ultrassonografias, cateterismos, ressonâncias magnéticas, tomografias solicitadas pelos especialistas que atendem no centro médico do município. Toda essa demanda reprimida estava sob controle e gestão do próprio Município B.

O serviço de APS do Município B garante cobertura de 100\% das zonas urbanas e rurais, incluindo os 5 aglomerados de assentamentos. Estes formam uma área extensa, que possui 2 agentes comunitárias trabalhando junto a 240 famílias da área rural.

[...] são duas agentes de saúde, uma faz uma parte e a outra faz a outra área (assentamentos). Elas vão de carro, de moto... são cerca de 120 famílias cada uma... (gestor SMS B)

Conforme a Tabela 4.7, é possível verificar que o Município B agenda toda a oferta disponibilizada e aproveita as vagas disponibilizadas no bolsão ${ }^{26}$. Entretanto, manteve as taxas de absenteísmo acima de $15 \%$ por quase todo o período da amostragem. Os profissionais responsáveis pelo fluxo de atendimento se esforçam nas atividades de agendamento e organização do transporte, mas não conseguem bons resultados.

\footnotetext{
${ }^{26}$ Período de 7 dias, no qual a oferta de consultas e exames do Portal CROSS ficam disponíveis para todos os usuários do sistema, ou seja, independente da oferta recebida, com 1 semana de sua ocorrência, a vaga é automaticamente disponibilizada para agendamento.
} 
Tabela 4.7 - Oferta e agendamentos/mês de consultas em especialistas do município B, nos meses de novembro de cada ano no período de 2010 a 2017

\begin{tabular}{|c|c|c|c|c|c|c|c|c|c|c|}
\hline \multirow[b]{2}{*}{ Solicitante } & \multirow[b]{2}{*}{ Período } & \multirow[b]{2}{*}{ Oferta $^{1}$} & \multicolumn{3}{|c|}{ Agendamentos } & \multicolumn{5}{|c|}{ Recepção } \\
\hline & & & Total $^{2}$ & $\operatorname{Cota}^{3}$ & Bolsão $^{4}$ & Pre $^{5}$ & Aus $^{6}$ & $\mathrm{Dis}^{7}$ & Alta $^{8}$ & Abs $\%^{9}$ \\
\hline \multirow{8}{*}{ Município B } & nov/10 & 14 & 12 & 11 & 1 & 8 & 4 & - & - & 33,33 \\
\hline & nov/11 & 29 & 38 & 24 & 14 & 29 & 9 & - & - & 23,68 \\
\hline & nov/12 & 22 & 34 & 16 & 18 & 25 & 9 & - & 1 & 26,47 \\
\hline & nov/13 & 24 & 25 & 20 & 5 & 22 & 3 & - & 2 & 12,00 \\
\hline & nov/14 & 13 & 16 & 11 & 5 & 16 & & - & 5 & 0,00 \\
\hline & nov/15 & 15 & 28 & 15 & 13 & 23 & 5 & - & 6 & 17,86 \\
\hline & nov/16 & 17 & 17 & 17 & - & 12 & 4 & 1 & 5 & 23,53 \\
\hline & nov/17 & 18 & 19 & 17 & 2 & 14 & 5 & - & 4 & 26,32 \\
\hline
\end{tabular}

Fonte: São Paulo ([2010)].

1. Oferta

2. Total de agendamentos

3. Cotas agendadas

4. Bolsão vagas agendadas

5. Presente na consulta

6. Ausente na consulta

7. Dispensado da consulta

8. Alta

9. Absenteísmo em \%

\subsubsection{1 organização e fluxos de agendamento das consultas e exames do Município B}

A organização dos atendimentos e agendamentos foi descrita pela equipe de ACS e setores de agendamento e transporte. Segundo esses atores, após o atendimento com o clínico ou com especialistas, todos os encaminhamentos e solicitações de exames são enviados para o setor de agendamento. Esta documentação é conferida pelo setor de agendamento, quando já é verificado se há vaga disponível no Portal ou se o usuário deve ser inserido no CDR.

Depois que o paciente passar por consulta médica ou trazer o encaminhamento de outro atendimento, esse pedido encaminhado para a secretaria para o setor de agendamento. (ACS B1 do município B)

Bom... o agendamento então é realizado pelo pessoal lá de baixo, do agendamento, e a questão do transporte... é disponibilizado para todos a ambulância. (ACS B2 do município B)

[...] a gente tenta ver no sistema se tem ou não a vaga. A gente separa conforme nossa cota, tiramos a lista de tudo que nós temos no CROSS e vamos agendando conforme dá... conferindo os pedidos se tem carimbo e assinatura. (agendador do município B)

O setor de agendamento realiza um fluxo sem critérios pré-estabelecidos para a priorização das consultas e exames. Os agendamentos são priorizados conforme a indicação dos médicos, dos ACS e até mesmo dos usuários. 
[...] a doutora faz o encaminhamento, a unidade de saúde desce para nós aqui no centro de especialidade o encaminhamento. Quando a doutora tem agendamento com prioridades ou às vezes ela liga e pede um exame ou pergunta se tem uma vaga. (agendador B)

Aqueles que precisam de maior atenção, quando o médico solicita, quando o próprio paciente ou até mesmo os próprios agentes de saúde... O setor de agendamento é bem acessível. (ACS B1 do município B)

Os responsáveis pelo setor de agendamento e do transporte trabalham na mesma sala. A organização do transporte é realizada assim que agendada a consulta ou o exame. A fim de melhorar as informações ao usuário, foi implantado o uso de etiqueta com dados sobre horário e local de saída da ambulância.

Nosso agendador... ele destaca sempre com um bilhete: "não falte", com orientação
de não faltar, de avisar com dois dias antes se for faltar. Apesar que o próprio AME
na filipeta já avisa. Mas ele reforça isso aí. E as agentes comunitárias que entregam
os pedidos, vão entregando e reforça de novo se caso não for... avisar com 2 dias de
antecedência para poder ser colocada outra pessoa no lugar. (gestor do município B)
Nós criamos uma etiqueta... agora todos os agendamentos já saem com a etiqueta,
com horário de ambulância... tem dado certo! A gente não teve mais reclamação de
paciente, ele já recebe o agendamento com horário que o transporte vai sair.
(agendador do município B)

Os documentos do agendamento são grampeados e enviados à equipe de USF. Já na unidade de saúde, eles são separados por microárea e entregues aos ACS de referência. Desta forma, cada ACS se responsabiliza pela comunicação do agendamento, a explicação e entrega dos medicamentos para o preparo de exames.

[...] é por microárea, cada ACS (agente comunitário de saúde) tem uma área para trabalhar. Por exemplo, saiu a consulta do Sr. José, então a agente de saúde sabe se é da região dela ou não é. Aquela agente de saúde pega a consulta ou o exame e saí para entregar. (gestor do município B)

\subsubsection{2 organização da fila, comunicação aos usuários, transporte, cancelamento de consultas e exames no município B}

A comunicação e entrega dos documentos de agendamento ocorre geralmente em tempo hábil para o usuário conseguir se planejar. Em alguns casos acontece de o prazo ser mais curto, como nas situações em que o AME Araçatuba não consegue contato com o usuário para avisar sobre os retornos; nas situações de exames, como tomografias e cateterismos, que necessitam de autorização prévia do laudo no DRS II Araçatuba.

As ACS levam os pedidos, eu peço que elas orientem a respeito do preparo e os documentos necessários. (agendador SMS B) 
A não ser agendamentos de retorno dentro do AME, que eles não estão conseguindo contato e pedem para que nós avisemos os pacientes nas suas casas. E exames como tomografia, que vão para o DRS para autorizar e chegam em cima da hora também! (ACS B1 do município B)

O gestor da SMS B, a equipe da ESF, o responsável pelo agendamento e pelo transporte estão cientes do alto índice de faltas do Município B. As ACS também monitoram a presença dos usuários no serviço durante as visitas domiciliares. As microáreas possuem características diferentes entre a população urbana e rural. A população da área urbana tem perfil mais adulto jovem, a maior parte trabalha e possui plano de saúde ou utiliza serviços particulares.

[.... nas visitas domiciliares a gente pergunta: você foi na consulta? A minha área é urbana... é uma população mais adulta jovem e trabalham... Alguns vão em médicos particulares! Outros tem convênio da usina! (ACS B1 do município B)

$\mathrm{Na}$ minha (região rural, em especial os assentamentos) eles aderem sim, quando está chovendo eu ligo e já deixo avisado, eles vêm buscar ou a gente já deixa tudo acertado com ambulância. Deixo tudo organizado. Quase não tem falta deles, quando pergunto... como são pessoas que geralmente trabalho na roça, e não vão muito no médico, quando eles têm algum agendamento é algo muito importante para eles. (ACS B2 do município B)

Todas as orientações de exames e preparos são realizadas pelos ACS durante a visita domiciliar. As ACS descreveram a orientação de preparo, a entrega de medicamentos necessários, as dificuldades enfrentadas e as estratégias utilizadas. Porém, alguns usuários procuram o centro médico para confirmar todas as informações com o médico.

Não, a gente não tem dificuldades, porque aqui até fornece o medicamento, a gente leva junto com a guia os medicamentos, explica como tomar certinho! Muito raro ter que comprar algum medicamento! (ACS B1 do Município B)

Temos dificuldade com os mais idosos... que moram sozinhos... às vezes tem que desenhar, colocar um sol para de manhã, garfo e faca na hora do almoço e uma lua à noite! A gente acaba tendo essa didática! (Risos). Chamamos um parente ou um vizinho... alguém que possa ajudar! (ACS B1 e ACS B2 da SMS B, Município B)

Acontece de algumas vezes a gente explicar e o paciente ter dificuldade de entender e algumas vezes até não confia no agente de saúde e quer passar em consulta médica para pegar a orientação sobre o preparo. Conseguem, às vezes, falar com o médico no corredor... vai perguntando por ali mesmo, assim o médico tem que repetir tudo que já está na filipeta... é a figura do médico sei lá... (agendador B do município B)

A fila de demanda por recursos de saúde também é organizada com auxílio do Portal CROSS. Os encaminhamentos e pedidos de exames são guardados no setor de agendamento em pastas, por ordem cronológica, salvo as prioridades já descritas na organização dos agendamentos. 
E aí a gente divide o que é exame e o que é consultas em cada pasta que está aqui. É uma fila! E conforme a possibilidade... o agendamento é realizado (agendador B do Município B)

Esse pedido é colocado na fila espera. Nessa fila é colocado na ordem de data! (ACS B1 do Município B)

Caso o usuário desista ou falte no agendamento realizado, o motivo é registrado e assinado pelo usuário na filipeta com o encaminhamento para arquivo em prontuário. Anteriormente, os munícipes faltavam e utilizavam aquele mesmo pedido ou encaminhamento para novos agendamentos, sem demonstração de preocupação ou consciência sobre desperdício de vaga e recurso público.

O pessoal faltava... depois devolvia e pedia para remarcar... daí ia de volta para a fila, e assim ficava muito cômodo!

Melhorou muito depois que começamos a pegar a assinatura do paciente e colocar no prontuário dele e dizer que não iríamos remarcar mais! Por que aqui tem um costume disso! Já fazem uns dois anos! Eles iam quando queriam, agora não, a gente colhe a assinatura, pois ele não vai mais ser agendado com aquela guia! (ACS B1 da SMS B)

Toda informação vai para o prontuário do paciente, por que se ele questionar alguma coisa sobre exames e aí o médico vê... já fala, você foi agendado e não foi. Estando no prontuário o médico já sabe que ele faltou!(gestor SMS B)

[...] colocando no prontuário do paciente, o médico também sabe o que aconteceu e os agendamentos perdidos! (agendador SMS B)

Esta ação de documentar e arquivar em prontuário realizada pela equipe de saúde resultou em impacto positivo, evidenciado pelos entrevistados. Porém, os casos de absenteísmo justificados por motivos relevantes, são recolocados na fila de prioridade, ainda que também anotado em prontuário.

Salvo o exame de ultrassom vaginal, que as vezes a gente entrega, mas a mulher menstrua e não tem como fazer. Ou qualquer outra falta que tenha uma justificativa importante. (ACS B3 da SMS B)

O transporte disponibilizado aos usuários do Município B é agendado na sequência da consulta ou exame. Diariamente, um carro faz o transporte de usuário no período da manhã, com saída às $6 \mathrm{~h}$ e retorno às $10 \mathrm{~h}$ para que às $12 \mathrm{~h} 30$ aconteça o segundo turno com retorno no final da tarde, após os atendimentos de todos os usuários. Os profissionais de saúde explicaram sobre os horários e as dificuldades identificadas pelos usuários.

Com o transporte, graças a Deus, não temos nenhum problema. A gente tem uma ambulância que sai às 6:00 da manhã e outra que sai 12:30. A gente faz 2 turnos. (gestor de saúde da SMS B)

[...] não é sempre que os pacientes ocupam o transporte público. Muitos deles vão de carro próprio. Porque a ambulância sai às $6 \mathrm{~h}$ da manhã e muitos não querem ficar esperando. Esta ambulância volta lá pelas $11 \mathrm{~h}$ ou $12 \mathrm{~h}$ para levar os pacientes do 
período da tarde. Tem pacientes que são do período da tarde, por exemplo uma consulta $15 \mathrm{~h} 30$, mas ele tem que sair na ambulância $12 \mathrm{~h} 30$ !

Às vezes acontece de ser um agendamento às $12 \mathrm{~h} 00 . . . \mathrm{e}$ o carro da tarde não chega a tempo, ele tem que sair 6h da manhã daqui! E como é troca dos carros, ele volta só no retorno das ambulâncias às 17 - $18 \mathrm{~h}$ da tarde! Então isso também é uma dificuldade para os pacientes! (ACS B3 da SMS B)

Quando há alguma condição especial, o setor de transporte organiza um carro para atender a necessidade do usuário. Como o município é pequeno, os setores de agendamento e transporte conseguem avaliar as especificidades de cada caso, com auxílio de outros profissionais.

[...] quando é um paciente que a gente vê que tem dificuldade, quando o paciente é acamado ou que tem alguma necessidade especial, eles disponibilizam um carro ou ambulância para este paciente.

[...] avaliam os pacientes e aquele que necessita de acompanhante ou de um carro específico para ele... organizam um veículo só para ele!

(ACS B2 da SMS B)

[...] a gente pede para o próprio paciente falar com pessoal da secretaria sobre transporte. (ACS B3 da SMS B)

Em situações específicas, o motorista busca o usuário na residência ou sítio para conduzi-lo até o local de saída do transporte. As orientações são fixadas em um quadro com identificação do usuário, local, horário e cuidados específicos necessários.

[...] o transporte sai do centro de especialidades. Se o paciente precisar..., ele (motorista) que vai buscar o paciente no sítio, traz ele até o centro de especialidades, de onde sai o transporte com todos os pacientes. Já fica no quadro para os motoristas: buscar os pacientes tal, em tal horário, e todos os cuidados que tem que ter! (ACS B2 da SMS B)

Os cancelamentos ou desistência do recurso de saúde são identificados no momento da comunicação do agendamento. Algumas justificativas são comuns, como já realizado na rede particular ou convênio, já ter realizado em outro local agendado pela prefeitura, ter demorado muito e não necessitar mais, não ter conseguido dispensa no trabalho, não querer esperar o transporte municipal, entre outros.

Quando eles falam que já fizeram, ou que demorou muito e melhorou, se for falado na hora que a gente escreve que não querem e a gente já traz de volta com justificativa e assinado. $\mathrm{O}$ agendamento coloca outra pessoa no lugar. Mas se esse paciente, pegou o agendamento e ficou com ele e não avisou a equipe, a gente não sabe se ele foi ou não. (ACS B2 da SMS B)

[...] ninguém mais quer esperar! Ou ele falta e depois vem de novo pedindo para agendar novamente! (responsável do transporte SMS B)

Os funcionários dos setores de agendamento e transporte complementaram que, quando os usuários dizem não querer ir, havia possibilidade de reagendamento em alguns casos. Porém, a maioria procurava o serviço depois de ter faltado ou fora do prazo de 48 horas para 
realizar a troca. Esses atores descreveram seu esforço em realizar os agendamentos, planejar o transporte adequado, mas o número de faltas era desanimador.

Ontem nós estávamos falando sobre isso, pois a gente entrega o agendamento na mão das agentes de saúde, com a ambulância já agendada! Isso acontece muito com a mamografia, que nós conseguimos no bolsão, e tem aquelas mulheres que precisam fazer para acompanhamento ou rastreamento. Então, já aconteceu de agendarmos 12 - 14 mulheres, ... A gente organizar o carro, arruma a condução pra levar, e a gente até pensa numa ambulância normal não dá, então planejamos o melhor carro... E aí o motorista volta e a gente pergunta, deu certo? O motorista diz: Deu! Foram 3 pacientes de 12 agendadas! (responsável pelo transporte da SMS B)

\subsubsection{3 reflexões sobre o absenteísmo no Município B}

O gestor da SMS B foi o único ator deste estudo com conhecimento do valor médio da taxa de absenteísmo em seu município. Relatou que, mesmo com os desperdícios em saúde, a prefeitura utilizava muito recurso financeiro para atender as lacunas assistenciais existentes na região. O Plano Municipal apresentado pelo gestor SMS B, foi o da gestão anterior, pois o da gestão em curso estava em fase de elaboração. Esse gestor reconheceu que não há ações ou indicadores que contemplem esta problemática da saúde.

Ahh, a gente tem muita perda (consultas e exames), por mais que a gente avise, tem gente que vem entregar a guia depois que o exame já passou!

Tem sido de $25-30 \%$, pelo menos foi da última vez que eu vi. É alto sim, pelo tamanho do município.

E inclusive esse negócio de falta é complicado, por que até os exames que são caríssimos, a gente paga no consórcio, mesmo se faltar o médico quer receber, num tem essa! Muito das consultas e exames são recursos próprios. E a gente gasta muito! Por que se fosse trabalhar pelo SUS, não dava, é muito pouca a oferta. $\mathrm{O}$ AME devolveu todas as cirurgias, a gente está fazendo tudo pago... (gestor SMS B)

O gestor também reconheceu falhas no atendimento e fez algumas reflexões sobre o assunto. Relatou que há dificuldade em diminuir a taxa de absenteísmo, atribuindo parte dessa dificuldade à intolerância e impaciência dos usuários em aguardar. Explicou que a Prefeitura oferece transporte em dois turnos, mas os usuários não querem esperar, principalmente porque o AME inicia o atendimento às $6 \mathrm{~h}$ e termina às $18 \mathrm{~h}$. Diferentes disso, os consórcios atendem em apenas dois horários: às $7 \mathrm{~h}$ e às $13 \mathrm{~h}$; os usuários são atendidos por ordem de chegada e ficam menos tempo aguardando.

[...] eles querem que eu arrume uma ambulância para levar ele no horário da consulta. Aí eles falam: vou falar com o prefeito! Eu não tenho condições de fazer isso... se eu fizer isso eu abro brecha para a população toda...

Eles (usuários) têm muita regalia! O prefeito trabalhou na saúde por 14 anos, então o pessoal já pegou esse jeito. (gestor SMS B)

E a gente gasta muito! No consórcio é um pouco diferente, por que eles trabalham até as 14:00. Os pacientes preferem, num tem tanta espera. Então eles marcam tudo 
às 7:00 ou às 13:00. Não é igual ao AME que agenda às 10:00, 10:30 ... tem gente agendado até 18:00. No consórcio não, ou é todo mundo $7 \mathrm{~h}$ ou $14 \mathrm{~h}$, tem menos falta. Creio que esse número de falta grande é devido isso aí.

[...] pelo prefeito ter trabalhado na saúde, ele zela muito por esse lado. Ele não deixa ninguém sem fazer cirurgia, sem fazer um exame, seja o valor que for! Ele fala: eu posso ir preso, mas por causa da saúde, por que eu não roubo nada, mas ali eu não deixo ninguém na mão. (gestor SMS B)

Esses índices de não atendimento nos serviços de saúde são agravados pelas intervenções políticas prevalentes na administração municipal. Foram evidenciados vários gastos da SMS B na compra de consultas, exames e cirurgias, e o esforço da equipe de saúde em atender as necessidades da população. Porém, alguns munícipes procuravam a prefeitura e acabavam sendo atendidos fora da ordem de espera. Essa facilidade, ou acesso direto à prefeitura, tem gerado inequidade ao acesso, pois uma parcela da população consegue agendamentos ou antecipações, os quais muitas vezes o setor da saúde desconhece.

\subsubsection{Município C}

A SMS C possui população estimada de 8.254 habitantes (IBGE 2017), com índice de desenvolvimento humano municipal em 2010 de 0,725. A SMS C possui um hospital filantrópico e um estabelecimento de saúde do SUS - um Centro de Saúde no qual trabalham duas equipes de ESF. A economia do município é predominantemente agrária. Possui uma usina de açúcar e álcool que produz empregos diretos e indiretos para a microrregião.

O Centro de Saúde do Município C é uma unidade mista na qual funciona a central de agendamento, o serviço de transporte, a UBS, as 2 equipes de ESF, a farmácia e a Secretaria Municipal de Saúde.

Os dados do Município C foram coletados do banco de dados do Portal CROSS, impressos internos; plano municipal de saúde; entrevista com o gestor e grupo focal com as equipes de saúde da ESF, além de agendadores e responsável pelo transporte. A seguir serão descritos os dados dessa coleta.

\subsubsection{1 entrevista com o gestor do Município C}

A entrevista semiestruturada com o gestor municipal ocorreu na Secretaria de Saúde (SMS) do Município C, no período da tarde, com duração de 55 minutos. O gestor relatou que permanece neste cargo há já três mandatos. Contou em detalhes sua participação nas reuniões 
de criação do AME Araçatuba. Informou em detalhes os processos envolvidos no agendamento, comunicação aos usuários por meio das ESF, transporte e características de cada região do Município. Explicou sobre as regiões que não possuem cobertura de ESF e sobre áreas problemáticas; os planejamentos de ampliação da APS e a localização estratégica d e uma futura unidade de saúde. Descreveu como os setores de agendamento e transporte se organizam junto às USF.

$\mathrm{Na}$ ocasião, foram solicitados os documentos utilizados pelo serviço na organização interna e o Plano de Saúde Municipal, os quais foram disponibilizados para a pesquisadora. Ao final da entrevista, foi solicitado ao gestor a participação dos demais profissionais de saúde no grupo focal. O mesmo acompanhou a pesquisadora até a sala dos ACS, na qual já se encontroavam os profissionais que iriam participar da dinâmica.

4.2.4.2 descrição do grupo focal com a equipe da Unidade de Saúde, setor de agendamento e responsável pelo transporte da SMS C

O grupo focal, com duração de 95 minutos, foi organizado pelo gestor municipal na sala de reuniões dos ACS, na qual estavam reunidos em roda os representantes da USF: o enfermeiro, os ACS, os agendadores e o responsável pelo transporte, totalizando 14 participantes.

Todos os participantes se mostraram envolvidos, explicaram as especificidades das microrregiões, discutiram sobre os possíveis motivos que levam os usuários a faltar, as dificuldades em relação à comunicação de usuários que se mudam constantemente e dos que não fazem parte da cobertura de ESF. Descreveram com detalhes o trabalho das equipes, como organizavam as ações da central de agendamento e o setor de transporte.

Durante a dinâmica do grupo focal, foi possível identificar a boa interação entre os membros das ESF e entre as equipes, a central de agendamento e setor de transporte. Esses atores demonstraram interesse em discutir estratégias para a redução do absenteísmo e participaram intensamente das discussões.

4.2.4.3 caracterização dos serviços de saúde: Município C

O município $\mathrm{C}$ possui duas equipes de ESF, que trabalham na mesma Unidade de Saúde e são responsáveis pela cobertura de $90 \%$ a 95\% da população. São 2 equipes com 13 ACS e mais 2em licença saúde, a equipe de enfermagem, farmacêutico, sala de vacina e 1 
enfermeiro responsável pela Unidade de Saúde. A Central de Agendamento também funciona nesta unidade com dois agendadores.

[...] aqui trabalha além das duas equipes de ESF com 13 ACS, técnicas de enfermagem, farmacêutico, técnica da sala de vacina, uma enfermeira do centro de saúde e funcionários que não contemplam a ESF! E tem dois agendadores...

[...] a gente já está sentindo muito, eu estou com dois agentes comunitários afastados por licença saúde e precisamos contratar em caráter de urgência, por um período de seis meses, mas realmente a necessidade de uma terceira equipe. (gestor SMS C)

O gestor da SMS C planeja abrir nova Unidade de Saúde em local estratégico, descrito por ele como a região mais carente e populosa, com alta concentração de migrantes contratados por usina sucroalcooleira do Município C.

Estou com defasagem de equipe. Estamos estudando a possibilidade de contratação, pro ano que vem, de uma nova equipe. Enquanto isso os agentes de saúde fazem esse apoio.

Portanto a terceira equipe e a segunda unidade de saúde são estratégias, que já estão no papel, eu já vi até a área que é a mais carente e a mais populosa. Mesmo que a usina diminuiu contratação com a mecanização, a gente ainda tem muita migração, que se concentrar naquela área.

A população daquele bairro, é uma população, difícil de criar vínculos. Eles estão constantemente mudando! Já aconteceu de município pedir prontuário de pacientes que mudou para lá e quando nós fomos encaminhar, o paciente já estava de volta! Isso acontece muito, principalmente nesse bairro! (gestor SMS C)

O setor de agendamento da SMS C funciona em período integral e parceria constante com o serviço de transporte municipal. Os agendamentos para o AME Araçatuba são realizados pelo Portal CROSS conforme as vagas disponibilizadas pelo DRS II Araçatuba. Muitos outros serviços são comprados pela prefeitura no consórcio intermunicipal.

[...] são setores separados (agendamento e transporte), mas que se conversam diariamente. Eles se conversam bastante sabendo fluxo certinho! (gestor SMS C)

O Município C também utiliza exclusivamente o sistema CROSS para realização da gestão de agendamento por meio de relatórios de agendamentos com os dados de usuários presentes, ausentes e dispensados. Na ocasião da entrevista, o gestor apresentou o Plano de Saúde Municipal vigente, da gestão anterior, pois ainda estava em elaboração o plano para a nova gestão.

[...] geralmente o agendamento me entrega, oficialmente, os dados logo após a reunião com o AME. Esses dados são importantes porque nos mostram a realidade, onde temos dificuldades, que não é só nossa. (gestor SMS C)

Desde 2011, o Município C manteve as taxas de absenteísmo abaixo ou próximas de 15\% (Tabela 4.8). As dispensas foram esporádicas e a demanda reprimida mantida sob controle, com gestão do próprio município. 
Tabela 4.8 - Oferta e agendamentos/mês de consultas em especialistas do Município C, nos meses de novembro de cada ano no período de 2010 a 2017

\begin{tabular}{|c|c|c|c|c|c|c|c|c|c|c|}
\hline \multirow[b]{2}{*}{ Solicitante } & \multirow[b]{2}{*}{ Período } & \multirow[b]{2}{*}{ Oferta $^{1}$} & \multicolumn{3}{|c|}{ Agendamentos } & \multicolumn{5}{|c|}{ Recepção } \\
\hline & & & Total $^{2}$ & $\operatorname{Cota}^{3}$ & Bolsão ${ }^{4}$ & Pre $^{5}$ & Aus $^{6}$ & $\mathrm{Dis}^{7}$ & Alta $^{8}$ & Abs $\%^{9}$ \\
\hline \multirow{8}{*}{ Município C } & nov/10 & 66 & 69 & 59 & 10 & 60 & 9 & - & - & 13,04 \\
\hline & nov/11 & 59 & 69 & 54 & 15 & 56 & 13 & - & - & 18,84 \\
\hline & nov/12 & 45 & 54 & 43 & 11 & 48 & 6 & - & 3 & 11,11 \\
\hline & nov/13 & 57 & 61 & 57 & 4 & 52 & 9 & - & 10 & 14,75 \\
\hline & nov/14 & 53 & 59 & 52 & 7 & 53 & 6 & - & 11 & 10,17 \\
\hline & nov/15 & 74 & 73 & 66 & 7 & 69 & 4 & - & 16 & 5,48 \\
\hline & nov/16 & 48 & 48 & 46 & 2 & 42 & 4 & 2 & 8 & 8,33 \\
\hline & nov/17 & 46 & 46 & 44 & 2 & 44 & 2 & - & 11 & 4,35 \\
\hline
\end{tabular}

Fonte: São Paulo ([2010)].

\section{Oferta}

2. Total de agendamentos

3. Cotas agendadas

4. Bolsão vagas agendadas

5. Presente na consulta
6. Ausente na consulta

7. Dispensado da consulta

8. Alta

9. Absenteísmo em \%

Como mencionado anteriormente, o gestor da saúde no Município C tem ocupado há vários mandatos o cargo. Ele expôs que participou de toda a criação da AME Araçatuba, inclusive da escolha de especialidades deste AME.

[...] eu estou aqui desde quando iniciou (AME)... A gente participou da seleção de especialidades que fariam parte do AME. Faz muito tempo que eu estou aqui... (Risos). (gestor da SMSC)

\subsubsection{1 organização e fluxos de agendamento das consultas e exames: Município $C$}

Os agendamentos de consultas e exames do Município C ocorrem no setor de agendamento, localizado na Unidade de Saúde e ao lado do hospital. Os encaminhamentos e os pedidos de exames ficam retidos no setor de agendamento para ser conferidos e colocados na demanda reprimida, conforme ordem de data ou prioridade.

[...] nós seguimos uma lista de espera, daí a gente agenda conforme as vagas são ofertadas, por exemplo, agora estamos em outubro já agendando o mês de novembro. Então eu agendo agora guardo comigo e aí quando é a última semana do mês de outubro eu entregarei as guias para os Agentes Comunitários de Saúde para ser entregue aos pacientes. (agendador C1 da SMS C)

Quando o paciente passa em consulta ou vem com a guia de encaminhamento... vai para o setor de agendamento! As meninas ficam com as guias e solicitam as vagas ou agendam de acordo com oferta conforme a ordem de chegada ou prioridade!

As meninas do agendamento, retém as guias, e somente próxima à data de agendamento elas liberam os documentos na Unidade! (gestor SMS C) 
O gestor da SMS C relatou que, em casos de maior prioridade ou quando a demanda é maior do que a oferta de vagas disponibilizadas, o setor de agendamento realizava um tipo de triagem junto à gestão municipal para organizar a compra de serviços de saúde e complementar a oferta na programação pactuada integrada (PPI).

[...] realizam um tipo de triagem e selecionam o que é mais urgente, até para otimizar a oferta que a gente tem!

Por exemplo, eu tive que comprar mais cirurgias em Buritama, porque o que eu tenho em PPI (programação pactuada integrada) é insuficiente. (gestor SMS C)

\subsubsection{2 organização da fila, comunicação aos usuários, transporte e cancelamento de consultas e exames no município $C$}

A comunicação sobre o agendamento de exames e consultas pode ocorrer de duas maneiras: por intermédio dos ACS ou telefonema do setor de agendamento. A entrega dos documentos pode ser feita diretamente no setor de agendamento, com prazo determinado para a retirada da filipeta, ou pelos ACS, nas visitas domiciliares. Foram estabelecidos alguns critérios para a organização da comunicação. O gestor SMS C explicou que, devido ao fato de o município ser pequeno, era possível conhecer a comunidade e, desse modo, organizar a entrega dos agendamentos.

\footnotetext{
Adotamos alguns critérios: tem aqueles pacientes que a gente manda apenas a informação do agendamento de consulta, com prazo estabelecido para ele vir até a unidade e retirar a filipeta e a guia de consulta!

Agora, quando a gente sabe que é um paciente comprometido, ou que sabe que ele não vai faltar, as próprias agentes comunitárias entregam as guias .... cidade vem crescendo, mesmo não sendo área do ACS, eles vão até a área para entregar as guias, mas não tem aquele vínculo!

Mas se é um paciente que ...ficamos na dúvida por que ele já faltou antes! A gente coloca um prazo para que ele venha buscar aqui no setor de agendamento, porque se ele não vier até determinada data, não dá tempo de a gente trocar para outro paciente. Tudo para não perder essa vaga! (gestor SMS C)
}

No caso (demanda muito antiga), a gente acaba ligando sim. Tem casos que a gente liga antes para saber se já passou por outro médico ou se não houve melhora. Por que tem muitos que acabam sendo atendidos no particular. Então quando é muito velho nós acabamos ligando sim! (agendador C2 da SMS C).

O enfermeiro da ESF do Município C explicou a dinâmica da equipe sobre os documentos de agendamentos. Os documentos são separados por equipes da ESF. Os respectivos ACS identificam suas famílias e já programam a entrega, conforme realizam as visitas domiciliares. Em algumas localidades, o gestor da SMS C tem mantido visitas aos sábados, devido ao fato de famílias não serem encontradas durante a semana. 
Quando chega aqui os agendamentos na nossa sala de ACS nós somos divididos por equipe. [...] cada uma delas pegam os encaminhamentos de seus pacientes e conforme vão fazendo as visitas estão entregando. (enfermeiro da ESF do município C)

[...] a maioria dos moradores da minha área trabalham o dia inteiro e depois das $18 \mathrm{~h}$ eles já não querem atender por que fazem as atividades da casa. Então eles pedem para ir aos sábados para fazer os cadastros e fazer as visitas. (ACS C8 da SMS C)

Tem agente comunitário que eu pago hora extra para trabalhar aos sábados, por que não encontra ou os pacientes querem receber o ACS no final de semana! (gestor SMS C)

A comunicação dos agentes comunitários com os usuários é realizada sempre nas semanas próximas à data agendada, para prevenir o esquecimento. Todas as ACS concordaram e reforçaram que é muito comum o esquecimento.

Eu agendo agora e guardo comigo. E quando é a última semana do mês de outubro, por exemplo, eu entregarei as guias para os Agentes Comunitários de Saúde para ser entregue aos pacientes. (agendador C1 da SMS C)

Por que se entrega muito antes, eles acabem esquecendo...

[...] eu já peço a certeza, por que se não for eu já trago de volta (a filipeta). Em caso de dúvida, dou um prazo de dois dias e deixo meu telefone ou pego o telefone do paciente para ligar. Já aviso que antes de dois dias essa guia tem que ser levada no agendamento, pois essa vaga não pode perder! Se você não for temos que passar para outra pessoa! (ACS C1 da SMS C)

E eu sempre oriento a colocar os papeis do agendamento em local visível, como na porta da geladeira para não esquecer! (ACS C4 da SMS C)

[...] conforme chegam, vamos priorizando esses encaminhamentos, são separados por data de agendamento. (enfermeiro da ESF do município C)

A orientação sobre os agendamentos e preparos de exames é realizada pelas próprias ACS, no ato do aviso de agendamento. O enfermeiro da ESF do Município C explicou que, em casos de preparos de exames, as equipes de ESF auxiliavam nas orientações e ofereciam suporte com os serviços de saúde.

[...] tem caso de pacientes que não conseguem fazer o preparo. A gente avisa o serviço social para solicitar a internação social. O paciente realiza o preparo dentro do hospital, principalmente o de colonoscopia que é o mais chato dos preparos! (enfermeiro da ESF do Município C)

Se o paciente não for mesmo a gente já troca. Ressonância, por exemplo, é uma vaga por mês e se eu marco e o paciente não for é duro, exame caro! Dá até dor no coração (risos)! (agendador C2 da SMS C).

A fila de demanda por recursos de saúde é organizada com auxílio do Portal CROSS e os encaminhamentos e pedidos de exames ficam guardados no setor de agendamento em 
ordem cronológica. O profissional médico é o único que solicita prioridade, a qual vem identificada no encaminhamento ou pedido de exame.

[...] depois da pós-consulta, ... colocamos na fila por ordem de data ou se o médico solicitar prioridade esse encaminhamento é passado na frente para $\mathrm{o}$ agendamento.(agendador C2 da SMS C)

Os documentos de agendamento são devolvidos ao setor de agendamento, quando os usuários não são encontrados pelos ACS nas visitas domiciliares, por telefone ou mesmo deixando recados com a vizinhança. Os agendadores entram em contato novamente com o usuário. Caso haja novo desencontro, oferecem a vaga para o próximo da demanda reprimida.

Acontece também de a gente não encontrar a pessoa. A gente volta aqui no agendamento e avisa as meninas que mesmo ligando não atende, e entrega para as meninas do agendamento. (ACS C4 da SMS C)

E nós vamos atrás de novo e se realmente não conseguirmos avisar a gente troca. (agendador C1 da SMS C)

A documentação e arquivo em prontuário auxiliou na conscientização sobre a importância de avisar desistência em tempo útil para disponibilizar a vaga para outra pessoa. Somente os casos de absenteísmo por motivo relevante são reinseridos na fila. Esta ação possibilita aos demais profissionais acompanharem os cuidados propostos, mas, principalmente, ao médico, que pode consultar os agendamentos e os motivos do não comparecimento.

A guia é devolvida para a unidade e arquivada no prontuário com observação do por que o paciente se recusou em comparecer na consulta. E quando essa pessoa volta para atendimento médico e faz alguma queixa, o médico vê que já foi agendada e não quis ir na consulta ou exame. (enfermeiro da ESF do município C)

Todas as guias que elas entregam são assinadas na folha de relatório de visita domiciliar. Não dá para dizer que perderam, pois tem tudo documentado. (agendador C2 da SMS C)

Eu tive uma situação que a mulher dizia que não recebia minha visita, mas eu tinha tudo assinado pela empregada. Esse caso veio até para conhecimento da secretária. de saúde. E eu só consegui mostrando a planilha assinada (ACS C3 da SMS C)

Além da documentação em prontuário, os ACS registram todas as ações no relatório de visitas domiciliares. Eles acreditam na importância da documentação dos cuidados em saúde.

O transporte aos usuários do Município C é disponibilizado diariamente, em dois turnos. Um veículo realiza o período da manhã com saída às 5 h50 e retorna às 10 h30 para que, às $11 \mathrm{~h} 50$ saia o veículo da tarde com retorno após atendimento de todos do período da 
tarde. Os profissionais de saúde explicaram sobre os horários e as dificuldades identificadas pelos usuários. A equipe de saúde explicou que nem todos os usuários necessitam de transporte municipal.

[...] veículos todos os dias, tem a van que sai 5 h50 do município, com agendamento antecipado, mediante a guia do encaminhamento. Lá no setor de transporte vai ser verificado se precisa de acompanhante, dependendo do exame ou se é idoso. Esse veículo volta na hora do almoço e vai outro $11 \mathrm{~h} 50$ no período da tarde! Na verdade, é o mesmo veículo, a não ser em casos de ter muitos pacientes para o mesmo período, a gente tenta colocar mais um no período. Se a consulta do paciente não terminar antes do horário da van voltar ele acaba ficando para o período da tarde ou algum carro extra que estiver por lá traz esse paciente. Nós enviamos pacientes de sábado, ponto facultativo... tudo depende dos agendamentos! Agendamento e o transporte são setores separados, mas que se conversam diariamente. (gestor da SMS C)

A gente conhece as pessoas que vão precisar do transporte, os que vão de carro... então, do jeito que a gente pega as guias, eu já passo para ele, senão eu pego o livro e agendo.... (risos)! (ACS C2 do SMS C)

As pessoas idosas ou que tenha dificuldade, ou muito doente, ou que tem algum defeito físico e necessita de ambulância para ir sozinho... também tem caso de buscar em casa, por que nós temos 3 pontos de saída na cidade. E se precisar a gente busca! (responsável do transporte da SMS C)

O responsável pelo transporte do Município C explicou que o usuário passa geralmente pelo setor de transporte de4 até 7 dias antes da data do serviço, mas a orientação é de que deve agendar pelo menos 2dias, antes do compromisso agendado no AME Araçatuba. É comum ele receber ligações na véspera ou na madrugada.

Geralmente dá mais tempo, geralmente elas entregam com uns 4 dias. Tem vezes que elas entregam com até mais de uma semana. Aqui a gente agenda até um dia antes, se o exame é amanhã e ele vem agora a gente agenda. A partir do momento que ele recebeu o exame ele pode já vir agendar.

[...] tem paciente que liga $4 \mathrm{~h}$ da manhã e fala que precisa ir para Birigui hoje, ou para Araçatuba, e esqueci de dar o nome.... pode ir?! E nós agendamos. O nosso primeiro carro sai às 6:00 da manhã, (responsável do transporte da SMS C)

[...] a gente faz de tudo para a pessoa ir! (ACS C2 da SMS C).

A equipe de saúde pontuou que, em alguns casos, os usuários estavam no trabalho, por exemplo, ou eram usuários assíduos que eles conheciam e sabiam da necessidade do transporte, a equipe leva os documentos de agendamentos com o veículo agendado. $\mathrm{O}$ responsável pelo transporte explicou o esforço realizado para atender as necessidades dos usuários, como disponibilizar um carro em situação específica para buscar o usuário.

Já aconteceu, dependendo da pessoa, se ela trabalha e não conseguir vim ... gente agenda o transporte para ela (ACS C7 da SMS C). 
A gente já sabe aquelas pessoas que vão precisar do transporte, os que vão de carro... então, do jeito que a gente pega as guias, eu já passo para ele, senão eu já pego o livro (risos)... (ACS C8 da SMS C)

Aqui tem muito esse problema, muitas mulheres trabalham nas fábricas aqui de Birigui e elas já agendam. Elas pegam o meu livro e já agendam tudo certinho! (risos). Eu só passo no computador. Quando é assim elas já agendam!

E se deu o horário da van, por exemplo, com 25 pacientes prontos e falta só um (paciente)... ou teve um problema e tal... se eu tiver motorista disponível para buscar este paciente, eu mando vir embora e o motorista vai buscar o que ficou! Os motoristas sempre me ligam e a gente vê como vai fazer! (responsável do transporte. da SMS C)

O cancelamento ocorre geralmente durante o aviso ou a entrega do agendamento pelas ACS, quando o usuário diz que não poderá ir ou não precisa mais da consulta ou exame. No caso de não encontrar o usuário depois de várias tentativas, os ACS trocam o agendamento para próximo da fila.

A gente avisa... se não for... comunicar em até uns três dias antes! (ACS C2 da SMS C)

Nós colocamos outro no lugar, a gente nunca deixa de trocar, só não trocamos mesmo quando o sistema não deixa (risos)! (agendador C2 da SMS C)

Em caso de falta ou desistência no agendamento realizado, o motivo é registrado e assinado pelo usuário na filipeta com o encaminhamento para arquivo em prontuário. $\mathrm{Na}$ unidade não é utilizado o mesmo pedido ou encaminhamento. O usuário deve ser novamente atendido na APS e um novo encaminhamento deve ser realizado.

A gente fala: se você faltar, vai ter que pegar outra guia passar tudo de novo. E que o agendamento não será necessariamente de novo no AME. (agendador C2 da SMS C)

A gente fala de uma forma até meio firme, pois se faltar e não avisar vai ter que voltar do final da fila... dá um susto neles! (ACS C1 da SMS C)

Os fatores relacionados pelas equipes do Município $\mathrm{C}$ à falta e desistência foram o tempo de espera para o agendamento; a localização do AME Araçatuba, devido ao transporte; medo; esquecimento, e falta de responsabilidade.

O tempo de espera pela consulta é muito grande. (gestor da SMS C)

O fator tempo foi apontado pelo gestor da saúde e por toda a equipe de saúde da SMS C como o principal condicionante do absenteísmo. 


\subsubsection{3 reflexões sobre o absenteísmo no Município $C$}

O Município C possui todo o serviço de saúde centralizado junto à SMS. O Centro de Saúde, as equipes de ESF, o setor de agendamento e o de transporte estão instalados no mesmo prédio e realizam em conjunto o atendimento à população.

No decorrer da entrevista, o gestor da SMS fez algumas reflexões sobre as possíveis razões do absenteísmo no Município $\mathrm{C}$, e acrescentou que a demanda, muitas vezes, não era a real, pois a própria população gerava demanda; diante de demora, voltava a passar por consulta na APS e recebia outro encaminhamento. Para tentar melhorar o controle sobre os agendamentos, ele explicou que centralizou todos os encaminhamentos no setor responsável.

[...] o excesso de solicitações... as demandas que as vezes não é realmente necessária e a demora para o agendamento... porque quando sai a vaga, muitas vezes ele já fez ou até melhorou! Enquanto isso a fila fica enorme, a guia de agendamento fica aqui parada! E tem também os casos que estão na espera e são novamente atendidos... o médico solicita de novo o encaminhamento para a especialidade... (gestor da SMS C)

A relação colaborativa entre as equipes nos processos de trabalho ocorria de maneira espontânea. Isso foi captado nas falas que se complementavam durante o grupo focal. A USF e o setor de agendamento, juntos, conseguiam identificar os grupos de maior risco de faltar ou desistir, confirmando as consultas e exames por meio das ligações e apoio intensificado dos ACS.

E quando a equipe está desfalcada... elas (ACS) pegam as guias que são de cada uma... e o restante elas passam com a ajuda do transporte ou até as meninas do agendamento se dispõe a entregar as guias de regiões que está sem ACS. (enfermeiro da ESF do município C)

O gestor da SMS C analisou a demanda reprimida do Município C, o fluxo de informações e a necessidade de conscientização da população. Sobre o serviço oferecido pelo AME Araçatuba, o gestor fez algumas considerações.

Eles (usuários) elogiam muito, depois que o AME veio pra região, mudou um pouco o padrão de atendimento. A referência de atendimento mudou, porque eu estou aqui desde quando iniciou... O padrão parecido com a rede particular, esse padrão se manteve, o que diminuiu foram as vagas que nós estamos tendo dificuldade. Sobre o atendimento, ninguém reclama de forma alguma.

No início a questão do horário, o rigor, acabou educando.

aumento das vagas, por que a população aumenta e não temos como atender toda essa população.(gestor da SMS C) 


\subsubsection{Município D}

A SMS D conta com uma população estimada de 2016 habitantes (IBGE 2017) e índice de desenvolvimento humano municipal (IDH), em 2010, de 0,751. A SMS D possui 2 estabelecimentos de saúde do SUS: UBS e USF com 1 equipe cada. A economia predominante nesse município é a agropecuária e tem tido destaque sobre o valor agregado bruto no setor de agronegócios acima da média nacional.

\subsubsection{1 entrevista com o gestor do município D}

A entrevista semiestruturada com o gestor municipal ocorreu na Secretaria de Saúde (SMS) do Município D, no período da manhã, com duração de 70 minutos.

O gestor informou em detalhes os processos envolvidos no agendamento, comunicação aos usuários por meio das ESF e a organização do serviço de transporte. Explicou também sobre a organização interna que realizou ao assumir a gestão da Secretaria de Saúde.

No decorrer da entrevista, demonstrou empenho em valorizar as equipes de saúde, em realizar a gestão participativa, distribuir as responsabilidades e as funções. Relatou vários planejamentos sobre a qualidade de atendimento à população, melhorando o sistema de transporte municipal, aumento de alguns indicadores no plano municipal e proposta de reuniões com os demais departamentos da Prefeitura.

$\mathrm{Na}$ ocasião, foram solicitados os documentos utilizados pelo serviço na organização interna e o Plano de Saúde Municipal, os quais foram disponibilizados para a pesquisa. Ao final da entrevista, foi solicitada ao gestor a participação dos demais profissionais de saúde no grupo focal. O mesmo acompanhou a pesquisadora até sala de reuniões com os profissionais de saúde, onde já estavam os profissionais que iriam participar da dinâmica.

4.2.5.2 descrição do grupo focal com a equipe da Unidade de Saúde, gestor de saúde, responsável pelo agendamento e transporte, agendador e motoristas da SMS D

O grupo focal já havia sido comunicado e organizado pelo gestor municipal na sala de reuniões, onde estavam reunidos o gestor e o enfermeiro da USF, os ACS, os agendadores, os motoristas e o responsável pelo transporte, totalizando dez participantes. O grupo focal teve duração de 65 minutos. 
O grupo estava organizado em roda, em torno de uma mesa. Todos os participantes se mostraram envolvidos, explicaram as especificidades das microrregiões, discutiram sobre algumas dificuldades em relação à demora de agendamento, o que acarreta na desistência ou cancelamento dos agendamentos.

Os atores descreveram algumas estratégias que implementaram nos fluxos e nas ações desempenhadas junto à população.

Durante a dinâmica, foi possível identificar a boa interação entre os membros das ESF e entre as equipes, o entusiasmo e o orgulho na descrição dos feitos sobre a redução do absenteísmo.

\subsubsection{3 caracterização dos serviços de saúde: Município D}

A coordenação da saúde no Município D foi organizada sob a responsabilidade do gestor da SMS D, em 5instâncias: UBS, ESF, média complexidade, saúde bucal e agendamento/transporte. A gestão participativa proposta pelo gestor da SMS D, tem sido realizada por meio das reuniões quinzenais com os coordenadores e mais alguns profissionais do departamento de tecnologia da informação e vigilância sanitária.

Quando assumimos a saúde, nós dividimos em coordenação da ESF, eu fiz uma
coordenação de agendamento/transporte, ou seja, a mesma pessoa responsável pelos
agendamentos e regulação, é a responsável pelo transporte nosso também. Nós
dividimos em coordenação para ficar melhor organizado, como se fosse uma
pirâmide... trabalhar com hierarquia e cada um tendo a autonomia na sua
coordenação.(gestor SMS D)

A participação da comunidade na gestão dos serviços de saúde ainda é baixa. O gestor da SMS D mantém uma caixa de sugestões para promover um canal de comunicação com a população. Visando a ampliar a participação popular na promoção e prevenção, a SMS D faz parceria com outros órgãos públicos para aproveitar todas as chances de oferecer serviços e educação em saúde aos usuários.

A comunidade não participa das atividades feitas pela saúde. Eu mantenho uma caixinha de sugestão na UBS.

A população não é participativa, mas a gente usa outros órgãos públicos como trampolim... (gestor da SMS D)

Existem interfaces da saúde com os outros serviços municipais, como a assistência social, educação, entre outras.

A assistência social também trabalha... exemplo o NASF identifica um problema que é social, a gente já dispara para o serviço social e se eles notam que tem algum 
problema de saúde... eles nos passam para nós. A gente tenta fazer essa rede...(gestor da SMS D)

Conforme a Tabela 4.9, é possível verificar que o Município D manteve oscilações nas taxas de absenteísmo de 2010 a 2017. A maior taxa registrada foi em 2012, no com 30,77\%, e manteve próxima ou abaixo de 15\% nos anos de 2010, 2013, 2015, 2016 e 2017. Em todo esse período de agendamentos, por mês de referência, não houve registro de dispensas, e geralmente foi agendada toda a oferta disponibilizada. A demanda reprimida foi mantida sob controle e gestão do próprio Município D.

Tabela 4.9 - Oferta e agendamentos/mês de consultas em especialistas do município D, nos meses de novembro de cada ano no período de 2010 a 2017

\begin{tabular}{|c|c|c|c|c|c|c|c|c|c|c|}
\hline \multirow[b]{2}{*}{ Solicitante } & \multirow[b]{2}{*}{ Período } & \multirow[b]{2}{*}{ Oferta $^{1}$} & \multicolumn{3}{|c|}{ Agendamentos } & \multicolumn{5}{|c|}{ Recepção } \\
\hline & & & Total $^{2}$ & Cota $^{3}$ & Bolsão $^{4}$ & Pre $^{5}$ & Aus $^{6}$ & Dis $^{7}$ & Alta $^{8}$ & Abs $\%^{9}$ \\
\hline \multirow{8}{*}{ Município D } & nov $/ 10$ & 19 & 25 & 11 & 14 & 21 & 4 & - & - & 16 \\
\hline & nov/11 & 32 & 51 & 33 & 18 & 39 & 12 & - & - & 23,53 \\
\hline & nov/12 & 12 & 13 & 12 & 1 & 9 & 4 & - & 1 & 30,77 \\
\hline & nov/13 & 18 & 17 & 15 & 2 & 17 & & - & 3 & 0 \\
\hline & nov/14 & 26 & 30 & 25 & 1 & 23 & 7 & - & 6 & 23,33 \\
\hline & nov/15 & 16 & 16 & 14 & 2 & 16 & & - & 1 & 0 \\
\hline & nov/16 & 13 & 13 & 13 & - & 11 & 2 & - & 2 & 15,38 \\
\hline & nov/17 & 26 & 25 & 25 & - & 22 & 3 & - & 4 & 12 \\
\hline
\end{tabular}

Dados extraídos do Portal CROSS (2018)
1. Oferta
2. Total de agendamentos
3. Cotas agendadas
4. Bolsão vagas agendadas
5. Presente na consulta

6. Ausente na consulta

7. Dispensado da consulta

8. Alta

9. Absenteísmo em \%

O Plano de Saúde Municipal vigente também é o da gestão anterior, pois o novo estava em fase final de formulação. O gestor da SMS D desconhece o índice de absenteísmo, mas sabe que tem sido mantido abaixo do limite de $15 \%$ estabelecido pela Secretaria Estadual de São Paulo.

As unidades de UBS e USF são sediadas em estabelecimentos distintos e possuem equipes distintas. A APS mantém a cobertura da ESF em 100\% do território urbano e rural, num total de quatro microáreas, sob os cuidados de cinco ACS, enfermeiro, auxiliar de enfermagem e médico da ESF. A equipe da UBS é composta por enfermagem, dentistas, 
fisioterapeuta e médicos. Os setores de agendamento e transporte são gerenciados pela mesma coordenadora e possuem mais um agendador em período integral.

[...] a responsável pelo agendamento e transporte é muito trabalhadora e tem muito comprometimento. Ela controla bem os dois piores setores: agendamento e transporte.

[...] temos médicos que atendem das 7:00 - 20:00. Mas não tenho pediatra, ...os médicos atendem as crianças, adultos e idosos. Tento estimular as equipes em sempre querer desenvolver mais, fazer pela população, ou seja, para o povo! (gestor da SMS D).

Durante o grupo focal com a equipe de saúde, com a participação do gestor da SMS D, foi proposto pela equipe acrescentar o absenteísmo como um indicador a ser monitorado no mapa de territorialidade.

\subsubsection{1 organização e fluxos de agendamento das consultas e exames do Município D}

No município D, o Portal CROSS é o único sistema informatizado, no qual o setor de agendamento da SMS D insere toda demanda por recursos, sinalizando as prioridades, mantendo cadastro atualizado dos usuários. Os encaminhamentos e pedidos de exames são trazidos pela recepção após consulta com o médico da família ou da UBS do Município D. O pedido é separado no setor de agendamento por especialidades ou exames conforme a data da solicitação.

O encaminhamento chega para a gente, através da recepção. Elas trazem para a gente os encaminhamentos, guias de exames, tudo! E aí a gente tem um arquivo separado por especialidades e aí a gente abre nossa cota pelo CROSS... e a gente faz o agendamento (agendador D1 da SMS D).

$\mathrm{O}$ agendamento é feito conforme a fila e a cota. Tem especialidades que têm a fila de espera e então a gente prioriza pela data, assim, por quem está mais tempo esperando na fila (agendador D2 da SMS D).

O agendamento é realizado conforme as vagas do AME Araçatuba. Estas são disponibilizadas, respeitando a ordem da demanda por recursos do Município D. Em casos graves indicados pelo médico como urgência, são priorizados para agendamento no AME Araçatuba ou para outros serviços de saúde.

Os casos graves ou que o médico pede com urgência, a gente dá prioridade, tanto no sistema CROSS ou em outros lugares como consórcio e hospital de referência. (gestor SMS D)

Assim que realizado o agendamento pelo sistema CROSS, o encaminhamento ou a solicitação de exames é anexado à filipeta. Em sequência, esses documentos de agendamento são encaminhados para a equipe da ESF. 


\subsubsection{2 organização da fila, comunicação aos usuários, transporte e cancelamento de consultas e exames no Município D}

A comunicação de agendamentos no Município D é exclusivamente realizado por ACS. Os documentos de agendamento são separados por microárea, sendo guardados pelos ACS. A entrega e comunicação do agendamento são entregues apenas no período de sete a dez dias antes da consulta, para evitar o esquecimento.

[...] nós temos um mapa da estratégia saúde da família. assim que agendado, nossa regulação faz contato primeiramente com os agentes comunitários de Saúde (ACS). (gestor da SMS D)

A gente sempre deixa a entrega para 3-4 dias antes da consulta assim, justamente para não estar esquecendo... (ACS D2 da SMS D)

[...] exatamente, por enquanto fica com a gente. Normalmente é isso 5-3 dias a gente entrega essa guia né?! Para não ficar muito em cima da hora também, né?! (ACS D1 da SMS D)

As orientações aos usuários sobre as consultas e preparos de exames ou procedimentos são oferecidas pelos ACS. A equipe da ESF conversa sobre as dúvidas e orientações antes dos ACS saírem para as visitas domiciliares. Para otimizar as informações ao usuário, os agendadores já indicam nos documentos de agendamento as informações relevantes.

O papel do ACS fundamental em avisar o paciente também, pois ele sabe quem são os pacientes por microárea, já aproveita e faz uma visita domiciliar. O paciente é agendado por mensagem no celular, ligação do AME ou da regulação e pelo ACS. (gestor da SMS D)

A gente passa aquele grifa texto e pede para eles explicarem para o paciente. [...] o pessoal da estratégia... orienta a respeito do preparo, ou exame, se for consulta ou se o paciente não tiver condições de ir... para ele estar avisando para a gente passar a vaga para outra pessoa que estiver esperando. A gente passa aquele grifa texto e pede para eles explicarem para o paciente. (agendador D1 da SMS D)

A gente lê e explica tudo certinho, a gente sai daqui já sem a dúvida. Por que a gente vem aqui e já pergunta para elas, se tem jejum, algum preparo! Saí daqui pronto para deixar o paciente bem esclarecido. (ACS D1 da SMS D)

A guia de agendamento e a solicitação médica já sai daqui com data, hora e documentação necessária. Só fica de confirmar a saída de condução. Quando eles não ligam as responsáveis pelo agendamento e transporte ligam para eles na véspera. (ACS D2 da SMS D)

Em caso de os usuários serem idosos ou terem dificuldade na compreensão das orientações, os profissionais de saúde descreveram algumas estratégias.

A gente passa para alguém da família. (ACS D4 da SMS D)

Ou para algum responsável. (ACS D1 da SMS D) 
Se o paciente for muito idoso, com dificuldade, a gente já fala passar na casa para pegar! Nos casos de radioterapia, ou muito idoso! (agendador D1 da SMS D)

A gestão da demanda por recursos ocorre com auxílio do Portal CROSS, por meio do CDR. Os agendadores analisam a demanda e o serviço de saúde adequado para a necessidade. Os encaminhamentos para especialidade e pedidos de exames ficam guardados em pastas por ordem cronológica.

As especialidades da fila de espera, a gente prioriza por quem está mais tempo esperando. (agendador D2 da SMS D)

O que dá para agendar no AME já são separadas, o que não tem vai via consórcio.(agendador D1 da SMS D)

Nos casos de faltas ou desistência da vaga, o setor de agendamento reserva os encaminhamentos e pedidos de exames em outra pasta. Ele os mantêm para, em caso de necessidade, não seja necessário passar por nova avaliação médica.

\begin{abstract}
Nós temos o costume de marcar em algumas guias que o paciente alega ter feito tal procedimento particular, que não precisa mais, coloco data e horário. Eu coloco no prontuário do paciente ou que não compareceu no exame ou coleta. Nós temos um arquivo no prontuário ali, nós guardamos todos os pacientes de retorno ou aqueles que não querem a consulta. Mas a gente deixa anotado tudo e deixar ali porquê de repente eles mudam de ideia e procuram eu tenho lá guardado! (agendador D2 da SMS D)
\end{abstract}

No Município D, o transporte de usuários é disponibilizado em dois turnos: uma saída às $6 \mathrm{~h}$ e outra às $11 \mathrm{~h} 30$. Atualmente, o agendamento de consultas e de transporte é realizado pela mesma pessoa. Isso facilitou o controle e o fluxo de comunicação entre os setores. $\mathrm{O}$ serviço de transporte foi reestruturado e reorganizado, foi otimizada a comunicação do motorista com o setor de transporte e adquirido um sistema de rastreamento de veículos pela Prefeitura.

O motorista saiu para as consultas das 7:00 da manhã e o último (paciente) será para o $12 \mathrm{~h}$, ele espera até o último a sair. O motorista que levou os pacientes sempre esperará todos que foi com ele. Salvo exceção de casos, de uma consulta que acontecerá somente as 15:00, por exemplo, o motorista faz contato com a regulação. A comunicação é importantíssima para evitar o absenteísmo. O motorista sempre tem contato prévio, e se o motorista vier sem trazer algum paciente, sem termos organizado quem irá traze-lo, o motorista volta para busca-lo.

Por isso tem divisão de dois horários, pois é desumano deixar o paciente o dia todo aguardando, se a gente tem condição de fazer, a gente faz. Nossa demanda aumentou tanto que tem vezes que não cabe na van, temos que pedir para prefeitura o microônibus da prefeitura e leva os pacientes.

[...] rastreamento de veículos por celular. Esse sistema dá informações sobre o local que a viatura está, quanto tempo está parada, se excedeu o limite de velocidade, pois nós tínhamos muita reclamação de usuários sobre motoristas que corriam muito. Então se alguma viatura ultrapassar de $120 \mathrm{~km} / \mathrm{h}$ o sistema começa a apitar e envia mensagens no celular que alguma viatura está acima do limite de velocidade ... o gasto médio é de R\$ 8.500,00 de combustível/mês. Fica em torno de R\$ 13,00 o 
custo do paciente (transporte). O Estado está dando o exame e a consulta... essa é a nossa contrapartida. (gestor da SMS D)

Em caso de necessidades especiais ou intercorrências, são tomadas decisões específicas pelo responsável do transporte e pelo gestor de saúde, como disponibilização de carro pequeno para locomover um usuário mais idoso ou que tenha dificuldade para se deslocar em transporte coletivo.

Exemplo, eu tenho uma paciente de 83 anos... A consulta será às 10:00 da manhã, eu vou disponibilizar um carro pequeno para leva-la e já trazer de volta. Tem isso também, a regulação me avisa. Por ser uma cidade pequena, ela me procura e já pede ajuda sobre determinado caso. (gestor da SMS D)

O agendamento do transporte é realizado pelo usuário, o que acontece geralmente na véspera do compromisso agendado no AME Araçatuba. Caso o usuário procure a unidade depois das $17 \mathrm{~h}$, a Unidade de Saúde e os motoristas que permanecem atendendo podem consultar a planilha de viagem e marcar, se houver vaga.

Sobre o transporte... o paciente agenda um dia antes do agendamento. (ACS D1 da SMS D)

Um dia antes a gente digita a lista com horários e as cidades para o transporte, e no final da tarde, a gente fixa essa lista no mural do motorista e fica uma lista na recepção. (agendador D2 da SMS D)

Por que a unidade fica aberta até 20:00 da noite, e tem gente que liga depois das 17:00. Nós temos o motorista plantonista, então tem sempre gente que liga a noite e pergunta para o motorista. (agendador D1 do município D)

Os motoristas visualizam a planilha de viagens diárias fixada na recepção da unidade com todos os nomes dos usuários e acompanhantes distribuídos por período: manhã e tarde. $\mathrm{O}$ agendador D2 do município D explicou que, ao realizar a planilha do próximo dia de viagens, confirma aqueles que não vieram agendar o transporte.

[...] já sei quem é o paciente, onde eu pego eles e quem vai com acompanhante. As meninas do agendamento já entregaram tudo certinho para o paciente. Eles não esquecem nenhum documento... elas (agendamento) orientam que sem documentos não será atendido no AME. Mas se eles esquecerem, a gente passa lá (casa do paciente) e pega! Não vou deixar ele perder a consulta... se chega lá na casa, a maca não entra... eu entro e pegou no colo mesmo (risos)! (motorista D1 do município D)

Em relação ao transporte, a única queixa foi relativa ao período de espera do usuário no AME Araçatuba, principalmente quando as consultas são agendadas entre 10h e $12 \mathrm{~h} 30$. Nesses casos, o usuário tem que permanecer o dia todo no local, devido à troca de carros dos municípios próximos.

E o horário tem alguns que não gostam de ser atendido depois das $10 \mathrm{~h}$ porque ambulância sai cedo e eles só voltam no final da tarde. E eles não querem ficar... a 
gente ouve essa questão do horário como uma queixa frequente! (enfermeiro da ESF do município D)

Aqui é muito difícil, mas é uma queixa frequente a questão da espera e quando tem algum imprevisto! (agendador D1 do município D)

Teve uma situação que eu presenciei que a paciente disse que não quis ser atendida, ela foi na van, mas não quis ser atendida lá... aí o que a gente fez a gente pegou documento encaminhamento e arquivou! (agendador D1 do município D)

O gestor da SMS D relatou a necessidade de envolvimento de todos na prevenção ao absenteísmo. Fez algumas colocações sobre o atendimento do AME Araçatuba para melhorar o atendimento e, indiretamente, os índices de absenteísmo.

\footnotetext{
Eu já pedi para as funcionárias da regulação e ainda não estão fazendo! Colocar na lista de pacientes por dia de consulta e exames agendados, todos os números de telefone para que os motoristas consigam entrar em contato com o paciente se houver atraso ou qualquer imprevisto.

É algo que eu acho que pode até melhorar os índices de absenteísmo. Por exemplo: tenho um agendamento de cardiologia, esse paciente foi na consulta que solicitou 3 exames para ele, o AME marca 3 datas diferentes esses exames e o retorno será em outra data. Aí num mês aparece transporte de 10 pacientes, mas na verdade foram 50 viagens para 10 pacientes só! Teria a possibilidade do AME fazer uma integração... fazer de forma articulada os exames e retorno?! Esse pode ser um ponto de aumento de absenteísmo para muitos municípios. (gestor da SMS D)
}

O cancelamento e a desistência do agendamento não são frequentes no Município D. O prazo de troca de usuários no Portal é de 48 horas e, por isso, o setor de agendamento e os ACS monitoram a entrega de agendamento e documentam todas as informações possíveis. O prazo de troca ou cancelamento é diferente dos outros serviços de saúde, os quais permitem cancelamento até 24 horas antes, informações que ainda não estão claras para a população.

[...] a troca é até com 48 horas antes, por isso nós estamos entregando as guias com antecedência porque aí eles já se programam! Assim com cinco dias as pessoas poderiam já estar avisando para dar tempo de dar a vaga pra outra pessoa. (agendador D2 da SMS D)

Eu não sabia desse prazo eu achava que podia trocar até com dia! (gestor da SMS D)

Não, somente no consórcio pode com 24 hs. Mas já aconteceu de eu não conseguir ir eu mandar um e-mail para o AME e eles conseguem fazer a troca pra gente! (agendador D1 da SMS D)

Portanto, é importante informar a população sobre os prazos de troca ou cancelamentos, além da necessidade de não perder a vaga que poderia ser ocupada por outro usuário. Também é importante considerar o trabalho da equipe de saúde na busca ativa dos faltosos e na busca da transformação de concepções e participação do cuidado. 
Já aconteceu, né enfermeiro, da gente ter falta de gestante alto risco e a gente fazer a busca ativa. E conseguir que ela aderisse e ela não está faltando... está indo certinho! (agendador D2 da SMS D)

É uma gestante de alto risco que nós conseguimos reagendar e acompanhar! Era uma gestante jovem, rebelde e um pouco difícil, mas que já teve bebê. Tivemos que falar com ela que se ela não começasse aí a gente teria que acionar o conselho tutelar! Porque ela precisa né e aí a mãe dela começou a acompanhar e deu certo! (enfermeiro da ESF do município D)

Durante a discussão no grupo focal, foram sugeridas algumas propostas pela equipe, como: lembrete ou confirmação por telefone, ações para melhorar a divulgação e conscientização da população, trabalho com os dados de absenteísmo com os indicadores no mapa.

Podemos começar a ligar para confirmar o paciente. Nós podemos também pegar a lista de pacientes agendados e verificar aqueles que não ligaram para agendar o transporte até umas 4 horas da tarde... a gente pode entrar em contato via telefone... Fazer a relação dos faltosos por especialidade em quantidades, não pra expor os nomes, mas seria um cartaz para conscientização de tantas vagas por exemplo perderam-se tanto! (agendador D1)

[...] importante... fazer um levantamento de dados pra poder trabalhar os faltosos! A partir do motivo traçar uma estratégia! E acrescentar o absenteísmo como indicador, colocar no mapa que eu mandei fazer vai ficar quase do tamanho dessa parede! (risos) E aí a gente vai ter as legendas e colocamos o absenteísmo com uma cor! (gestor D)

\subsubsection{3 reflexões sobre o absenteísmo no Município D}

Todos os serviços de saúde disponibilizados no Município D estão localizados ao lado da Secretaria Municipal de Saúde. O gestor iniciou seus trabalhos no ano de 2017. Ele tem realizado mudanças na organização gerencial, com reuniões periódicas junto aos coordenadores, visando a uma gestão participativa no planejamento das ações.

Nós discutirmos juntos os problemas de cada setor, eles têm autonomia para trabalhar em seus setores... eu não sou centralizador, eu procuro fazer uma gestão participativa... discutir e planejar a melhor solução na nossa equipe de planejamento.(gestor da SMS D)

Este foi o único grupo focal de equipes em que o gestor de saúde participou. Todos os participantes forneceram contribuições importantes e demonstraram elevado nível de compromisso, respeito e compreensão sobre o papel e responsabilidade de cada um na APS.

A articuladora da atenção primária diz: atenção básica tem que resolver $80 \%$ da demanda. Eu não posso reclamar do meu corpo médico, são 4 médicos que atendem das 7:00 - 20:00. É difícil entrar em relação às condutas médicas. Eu não tenho pediatra, mas os médicos atendem todas as idades criança, adultos e idoso. Tento estimular as equipes em sempre querer desenvolver mais, sair do "quadradinho", 
fazer pela população, ou seja, para o povo! E se a atenção básica não vai bem, a culpa é minha! (gestor da SMS D)

No decorrer do grupo focal, o gestor e a equipe de saúde fizeram algumas reflexões sobre as possíveis razões do absenteísmo, como a falta de transporte seguro e adequado; o tempo de permanência na fila de espera, e a falta de conscientização da população. Os agendadores descreveram o trabalho de conscientização e a busca ativa dos usuários faltosos pela equipe da ESF.

Uma coisa legal que a gente vem percebendo, é que com trabalho realizado por nós junto a população, os pacientes estão vindo falar quando não dá pra ir! E a gente mostra o que tem de fila de espera, as cotas... algumas pessoas vem com intuito "brigar" com nós duas! Mas a gente mostra todas as nossas pastas, como funciona, aí depois desse contato a pessoa se acalma e vai embora mais consciente por isso é importante trocar uma ideia sempre! (agendador D2)

Em concordância com a indicação do AME Araçatuba sobre ser exitoso no controle do absenteísmo, o serviço de saúde do Município D demonstrou ser organizado, possuir um esforço em se interagir com os demais departamentos, como o de educação, serviço social, entre outros. 


\section{REFLEXÕES SOBRE OS DADOS}

Os dados advindos das entrevistas e grupos focais foram correlacionados com os documentos, relatórios e banco de dados do Portal CROSS apresentados pelos municípios e pelo AME Araçatuba. A análise descritiva e a analítica da realidade foram fundamentadas pelo levantamento bibliográfico.

\subsection{Por que os usuários faltam aos serviços de saúde do DRS II Araçatuba?}

São vários os motivos atribuídos ao absenteísmo: o esquecimento; a confusão sobre local, data e horário; a falta ou atraso do transporte; a percepção equivocada da relação saúdedoença; o imprevisto com familiares; a sensação de melhora; o desconhecimento do agendamento, e o agendamento realizado mesmo após o cancelamento ou o aviso que já não havia mais necessidade (Koshy et al., 2008; Perron et al., 2010; Travassos; Castro, 2012; Cavalcanti et al., 2013).

Os motivos encontrados na literatura, que condizem com os citados nesta pesquisa, foram: 1. Medo; 2. Esquecimento; 3. trabalho; 4. tempo de espera prolongado entre a solicitação e a data de agendamento; 5 . falhas na comunicação dos serviços com o usuário, o qual alega desconhecer o agendamento; 6. erros técnicos ou processuais;7. problemas com o transporte; 8. desconhecimento da importância do procedimento; 9. intercorrências no dia; 10. desconhecimento ou confusão em relação ao local, e 11. já havia realizado ou estava em tratamento na rede particular.

Dentre os motivos discordantes, ou seja, aqueles encontrados apenas na pesquisa, estão: 1. população idosa que necessita de acompanhante e acaba faltando na ausência deste; 2. insatisfação do usuário em aguardar o tempo de espera do transporte municipal, ou seja, aquele que depende de viagens e precisa ficar um período ou o dia inteiro em outro município, e 3. organização interna local sobre a manutenção de encaminhamentos e pedidos com o usuário, e este perder ou confundir os documentos.

Os motivos que apareceram somente na literatura e não fizeram parte dos resultados da pesquisa foram: 1. transtornos psiquiátricos ou dependência química; 2. morosidade no atendimento médico ou no exame (atrasos); 3. barreiras geográficas; 4. agendamentos 
realizados com mais de 30 dias de antecedência; 5. cuidado com dependentes, e 6. consulta concomitante.

As barreiras de acesso por dificuldade com o serviço de transporte são complexas e envolvem vários fatores, como oferta ou disponibilidade de veículo, tempo de espera, distância, atrasos e a quebra do veículo (Pesata et al., 1999; Hamilton; Gourlay, 2002; Van Van der Meer; Loock, 2008; Syed et al., 2013; Menendez; Ring, 2015). Chopra; Hookey (2016) e Hamilton; Gourlay (2002) acrescentam alguns outros desafios no processo de transporte, como dependência de transporte público; problemas de logística; necessidade de realizar parte da viagem de ônibus e a outra de trem, e as condições climáticas extremas.

Segundo estudo realizado por Menendez e Ring (2015), os usuários que vivem mais perto dos serviços de saúde são os mais propensos a perder consultas. O presente estudo apresentou outro dado. No município sede do AME Araçatuba, o motivo mais limitante, na percepção dos profissionais das quatro unidades de saúde: I, M, U e T, foi a barreira geográfica. Os funcionários relataram que os primeiros horários de atendimento no AME Araçatuba são complicados para a população que depende do transporte coletivo público.

O primeiro ônibus começa 6 h00 da manhã e tem que pegar dois ônibus, ou seja, daqui até o terminal, e do terminal até o AME. Não dá tempo de chegar até 6:30 no AME! (ACS I8 do Município A)

Eu já peguei (usuária que pertencia à microárea) e levei a paciente as 6:00 da manhã no AME, por que ela não ia chegar a tempo! (ACS U1do Município A)

No Município A, os problemas relacionados pelos profissionais com o transporte local foram: 1. a população em geral não tem auxílio e nem transporte para o AME pela Prefeitura; 2. inexistem linhas em algumas localidades, principalmente nas áreas rurais; 3. a logística do transporte municipal não é adequada, ou seja, há troca de carros no terminal da cidade para vários trajetos e há dificuldade de locomoção para alguns bairros da própria unidade de referência; 3. o horário de início do serviço é concomitante com os primeiros horários de atendimento no AME Araçatuba; 4. há risco de quedas; 5. há locais inadequados para esperar o coletivo; 6. há atrasos dos ônibus, entre outros motivos.

Não tem linha que vá até lá. Eles não têm condições de vim nem aqui. Então se tiver que vim aqui bem cedo, ... dependem de carona. (ACS M1 do Município A)

Temos pacientes que pegam um coletivo e vão até o terminal, lá no centro, e do terminal vem para cá para pegar o material com a gente. Para ir para casa, eles pegam o coletivo na rua de baixo, vão para o terminal novamente e para depois voltar para o bairro de residência. Na unidade, dependendo da hora da consulta do médico, se o coletivo atrasar, eles também perdem a consulta aqui. Por exemplo, 
agendou a paciente $10 \mathrm{~h} 00$ da manhã, ela tem que sair da casa dela umas $8 \mathrm{~h} 00 \ldots$ levam duas horas para chegar na USF! (auxiliar enfermagem M).

Muitos idosos que na hora que está subindo ou descendo do ônibus, motorista não espera! Eu sei porque a minha mãe passar por isso, ela tem 70 anos e não sabe dirigir! Ela está com os pés inchados, joelhos inchados, marca para ela no AME, ela pega coletivo, desce com maior dificuldade... quase acontecendo um acidente! Os motoristas não têm muita paciência, porque eles têm horário pra chegar no terminal, é uma correria e ao mesmo tempo atrasa!

[...] o idoso sai daqui, pega o ônibus até o terminal e troca por um outro (veículo) que vai chegar até próximo ao AME... (ACS T3 do município A)

Em dias de chuva, só vão aqueles que realmente estão morrendo de dor, porque se é algum que acha que pode aguentar mais um pouco eles faltam e avisam que não conseguiram ir... (enfermeiro I do município A).

Para o transporte de usuários dos Municípios B, C e D, que necessitam viajar diariamente, o tempo de permanência no AME foi descrito como fator determinante da maior parte das faltas e desistências. As prefeituras desses três municípios disponibilizam o deslocamento em dois turnos, geralmente uma saída às $5 \mathrm{~h}$, e outra às $12 \mathrm{~h}$ para os atendimentos do período da tarde, com retorno após o atendimento de todos no período, ou seja, após as $18 \mathrm{~h}$. A dificuldade apontada por todos os municípios foi a espera, principalmente dos usuários agendados no período das $10 \mathrm{~h}$ às $12 \mathrm{~h}$, pois o usuário tem que permanecer o dia inteiro no local devido a ser o horário de troca entre os turnos e a busca daqueles do período da tarde.

Foi marcada uma consulta para as 16:00 no AME Araçatuba, eles não querem ir de ambulância ao 12:30. Eles não querem esperar! Eles querem que eu arrume uma ambulância para levar ele no horário da consulta. (gestor do município B)

[...] o paciente que tem consulta na hora do almoço, vem desde cedinho e não consegue ser atendido a tempo para voltar com a condução da manhã. Muitas vezes eles vão embora, porque não consegue ficar o dia inteiro. (gerente de atendimento do AME Araçatuba)

Esse horário das 11:00 até 13:00 da tarde ... ou 10:30 ao 12:30 ... é muito puxado, por que ele (paciente) tem que ficar o dia todo. Por exemplo, o paciente agendado para 11:00, tem que sair 6:00 e voltar só no final da tarde, é muito ruim para o paciente. Por que eu tenho que sair com a minha van de lá no máximo 10:50, por que eu faço a linha da tarde, eles saem as 11:50. (responsável do transporte da SMS C)

Por exemplo as gestantes, são as agendadas para todas as consultas possíveis, para aproveitar o dia: psicóloga, nutricionista, médico, os exames... E elas não querem ficar aqui o dia todo.(CALL center do AME Araçatuba)

Em estudos realizados nos serviços de Atenção Secundária e Terciária, foram evidenciadas queixas sobre o tempo de espera entre a indicação e o agendamento das consultas, exames ou cirurgias, ou seja, quanto maior o tempo de espera, maiores são as 
chances de faltas do usuário (Collins et al., 2003; Chung et al., 2004; Partin et al., 2016). As equipes de saúde dos Municípios A, B, C e D concordaram com esse dado, e demonstraram em suas falas a influência direta no absenteísmo, como a realização no sistema particular ou no serviço de urgência e emergência; a melhora do quadro clínico.

[...] eles falam... “eu já até sarei!” ... eu estava com dor em tal lugar e já melhorei! Não vou mais não! (ACS C1 do município C)

[...] estava com dor de cabeça e a doutora passou oftalmo, e ele precisa urgente, mas ele fica meses na fila de espera! Muitas vezes eles pagam. Teve um caso de eu ir entregar a guia e o paciente já estava com os óculos no rosto! (ACS B3 do município B)

Acho que quando aumenta vaga na especialidade, a possibilidade é menor do paciente faltar! (médico do Município A)

[...] ultrassom, neurologista, ortopedista, endócrino às vezes o paciente nem lembra mais! (ACS M5 do Município A)

Porque demora tanto? Porque na minha área, os meus pacientes reclamam que esperar muito tempo, muitas vezes anos, e quando chama muitas vezes já está curado ou encontrou algum outro meio ou pagou no particular! (ACS I8 do Município A)

Se você está faltando no serviço, com dor... Você vai na consulta! Agora se demorar muito tempo, as vezes ele já melhorou, acabou sendo atendido com algum medicamento aqui pelo médico da família, por que o médico tem que iniciar algum tratamento! O paciente acaba fazendo o tratamento. Se ele se sentir melhor ele não vai mais! Acontece muito! (ACS M4 do Município A)

O paciente alega ter feito tal procedimento particular, que não precisa mais... (agendador D2 do Município D)

Segundo Bender et al. (2010), em estudo realizado com os usuários, profissionais de saúde e gestores da atenção secundária, os motivos de esquecimento, confusão de data e local são comuns. O esquecimento, dentre os motivos apontados na literatura, foi o mais comum, tanto nos primeiros estudos sobre absenteísmo como nos mais recentes (O’Brien; Lazebnik, 1998; Stone et al., 1999; Jamil; et al., 2011; Roberts et al., 2011; Izecksohn; Ferreira, 2014; Jeppesen; Ainsworth, 2015; Samuels et al., 2015; Ferreira et al., 2016).

Izecksohn e Ferreira (2014) investigaram a percepção dos usuários e equipes de saúde da família em um município brasileiro. O esquecimento também foi o fator mais identificado nas entrevistas. Porém, também houve referência ao desconhecimento e desinteresse dos usuários com a própria saúde.

O esquecimento foi apontado pelos profissionais de saúde da região do DRS II Araçatuba, mas, diferente da literatura, não foi o mais debatido nas entrevistas e nos grupos 
focais. O esquecimento esteve presente nos motivos relatados pelos participantes dos 4 municípios, e, como descrito na literatura, os profissionais relataram algumas tentativas de auxiliar os usuários, como a entrega do agendamento mais próximo da data, ficar relembrando durante as visitas domiciliar, sugerir a colocação do agendamento em locais de fácil visualização, entre outros, e também orientação sobre autocuidado - responsabilidade e conscientização sobre o próprio cuidado.

De uma maneira em geral os motivos são muitos ruins: chegou visita na hora que eu estava indo, perdi o ônibus, estava chovendo, esqueci, na hora aconteceu algum imprevisto, o coletivo atrasou, cheguei atrasado e fui dispensada, e até a justificativa de que naquele dia não estava doendo mais e ele não foi! (agendador SMS A).

Muitos esquecem da consulta ou marcaram outra consulta na mesma data. Tem muito disso aqui. (ACS C1)

[...] as ACS..., já tentaram entregar com antecedência, mas as pessoas esquecem. (agendador B)

Por que se entrega muito antes... o paciente acaba esquecendo. (agendador C1)

E eu sempre oriento a colocar os papeis do agendamento em local visível, como na porta da geladeira para não esquecer! (ACS C3 do Município C)

[...] eles perdem ou esquecem a consulta e vem aqui depois! (ACS T2 do Município A)

Sim... esqueceu, mas pra mim é tudo irresponsabilidade, por que são avisados! (responsável do transporte do Município C)

[...] tem aqueles que dizem: ahhh deixa, eu volto para fila e agendam de novo. Por isso que eu acho errado remarcar quem faltou! Porque quem precisa não falta! A não ser que tenha uma justificativa! (ACS U1 unidade U do Município A)

Dependendo da especialidade ou procedimentos, autores descreveram como causas mais comuns das faltas ou desistências o medo, a ansiedade ou avergonha, geralmente associadas a exames e procedimentos, como cirurgias e exames endoscópicos (Gonçalves et al., 2015; Ferreira et al., 2016; Chopa; Hookey, 2016). Estes preditivos foram relatados pelos profissionais que trabalham no AME Araçatuba e pelos ACS das USF do Município C, por meio das situações de falta ou desistência vivenciadas no trabalho com a população.

Em alguns exames como colonoscopia, as biópsias e ressonâncias... cirurgia de catarata também, tem muitas pessoas que faltam duas, três vezes, eu acho que é porque eles estão com medo da cirurgia.

A maior parte são senhores idosos que não entendem o preparo, outros tem medo, quando você liga e ele te fala: "ai fia, eu não fui por que tive medo".(CALL center do AME Araçatuba)

[...] na minha área já aconteceu, era um USG de próstata... E eu tinha confirmado, você vai mesmo? Certeza? Ele disse que iria, mas depois na visita domiciliar ele 
disse que acabou desistindo. Mesmo eu explicando que não era o toque retal... ele faltou! Acho que foi por vergonha.(ACS C6 do município C)

As faltas relacionadas a compromissos com o trabalho foram citadas nas publicações que relacionam os horários agendados ao período de trabalho ou recusa de dispensa ao trabalhador para cuidar da saúde (Gonçalves, 2013; Izecksohn; Ferreira, 2014; Ferreira et al., 2016). Esta razão foi apresentada pelos atores do Município B, pois muitos usuários argumentaram que não podiam perder o dia de trabalho nas fábricas. Os ACS do Município B explicaram que não é fornecido atestado médico na realização de exames e que, para não perderem os benefícios trabalhistas e na insegurança de perder o emprego, os trabalhadores acabam desistindo do atendimento. Já no caso de usuários idosos que dependiam dos filhos que trabalham para acompanhá-los, essa situação pontuada pela equipe T do Município A. Os usuários não compareceram devido à falta de acompanhantes.

$\mathrm{Na}$ nossa região, nós temos muitos idosos. E estes idosos moram sozinhos... Os filhos estão trabalhando, e hoje é difícil, porque o próprio trabalho está complicado para ficar liberando! E na crise de hoje, todo mundo tem medo de perder o emprego... (ACS T2 do Município A)

Se for na sexta-feira (a falta no trabalho), nas de fábrica de calçados, o trabalhador perde a sexta, sábado, domingo e até a cesta básica... (ACS B2 do Município B)

Ou por falta de atestado, devido ao serviço! O AME dá declaração para exames e atestado só para a consulta! Eles reclamam muito, por quê dependendo da firma, não aceita declaração! (ACS B1 do Município B)

Uma situação levantada pelas equipes da unidade I e T do Município A, e pelos motoristas do município $\mathrm{C}$ e $\mathrm{D}$, e não encontrada na literatura, foram os atrasos e intercorrências durante o trajeto ao AME Araçatuba. Os profissionais do AME Araçatuba relataram que o atraso estava sendo tratado de maneira diferente do que vinha sendo praticado no passado. As intercorrências com transportes durante o percurso, os idosos, os acamados ou com alguma necessidade especial e usuários em preparos de exames estão sendo atendidos, mesmo quando ocorre atraso.

A paciente estava indo, pneu do carro furou, o filho se atrapalhou um pouco pra trocar e mesmo saindo com antecedência de casa ela não chegou no horário do agendamento que ela estava esperando há dois anos. (ACS I9 do Município A)

[...] todo mundo estava trabalhando... daí o único jeito foi leva-la de moto, bem devagarzinho, nós saímos bem antes, mesmo assim a gente chegou uns minutinhos atrasados! Fiquei arrasada! (ACS T4 do Município A)

Já aconteceu comigo uma vez, eu expliquei que tinha acontecido um acidente na estrada e todos entraram! (motorista D1 do Município D) 
$\mathrm{Na}$ parte do transporte, o tempo que eles dãode tolerância (entrada no AME Araçatuba) é muito pouco. Já aconteceu de atrasar o carro e os primeiros pacientes não foram atendidos. Por exemplo os pacientes das 7:00 da manhã, não são todos que estão nesse horário, mas já aconteceu. Tentamos conversar, mas disse que não tinha jeito. (responsável pelo transporte do Município C)

O paciente aqui dentro tem um trâmite, para poder estar no consultório com a pasta e todos os documentos prontos para a consulta (Recall do AME Araçatuba)

Alguns municípios, quando quebra um veículo ou estão no caminho eles ligam avisando que vão atrasar... a gente consegue lidar. Mas parece mentira, os pacientes que mais atrasam são os daqui.(enfermagem do AME Araçatuba)

Hoje nós temos algumas exceções: o paciente idoso, acamado, com alguma necessidade especial ou em preparo de exames. Se for algum atendimento também não médico, a gente acaba dando uma contornada e atende..., mas dependendo do médico, ele não aceita! (gerente de atendimento do AME Araçatuba)

As instituições de saúde podem ser promotoras do absenteísmo. Na literatura, foram citadas razões para isso: 1. suspensão de procedimentos; 2. dificuldade com as agendas médicas e de exames; 3. avanço do horário programado, e4. indicações impróprias de encaminhamentos ou exames. Estas situações podem muitas vezes ser minimizadas por meio de medidas internas junto aos trabalhadores de saúde (Lira et al., 2001;Cavalcanti et al., 2013).

Estudo realizado por Pereira-Victorio et al. (2016) sobre o absenteísmo em consultas de um hospital universitário, indica que cerca de $13 \%$ das referências recebidas eram inadequadas do ponto de vista clínico. Dentre as justificativas de falta, a mais comum foi a melhora da doença.

Em concordância com os problemas apontados entre o não atendimento e a instituição de saúde, os profissionais da saúde dos Municípios A, B e C expuseram a necessidade da qualificação dos casos clínicos e preenchimento dos encaminhamentos realizados pela APS. Atores do AME Araçatuba comentaram as transferências de agendas médicas como um fator preditivo ao absenteísmo.

Agenda profissional daqui... hum, as transferências de agenda médica. Por mais que a gente tem todo um trabalho de organizar a agenda e a fala de que não pode fazer as transferências..., mas acaba tendo transferência! A transferência de agenda é uma coisa negativa! (gerente administrativo do AME Araçatuba)

A fila de espera cada vez aumenta mais! Então... O excesso de solicitação, de demandas que as vezes não é realmente precisa... porque quando sai a vaga, muitas vezes ele já fez!

É uma demanda que a própria população cria. Não é realmente pela necessidade. Eu vejo isso: quem realmente precisa não falta! Quem está com dor, eu acho que não falta! Ou as vezes, o tempo de espera pela consulta muito grande. (gestor SMS C) 
O grande problema nosso é o médico! Eles passam exames e consultas para qualquer paciente que pede o encaminhamento exame. Nosso problema é interno! (agendador do Município B)

[...] vem na consulta pedindo encaminhamento... é um costume que tem por aqui. Mas se deve avaliar se realmente precisa! Tem muito clínico fazendo consulta e encaminhando todo mundo! E aí descompensa a função do postinho com o que tem na especialidade! (médico da unidade M do Município A)

Outras pesquisas evidenciaram que muitos motivos podem ser reduzidos ou eliminados por meio da reorganização de fluxos internos e melhora no processo de comunicação (Garg et al., 2009; Bender et al., 2010; Hovlid et al., 2013; Tristão et al., 2016). As equipes do Município A e do AME Araçatuba descreveram os motivos relacionados à comunicação, como: 1. dificuldade do usuário em entender as informações dadas e 2. erros no fluxo de comunicação, em que o usuário não é avisado ou não sabe qual o serviço que entrou em contato ou em qual serviço ele deverá comparecer.

[...] acontece nas orientações simples... ontem mesmo veio um paciente e a recepcionista orientou que ele deveria ter parado de usar o cálcio, mas o paciente entendeu que não podia vim de calça! Eles têm muita dificuldade de compreensão. (gerente de atendimento do AME Araçatuba)

Tem muitos pacientes que nós ligamos para reforçar os exames externos e o paciente fala que nem estava sabendo do agendamento do exame! (Recall do AME Araçatuba)

Às vezes a pessoa tem um retorno, e aguarda outros agendamentos, e ela não sabe dizer quem foi que ligou. Não sabe se foi alguma consulta que o médico da família solicitou ou se é seu retorno do AME! (Auxiliar enfermagem M)

Ainda em relação à instituição de saúde e reorganização de fluxos, alguns estudos descrevem o não atendimento de usuários, principalmente em centro cirúrgico e ambiente hospitalar. São motivos denominados como erro técnico ou administrativo e de comunicação, e foram descritos como dispensas ou faltas evitáveis pelos serviços de saúde (Andrews et al., 1990; Rodriguez et al., 2007; Garg et al., 2009). O AME Araçatuba propôs mudanças de fluxos internos e a realização de reuniões junto ao Núcleo de Regulação do DRS II Araçatuba para conscientizar e sensibilizar os atores dos 27 municípios de sua referência.

[...] a outra estratégia que usávamos eram nas reuniões do DRS com os municípios, era levado essa questão do absenteísmo para os gestores afim de sensibilizar os municípios. (enfermeiro do AME Araçatuba)

[...] agora estas reuniões são trimestrais, com pessoal do DRS, do AME e municípios da área de abrangência. É falado sobre a importância do paciente não faltar nas consultas médicas e exames. A gente apresenta os dados mais relevantes e tentar sensibilizar mesmo os representantes dos municípios! Esta reunião é para os gestores, agendadores e representantes da atenção primária dos municípios! (gerente administrativo AME Araçatuba) 
Os motivos do absenteísmo são variados e mudam conforme o cenário no qual ocorrem, mas as ações gerenciais podem fortalecer junto à população a conscientização e a responsabilidade sobre o autocuidado. Para tanto, é necessário que os profissionais de saúde compreendam seu papel no processo de acesso do usuário ao serviço de saúde, para que contribuam para a comunicação efetiva e reorganização dos fluxos. A criação do setor de Recall do AME Araçatuba pode ser um exemplo das ações citadas, inicialmente nos exames de colonoscopias e endoscopias, pois os relatórios do Portal CROSS possibilitavam conhecer quem eram os faltosos, mas não os motivos que levavam os usuários a faltar.

\subsection{Conceitos, tecnologias e estratégias de enfrentamento do absenteísmo nos serviços de saúde da DRS II Araçatuba}

Foram várias as tecnologias e estratégias sugeridas e implantadas pelos serviços de saúde pesquisados da região do DRS II Araçatuba. A maioria delas era condizente com as publicações estudadas.

\subsubsection{Sistema de informação em saúde}

Os sistemas de informação e a tecnologia móvel têm sido desenvolvidos rapidamente e conquistado espaço importante nos serviços de saúde (Paschoal e Gatto, 2006). A SES utiliza o Portal CROSS no auxílio à regulação de vagas na maioria dos serviços do estado e disponibiliza aos municípios a ferramenta de apoio para inserção de serviços sob gestão municipal. O Município A difere dos Municípios B, C e D, pois possui uma central de agendamento que gerencia a demanda por recurso inserida em sistema de informação próprio.

$\mathrm{O}$ agendamento do Município A ocorre conforme a fila de espera do sistema próprio municipal, mas somente depois de contato telefônico com o próprio usuário para confirmar a necessidade e interesse pela vaga. Após agendado, o usuário é orientado a buscar a filipeta na unidade de saúde de sua referência com o encaminhamento ou pedido de exame. A entrega e orientações são realizadas pela recepção das unidades de saúde. As unidades de saúde recebem semanalmente uma planilha com todos os agendamentos de seus munícipes por email. 
...eles (AME Araçatuba) passam sempre os relatórios, que já chegou a 30\% (o absenteísmo) e agora deu uma caída, as meninas me passam os relatórios e eu vou olhando. (gestor da SMS A do Município de Araçatuba)

Recebemos, mensalmente, relatórios sobre os pacientes dispensados por falta de encaminhamento, de pacientes que chegaram atrasados, agendamentos incorretos...(responsável pela central de agendamentos do Município A)

Os Municípios B, C e D utilizam o sistema CROSS como recurso informatizado para auxílio na gestão da saúde. O gestor do Município C utiliza os relatórios do Portal CROSS e tem o costume de discutir com os responsáveis pelo agendamento para tomar decisões administrativas, como a compra de serviço em consórcio. O Município D possui serviço de tecnologia de informação que auxilia com relatórios, mas pouco utiliza os serviços oferecidos pelo Portal CROSS. E os Municípios B, C e D utilizam do trabalho da ESF no aviso, entrega e orientações sobre agendamentos de consulta e exames.

O AME Araçatuba também utiliza o Portal CROSS para disponibilizar oferta. Utiliza SMS para celulares, e-mails e ligações telefônicas por meio do Call Center e Recall para avisar aos usuários sobre agendamentos das interconsultas, retornos e exames internos. Mais recentemente foi criado o controle na portaria de acesso ao atendimento, por meio de registro diário preenchido pelos porteiros sobre os motivos das dispensas. Este relatório mensal é enviado aos municípios por e-mail para ciência e providência.

Sem dúvida o sistema de informação e as tecnologias são importantes para auxílio na comunicação e regulação da oferta de serviço público do estado de São Paulo, mas ainda falta aprimorar módulos do sistema CROSS, como os relatórios anuais por município, a exclusão do usuário agendado no CDR por cruzamento de palavras-chave e a integração ou interface com os sistemas municipais já existentes.

5.2.2 Utilização da estratégia da saúde da família como ferramenta na prevenção de faltas

A visita domiciliar é a principal atividade dos ACS e deve ser um mecanismo de enfrentamento ao absenteísmo (Cavalcanti et al., 2013). Segundo Tristão et al. (2016), em comparação às características entre as unidades de saúde, foi possível identificar menores taxas de absenteísmo nas USF quando comparadas com as taxas na UBS. O Ministério da Saúde preconiza que cada agente de saúde seja responsável por uma microárea que corresponda a pequenos aglomerados de famílias, não ultrapassando 750 pessoas (Brasil, 2017). 
O Município A é o maior dentre os entrevistados e possui uma cobertura de $80 \%$ de ESF. O gestor de saúde descreveu várias reuniões realizadas junto à APS e, em diversas situações, valorizou o trabalho das equipes no cuidado próximo ao usuário, em especial a dos ACS. Durante toda a sua entrevista, mostrou-se interessado e disposto a reorganizar os fluxos, buscar experiências exitosas e otimizar os recursos existentes. As quatro unidades I, M, T e U indicadas pelo gestor, possuem dinâmicas e fluxos distintos no mesmo município.

Portanto, mesmo o Município A sendo apontado como um caso traçador de dificuldade no controle do absenteísmo, as duas equipes exitosas, Unidades de Saúde I e M, demonstraram interesse pela problemática discutida e contaram com a participação de equipes mais completas nos grupos focais. Demonstraram ações isoladas por iniciativa das próprias equipes como a sobrecarga de agenda para reavaliar os usuários que perderam o encaminhamento; a impressão das filipetas dos usuários que não vieram buscar; o auxílio dos ACS nos avisos, e a entrega da filipeta com "grampeadores" nas bolsas, para organizar os documentos necessários no sentido de o usuário não ser dispensado.

Nas Unidades T e U do Município A foi possível identificar falha de comunicação, mesmo na organização de grupo focal, e o baixo grau de integração das equipes. Os ACS e a recepção não tinham conhecimento da atividade proposta. Em cada um desses grupos focais participaram apenas os ACS e um representante da recepção. Os grupos focais foram espaços de manifestação de ansiedade e angústia em algumas situações, uma percepção equivocada sobre a distribuição de vagas, conflitos internos e sobrecarga de trabalho.

O Município B é pequeno, com cobertura de $100 \%$ de ESF. Possui um Centro de Especialidades, utiliza grande parte dos recursos financeiros da Prefeitura na compra de serviços em saúde, mas demonstrou ter dificuldade na organização gerencial. Foi possível verificar esforço e compromisso de todos os setores estudados, pois agendam em bolsão consultas e exames além do disponibilizado; possuem organização de transporte, considerando as necessidades dos usuários e em dois turnos, e realizam os avisos de agendamentos pelos ACS, inclusive da extensa região de assentamentos. Porém, as equipes trabalham de maneira fragmentada. Isso foi observado nos grupos focais que ocorreram separados por locais onde estão alocados e por categorias profissionais. No grupo focal com a ESF, participou apenas os ACS, pois o profissional enfermeiro permaneceu no local em que acontecia a atividade, mas não contribuiu com qualquer explanação. $\mathrm{O}$ grupo focal com os setores de transporte e agendamento ocorreram em um segundo momento. 
As faltas ocorrem na cidade em geral, não é exclusivo das áreas mais vulneráveis. Sobre o enfrentamento do absenteísmo... eu por aqui não consegui fazer nada, agora eu não sei se o agendador conseguiu fazer alguma coisa... alguma inovação ou pensou alguma coisa. Por que o agendamento fica lá em baixo mesmo. (gestor do município B)

Todos os aspectos supracitados decorrem do tipo de gerência, que produz ansiedade, insegurança e conflito nas equipes. Não basta que os trabalhadores compartilhem a mesma situação de trabalho ou que estabeleçam relações pessoais, é imprescindível a prática comunicativa para que haja reconhecimento e entendimento mútuo na realização de um trabalho articulado e planejado.

Os gestores dos Municípios C e D demonstraram integração entre a gestão de saúde e as equipes da APS. Estes dois municípios evidenciaram, por meio dos grupos focais, participação ativa e organização dos atores envolvidos no processo de atendimento dos usuários no AME Araçatuba, além dos relatórios sobre o controle de absenteísmo. Por meio dos relatos dos gestores destes municípios foi possível identificar compromisso e responsabilidade na atenção primária, na prevenção e promoção de saúde e na função reguladora para os demais níveis de complexidade. A gestão que se apropria da situação de saúde do município e mantém relação de integração com as equipes consegue manter o controle do absenteísmo e, consequentemente, contribui para o fortalecimento do SUS.

Segundo Gonçalves et al. (2015), as estratégias de valorização do trabalho em equipe, por meio da seleção dos problemas a partir do interesse coletivo e a viabilização de resolução de problemas pelos profissionais, conseguiu reduzir em $66 \%$ o absenteísmo e problemas de adesão na experiência estudada. A educação dos profissionais da porta de entrada no SUS e o matriciamento da atenção primária pela atenção secundária foram sugeridas como estratégias para prevenir a ocorrência de absenteísmo (Bender et al., 2010; Gonçalves, 2013). A qualificação pelo matriciamento, segundo o gerente administrativo do AME Araçatuba é uma proposta em discussão e deverá ser implantada em breve. A equipe I do Município A identificou a resistência da população em ser avaliada pelo médico da Atenção Primária.

Porque o paciente chega para o médico e já fala: quero ortopedia no AME, oftalmologista do AME... E você vai conversar com os pacientes, e pergunta porque o AME? E aí pensamos... O paciente passa pelos nossos médicos da atenção básica, depois no médico especialista que faz outro encaminhamento e em um papel errado, o paciente volta para o nosso médico para transcrever, e ele é colocado na fila novamente... até que por último e quarta vez é atendido no AME! (enfermeiro da Unidade M do Município A) 
Os médicos do ambulatório do município, estão se aposentando e não está havendo reposição! E aí vai ficando mais sobrecarregado o AME. Imagino o tamanho da fila! (ACS M9 do Município A)

A população, por outro lado, deve ser orientada a reconhecer a importância dos níveis de atenção à saúde, sobre sua responsabilidade na saúde individual e coletiva, sobre as consequências das faltas na interrupção do tratamento e consequente diminuição de acesso aos demais usuários que aguardam tratamento. A postura autoencaminhadora dos usuários, desvalorizando a função da APS por meio da solicitação de exames e encaminhamentos aos especialistas, gera uma demanda por recursos desnecessária. Além de não ser uma demanda real, a maioria desses usuários falta aos compromissos, o que caracteriza um comportamento consumista e não de usuários da saúde que necessitam de cuidados.

[...] minha médica é do programa mais médico, que solicita os exames e avalia, mas o paciente sai e reclama eu queria encaminhamento para ortopedia e não um raio X! Mas a doutora disse, eu preciso primeiro do seu raio X, para saber se realmente você precisa ir para o ortopedista!

Os pacientes falam: eu não quero uma consulta! ...enfermeira, eu quero um encaminhamento! Aos poucos, estamos tentando mudar isso, nós levamos a médica lá na casa do paciente, agendamos com prioridade em alguns casos... e é um trabalho cultural também! (enfermeiro I do Município A)

Os gestores e profissionais que trabalham na saúde devem ter o compromisso de fortalecer as equipes de saúde da APS, além da efetividade do cuidado nos ambulatórios municipais e consórcios para absorver a extensa demanda por recursos, principalmente considerando a de necessidade de cuidados crônicos e de acompanhamento contínuo.

\subsubsection{Otimização dos meios de comunicação}

A melhora na comunicação entre os serviços é abordada no estudo de Killaspy et al. (1999), no qual foi detectada a necessidade de referência e contrarreferência de qualidade, além de responsabilização sobre o usuário faltoso, a falha de comunicação entre o clínico geral que encaminha e o especialista que não efetiva a avaliação e também não se sensibilizava. Neste sentido, para a conscientização e controle de usuários faltosos e dispensados, o AME Araçatuba informa todos os municípios mensalmente por e-mail relatórios com a data, identificação dos usuários e motivo de dispensas.

[...] a partir destes relatórios a gente começou a buscar alguns casos... aquelas faltas que o AME está mandando para nós, para saber os motivos das faltas! (enfermeiro Ido Município A) 
[...] a gente pega estas listas e vai ver o que está acontecendo, e uma dessas questões eram estas: foi avisado? Mas eles não tinham sido avisados... e foi aí que nos levou a atitude de confirmação direta com o paciente! (agendador do Município A).

A comunicação adequada entre médicos da APS, usuários e especialistas é fundamental para o acompanhamento e sequência do cuidado proposto. Nos serviços de saúde, o compartilhamento adequado das informações entre cuidados primários e secundários ocorre por meio de referências e contrarreferências. As referências devem conter informações sobre o motivo de encaminhamento, medicação em uso, história pregressa, sintomas atuais e legibilidade. A contrarreferência deve caracterizar o estado atual do usuário, um resumo do problema, diagnóstico, tratamento proposto e arranjos de acompanhamento (Killaspy et al.; 1999). Segundo estudo realizado por Bender et al. (2010), os encaminhamentos são provenientes de outros serviços de saúde, públicos e privados, para as especialidades na AS. Os usuários encaminhados são reavaliados, tendo em vista, respectivamente, a necessidade de contrarreferência completa e alguma forma de regulação necessária.

O AME Araçatuba atende os usuários encaminhados pela atenção primária ou secundária com a guia de referência e solicitação de exames. As contrarreferências são encaminhadas por malotes aos municípios uma vez por semana, mas o Município A foi o único que havia optado pela entrega direta aos usuários. As equipes de saúde da Unidade I, uma das unidades exitosas do município A, fizeram alguns apontamentos sobre a necessidade de receber as contrarreferências do AME Araçatuba e a dificuldade com as altas acompanhadas de orientação de retorno em seis meses, pois o usuário não entrega na unidade e a fila fica com um ano de espera.

Não recebermos as contrarreferência dos diagnósticos já fechados, a gente não sabe
quais orientações foram dadas, nós não temos o controle dos medicamentos que
deveriam ser acompanhados e os retornos.
[...] altas com indicação de retorno depois de seis meses. Sendo que aquela
especialidade para nós tem fila de um ano de espera. Muitas vezes o paciente
(guarda o relatório de alta) vem com esse papel somente próximo à data do retorno!
(enfermeiro I do Município A).

O uso de telecomunicação para aviso e informação aos usuários é utilizado amplamente, pois há estudos que descrevem a eficácia e a viabilidade financeira. O recurso de SMS é utilizado isoladamente ou em conjunto com outras ferramentas no aviso de agendamentos, como a ligação telefônica. A utilização destes recursos são estratégias recomendadas por pesquisadores e são consideradas econômicas e eficazes na diminuição do absenteísmo (Youssef, 2014; Guy et al., 2012). A telefonia móvel se tornou um fácil, rápido e eficiente canal de comunicação (Nhavoto; Gronlund, 2014). 
Os lembretes por $S M S$, além de ser a estratégia mais econômica, facilitam o cancelamento por resposta em contato telefônico disponibilizado ou por resposta pelo próprio sistema de SMS (Koshy et al., 2008; Altuwaijri et al., 2012). Segundo Roberts et al. (2011) $52 \%$ dos entrevistados concordaram com um sistema "amigo de lembrete", ou seja, aviso de agendamento para o usuário e para um amigo ou parente.

$\mathrm{Na}$ utilização de recursos de telecomunicações, alguns autores recomendam o uso de "pacotes de informações", que são intervenções sequenciais: cartas de comunicação, seguidas de $S M S$ e, por fim, ligação na antevéspera ou véspera. Esta medida permitiu o reaproveitamento de 28\% das vagas canceladas (Hardy et al., 2001; Perron et al., 2010). Os lembretes múltiplos, segundo Hasvold e Wootton (2011) são os conhecidos como "fadiga de lembrete", que consiste no envio de mais de um SMS automatizado, programado para o mesmo destinatário. O AME Araçatuba faz uso dessas estratégias de lembretes por SMS, ligações de avisos, além de religações pelo Recall nas 48 horas que antecedem a consulta ou exames.

A estratégia que teve mais impacto positivo no absenteísmo foi o Recall! Além das ligações de comunicação que são feitas com sete dias de antecedência... o Recall com 48 hs foi o que ajudou muito! A ponto deles, no começo, até reclamar! (risos). Porque estávamos ligando demais. Hoje eles não estão reclamando porque já acostumaram! (gerente administrativo do AME Araçatuba).

Apesar dos estudos citados, os recursos de sistema de lembrete por SMS e e-mail para o usuário - com data, local e horário da consulta ou exame -, implantado pela Secretaria de Saúde do Estado de São Paulo para fortalecer a regulação de ofertas foram considerados pelos trabalhadores da equipe do AME Araçatuba ineficientes na proposta de auxiliar nos avisos de retornos, interconsultas e exames. Segundo esses atores, tais recursos até confundiam os usuários em algumas situações. Alguns experimentos e auditorias também consideram que tanto o uso de lembretes quanto os e-mails não causaram impacto significante (Haynes; Sweeney, 2006; Narring et al., 2013).

Na verdade, nós não temos governabilidade sobre esse serviço, não conseguimos saber se a informação realmente ajuda.... se a cobertura é de $100 \%$. Porque eu sei que tem pessoas que recebe e outras que não! E nem o tempo de antecedência que eles irão receber! (gerente administrativo AME Araçatuba)

[...] mandam (CROSS) mensagens para todos os pacientes que possuem no cadastro o número de celular. Eu enquanto paciente não acho o $S M S$ efetivo, porque eu recebi algumas vezes e as informações são muito sucintas e incompletas! (enfermagem AME Araçatuba)

Muitos pacientes estão acostumados com o $S M S$ e falam que não podem atender no momento e que depois vão ler a mensagem. (Call Center do AME Araçatuba) 


\begin{abstract}
A mensagem só traz que você tem uma consulta... tal horário e tal data, e não fala qual é a especialidade! (gerente administrativo AME Araçatuba)

[...] prefiro avisar pacientes que não receberam nenhum SMS... e não é todo mundo que recebe realmente! (Call Center do AME Araçatuba)

O paciente fica confuso, essa mensagem padrão orienta levar a filipeta. Daí a paciente briga no postinho briga com a gente e temos que orientar que para o retorno não é obrigatório porque é um agendamento interno nosso! E aí a gente tem que fazer a orientação explicar tudo certinho! (Recall do AME Araçatuba)
\end{abstract}

A mensagem de texto padrão do $S M S$ enviado pela SES com a CROSS não diferencia as informações entre os agendamentos de primeira consulta e os de retorno e interconsulta. Portanto, há orientação de levar filipeta com o encaminhamento no dia, horário e local. Porém, por serem solicitações internas do próprio AME Araçatuba, nos casos de retornos e interconsultas, o usuário não recebeu o encaminhamento e essas informações equivocadas geram mais dúvidas e retrabalhos para o Recall e para os profissionais de saúde do Município. Nos casos de transferência de agendas, dependendo do período, o sistema envia SMS para os usuários com a data anterior à de agendamento, e o usuário liga para esclarecer o conflito de informações. Ainda tem aqueles que acabam indo na data indicada no SMS.

Os lembretes por $S M S$ e e-mails para os usuários são ferramentas de comunicação convenientes, econômicas de autogestão, e eficazes na prevenção de absenteísmo. As mensagens enviadas pelo CROSS podem e devem ser reavaliadas e alteradas, como modificar o texto padrão, personalizar quando for aviso de primeira consulta e quando for de retorno e interconsulta, e, até mesmo, implantar um sistema de confirmação, ou seja, SMS ou e-mail com opção de resposta: 1. Confirme, 2. Cancelar e 3. Mudança, facilitando e orientando as prioridades do Recall para um novo contato ou até uma linha exclusiva para o contato do usuário que quiser realizar cancelamento ou mudança.

\title{
5.2.4 Manutenção dos cadastros atualizados
}

Outra importante estratégia que se faz necessária, inclusive para garantir o funcionamento dos meios de comunicação citados anteriormente, é a atualização constante dos cadastros dos usuários atualizados. O uso de lembrete telefônico reduz o não atendimento dos usuários, porém os cadastros devem conter número de telefones atualizados. Estudos descrevem que mais de $50 \%$ dos indivíduos não contatáveis possuíam cadastros desatualizados (Roberts et al., 2007; Bender et al., 2010; Jamil et al., 2011; Altuwaijri et al., 
2012; Filippidou et al., 2014). Todas as equipes dos Municípios A, B, C e D e do AME Araçatuba relataram a dificuldade com os dados cadastrais desatualizados e o uso de endereços de outras pessoas para ter acesso a serviço de outras localidades.

[...] as trocas de endereço e aqueles que usam endereço de outras pessoas, por exemplo, a minha mãe mora no bairro e eu uso o endereço dela para passar na unidade básica de Saúde X, entendeu! Aí a pessoa vai lá faz a consulta e entrou no sistema. Depois na hora de localizar essa pessoa, ninguém sabe quem é, as agentes não conhecem esse paciente. Isso ocorre muito e dificulta o trabalho deles também. E o nosso também porque você acaba perdendo tempo em buscar localizar esse paciente! (enfermeiro M do Município A)

Os profissionais do AME Araçatuba salientaram que as ações realizadas pela comissão interna de acompanhamento do absenteísmo do AME Araçatuba relacionados à manutenção de cadastros atualizados devem ser constantes. As campanhas realizadas nas dependências do AME Araçatuba - como o teatro, coral, vídeos, mensagem eletrônica para os usuários, e reuniões junto aos agendadores e gestores municipais-são importantes para a conscientização e corresponsabilidade de todos na saúde.

[...] foi feito também o teatro, vídeos para passar na recepção falando justamente disso, sobre a importância de não faltar nas consultas e a importância de manter atualizado o cadastro. (telefonista do CALL center do AME Araçatuba)

Sobre isso aí (cadastros atualizados) precisa de um incentivo maior, não só o AME isoladamente, mas a própria Secretaria do Estado, ela tem as campanhas dela e deveria fazer uma propaganda, mas intensificada a respeito desse problema! $\mathrm{O}$ paciente usa o serviço do AME, ele tem que manter os dados dele atualizado!

Eu realmente não sei se os municípios têm a noção da importância do cadastro atualizado para o trabalho de todos! Às vezes a gente vê que um paciente foi cadastrado com o nome errado. E a gente fica procurando! Eu já enviei os dados do paciente para a Secretaria Municipal e eles encontraram, porém, o cadastro estava com o nome errado do paciente, estava com "i" ao invés de "e". (gerente administrativo do AME Araçatuba)

Portanto, as ações junto aos usuários e serviços de saúde relativas à importância e à conscientização para que mantenham os cadastros atualizados é fundamental para viabilizar a comunicação efetiva.

5.2.5 Utilização de audiovisuais, tecnologias e cartazes na educação e prevenção do absenteísmo

Sobre as estratégias que ainda podem ser implantadas para melhorar a prevenção do absenteísmo, as equipes pesquisadas sugeriram ações de conscientização da população por meio das ESF durante as visitas domiciliares, o uso de banners ou cartazes para divulgação de indicadores e planilhas com quantidade de perdas e demanda reprimida. 
Se você perde, ... é você e outro paciente que aguarda que perde! Eu fico lá lembrando... não esquece, você tem a consulta! Falamos em todas as visitas domiciliares! A gente explica da importância. (ACS C4 do município C)

[...] colocar uma relação de número de faltosos por especialidade ...um cartaz para conscientização de tantas vagas desperdiçadas por exemplo. (agendador D1 do município D)

[...] 857 pessoas deixaram de ir nas consultas do ambulatório da Santa casa Araçatuba, dá pra ver na hora que você chega lá... tinha um cartaz falando que as pessoas não foram e não avisaram. No AME eu acredito que é assim, deve ser parecido. (auxiliar enfermagem, unidade de saúde I do município A)

[...] numa cidadezinha aqui perto, estão colocando banner na frente da o UBS, pra conscientizar o pessoal e não perder a consulta, porque estão faltando muito, quantas consultas eles perderam no mês. Eles já estão fazendo isso! É uma estratégia... (ACS M9, unidade de saúde M do Município A)

O núcleo de regulação do DRS II, em conjunto com o AME Araçatuba, tem discutido e fortalecido as estratégias para diminuir o absenteísmo, e tem trazido para as reuniões trimestrais exemplos de municípios com experiências exitosas para um relato de experiência e apresentação de ideias e enfrentamentos.

5.2.6 Os encaminhamentos e pedidos de exames que aguardam por agendamento devem permanecer guardados pelo usuário ou pelos serviços de saúde?

O fluxo e a organização dos encaminhamentos para especialidades e os pedidos de exames não foram descritos nas publicações estudadas. Os Municípios A, B, C e D possuem características diferentes, tanto na dinâmica de agendamento como na dinâmica de aviso aos usuários agendados.

O Município A foi o único dentre os quatro estudados que mantinha os documentos de encaminhamento e pedidos sob a guarda dos próprios usuários. Houve um período em que a guarda e o agendamento das consultas e exames foram realizados pelas unidades da APS, mas isso foi mudado justamente por causa do desperdício de recursos. Nos grupos focais, foram identificadas muitas divergências de informação e opinião entre as equipes $M, U$ e T. A equipe de saúde I não refletiu sobre essa situação, pois já realiza ações isoladas para melhorar o contato com os usuários. As equipes de saúde $\mathrm{M}$ e U descreveram como era a organização do agendamento, comunicação com o usuário, cancelamento e troca de usuários quando os documentos permaneciam nas unidades de saúde.

Antigamente, os encaminhamentos ficavam aqui no posto. Aí a própria recepção era quem ligava para marcar e era o agente que entregava. Aí o que acontece, quando a 
gente entregava e a pessoa dizia que não queria, e nós já sabíamos quem era a outra pessoa do bairro que precisava e já remarcava. E aí não perdia tanto, porque a gente já sabia quem estava precisando verdadeiramente. (ACS M1 do município A)

Houve uma época, que o agente comunitário entregava o agendamento para o paciente. Nessa época não tinha tanta falta... A gente levava diretamente na mão do paciente, já sabia se ele realmente ia ou não. E tudo era marcado na nossa folha de visita e a gente voltava lá para cobrar! Hoje em dia isso se perdeu, a gente nem fica sabendo paciente que está agendado. (ACS U1 do município A)

Nas equipes de saúde da APS, o gestor e o responsável pela central de agendamento do Município A e os representantes do AME Araçatuba apresentaram opiniões e sugestões sobre os encaminhamentos para especialidades e os pedidos de exames, assim como para a realização dos agendamentos destes. A trabalhadora do AME Araçatuba advertiu sobre a ocorrência de dispensas motivadas por erro na documentação, e salientou que os usuários, muitas vezes, aguardam mais de um recurso de saúde e comparecem no AME Araçatuba com encaminhamento ou pedido incorreto.

Eu acho que voltando para a unidade, iria melhorar muito. Porque nós, não estaríamos fazendo nada mais que a nossa função, porque nós vamos na casa dos pacientes e dá para ver de perto se ele vai, se ele foi... E a gente poderia realizar um relatório, até lançar no prontuário eletrônico, para ele não ser agendado mais... porque quem precisar vai! (ACS U1 do Município A)

Isso tudo saiu das nossas reuniões, eles disseram que os pacientes perdem os encaminhamentos, então uma de nossas propostas será de rever dos encaminhamentos ficarem nas unidades básicas (gestor do município A).

Se o encaminhamento ficar nas unidades básicas de saúde, dá para fazer um trabalho muito melhor, modifica toda a logística. A gente manda tudo... aí na unidade Básica de Saúde, eles separam os encaminhamentos por agente comunitário e eles voltam a entregar! Muda muito! (central de agendamento do Município A)

Eu acho que esses pedidos de exame e consultas não deveriam ficar com os pacientes porque eles perdem! E aí ele vai na UBS e eles falam que era obrigação dele guardar e aí a gente não consegue ajudá-lo aqui pelo AME. Agora tem municípios que ficam com eles no setor do agendamento os encaminhamentos médicos! E aí tem mais controle, é muito mais efetivo do que deixar com paciente... porque eles perdem ou tem mais de três pedidos e na hora de pegar o pedido correto... eles se confundem e aparecem com pedido errado aqui! (Recall do AME Araçatuba)

Houve opiniões divergentes nas unidades de saúde T e U quanto à permanência dos encaminhamentos com os usuários ou nas unidades de saúde. Também em relação ao aviso e entrega da filipeta voltar a ser realizada pelas unidades.

Antes, o agendamento era aqui! Mas era a mesma coisa! Mesmo a gente entregando a filipeta, os pacientes não vão! (ACS T2 do Município A)

Todos: sim, muitos perdem o encaminhamento... a maioria!

Tem gente que perde com um mês! Não sabe onde colocou! (ACS T5 do Município A) 
Teve uma época que era assim, os encaminhamentos eram guardados nas unidades de saúde, mas perderam todos os encaminhamentos. Perde-se na mão do paciente, ...perde também na unidade. Assim que abriu o AME... foram caixas e caixas jogadas no lixo de encaminhamentos! Foram jogados fora! Eu sei por que eu estava aqui! É por isso que não deixam mais aqui. Guarda na pasta do paciente, de repente esta pasta some!

Acho que os encaminhamentos devem ficar com os pacientes, eles têm que ter responsabilidade sobre a saúde deles (ACS U10 do Município A)

A discussão sobre o assunto surgiu nos grupos focais espontaneamente, como uma inquietação, e foram exploradas conforme a necessidade e atitudes dos grupos. Foi realizada pela pesquisadora uma provocação da discussão de ideias, de opiniões e o encorajamento para discutir estratégias e perspectivas sobre o absenteísmo no Município A.

Nos Municípios B, C e D, o controle e organização dos encaminhamentos e pedidos de exames são realizados pelas unidades de saúde ou setores de agendamento, e não foram apontados problemas sobre a perda de encaminhamentos, dispensas por documentos incorretos, entre outros problemas discutidos no o Município A.

5.2.7 Tempo adequado para o aviso, mensagens e telefonemas para o usuário não esquecer!

Em relação ao tempo de antecedência do aviso por mensagens ou telefonemas, experimentos e estudos retrospectivos evidenciaram a diminuição da taxa de falha no atendimento e recomendaram como estratégia de prevenção, considerada a economia, a autogestão, a conveniência e a eficácia (Downer et al., 2006; Gurol-Urganci et al., 2013). As mensagens e telefonemas foram testados e tiveram resultado positivo quando utilizados com 24 horas de antecedência e até sete dias antes do compromisso agendado (Tzias et al., 2006; Perron et al., 2010).

O lembrete por SMS e o e-mail são enviados automaticamente pelo sistema CROSS nos sete dias que antecedem a consulta ou exame. Os Municípios A, B, C e D e o AME Araçatuba aplicam essa estratégia do tempo de antecedência nos avisos realizados pelo Call Center e Recall do AME Araçatuba, e nos municípios pela entrega das filipetas e documentação aos usuários.

[...] eu, por exemplo, já peguei filipeta para dezembro, e não costumo entregar muito antes, porque se eu entregar muito antes, eles podem esquecer ou perder o encaminhamento... Todos os encaminhamentos que entregamos a gente registra e o paciente assina! Para não dizer que não recebeu! (ACS I7 do Município A)

[...] eu também não entrego muito antes! Eu espero o final do mês para entregar! (ACS I6 do Município A) 
As agentes de saúde, já tentaram entregar com antecedência, mas as pessoas esquecem. E aí elas começaram a estratégia de entregar uma semana antes, mas as pessoas que trabalham na fábrica reclamam por que precisam pegar uma autorização para faltar no serviço ou que precisam se organizar também. Esta é a dificuldade! (agendador do Município B)

Após agendado, a gente sempre encaminha para o pessoal da estratégia, que é dividido por setor, e eles entregam geralmente uma semana ou 10 dias antes do agendamento da consulta ou exame do paciente. (agendador D1 do Município D)

[...] minha equipe retém as guias, e somente próxima à data de agendamento elas liberam os documentos na Unidade! (gestor do Município C)

Todos os municípios pesquisados demonstraram não entregar lembrete ou avisar muito antes da data da consulta ou exame para evitar o esquecimento ou perda da documentação. As equipes de saúde I, indicadas na categoria de exitosa pelo Município A, realizam o controle e a entrega pelas ESF por iniciativa própria da unidade. As demais unidades $\mathrm{M}$, $\mathrm{T}$ e U não discutiram sobre o tempo de aviso, pois a comunicação aos usuários é realizada por telefone, pela central de vagas. As unidades não realizam o controle ou o acompanhamento da entrega das filipetas realizadas pela recepção das unidades.

Os Municípios B, C e D realizam o agendamento, mas aguardam a proximidade do procedimento para entregar os documentos. Os atores do Município B relataram a dificuldade na entrega com antecedência, pois ela predispõe ao esquecimento. Se entregarem com uma semana de antecedência, haverá queixas de usuários sobre não ter tempo hábil para avisar no trabalho e se organizar. O setor de agendamento do Município D realiza os agendamentos assim que as vagas são ofertadas e já entrega a equipes de ESF. Desse modo, todos os ACS já têm conhecimento do agendamento realizado e já avisa o usuário, mas a entrega e confirmação ocorrem apenas com sete a dez dias de antecedência.

5.2.8 Tempo de espera muito longo desde a solicitação até o agendamento e a qualificação da demanda reprimida

A redução do tempo de espera tem sido muito discutida e foi apontada como uma solução eficaz na diminuição do absenteísmo. Quanto maior a duração do intervalo entre o dia em que o agendamento é feito e o dia da consulta real, maior será o risco de não comparecimento do usuário (Margolis et al., 1993; Hamilton et al., 2002; Dreiher et al., 2008; Goldbart et al., 2009; Giunta et al., 2013; Norris et al., 2014; Machado et al., 2015; Partin et al., 2016). 
Para Cohen et al. (2005), a taxa de não comparecimento é maior para aqueles que esperam mais de uma semana, em comparação com aqueles que ocorrem em uma semana. Nos trabalhos de Margolis et al. (1993), a taxa de faltas variou significativamente com o intervalo de espera, com uma taxa de falha com pico de $27 \%$ para compromissos agendados com 14-27 dias de antecedência. Norris et al. (2014) concluíram que o intervalo de tempo entre a solicitação e o agendamento é o fator que mais contribui para o não comparecimento do usuário.

O tempo de espera relacionado ao absenteísmo esteve presente nas falas dos profissionais de saúde do AME Araçatuba e dos Municípios A, B, C e D. No município A o problema foi mais expressivo, pois, em todos os grupos focais realizados, foi citado o tempo como preditor e muitas vezes angustiante para as equipes e para a população.

\footnotetext{
Eu recebi o agendamento de um paciente da minha área! E fiquei super feliz, pois fazia muito tempo que estava aguardando. Quando fui na casa o paciente tinha morrido. A família ficou muito brava comigo, me falou um monte! Pois ele tinha morrido nas minhas férias, eu não sabia! (ACSU8 do Município A)
}

No momento da euforia, ...por que faz muito tempo que eles estão na fila! Não percebem que naquele horário ou naquele dia ele já tem algum compromisso, ou terá dificuldade para ir na consulta! (recepção T do município A)

Se aumentassem as vagas na especialidade, acho que a possibilidade seria menor do paciente faltar! Se não esperassem tanto, não perderiam os encaminhamentos e seria um incentivo ao comparecimento! (médico da família M do município A)

O ultrassom de mama, por exemplo, por demora muito o agendamento do ultrassom que leva mais de um ano. Quando agenda o ultrassom de mama no AME, a mamografia já está antiga. E então ela perde ultrassom por causa do tempo de espera... (ACS I3 do município A)

Existem algumas estratégias que atuam diretamente no tempo de espera por acesso a serviços de saúde, como a qualificação da demanda por recursos realizada pelos municípios e a alta administrativa pelo AME Araçatuba. Uma estratégia importante relatada pelos atores do Município A foi a verificação de real necessidade do usuário, pois, como o tempo de espera é extenso, muitos usuários conseguem atendimento na urgência ou emergência, realizam tratamento em serviço privado ou com o médico da atenção básica, e/ou acabam melhorando. Essa qualificação da fila foi realizada a princípio pelos ACS em conjunto com os clínicos gerais ou especialistas do ambulatório de gestão municipal, mas atualmente é realizada no momento do agendamento, por meio da confirmação por telefone pela equipe da central de agendamento.

[...] muitas vezes quando chama, depois de $6-8$ meses ...o paciente já fez ou melhorou com o tratamento que demos. (médico da família $\mathrm{M}$ do município A) 
Teve um período que nós fizemos uma busca dos pacientes. A Secretaria mandava pra nós, para saber se realmente precisava ainda daquela consulta. E outros eram avaliados lá no NGA, mas agora parou! E tinha muita gente que não precisava mais! (ACS I3 do Município A)

O agendamento é feito com a confirmação direta com o paciente, não é da mãe ou do filho ou de algum conhecido. Eles ligam para dona Maria, por exemplo, ela não está, então deixo recado de pedir para dona Maria pegar o encaminhamento dela e procurar a unidade Básica de Saúde. Porque a gente só faz o agendamento mediante o contato direto com o paciente. Salvo os casos de crianças que o contato é feito direto com a mãe ou com pai. A gente não faz mais o agendamento sem antes confirmar. (central de agendamento do Município A)

Essa ação realizada pelo Município A, já era realizada nos Municípios C e D, mas geralmente com o apoio da ESF. Os agendadores do Município C ligam antes de agendar para o usuário, principalmente se forem exames de alta complexidade, pois as vagas são escassas e necessitam da autorização prévia no DRS. Por se tratar de municípios pequenos, os ACS possuem aproximação da comunidade e conseguem trazer para a equipe os riscos, as mudanças na vida das famílias e as necessidades de saúde locais.

Sim, a gente que identificou através da visita e a nossa cidade é pequena. Aqui a gente sabe de tudo, quem está grávida... quem está querendo (risos). (ACS D1 do Município D)

Quando são tomografias e ressonâncias eu já ligo para todos os pacientes, pois a autorização é feita direto na regional de saúde e são exames mais difíceis de agendar. A gente liga e se for preciso vamos até na casa do paciente. (agendador C2 do Município C)

Em 2015, o AME Araçatuba possuía muitos usuários sem finalização do diagnóstico ou em tratamento interrompido por motivo de faltas consecutivas. A comissão interna de acompanhamento do absenteísmo do AME Araçatuba identificou o problema, demonstrou em reunião CIR Central e CIR Consórcio as mudanças realizadas durante o ano, como a reorganização do Call Center e a criação do setor de monitoramento e Recall. Porém, em 2016, a alta administrativa foi aprovada em 27 municípios junto do DRS II.

A gente implantou alta de administrativa, foi pactuado em reunião CIR, que o paciente que faltar em dois retornos consecutivos da mesma especialidade, ele terá alta administrativa. (gerente administrativo)

[...] principalmente nos atendimentos não médicos, como a fisioterapia, psicologia, nutricionista... agora eles possuem uma preocupação se eles faltarem duas seguidas eles sabem que interromperam o tratamento. Melhorou essa conscientização! (CALL Center)

É importante ficar claro que as estratégias apresentadas para a demanda reprimida e a diminuição do tempo de espera não resolverão os problemas em relação à dificuldade de 
acesso e à desassistência. Todas as estratégias apresentadas anteriormente auxiliam de forma direta ou indireta a gestão da fila de espera e, consequentemente, melhoram o acesso à saúde, diminuindo o tempo de espera para agendamento de consultas, exames e procedimentos.

\subsubsection{Reuniões periódicas em equipes}

De acordo com Paschoal e Gatto (2006), Ávila e Bocchi (2013) e Hovlid et al. (2013), a maior parte dos cancelamentos e faltas pode ser evitada com a reorganização dos processos internos, melhora no planejamento e gestão, avisos eletrônicos e realização de acolhimento na consulta.

Em relação aos processos de reorganização interna, os Municípios A, B, C e D são distintos, desde os atores envolvidos, o fluxo de documentação, a gestão da fila de espera, a comunicação com os usuários, o cancelamento ou trocas e o transporte.

O gestor da Secretaria de Saúde e o responsável pela central de agendamento do Município A descreveram que o município possui um gestor da APS que realiza reuniões periódicas com a OSS contratada pela Prefeitura. Nessas reuniões, segundo o representante da central de agendamento, são demonstradas as taxas de faltas e as planilhas com os motivos de dispensas. O gestor da saúde relatou que, recentemente, iniciou reuniões in loco nas unidades, com os ACS de cada uma das 18 unidades da APS. Descreveu em detalhes as muitas dificuldades enfrentadas pelas unidades de saúde e esboçou alguns enfrentamentos para reduzir o absenteísmo.

Por isso que a gente está ouvindo todos eles... com isso está surgindo várias ideias, eles são muito bons e participativos. Eles têm trazido várias contribuições. Eu falei pra a responsável da APS, vamos parar um pouco, vamos dar os encaminhamentos das 5 unidades e aí a gente prossegue! Porque senão, eu visito as 18 Unidades e eles podem falar: "ela veio aqui e não aconteceu nada". (gestor da saúde do Município A)

Então esse vai ser um trabalho contínuo, termino e vou voltando. E é muito legal esse contato né! É um contato do gestor com eles, hoje eu já comecei a ter algumas devolutivas, anotamos tudo. (gestor da saúde do Município A)

Esse é o tipo de coisa, que numa cidade grande acontece, a falta de nós estarmos juntos nas unidades. Essa proximidade, o nosso papel... Se eles não tiverem as regras bem firmes e que ter certeza que ninguém irá cortar a regra que ele (unidade) colocar... o primeiro (paciente) que vier gritando ele vai agendar! E sempre vai sobrecarregar aqui!

Ahhhhh, isso a gente vai ter que mudar! (gestor da saúde do Município A) 
Não houve no Município B menção a reuniões programadas ou alguma estratégia de reunião da gestão da saúde com as equipes. Entre os outros profissionais houve falas de orientação e planejamentos do setor de agendamento e de transporte com os trabalhadores ACS da ESF. As reuniões são realizadas periodicamente entre gestor e as unidades, e internamente nas equipes dos Municípios C e D. O gestor da Secretaria Municipal da Saúde descreveu que as reuniões de coordenadores são quinzenais, para discutir e planejar das ações na área de saúde do Município D. O gestor SMS D também exemplificou as várias interfaces com os demais setores, como o Centro de Referência de Assistência Social (CRAS), a Secretaria de Educação, entre outros, para a promoção e educação em saúde.

\begin{abstract}
Nós (gestor da SMS D e coordenadores) fazemos reuniões quinzenais lavradas em ata, para discutirmos juntos os problemas de cada setor e passo a hierarquia para cada um deles, eu dou autonomia para eles, eles têm autonomia para trabalhar em seus setores... eu não sou centralizador, eu procuro fazer isso, eu procuro fazer uma gestão participativa... bom, a gente tenta levar um problema, e não chego falando que tem que fazer desse jeito, vamos discutir e planejar a melhor solução na nossa equipe de planejamento.

[...] a gente usa o CRAS, até por que tem espaço maior lá para organizar as palestras, pois a comunidade sabe que se eles não forem vão perder a recompensa no final de ano... viagem para o thermas, almoço, levam para a praia ....mas infelizmente a gente não consegue trazer um grande público para a saúde nas palestras, pois muitos ainda pensam "eu dou e eu quero receber.(gestor da SMS D)
\end{abstract}

\title{
5.2.10 O papel do gestor na governança do SUS
}

A governança é a forma pela qual a gestão é exercida na administração no SUS, ou seja, a organização e a responsabilização sobre os serviços de saúde. Todos os gestores da saúde neste sistema de governança devem realizar a gestão de recursos, o planejamento, o monitoramento do serviço e a gestão financeira. A efetiva regulação da rede de atenção à saúde, em especial a organização da oferta e da demanda das necessidades de saúde, são influenciadas diretamente pelos desafios que comprometem a governança (Barbosa et al., 2016; Paim; Teixeira, 2007). Dentre os processos de condução político-gerencial do sistema e as relações estabelecidas entre as três esferas de Governo - municípios, estados e União responsáveis pela saúde, existem tensões como: 1. a dificuldade na comunicação entre as esferas do governo ainda recorrente, em parte pela diferença estrutural e histórica entre as Secretarias Estaduais e Municipais de Saúde, além da prevalência das relações intergovernamentais por interesses político-partidários; 2. a privatização ou desresponsabilização, tanto do estado como dos municípios na privatização de equipamentos públicos, comprometendo a autonomia da gestão compartilhada e do planejamento de ações 
direcionadas às dificuldades e iniquidades locais das regiões e dos municípios; 3. o clientelismo, o favoritismo e o fisiologismo político, que deslocam recursos em saúde para favorecimento próprio ou interesses de representantes políticos, e 4. a falta de gestão profissionalizada, ou seja, persistência não-técnica em cargos e funções degestão em todos os níveis do sistema no exercício das complexas tarefas relacionadas ao planejamento, controle e avaliação, regulação e gestão de recursos e serviços (Paim; Teixeira, 2007).

A comunicação e a troca de informações entre as três esferas do governo, em especial entre o DRS II Araçatuba e os municípios, e entre os setores da saúde dos municípios, ainda é um desafio. De acordo com Paim e Teixeira (2007), é necessário debater o que extrapole as instâncias de gestão colegiada do SUS, devendo envolver, necessariamente, os atores políticos: gestores e profissionais de saúde, frentes populares, espaços de comunicação social e mídia, para o fortalecimento dos interesses da população e do SUS. Nos Municípios A, B e C não foi evidenciado pelas equipes e gestor de saúde a participação popular nas atividades de planejamento e de gestão da saúde. Apenas a SMS do Município D demonstrou aproveitar, junto às outras secretarias do município, os espaços e eventos comunitários para discutir a saúde.

Para que a governança da saúde no SUS seja efetiva, a autonomia de gestão deveria ser um fator determinante. Entretanto, qualquer gestão, seja pública ou terceirizada, está carregada de necessidades e vieses. Na região do DRS II Araçatuba existem vários serviços administrados por OSS, tanto estaduais como municipais. Dentre os serviços estaduais, destacou-se nesta pesquisa o AME Araçatuba sob gestão de OSS que tem realizado papel fundamental para a região no apoio diagnóstico e tratamento cirúrgico em algumas especialidades. Este equipamento público está sob gestão do Terceiro Setor, mas é avaliado e monitorado por indicadores de qualidade, de produção e por metas trimestrais com participação de representantes da SES, do DRS e do prestador de saúde. Já dentre os serviços municipais, houve a privatização de todas as unidades de saúde do nível primário do Município A. Segundo os demais entrevistados nos Municípios B, C e D, foi mantida gestão própria de suas unidades de saúde.

As dificuldades identificadas, principalmente nos Municípios A e B com gestão terceirizada e própria consecutivamente, estavam relacionadas às premissas discutidas pelos autores supracitados, como gerenciamento fragmentado, ou seja, falta de um gestor 
articulador entre os serviços de saúde local, e deficiências na função reguladora dos serviços e na comunicação entre os níveis administrativos.

No Município A, mesmo com reuniões periódicas entre os representantes da Prefeitura e da OSS com os responsáveis técnicos das unidades da APS, não foi possível garantir o engajamento e a uniformidade nas ações em saúde. Os processos organizativos centrais estavam falhos, por exemplo, nas solicitações médicas da APS. Estas são mantidas com os usuários até o agendamento realizado pela Central de Agendamento. Esse fluxo provoca demanda para a própria rede de atenção quando o usuário, após contatado pela Central de Agendamento, relata que perdeu a solicitação médica.

Para um problema comum às unidades de saúde, o estudo revelou ações são diferentes. Nas Unidades I e M ocorre sobrecarga da agenda médica para reavaliação e nova solicitação; na Unidade U, a reavaliação médica é agendada conforme a demanda programada, na ocasião com três meses de espera; na Unidade $\mathrm{T}$, alguns casos eram priorizados (idosos, crianças ou indicados pelos ACS) e os demais aguardavam a agenda programada. É importante salientar, como agravante, o tempo de espera no Município A para consultas em especialistas e exames. Ele é de um a dois anos, como apontado em todos os grupos focais.

No Município B a fragmentação do processo de gestão resultou no enfraquecimento de planejamento e organização entre os setores da saúde. Na deficiência de reuniões em equipe e gestão profissional-técnica, os trabalhadores da saúde produzem em seus espaços e quase não se articulam entre si, o que impossibilita a gestão junto às equipes nas decisões ou planejamento, e na corresponsabilização dos envolvidos no processo.

As medidas de prevenção ao absenteísmo, a otimização dos serviços disponíveis na rede, e o aproveitamento dos recursos financeiros do município para a priorização das ações em saúde são essenciais para a regulação de acesso à saúde. Pois, caso não sejam bem planejadas, isso pode ser autogerador de demandas. Por exemplo, o Município B contratou médicos especialistas que, a princípio, atenderam uma fila extensa de espera, mas, ao invés de qualificar os encaminhamentos, solicitaram exames extremamente caros e de difícil acesso na região - como as cintilografias, as ressonâncias, os cateterismos -, levando apenas à transferência de fila das especialidades para os exames. Havendo uma confirmação de diagnóstico, esses casos não poderão ser tratados localmente. Em contrapartida, poderia ser criada uma carteira de exames de baixa complexidade para apoio diagnóstico, como um 
serviço de radiologia, que não necessitasse levar todos os usuários a serviços de outros municípios.

Os Municípios C e D demonstraram ter coordenação mais eficiente, organizada e com efetiva comunicação entre as equipes profissionais e entre os profissionais. Na área de orçamento e planejamento, realizam projetos e "rearranjos" internos direcionados às necessidades locais. No Município C, existe a necessidade da terceira equipe de ESF e a abertura de uma nova unidade de saúde em local estratégico. Enquanto este projeto não se tornar realidade, o gestor e a equipe se organizam com horas extras para estender horário e trabalhar com o ACS aos sábados. No Município D, houve melhora no transporte público e coordenação do setor. Investimentos estão sendo realizados para adquirir novos carros e implantar um sistema de rastreio e controle dos carros de viagem que levam os usuários para outras cidades.

Em relação ao clientelismo e o fisiologismo político, ele está presente em todas as instâncias governamentais, gerando consequentemente o problema denominado por Paim e Teixeira (2007) falta de gestão profissionalizada. Nesse caso, as indicações de ocupantes para os cargos municipais e estaduais são realizadas sem critério técnico e profissional. A forma organizacional das prefeituras e das secretarias favorecem o ciclo de indicação não-técnica para os cargos e funções da gestão, pois a cada eleição de governantes uma cascata de decisões político-administrativas é acionada por parte do novo dirigente ou gestor.

[...], mas talvez devido à alta rotatividade de pessoas, pois mudam muito as pessoas
nas secretarias municipais (de saúde), talvez não entendam a importância de
trabalhar isso certinho... (gerente administrativo do AME Araçatuba)

Especificamente no âmbito da formação de dirigentes e técnicos qualificados nos vários níveis de organização e gestão do SUS, é importante ressaltar os compromissos com a qualidade, efetividade e inovação das ações, eficiência e eficácia nas ações planejadas. Acima de tudo, os serviços públicos necessitam de pessoas comprometidas com o SUS em todas as áreas e com a menor influência de interesses político-partidários ou pressões corporativas possíveis. 


\section{CONSIDERAÇÕES FINAIS}

Os processos administrativos político-gerenciais do sistema SUS dependem das relações estabelecidas entre os gestores das três esferas de governo: municipal, estadual e federal. Os princípios e diretrizes do SUS requerem ações em saúde integradas, comunicação efetiva entre os níveis administrativos, resolutividade e acesso na assistência ofertada; governança dos recursos e do planejamento em saúde e a superação das diferenças estruturais e históricas, principalmente entre as secretarias estaduais e municipais de saúde.

A ética é transversal nos princípios e diretrizes do SUS, na universalidade do acesso, na integralidade do atendimento prestado e na equidade pela eficiência, eficácia e efetividade dos serviços. Para tanto, as ações devem ser planejadas no sentido de reorganizar os serviços, reorientar o processo de trabalho e as práticas em saúde. A rede de atenção tem como proposta a distribuição de responsabilidades e oferta de serviços segundo os níveis de atenção em saúde.

A atenção primária, nesta estratégia de organização da atenção à saúde, está voltada para responder de forma regionalizada, contínua e sistematizada a maior parte das necessidades em saúde da população. A APS foi planejada de forma dispersa e em maior número de unidades para possibilitar a aproximação da comunidade para resolver a maior parte das necessidades do indivíduo e da comunidade. O nível primário possui o papel de regulador das demandas para os níveis de atenção secundária e terciária, pois estes apresentam maior complexidade, são menos numerosos e concentrados em locais estratégicos. Além disso, os desafios persistem quando as demandas são superiores ao oferecimento e os absenteísmos são recorrentes, o que torna imprescindível a discussão sobre estratégias na regulação do acesso.

A ausência ou a dificuldade de acesso à assistência e a baixa resolubilidade da Atenção Primária sobrecarrega os demais níveis. Três situações podem ser apontadas: 1. o aumento na busca por serviços de urgência como porta de entrada do sistema de saúde; 2 o aumento das filas de demanda por especialidades, e 3. a indução à procura por serviços particulares. A indicação inadequada ou a inviabilidade da contrarreferência do usuário para o acompanhamento pela APS, somada ao absenteísmo e à insuficiente oferta nos serviços de saúde, resulta em uma rede assistencial lenta, ineficaz e desacreditada. $\mathrm{O}$ atendimento 
especializado é oneroso, pois, além de manter a carteira de especialidades diversificada, necessita de vários exames internos.

Na região do DRS II Araçatuba, o AME Araçatuba se tornou o principal, senão o único serviço de diagnóstico para muitos municípios de sua referência. $\mathrm{O}$ enfraquecimento ou até o fechamento dos serviços de gestão municipais tem sido frequente, sobrecarregando o sistema de saúde.

O absenteísmo prolonga a permanência dos usuários em espera por assistência e aumenta o número de atendimentos nos serviços de urgência disponíveis, nos municípios e na região. Nos depoimentos dos profissionais de saúde, foi possível identificar a "cultura curativa e especialista" dos usuários, que se autorreferenciam para as especialidades durante as consultas na APS como se fosse livre a demanda. Eles desconhecem ou desvalorizam o trabalho das equipes de ESF na região de Araçatuba.

O DRS II Araçatuba tem o papel fundamental de articular e realizar propostas de capacitação e apoio técnico, principalmente às gestões municipais. Os gestores da saúde devem compor junto às suas equipes a coordenação técnico-profissional, com atuação e apoio nos processos organizativos e nas estratégias, a fim de diminuir o absenteísmo e ampliar o acesso à saúde. O matriciamento proposto pelo AME Araçatuba está em conformidade com a educação permanente aos serviços de saúde e melhora na formação de recursos humanos para o SUS. Desta maneira, todos os envolvidos na atenção à saúde poderão realizar educação em saúde para o usuário e para a comunidade, no sentido de valorizar as ESF, a cidadania, o papel de protagonista na própria saúde e a importância dos serviços disponibilizados a eles.

De acordo com os casos traçadores da pesquisa, é possível concluir que, mesmo com características distintas, os profissionais engajados e comprometidos com o SUS demonstraram conseguir realizar algumas ações de organização e controle na regulação da ofertaem equipe. Estes atores assumiram o papel de protagonistas e responsabilizaram-se pela saúde, atuando junto à população adstrita com ações que fortalecem a ESF e a autonomia da comunidade.

O não atendimento do usuário deve ser considerado em seu amplo aspecto e complexidade, principalmente no que tange à visão do profissional de saúde sobre o usuário e deste sobre o profissional -; as causas e os efeitos das ações planejadas e tomadas; a reflexão crítica sobre a realidade, para o redirecionamento da prática em saúde, e a construção das mudanças necessárias por todos envolvidos no SUS. 


\section{PRODUTO: FOLDER PARA EDUCAÇÃO EM SAÚDE}

Este instumento foi elaborado a partir dos dados levantados no presenteestudo de caso a respeito de traçadores sobre experiâncias, dificuldades e estratégias dos gestores das secretarias de saúde, das equipes da ESF e AME Araçatuba da região do DRS II Araçatuba. Será disponibilizado e utilizado para educação permanente dos profissionais de saúde dos 40 municípios da região estudada.
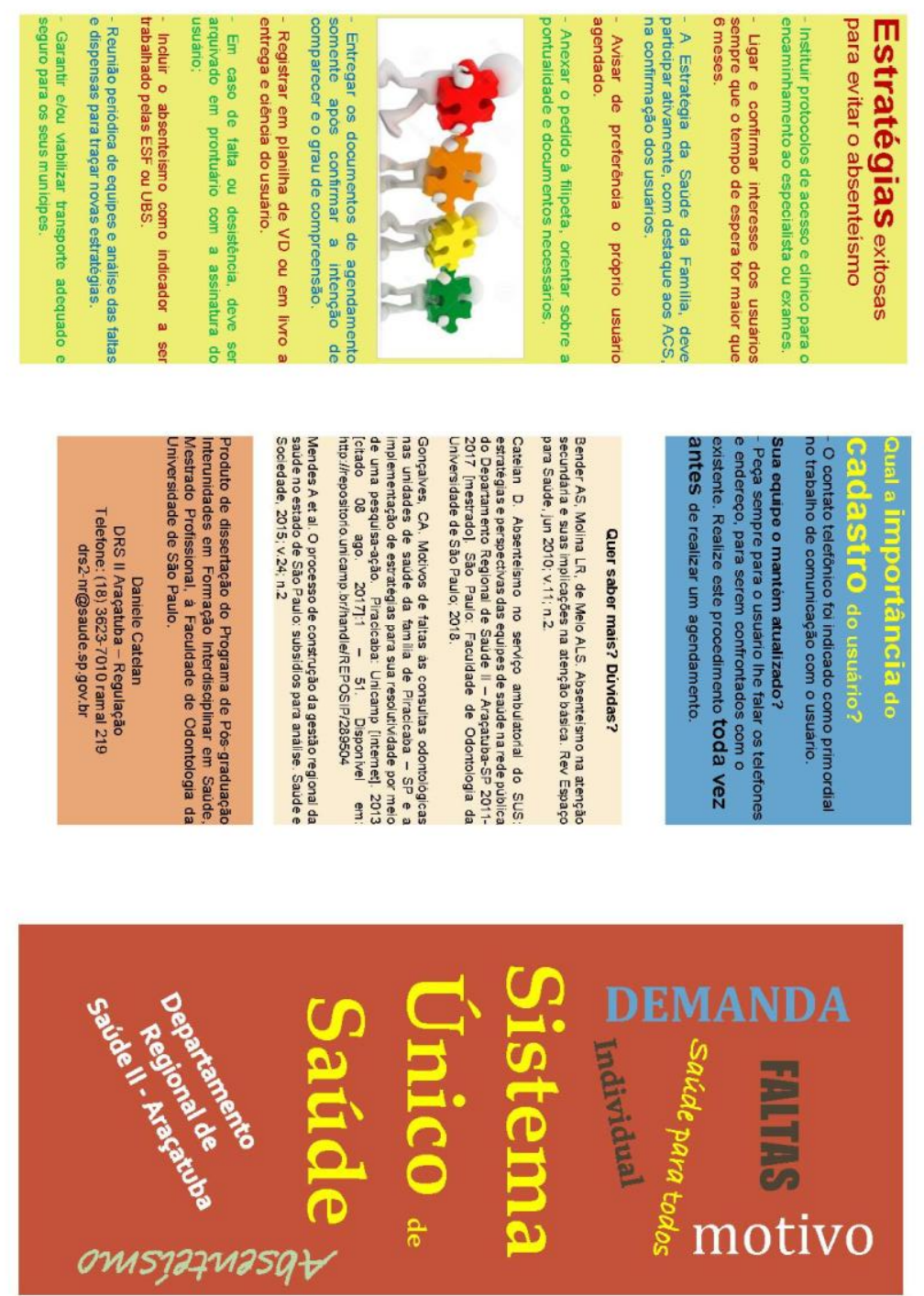

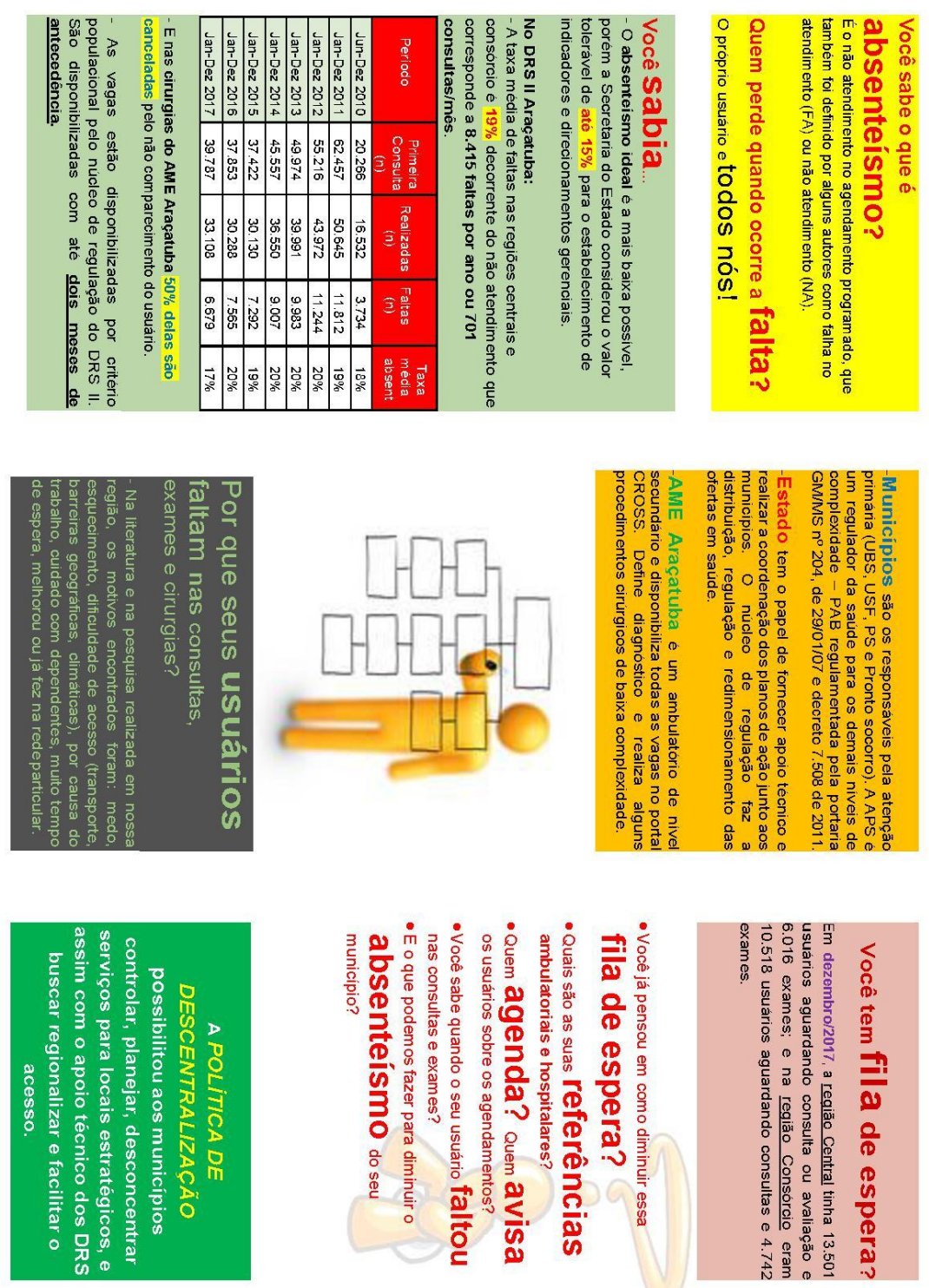


\section{REFERÊNCIAS $^{27}$}

Altuwaijri MM, Sughayr AM, Hassan MA, Alazwari FM. The effect of integrating short messaging services reminders with electronic medical records on non-attendance rates. Saudi Med J. 2012 Feb;33(2):193-6.

Andrews R, Morgan JD, Addy DP, McNeish AS. Understanding non-attendance in outpatient paediatric clinics. Arch Dis Child. 1990 Feb;65(2):192-5.

Ávila MAG, Bocchi SCM. Confirmação de presença de usuário à cirurgia eletiva por telefone como estratégia para reduzir absenteísmo. Rev Esc Enferm USP [Internet]. 2013 [citado 23 fev. 2015];47(1):193-7. Disponível em <http://www.scielo.br/scielo.php?script=sci_arttextepid=S008062342013000100024elng=ptenrm=iso >

Barata LRB, Mendes JDV, Bittar OJNV, Yamada ATT, Falcão LHB. Ambulatórios Médicos de Especialidades (AME) no Estado de São Paulo. Rev Adm Saúde [Internet]. 2010 [citado 17 fev. 2016];12(48):125-30. Disponível em <http//ses.sp.bvs.br/lildbi/docsonline/get.php?id=1828>

Barbosa S, Vieira D, Bezerra Barbosa N, Najberg E. Regulação em Saúde: desafios à governança do SUS. Rio de Janeiro: Cad Saúde Coletiva. 2016;24(1). doi: 10.1590/1414462X201600010106.

Barcelos, G. M. Aproveitamento de vagas de consultas eletivas em um hospital universitário [dissertação] [Internet] Ribeirão Preto: Universidade de São Paulo, Faculdade de Medicina de Ribeirão Preto, 2016 [citado 22 jun 2017]. Disponível em: http://www.teses.usp.br/teses/disponiveis/17/17157/tde-29032017-155338/en.php.

Bardin L. Análise de conteúdo. São Paulo: Edições 70; 1977.

Behi R, Nolan M. Quasi experimental research designs. Br J Nurs 1996 sep/oct;5(17):107981 .

Bender AS, Molina LR, de Mello ALS. Absenteísmo na atenção secundária e suas implicações na atenção básica. Rev Espaço Saúde-Rev Saúde Públ Paraná. 2010 jun.;11(2):56-65. doi: http://dx.doi.org/10.22421/1517-7130.2010v11n2p56

Bittar OJNV, Magalhães A, Martines CM, Felizola NBG, Falcão LHB. Absenteísmo em atendimento ambulatorial de especialidades no estado de São Paulo. BEPA [Internet] 2016 [citado 23 mar. 2016];13(152):19-32. Disponível em http://attosaude.com.br/assets/ conteudo/uploads/absenteismo-ambulatorial--art-original57eec18c360fb.pdf

\footnotetext{
${ }^{27}$ De acordo com o estilo Vancouver.
} 
Brasil. Ministério da Saúde. Secretaria de Atenção à Saúde. Departamento de Atenção Básica. Política nacional de atenção básica. Brasília, DF: Ministério da Saúde, 2017.

Britten N. Entrevistas qualitativas na pesquisa em atenção à saúde. In: Pope C, Mays N. Pesquisa qualitativa na atenção à saúde. 2a ed. Porto Alegre: Artmed; 2005, p. 22-8.

Cavalcanti RP, Cavalcanti JCM, Serrano RMSM, Santana PR. Absenteísmo de consultas especializadas no sistema de saúde público: relação entre causas e o processo de trabalho de equipes de saúde da família, João Pessoa - PB, Brasil. Tempus - Actas Saúde Colet. 2013;7(2):63-84.doi:http:/dx.doi.org/10.18569/tempus.v17i2.1344.

Chopra D, Hookey LC. Comorbid illness, bowel preparation, and logistical constraints are key reasons for outpatient colonoscopy nonattendance. Can Gastroenterol Hepatol, 2016: 2016:2179354. doi: 10.1155/2016/2179354.

Chung JW, Wong TK, Yeung AC. Non-attendance at an orthopaedic and trauma specialist outpatient department of a regional hospital. J Nurs Manag. 2004 sep;12(5):362-7.

Cohen AD, Kaplan DM, Shapiro J, Levi I, Vardy DA. Health provider determinants of nonattendance in pediatric otolaryngology patients. The Laryngoscope, 2005 oct;115(10):1804-8.

Collins J, Santamaria N, Clayton L. Why outpatients fail to attend their scheduled appointments: a prospective comparison of differences between attenders and non-attenders. Aust Health Rev. 2003;26(1):52-63.

Downer SR, Meara JG, Da Costa AC, Sethuraman K. SMS text messanging improves outpatient attendance. Aust Health Rev [Internet]. 2006 [citado 23 fev. 2015];30:389-96. Disponível em<http://www.ncbi.nlm.nih.gov/pubmed/16879098>.

Dreiher J, Froimovici M, Bibi Y, Vardy DA, Cicurel A, Cohen AD. Nonattendance in obstetrics and gynecology patients. Gynecol Obstet Invest. 2008;66(1):40-3. doi: 10.1159/000115844. Epub 2008 Feb 11. PubMed PMID: 18264023.

Erdmann AL, Andrade SR, Mello ALSF, Drago LC. A atenção secundária em saúde: melhores práticas na rede de serviços. Rev Latino-Am Enferm [Internet]. jan.-fev. 2013 [citado25 jun. 2016];21(Spec):[08 telas].Disponível em: <http://www.scielo.br/pdf/rlae/v21nspe/pt_17.pdf>

Ezike H, Ajuzieogu V, Amucheazi A. Reasons for elective surgery cancellation in a referral hospital. Ann Med Health Sci Res. 2011 Jul;1(2):197-202.

Ferreira MB, Lopes AC, Lion MT, Lima DC, Nogueira DA, Pereira AA. Absenteísmo em consultas odontológicas programáticas na estratégia saúde da família. Revista da Universidade Vale do Rio Verde. 2016 jan/jul; 14(1):411-9. doi: http://dx.doi.org/10.5892/ruvrd.v14i1.2601 
Feuerwerker LCM, Merhy EE. A contribuição da atenção domiciliar para a configuração de redes substitutivas de saúde: desinstitucionalização e transformação de práticas. Rev Panam Salud Publica. 2008;24(3):180-8.

Filippidou M, Lingwood S, Mirza I. Reducing non-attendance rates in a community mental health team. BMJ Qual Improv Rep. 2014 Sep 12;3(1). pii:u202228.w1114. doi: 10.1136/bmjquality.u202228.w1114.

Garg R, Bhalotra AR, Bhadoria P, Gupta N, Anand R. Reasons for cancellation of cases on the day of surgery-a prospective study. Indian J Anaesth. 2009 Feb;53(1):35-9.

Gil AC. Métodos e técnicas de pesquisa social. 6. ed. São Paulo: Atlas; 2008.

Giunta D, Briatore A, Baum A, Luna D, Waisman G, de Quiros FG. Factors associated with nonattendance at clinical medicine scheduled outpatient appointments in a university general hospital. Patient Prefer Adher. 2013 Nov. 8;7:1163-70. doi: 10.2147/PPA.S51841. eCollection 2013.

Gonçalves CA. Motivos de faltas às consultas odontológicas nas unidades de saúde da família de Piracicaba - SP e a implementação de estratégias para sua resolutividade por meio de uma pesquisa-ação. Piracicaba: Universidade Estadual de Campinas, Faculdade de Odontolgogia de Piracicaba. 2013 [citado 08 ago. 2017]. Disponível em:

http://repositorio.unicamp.br/handle/REPOSIP/289504.

Gonçalves CA, Vazquez FL, Ambrosano GMB, Mialhe FL, Pereira AC, Sarracini KLM, Guerra LM, Cortellazzi KL. Estratégias para o enfrentamento do absenteísmo em consultas odontológicas nas Unidades de Saúde da Família de um município de grande porte: uma pesquisa-ação. Ciência Saúde Colet [Internet]. 2015 [citado 22 jun. 2017];20:449-60. Disponível em: <https://doi.org/10.1590/1413-81232015202.00702014>. ISSN 1678-4561. https://doi.org/10.1590/1413-81232015202.00702014.

Goldbart AD, Dreiher J, Vardy DA, Alkrinawi S, Cohen AD. Nonattendance in pediatric pulmonary clinics: an ambulatory survey. BMC Pulmonary Medicine, 2009; 9(1):1-6.

Gondim SMG. Grupos focais como técnica de investigação qualitativa: desafios metodológicos. Paidéia, 2003;12(24):149-61.

Gurol-Urganci I, de Jongh T, Vodopivec-Jamsek V, Atun R, Car J. Mobile phone messaging reminders for attendance at healthcare appointments.Cochrane DatabaseSyst Rev [Internet].2013[citado 22 abr. 2015]; 12:1-50.doi: 10.1002/14651858.CD007458.pub3.

Guy R, Hocking J, Wand H, Stott S, Ali H, Kaldor J. How effective are short message service reminders at increasing clinic attendance? A meta-analysis and systematic review. Health Serv Res. 2012 Apr;47(2):614-32. doi:10.1111/j.1475-6773.2011.01342.x.

Hamilton K, Gourlay M. Missed hospital appointments and transport. Transport studies university East London [Internet]. 2002 [citado 10 ago. 2017];1-37. Disponível em: 
https://www.kingsfund.org.uk/sites/default/files/UEL-missed-hospital-appointmentstransport-Kerry-Hamilton-Marion-Gourlay-Kings-Fund-December-2002.pdf.

Hayden MP, Small JG. Absentee patients; a controlled study of missed appointments in a psychiatric clinic. J Psychiatr Nurs. 1966 Jul/Aug;4(4):342-50.

Haynes JM, Sweeney EL. The effect of telephone appointment-reminder calls on outpatient absenteeism in a pulmonary function. Respir Care [Internet]. 2006 [citado 24 abr. 2015];51:36-9. Disponível em: <http://www.ncbi.nlm.nih.gov/pubmed/16381615>.

Hardy KJ, O'Brien SV, Furlong NJ. Information given to patients before appointments and its effect on non-attendance rate. BMJ. 2001 Dec 1;323(7324):1298-300.

Hasvold PE,Wootton R. Use of telephone and SMS reminders to improve attendance at hospital appointments: a systematic review. J Telemed Telecare [Internet]. 2011 [citado 22 abr. 2015];17:358-64. Disponível em:

<http://www.ncbi.nlm.nih.gov/pmc/articles/PMC3188816/ pdf/JTT-11-07-007.pdf>.

Hovlid E, Plessen CV, Haug K, Aslaksen AB, Bukve O. Patient experiences with interventions to reduce surgery cancellations: a qualitative study. BMC Surg [Internet]. 2013 [citado 22 jul 2016];13:30. Disponível em:

<http://bmcsurg.biomedcentral.com/articles/10.1186/1471-2482-13-30>.

IBGE - Instituto Brasileiro de Geografia e Estatística. [2017]. Acesso 20 abr 2018 [Internet]. Disponível em: https://www.ibge.gov.br/estatisticas-novoPortal/por-cidade-estadoestatisticas.html.

Iervolino AS, Pelicioni MCF. A utilização do grupo focal como metodologia qualitativa na promoção da saúde. Rev Enferm USP. 2001;35(2):115-21.

Izecksohn MMV, Ferreira JT. Falta às consultas médicas agendadas: percepções dos usuários acompanhados pela Estratégia de Saúde da Família, Manguinhos, Rio de Janeiro. Revista Bras Med Fam e Comunidade [Internet]. 2014[citado 24 jul 2017];9(32): 235-41. Disponível em: https://rbmfc.emnuvens.com.br/rbmfc/article/view/960

Jamil MT, Ismail NZ, Zulkifli AB, Majid NA, Van Rostenberghe H. Non-attendance to the paediatric clinics in a Malaysian tertiary hospital: a sizeable problem and identification of an efficacious intervention. J Paediatr Child Health. 2011 Jun;47(6):346-9. doi: 10.1111/j.14401754.2010.01989.x.

Jeppesen MH, Ainsworth MA. Telephone reminders reduced the non-attendance rate in a gastroenterology outpatient clinic. Dan Med J. 2015 Jun;62(6). pii: A5083.

Kessner E., Kalk CY, Singer J. Assessing health quality. The case for tracers. New Engl J Med.1973 Jan; 288(4):188-94.

Killaspy H, Banerjee S, King M, Lloyd M. Non-attendance at psychiatricoutpatient clinics: communication and implications for primary care. Br J Gen Pract. 1999 Nov;49(448):880-3. 
Kitzinger J. Grupos focais com usuários e profissionais da atenção à saúde. In: Pope C, Mays N. Pesquisa qualitativa na atenção à saúde. 2a ed. Porto Alegre: Artmed; 2005. p. 31-3.

Koshy E, Car J, Majeed A. Effectiveness of mobile-phone short message service (SMS) reminders for ophthalmology outpatient appointments: observational study. BMC Ophthalmol [Internet]. 2008 [citado 24 abr. 2015];8:9. Disponível em $<$ http://www.biomedcentral.com/1471-2415/8/9>.

Lira RPC, Nascimento MA, Temporini ER, Kara-José N, Arieta CEL. Suspensão de cirurgia de catarata e suas causas. Rev Saúde Públ [Internet]. 2001 [citado 16 abr. 2015];35:487-9. Disponível em: <http://www.scielo.br/pdf/rsp/v35n5/6589.pdf> http://dx.doi.org/10.1590/S0034-89102001000500013.

Machado AT, Werneck MAF, Lucas SD, Abreu MHNG. Who did not appear? First dental visit absences in secondary care in a major Brazilian city: a cross-sectional study. Ciênc Saúde Coletiva. 2015;20(1):289-298.

Margolis KL, Lurie N, McGovern PG, Slater JS. Predictors of failure to attend scheduled mammography appointments at a Public Teaching Hospital. J Gen Int Med, 1993;8(11):6025. https://doi.org/10.1007/BF02599713.

Meihy JCSB, Holanda F. História oral: como fazer, como pensar. 2. ed. São Paulo: Contexto; 2007.

Mendel A, Chow S. Impact of health portal enrolment with email reminders at na academic rheumatology clinic. BMJ Qual Improv Rep. 2017 Mar 7;6(1). pii: u214811.w5926. doi: 10.1136/bmjquality.u214811.w5926. eCollection 2017.

Mendes A, LouvisonMCP, Ianni AMZ, Leite MG, Feuerwerker LCM, Tanaka OW, Duarte L, Weiller JAB, Lara NCC, Botelho LAM, Almeida CAL.O processo de construção da gestão regional da saúde no estado de São Paulo: subsídios para a análise. Saúde Soc [Internet]. 2015 [citado 21 abr. 2018];24(2):423-37. Disponível em: <https://doi.org/10.1590/S0104$12902015000200003>$.

Mendes EV. Health care networks. Ciênc Saúde Coletiva. 2010 ago;15(5):2297-305. Portuguese.

Mendes EV. As redes de atenção à saúde. 2.ed. Brasilia, DF: Organização Pan-Americana da Saúde. 2011. [citado em 28 ago 2016]. Disponível em: http://repositorio.asces.edu.br/handle/123456789/1314

Menendez ME, Ring D. Factors associated with non-attendance at a hand surgery appointment. Hand (N Y). 2015 Jun;10(2):221-6. doi: 10.1007/s11552-014-9685-Z.

Minayo MCS, Assis SG, Souza ER. Avaliação por triangulação de métodos: abordagem de programas sociais. $1^{\mathrm{a}}$ ed. Rio de Janeiro: Editora Fiocruz; 2005. 
Morgan D. Focus group as qualitative research. London: Sage Publications; 1997. Qualitative Research Methods Series;16.

Narring F, Junod Perron N, Dominicé Dao M, Camparini Righini N, Humair JP, Broers B, Gaspoz JM, Haller DM. Text-messaging to reduce missed appointment in a youth clinic: a randomised controlled trial. J Epidemiol Community Health. 2013 oct;67(10):888-91. doi: 10.1136/jech-2013-202510.

Nhavoto JA, Gronlund A. Mobile technologies and geographic information systems to improve health care systems: a literature review. JMIR M Health U Health [Internet]. 2014 [citado 24 abr. 2015] ;2(2):e21. Disponível em: http://www.ncbi.nlm.nih.gov/pmc/articles/PMC4114429/ ?report=reader.

Norris JB, Kumar C, Chand S, Moskowitz H, ShadeSA, WillisDR. An empirical investigation into factors affecting patient cancellations and no-shows at outpatient clinics. Decision Support Systems. 2014;57:428-43.

O'Brien G, Lazebnik R. Telephone call reminders and attendance in an adolescent clinic. Pediatrics. 1998 jun;101(6):e6.

Paim JS. Descentralização das ações e serviços de saúde no Brasil e a renovação da proposta "Saúde para Todos". Rio de Janeiro:UERJ/MS; 1998. Estudos em Saúde Coletiva.

Paim JS. Modelo de atenção à saúde no Brasil. In: Giovanella L, Escorel S, Lobato LVC, Noronha JC, Carvalho AI. Políticas e sistema de saúde no Brasil. 2.ed. Rio de Janeiro: Fiocruz; 2012. P. 459-85.

Paim JS, Teixeira CF. Configuração institucional e gestão do Sistema Único de Saúde: problemas e desafios. Ciênc Saúde Coletiva. 2007;12:1819-29.

Partin MR, Gravely A, Gellad ZF, Nugent S, Burgess JF Jr, Shaukat A, Nelson DB. Factors associated with missed and cancelled colonoscopy appointments at veterans' health administration facilities. Clin Gastroenterol Hepatol. 2016 Feb;14(2):259-67. doi: 10.1016/j.cgh.2015.07.051. Epub 2015 Aug 21.

Paschoal ML, Gatto MA. [Rate of surgery cancellation at a university hospital and reasons for patients' absence from the planned surgery]. Rev Lat Am Enfermagem. 2006 jan/feb;14(1):48-53. Epub 2006 Mar 8. Portuguese.

Perron NJ, Dao MD, Kossovsky MP, Miserez V, Chuard C, Calmy A, Gaspoz JM. Reduction of missed appointments at na urban primary care clinic: a randomised controlled study. BMC Family Pract [Internet]. 2010 [citado 23 fev 2015];1:1-8. Disponível em<http://www.biomedcentral.com/1471-2296/11/79>.

Pereira-Victorio CJ, Vázquez-Molinero A, Lizán-García M, Gómez-Guardiola JL, LópezValcárcel BG. Absentismo de pacientes a la consulta externa especializada en un hospital de tercer nivel en España. Med Gen Familia. 2016 [citado 23 fev 2015];5(3):83-90. Disponível em: https://doi.org/10.1016/j.mgyf.2016.02.002. 
Pesata V, Pallija G, Webb AA. A descriptive study of missed appointments: families' perceptions of barriers to care. J Pediatr Health Care. 1999 Jul-Aug;13(4):178-82. PubMed PMID: 10690082.

Pope C, Mays N. Pesquisa qualitativa na atenção à saúde. 3. ed. Porto Alegre: Artmed. 2009.

Pozzebon M, Freitas, HMR. Pela aplicabilidade: com um maior rigor científico - dos estudos de caso em sistemas de informação. Rev Adm Contemporânea. 1998;2(2):143-70. https://dx.doi.org/10.1590/S1415-65551998000200009.

Reid MW, Cohen S, Wang H, Kaung A, Patel A, Tashjian V, Spiegel B. Preventing patient absenteeism: validation of a predictive overbooking model. Am J Manag Care. 2015;21(12): p. $902-10$.

Reid M, May FP, Martinez B, Cohen S, Wang H, Williams Jr D L, Spiegel BM. Preventing endoscopy clinic no-shows: prospective validation of a predictive overbooking model. The American journal of gastroenterology. 2016;111(9).

Roberts K, Callanan I, Tubridy N. Failure to attend out-patient clinics: is it in our DNA? Int J Health Care Qual Assur. 2011;24(5):406-12.

Roberts N, Meade K, Partridge M. The effect of telephone reminders on attendance in respiratory outpatient clinics. J Health Serv Res Policy. 2007 Apr;12(2):69-72.

Rodríguez P R, Negro AJM, Campuzano LFJ, Pellicer OF, Murcia AT, Serrano SE, Villegas GM, Alcaraz QM. Non-compliance with appointments amongst patients attending an Allergology Clinic, after implementation of an improvement plan. Allergol Immunopathol (Madr). 2007 jul/aug;35(4):136-44.

Samuels RC, Ward VL, Melvin P, Macht-Greenberg M, Wenren LM, Yi J, Massey G, Cox JE. Missed Appointments: Factors Contributing to High No-Show Rates in na Urban Pediatrics Primary Care Clinic. Clin Pediatr (Phila). 2015 Sep;54(10):976-82. doi: 10.1177/0009922815570613. Epub 2015 Feb 12.

Silva KL, Sena RR, Feuerwerker LCM, Merhy EE. Atenção domiciliar como mudança do modelo tecnoassistencial. Rev Saúde Pública. 2010 fev;44(1):166-76.

Simões DR, Silva MHB. A importância do sistema computacional Regnet para o hospital São Vicente de Gália. Tecnol Gestão Empres [Internet]. 2010 [citado 26 abr. 2016];1:1-6. Disponível em: <http://www.fatecgarca.edu.br/revista/Volume1/6.pdf>.

São Paulo. Secretaria da Saúde. CROSS - Central de Regulação de oferta de Serviços de Saúde [2010]. [acesso 20 dez.2017]. Disponível em: www.cross.saude.sp.gov.br.

São Paulo. Secretaria da Saúde. Departamentos Regionais de Saúde. [2012]. [acesso 20 dez.2017]. Disponível em: 
http://www.saude.sp.gov.br/resources/ces/homepage/rras/estado_rras_drs_rs_2012_dpi_300.j pg.

Sodré RL, Fahl MAFE. Cancelamento de cirurgias em um hospital público na cidade de São Paulo. RAS. 2014 abr/jun;16(63):67-70: doi:10.5327/z1519-167220140063005.

Solla J, Chioro A. Atenção ambulatorial especializada. In: Giovanella L, Escorel S, Lobato LVC, Noronha JC, Carvalho AI. Políticas e sistema de saúde no Brasil. 2a ed. Rio de Janeiro: Fiocruz; 2012. p. 547-76.

Stone CA, Palmer JH, Saxby PJ, Devaraj VS. Reducing non-attendance at outpatient clinics. J R Soc Med. 1999 Mar;92(3):114-8.

Syed ST, Gerber BS, Sharp LK. Traveling towards disease: transportation barriers to health care access. J Community Health. 2013 Oct;38(5):976-93. doi: 10.1007/s10900-013-9681-1. Review.

Tao D, Xie L, Wang T, Wang T. A meta-analysis of the use of electronic reminders for patient adherence to medication in chronic disease care. J Telemed Telecare. 2015 Jan;21(1):3-13. doi: 10.1177/1357633X14541041.

Travassos C, Castro MSM. Determinantes e desigualdades sociais no acesso e na utilização de serviços de saúde In: Giovanella L, Escorel S, Lobato LVC, Noronha JC, Carvalho AI. Políticas e sistema de saúde no Brasil. 2.ed. Rio de Janeiro: Fiocruz; 2012. p. 215-43.

Travassos C, Martins M. Uma revisão sobre os conceitos de acesso e utilização de serviços de saúde. Cad Saúde Púb. 2004;20 Sup12. p. 190-8.doi: http://dx.doi.gor/10.1590/50102$311 \times 2004000800014$.

Tripp D. Pesquisa-ação: uma introdução metodológica. Edu Pesq. 2005 set/dez;31(3):443-63.

Tristão FI, Lima RCD, Lima EFA, Andrade MAC.Acessibilidade e utilização na atenção básica: reflexões sobre o absenteísmo dos usuários. Rev Pesq Saúde. 2016 jan/mar;18(1):5461.

Tzias V, Xirouchakis E, Margetis N, Kamberoglou D. Causes of non-attendance at an openaccess endoscopy outpatient clinic. Endoscopy. 2006 Apr;38(04):427.

Van der Meer G, Loock JW. Why patients miss follow-up appointments: a prospective control-matched study. East Afr J Public Health. 2008 Dec;5(3):154-6.

Wang D, Crilly J, Jaeger L, Palmer G. Assessing patient preferences for delivery of reminders on scheduled visits in a psychiatry ambulatory service. AMIA Annu Symp Proc. 2007 Oct 11:776-80.

Youssef A. Use of short message service reminders to improve attendance at na internal medicine outpatient clinic in Saudi Arabia: a randomized controlled trial. East Mediterr Health J. 2014 Jun;20(5):317-23. 


\begin{abstract}
ANEXOS
ANEXO A - Roteiro para entrevista dos gestores municipais

IDENTIFICAÇÃO

Nome (opcional):

Data de nascimento:

Função no serviço de saúde:

\section{ENTREVISTA}

1. Contem-me como acontece o agendamento, comunicação aos usuários, organização da fila de demanda por recurso, transporte e cancelamento, em todos os seus detalhes e fases.

2. Qual a taxa de absenteísmo de vosso município? Existe alguma estratégia para o enfrentamento do absenteísmo no AME Araçatuba?

3. Do seu ponto de vista, o que já melhorou sobre o absenteísmo e o que ainda precisa melhorar. Relate como você imagina que deve ser o enfrentamento desse problema.

4. Na sua opinião, por que os usuários faltam nas consultas e exames agendados no AME Araçatuba?

5. Das unidades de saúde primária, na sua opinião, cite duas que possuem melhor condição de enfrentamento do absenteísmo e quais possuem dificuldade no enfrentamento do mesmo. Justifique. 
ANEXO B - Roteiro para entrevista da equipe do AME Araçatuba

\section{IDENTIFICAÇÃO}

Nome (opcional):

Data de nascimento:

Função no serviço de saúde:

\section{ENTREVISTA}

1. Contem-me sobre a organização do agendamento, comunicação aos usuários, organização da fila de demanda por recurso e cancelamento, em todos os seus detalhes e fases.

2. Descrevam o trabalho que vocês estão realizando para o enfrentamento do absenteísmo no AME Araçatuba e quais seriam as suas sugestões para a melhoria dessas estratégias.

3. Com todo trabalho descrito por vocês, é possível perceber a melhora do absenteísmo e o que ainda precisa melhorar? Relate como você imagina que deve ser o enfrentamento desse problema.

4. Na opinião de vocês, por que os usuários faltam nas consultas e exames agendados no AME Araçatuba?

5. Pensando nos vinte e sete municípios que vocês atendem no AME Araçatuba, quais são os dois municípios que possuem maior controle do absenteísmo e quais os dois municípios com maior dificuldade no enfrentamento do problema citado. Justifique. 
ANEXO C- Roteiro para entrevista da equipe técnica e/ou agendadores municipais

\section{IDENTIFICAÇÃO}

Nome (opcional):

Data de nascimento:

Função no serviço de saúde:

\section{ENTREVISTA}

1. Contem-me como acontece o agendamento, comunicação aos usuários, organização da fila de demanda por recurso, transporte e cancelamento, em todos os seus detalhes e fases.

2. Descrevam o trabalho que vocês estão realizando para o enfrentamento do absenteísmo no AME Araçatuba e quais seriam as suas sugestões para a melhoria dessas estratégias.

3. Do seu ponto de vista o que já foi conseguido na melhora do absenteísmo e o que ainda precisa melhorar. Relate como você imagina que deve ser o enfrentamento desse problema.

4. Na sua opinião, por que os usuários faltam nas consultas e exames agendados no AME Araçatuba? 
ANEXO D - Termos de Consentimento Livre e Esclarecido

\section{TERMO DE CONSENTIMENTO LIVRE E ESCLARECIDO}

\section{DADOS DE IDENTIFICAÇÃO DO SUJEITO DA PESQUISA}

1. NOME:

DOCUMENTO DE IDENTIDADE $\mathrm{N}^{\mathrm{o}}$ : SEXO: $\quad \mathrm{M} \square \mathrm{F} \square$

DATA NASCIMENTO:

ENDEREÇO $\mathrm{N}^{\mathrm{o}}$ APTO:

BAIRRO CIDADE

CEP: TELEFONE: DDD (............)

\section{DADOS SOBRE A PESQUISA}

1. TÍTULO DO PROTOCOLO DE PESQUISA: Absenteísmo no serviço ambulatorial SUS: estratégias e perspectivas das equipes de saúde PESQUISADOR: DANIELE CATELAN No. USP 8217799 do Programa de Mestrado Profissional Interunidades em Formação Interdisciplinar em Saúde.

CARGO/FUNÇÃO: enfermeira / mestranda INSCRIÇÃO COREN Nº 0115984

ORIENTADOR: Eucenir Fredini Rocha, docente do Depto. de Fisioterapia, Fonoaudiologia e Terapia Ocupacional da Faculdade de Medicina da USP.

2. AVALIAÇÃO DO RISCO DA PESQUISA:

$\begin{array}{lcl}\text { RISCO MÍNIMO } & \mathrm{x} & \text { RISCO MÉDIO } \\ \text { RISCO BAIXO } & \square & \text { RISCO MAIOR }\end{array}$

3. DURAÇÃO DA PESQUISA: maio - outubro 2017

\section{FACULDADE DE MEDICINA DA UNIVERSIDADE DE SÃO PAULO}

Este projeto de pesquisa tem como objetivo de analisar a natureza do absenteísmo em quatro municípios da área de abrangência do AME Araçatuba - "Dr. Oscar Gurjão Contrim" do Departamento Regional de Saúde (DRS) II - Araçatuba. Os procedimentos adotados serão levantamento bibliográfico e documental para caracterizar o cenário de estudo, banco de 
dados dos sistemas de informação utilizados na organização e regulação das ofertas e entrevistas semi-estruturadas com as equipes responsáveis pelo agendamento dos retornos, interconsultas e exames do AME Araçatuba e de representantes municipais responsáveis pelos agendamentos de primeira consulta e exames solicitados pela rede de atenção básica. Serão selecionados quatro municípios, a serem definidos, através da indicação durante entrevista com AME Araçatuba. Estes casos traçadores serão dois municípios com maior controle do absenteísmo e dois com maior dificuldade no controle do mesmo. Espera-se com esta pesquisa, colaborar na confecção de um manual que poderá ser utilizado na educação permanente junto aos gestores, trabalhadores de saúde das microrregiões estudadas. Em qualquer etapa do estudo, terei acesso aos profissionais responsáveis pela pesquisa para esclarecimento de eventuais dúvidas. A principal investigadora é a mestranda Daniele Catelan e orientadora Professora Dra. Eucenir Fredini Rocha poderão ser encontradas nos e-mail (s): dacatelan@gmail.com; eucenir@usp.br e telefone: (18)996660260. Se você tiver alguma consideração ou dúvida sobre a ética da pesquisa, entre em contato com o Comitê de Ética em Pesquisa da Faculdade de Medicina da Universidade de São Paulo (CEP-FMUSP): Av. Dr. Arnaldo, 251 - Cerqueira César - São Paulo - SP -21º andar - sala 36- CEP: 01246-000 Tel: 3893-4401/4407 E-mail: cep.fm@usp.br. Poderei solicitar esclarecimento sobre o desenvolvimento do projeto de pesquisa e, sem qualquer tipo de cobrança, poderei retirar minha autorização. Os dados coletados e os resultados desta pesquisa serão divulgamos em meios acadêmicos e científicos, com garantia de sigilo da identidade dos participantes. Os resultados da pesquisa serão enviados para mim e permanecerão confidenciais. Meu nome ou o material que indique minha participação não será liberado sem permissão prévia. Não serei identificado (a) em nenhuma publicação que possa resultar deste estudo. Uma cópia deste consentimento informado será arquivada no Curso de Mestrado Profissional Interunidades de formação interdisciplinar em Saúde da Faculdade de Odontologia da Universidade de São Paulo e outra fornecida a mim. A participação no estudo não acarretará custos para mim e não será disponível nenhuma compensação financeira adicional. Acredito ter sido suficientemente informado a respeito das informações que li ou que foram lidas para mim.

Eu discuti com a mestranda Daniele Catelan sobre a minha decisão em participar nesse estudo. Ficaram claros para mim quais são os propósitos do estudo, os procedimentos a serem realizados, seus desconfortos e riscos, as garantias de confidencialidade e de esclarecimentos permanentes. Concordo voluntariamente em participar deste estudo e poderei retirar o meu 
consentimento a qualquer momento, antes ou durante o mesmo, sem penalidades ou prejuízo ou perda de qualquer benefício que eu possa ter adquirido, ou no meu atendimento neste Serviço.

Assinatura do participante/ instituição

Data

(Somente para o responsável do projeto)

Declaro que obtive de forma apropriada e voluntária o Consentimento Livre e Esclarecido deste participante ou representante para a participação neste estudo.

Assinatura do responsável pelo estudo

Data

Assinatura do responsável pelo estudo

Data l 1 
ANEXO E - Parecer do Comitê de Ética em Pesquisa

\section{USP - FACULDADE DE \\ MEDICINA DA UNIVERSIDADE \\ DE SĀO PAULO - FMUSP}

\section{PARECER CONSUBSTANCIADO DO CEP}

\section{DADOS DO PROJETO DE PESOUISA}

Título da Pesqulsa: Absenteísma na senviça ambulabrial da SUS: eslralégias a pers peclívas das equipes de saúde

Pesqulsador: Eucenir Fredini Rocha

Area Temátlca:

Versă 3

CAAE: 69511517.5 .0000 .0055

Instltulça Proponente: Faculdade de Medicina da Universidade de Saa Paula

Patroclnador Princlpal: Financiamanla Prápria

DADOS DO PARECER

Número do Parecer: 2.079 .796

Apresentaço do Projeto:

O absenleísma das usuários nas serviças de saúde da Sislema Único de Saúde (SUS) é um assunla de crescente inleresse devida aa grande númerade pessoas na es pera par alendimenta e conlexla econàmico alual.A problamálica acar rela prejuizos a ladas enwatuidas, pais prabnga a conclusa diagnós lica, prejudica - Lralamenta, diminui a pradulividade da prestadar, causa aumenla de lempa na espera par alendimanla dos demais usuárias e desperdício de recursas públicos.

Objetro da Pesqulsa:

Analisar a nalureza da absenteísma em qualra municípios da área de abrangảncia da AME Araçaluba - 'Dr. Oscar Gurja Conlrim' da Deparlamenla Regianal de Saúde (DRS) II - Araçaluba da Rede Regianal de Saúde 12, da Eslada de Så Paula.

Avallaço dos Rlscose Beneficlos:

Riscos mínimas, realizaçåa de entrevistas.

Comentárlos e Consideraçás sobre a Pesqulsa:

Prajala de pesquisa bem delienado.Tralase de pesquisa qual-quanlitaliva, na desenha da esluda de casa.

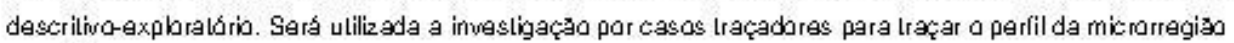
esludada.

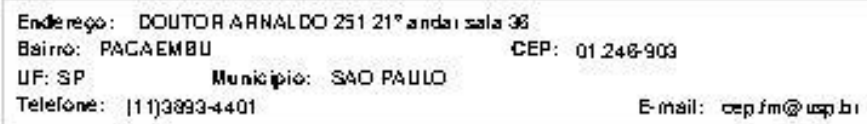




\section{USP - FACULDADE DE MEDICINA DA UNIVERSIDADE DE SÄO PAULO - FMUSP}

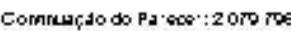

conslderaços sobre os Termos de apresentaça obro lgatorla:

Termas adequados para aesluda em relerancia.

Recomendaços:

Aproưça

Conclusóses ou Pendénclas e Llsta de Inadequaçzes:

Aprovado

Consideraçós Finals a crltérlo do CEP:

Este parecer fol elaborado baseado nos documentos abalxo relaclonados:

\begin{tabular}{|c|c|c|c|c|}
\hline Tipa Documanla & Arquino & Pastagem & Aular & Siluaçāa \\
\hline $\begin{array}{l}\text { Inlarmaçoes bésicas } \\
\text { da Prajala }\end{array}$ & $\begin{array}{l}\text { PE_INFORMACQOES_EASICAS_DO_P } \\
\text { ROJETO_79763.pdi }\end{array}$ & $\begin{array}{c}22 / 05 / 2017 \\
14: 55: 40\end{array}$ & & Acaila \\
\hline Oulras & TermoAularizacaoA.MEAracaluba.pdi & $\begin{array}{c}22 / 05 / 2017 \\
14: 54: 37\end{array}$ & $\begin{array}{l}\text { Eucenir Fredini } \\
\text { Roche } \\
\end{array}$ & Acaila \\
\hline Oulras & TermoAularizacaoDRSIlAracaluba.pdí & $\begin{array}{c}22 / 05 / 2017 \\
14: 53: 21\end{array}$ & $\begin{array}{l}\text { Eucenir Fredini } \\
\text { Rocha } \\
\end{array}$ & Acaila \\
\hline $\begin{array}{l}\text { Prajala Delalhada } \\
\text { Grachura } \\
\text { Invesligadar }\end{array}$ & PrajalaDANIELECATELAN.doc & $\begin{array}{c}22 / 05 / 2017 \\
14: 48: 59\end{array}$ & $\begin{array}{l}\text { Eucenir Fredini } \\
\text { Rocha }\end{array}$ & Acaila \\
\hline $\begin{array}{l}\text { TCLE / Termos de } \\
\text { Assentimenta / } \\
\text { Jus líficaliva de } \\
\text { Ausencia }\end{array}$ & TCLE_Pesquisa_absenleismoj.doc & $\begin{array}{c}22 / 05 / 2017 \\
14: 43: 33\end{array}$ & $\begin{array}{l}\text { Eucenir Fredini } \\
\text { Rocha }\end{array}$ & Acoila \\
\hline Cranograma & Cronogramadocx & $\begin{array}{c}30 / 00 / 2017 \\
20: 55: 25\end{array}$ & $\begin{array}{l}\text { Eucenir Fredini } \\
\text { Rocha }\end{array}$ & Aceila \\
\hline Oulras & Cadastro_anline_CEP.pdi & $\begin{array}{c}30 / 00 / 2017 \\
19: 24: 49\end{array}$ & $\begin{array}{l}\text { Eucenir Fredini } \\
\text { Roche }\end{array}$ & Acaila \\
\hline Falha de Fosta & blharasla_PG.pdi & $\begin{array}{c}30 / 09 / 2017 \\
19: 17: 31\end{array}$ & $\begin{array}{l}\text { Eucenir Fredini } \\
\text { Roche }\end{array}$ & Aceila \\
\hline
\end{tabular}

Situaça do Parecer:

Aprouado

Necessita Apreclaçăo da CONEP:

Nao

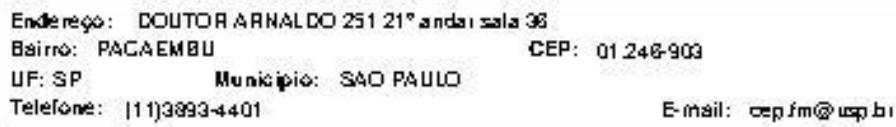




\section{USP - FACULDADE DE \\ MEDICINA DA UNIVERSIDADE \\ DE SĀO PAULO - FMUSP}

Comruç, do do $\mathrm{Pa} \cdot \cos : 200 \mathrm{~m}$

SAO PALLO, 24 de Maia de 2017

Assinado por:

Marla Apareclda Azeyedo Kolke Folguralra

(Coordenador)

Ende reço: COUTOR ARHALCO 251 $21^{\circ}$ anda I sla 33

Bvirn: PACAEMGU

CEP: 01 248-900

UF: SP Municipio: SAO PAULO

Tele[rone: |11]3893-4401

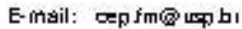


ANEXO F - Termos de autorização para realização da pesquisa

TERMO DE AUTORIZAÇÃO PARA REALIZAÇÃO DA PESQUISA

Eu Silvio Cesar Santos Órfão, RG: 22.842.544-x CPF: 087.827.298-40. Autorizo a Daniele Catelan, aluna co curso de mestrado a realizar o estudo intitulado como ABSENTEÍSMO NO SERVIÇO AMBULATORIAL SUS: ESTRATÉGIAS E PERSPECTIVAS DAS EQUIPES DE SAÚDE. Este projeto de pesquisa tem como objetivo de analisar a natureza do absenteísmo em quatro municípios da área de abrangência do AME Araçatuba - "Dr. Oscar Gurjão Contrim" do Departamento Regional de Saúde (DRS) II - Araçatuba. Os procedimentos adotados serão levantamento bibliográfico e documental para caracterizar o cenário de estudo, banco de dados dos sistemas de informação utilizados na organização e regulação das ofertas e entrevistas semi-estruturadas com as equipes responsáveis pelo agendamento dos retornos, interconsultas e exames do AME Araçatuba e de representantes municipais responsáveis pelos agendamentos de primeira consulta e exames solicitados pela rede de atenção básica. Serão selecionados quatro municípios, a serem definidos, através da indicação durante entrevista com AME Araçatuba. Estes casos traçadores serão dois municipios com maior controle do absenteismo e dois com maior dificuldade no controle do mesmo. Espera-se com esta pesquisa, colaborar na confecção de um manual que poderá ser utilizado na educação permanente junto aos gestores, trabalhadores de saúde das microrregiões estudadas.

Esta atividade não apresenta riscos aos envolvidos, podendo haver eventual desconforto em responder o questionário ou fornecer as informaçães solicitadas durante o processo de coleta de dados. No entanto, os entrevistados poderão ficar a vontade para responder o que desejarem. A fim de minimizar ou eliminar estes desconfortos, nenhuma informação será divulgada sem prévia autorização, portanto será preservado o anonimato dos participantes, assegurando a privacidade. As entrevistas realizadas serão devolvidas aos entrevistados para autorização final na sua utilização. Além disso, as instituições envolvidas paderão deixar de participar da pesquisa quando quiser.

Em qualquer etapa do estudo, você terá acesso aos profissionais responsáveis pela pesquisa para esclarecimento de eventuais dúvidas. A principal investigadora é a mestranda Daniele Catelan e orientadora Professora Dra. Eucenir Fredini Rocha poderão ser encontradas nos email (s): dacatelan@gmail.com; eucenir@usp.br e telefone: (18)996660260. Se você tiver alguma consideração ou dúvida sobre a ética da pesquisa, entre em contato com o Comitê de Ética em Pesquisa da Faculdade de Medicina da Universidade de São Paulo (CEP-FMUSP): Av.
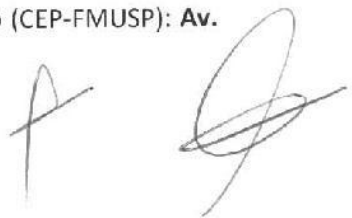
Dr. Arnaldo, 251 - Cerqueira César - São Paulo - SP -21andar - sala 36- CEP: 01246-000 Tel: 3893-4401/4407 E-mail: cep.fm@usp.br.

A qualquer momento vossa senhoria poderá solicitar esclarecimento sobre o desenvolvimento do projeto de pesquisa que está sendo realizado e, sem qualquer tipo de cobrança, poderá retirar sua autorização. Os pesquisadores aptos a esclarecer estes pontos e, em caso de necessidade, dar indicaçöes para solucionar ou contornar qualquer mal estar que possa surgir em decorrência da pesquisa.

Os dados obtidos nesta pesquisa serão utilizados na publicação de artigos científicos e assumimos a total responsabilidade de não publicar qualquer dado que comprometa o sigilo da participação dos integrantes de vossa instituição como nome, endereço e outras informações pessoais, nem das instituições participantes. Na eventualidade da participação nesta pesquisa, causar qualquer tipo de dano aos participantes, nós pesquisadores nos comprometemos em reparar este dano, e ou ainda prover meios para a reparação. A participação será voluntária, não fornecemos por ela qualquer tipo de pagamento.

Os pesquisadores acima qualificados se comprometem a:

1. Iniciarem a coleta de dados somente após aprovação do Comitê de Ética em Pesquisa com Seres Humanos.

2. Obedecerem às disposições éticas de proteger os participantes da pesquisa, garantindo-Ihes o máximo de benefícios e o mínimo de riscos.

3. Assegurar a privacidade das pessoas citadas nos documentos institucionais e/ou contatadas diretamente, de modo a proteger suas imagens bem como garantem que não utilizarão as informações colet6ados em prejuízo dessas pessoas e/ou instituição, respeitando desde modo as Diretrizes Éticas da Pesquisa Evolvendo Seres Humanos, nos termos estabelecidos na Resolução CNS n 466/2012 e obedecendo as disposições legais estabelecidas na Constituição Federal Brasileira, artigo $5^{\circ}$, incisos X e XIV e no Novo Código Civil artigo 20

Araçatuba, 23 de fevereiro, 2017

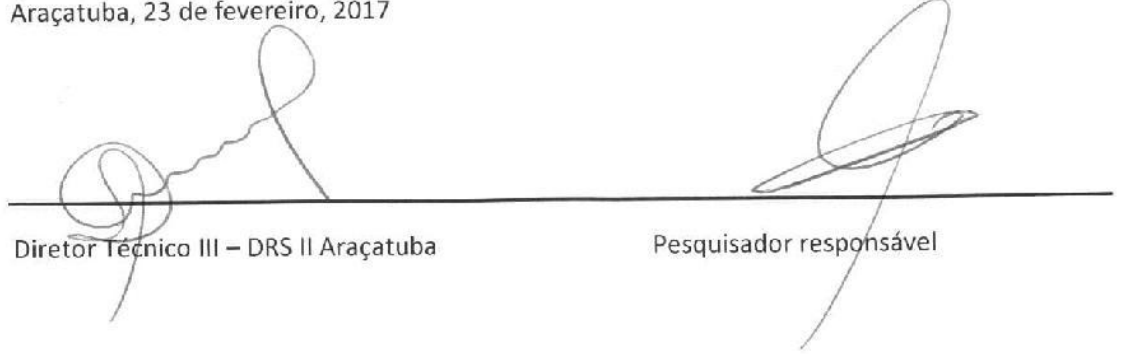


TERMO DE AUTORIZAÇÃO PARA REALIZAÇ̃̃O DA PESQUISA

Eu Renée Ariadne Duarte, RG: 28.307.684-7, CPF: 117.398.258-29. Autarizo a Daniele Catelan, aluna co curso de mestrado a realizar o estudo intitulado como ABSENTEÍSMO NO SERVIÇO AMBULATORIAL SUS: ESTRATÉGIAS E PERSPECTIVAS DAS EQUIPES DE SAÚDE. Este projeto de pesquisa tem como objetivo de analisar a natureza do absenteísmo em quatro municípios da área de abrangência do AME Araçatuba - "Dr. Oscar Gurjão Contrim" do Departamento Regional de Saúde (DRS) II - Araçatuba. Os procedimentos adotados serão levantamento bibliográfico e documental para caracterizar o cenário de estudo, banco de dados dos sistemas de informação utilizados na organização e regulação das ofertas e entrevistas semiestruturadas com as equipes responsáveis pelo agendamento dos retornos, interconsultas e exames do AME Araçatuba e de representantes municipais responsáveis pelos agendamentos de primeira consulta e exames solicitados pela rede de atenção básica. Serão selecionados quatro municípios, a serem definidos, através da indicação durante entrevista com AME Araçatuba. Estes casos traçadores serão dois municipios com maior controle do absenteísmo e dois com maior dificuldade no controle do mesmo. Espera-se com esta pesquisa, colaborar na confecção de um manual que poderá ser utilizado na educação permanente junto aos gestores, trabalhadores de saúde das microrregiões estudadas.

Esta atividade não apresenta riscos aos envolvidos, podendo haver eventual desconforto em responder o questionário ou fornecer as informações solicitadas durante o processo de coleta de dados. No entanto, os entrevistados poderão ficar a vontade para responder o que desejarem. A fim de minimizar ou eliminar estes desconfortos, nenhuma informação será divulgada sem prévia autorização, portanto será preservado o anonimato dos participantes, assegurando a privacidade. As entrevistas realizadas serão devolvidas aos entrevistados para autorização final na sua utilização. Além disso, as instituições envolvidas poderão deixar de participar da pesquisa quando quiser.

Em qualquer etapa do estudo, você terá acesso aos profissionais responsáveis pela pesquisa para esclarecimento de eventuais dúvidas. A principal investigadora é a mestranda Daniele Catelan e orientadora Professora Dra. Eucenir Fredini Rocha poderão ser encontradas nos email (s): dacatelan@gmail.com; eucenir@usp.br e telefone: (18)996660260. Se você tiver alguma consideração ou dúvida sobre a ética da pesquisa, entre em contato com o Comitê de Ética em Pesquisa da Faculdade de Medicina da Universidade de São Paulo (CEP-FMUSP): Av.
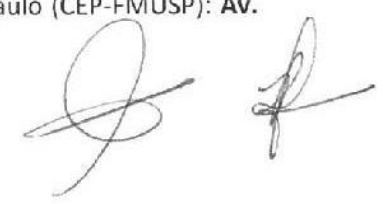
Dr. Arnaldo, 251 - Cerqueira César - São Paulo - SP -21a andar - sala 36- CEP: 01246-000 Tel: 3893-4401/4407 E-mail: cep.fm@usp.br.

A qualquer momento vossa senhoria poderá solicitar esclarecimento sobre o desenvolvimento do projeto de pesquisa que está sendo realizado e, sem qualquer tipo de cobrança, poderá retirar sua autorização. Os pesquisadores aptos a esclarecer estes pontos e, em caso de necessidade, dar indicações para solucionar ou contornar qualquer mal estar que possa surgir em decorrência da pesquisa.

Os dados obtidos nesta pesquisa serão utilizados na publicação de artigos científicos e assumimos a total responsabilidade de não publicar qualquer dado que comprometa o sigilo da participação dos integrantes de vossa instituição como nome, endereço e outras informações pessoais, nem das instituições participantes. Na eventualidade da participação nesta pesquisa, causar qualquer tipo de dano aos participantes, nós pesquisadores nos comprometemos em reparar este dano, e ou ainda prover meios para a reparação. A participação será voluntária, não fornecemos por ela qualquer tipo de pagamento.

Os pesquisadores acima qualificados se comprometem a:

1. Iniciarem a coleta de dados somente após aprovação do Comitê de Ética em Pesquisa com Seres Humanos.

2. Obedecerem às disposições éticas de proteger os participantes da pesquisa, garantindo-lhes o máximo de benefícios e o minimo de riscos.

3. Assegurar a privacidade das pessoas citadas nos documentos institucionais e/ou contatadas diretamente, de modo a proteger suas imagens bem como garantem que não utilizarão as informações colet6ados em prejuízo dessas pessoas e/ou instituiç̧ão, respeitando desde modo as Diretrizes Éticas da Pesquisa Evolvendo Seres Humanos, nos termos estabelecidos na Resolução CNS n 466/2012 e obedecendo as disposições legais estabelecidas na Constituição Federal Brasileira, artigo $5^{\circ}$, incisos X e XIV e no Novo Código Civil artigo 20.

Araçatuba, 23 de fevereiro, 2017

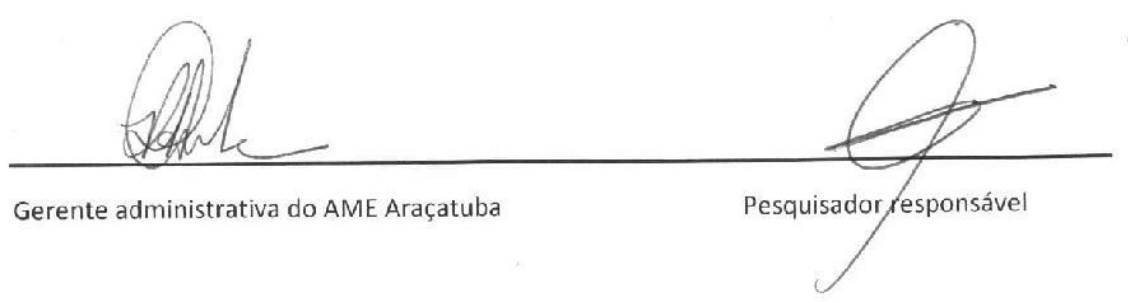

